\title{
Evaluating Catchment Models as \\ Multiple Working Hypotheses under Uncertainty
}

\author{
Sina Khatami \\ $\mathrm{BSc}, \mathrm{MSC}$ \\ ORCID: https://orcid.org/0000-0003-1149-5080
}

\begin{abstract}
Submitted in total fulfilment of the requirements of the degree
of Doctor of Philosophy
\end{abstract}

Department of Infrastructure Engineering

University of Melbourne

August 2020 


\section{Fields of Research:}

1: $\quad 040608$ - Surfacewater Hydrology

2: $\quad 090509$ - Water Resources Engineering

3: $\quad 090702$ - Environmental Engineering Modelling

4: $220304-$ Epistemology

\section{Supervisory Committee:}

Principal Supervisor Dr Murray Peel (University of Melbourne)

Co-supervisor Dr Tim Peterson (University of Melbourne, Monash University)

Co-supervisor Prof Andrew Western (University of Melbourne)

\section{Committee Chair:}

A/Prof Dongryeol Ryu (University of Melbourne)

\section{Examiners:}

Emeritus Prof Keith Beven (Lancaster University)

Prof Jan Seibert (University of Zurich)

\section{Chair of Examiners:}

Prof Nelson Lam (University of Melbourne) 
to

mom and dad for raising me, with the best of what was available to them, to think Kasra for keeping my company no matter what

Noam Chomsky for inspiring me to think no matter what

Murray Peel for smiling at my mistakes and encouraging me no matter what

Emma Carlsson for lighting up my life

"Three passions, simple but overwhelmingly strong, have governed my life: the longing for love, the search for knowledge, and unbearable pity for the suffering of [hu]mankind... Love and knowledge, so far as they were possible, led upward toward the heavens. But always pity brought me back to earth." - Bertrand Russell 


\section{Declaration}

This is to certify that:

1. this thesis comprises only of my original work towards the degree of Doctor of Philosophy (PhD),

2. due acknowledgement has been made in the text to all other material used,

3. the thesis is fewer than 100,000 words in length, exclusive of tables, figures, references, and appendices, and

4. the research of this thesis was conducted at Department of Infrastructure Engineering, University of Melbourne. I (Sina Khatami) have led the entire research, both analysis and writing, under the supervision of Dr Murray Peel, Dr Tim Peterson, and Prof Andrew Western. In addition, Dr Keirnan Fowler contributed to this work with his expertise and other resources (data, codes, etc.).

Sina Khatami

Melbourne, August 2020 


\section{Abstract}

Catchment models are conventionally evaluated in terms of their response surface or likelihood surface constructed from model runs using different sets of model parameters. Model evaluation methods are mainly based upon the concept of the equifinality of model structures or parameter sets. The operational definition of equifinality is that multiple model structures/parameters are equally capable of producing acceptable simulations of catchment processes such as runoff. Examining various aspects of this convention, in this thesis I demonstrate their shortcomings and introduce improvements including new approaches and insights for evaluating catchment models as multiple working hypotheses (MWH). First (Chapter 2), arguing that there is more to equifinality than just model structures/parameters, I propose a theoretical framework to conceptualise various facets of equifinality, based on a meta-synthesis of a broad range of literature across geosciences, system theory, and philosophy of science. I distinguish between process-equifinality (equifinality within the real-world systems/processes) and model-equifinality (equifinality within models of real-world systems), explain various aspects of each of these two facets, and discuss their implications for hypothesis testing and modelling of hydrological systems under uncertainty. Second (Chapter 3), building up on this theoretical framework, I propose that characterising model-equifinality based on model internal fluxes - instead of model parameters which is the current approach to account for model-equifinality - provides valuable insights for evaluating catchment models. I developed a new method for model evaluation - called flux mapping - based on the equifinality of runoff generating fluxes of large ensembles of catchment model simulations (1 million model runs for each catchment). Evaluating the model behaviour within the flux space is a powerful approach, beyond the convention, to formulate testable hypotheses for runoff generation processes at the catchment scale. Third (Chapter 4), I further explore the dependency of the flux map of a catchment model upon the choice of model structure and parameterisation, error metric, and data information content. I compare two catchment models (SIMHYD and SACRAMENTO) across 221 Australian catchments (known as Hydrologic Reference Stations, HRS) using multiple error metrics. I particularly demonstrate the fundamental shortcomings 
of two widely used error metrics - i.e. Nash-Sutcliffe efficiency and Willmott's refined index of agreement - in model evaluation. I develop the skill score version of Kling-Gupta efficiency (KGEss), and argue it is a more reliable error metric that the other metrics. I also compare two strategies of random sampling (Latin Hypercube Sampling) and guided search (Shuffled Complex Evolution) for model parameterisation, and discuss their implications in evaluating catchment models as MWH. Finally (Chapter 5), I explore how catchment characteristics (physiographic, climatic, and streamflow response characteristics) control the flux map of catchment models (i.e. runoff generation hypotheses). To this end, I formulate runoff generating hypotheses from a large ensemble of SIMHYD simulations (1 million model runs in each catchment). These hypotheses are based on the internal runoff fluxes of SIMHYD - namely infiltration excess overland flow, interflow and saturation excess overland flow, and baseflow - which represent runoff generation at catchment scale. I examine the dependency of these hypotheses on 22 different catchment attributes across 186 of the HRS catchments with acceptable model performance and sufficient parameter sampling. The model performance of each simulation is evaluated using KGEss metric benchmarked against the catchment-specific calendar day average observed flow model, which is more informative than the conventional benchmark of average overall observed flow. I identify catchment attributes that control the degree of equifinality of model runoff fluxes. Higher degree of flux equifinality implies larger uncertainties associated with the representation of runoff processes at catchment scale, and hence pose a greater challenge for reliable and realistic simulation and prediction of streamflow. The findings of this chapter provides insights into the functional connectivity of catchment attributes and the internal dynamics of model runoff fluxes. 


\section{Acknowledgements}

I suppose I did it all to write the next few lines...

I'm hugely indebted to Australia and Australians - both indigenous and non-indigenous - for providing me with the opportunity to pursue my passions, studying and working in the great city of Melbourne. They made it possible for an immigrant to feel welcome, to feel like having a new home, being relevant and a contributing member of a multicultural society. I'm also extremely grateful to my supervisors, mentors, colleagues, comrades, friends, and family - to every single one of them a glittering constellation of stars filling the empty void of existence and guiding me through its darkness.

Murray, it is outrageous to thank you within only a couple of sentences. Thank you for accepting and nurturing me as your student, putting up with all my peculiarities and eccentricities, investing so much of your time and resources in me, and never giving up on me. Tim, thank you for teaching and advancing my scientific programming, building up my confidence to keep pushing back my fears, and having my back during the tough patches of this research; as well as the studentship in the latest stage of my studies. Andrew, thank you for answering all my questions so patiently, inspiring and educating me with your superpower of simple and clear thinking. The three of you inspired me to translate theoretical knowledge into relevant research questions with useful outcomes. I always enjoyed our chats and your senses of humour. Thank you for taking the risk and bearing with a guy who was constantly poking around and wanted to try different things.

I had the pleasure of working with countless colleagues and friends across the University of Melbourne. Undoubtedly, Keirnan Fowler was one of a kind. Thank you Keir for your generosity. I've learnt a lot from you, and truly enjoyed our friendship. I would like to mention a few other colleagues with whom I studied, worked, shared office, and had many great conversations and memories: Natasha Ballis, Emma White, Margarita Saft, Naveen Joseph, Giancarlo Bonotto, Meghan Mussehl, Danlu Guo, Suwash Acharya, Shuci Liu, Jie Jian — and Alexander McCluskey who's badly missed...

The scholarships (tuition waiver and stipend) I received from University of Melbourne made it possible for me to do my PhD. Besides, I received several research and travel grants from University of Melbourne (Lorna Stirling Fund Scholarship, Melbourne School of Engineering, and Department of Infrastructure Engineering) and beyond (Tertiary Scholarship Fund and Geological Society of Australia) towards my professional development. Thanks to the generous support of Murray (and his 
ARC Future Fellowship FT120100130), I had the chance to go on numerous international research and study visits, conferences, and workshops. The highlight was attending Keith Beven's summer school at Uppsala University in 2016. Keith has been a great source of inspiration and influence on my thinking about hydrological modelling and uncertainty, and I thank him for his mentorship. Keith was also an examiner of this thesis along with Jan Seibert, and I thank both of them for their valuable (and kind) feedback on my work. I also received constructive feedback from Hoshin Gupta, Martyn Clark, Grey Nearing, Andrew Binley, Thorsten Wagener, among many others, which helped me improve my work.

I'm lucky for having so many friends, all over the world, who always have had my back. Enayat Moallemi, thank you for your genuine friendship that unifies us (I think you got the joke! ; ) ), your encouragement was essential to the completion of my thesis. Omid Fakhri, you were the best housemate ever. Our time together cooking, eating, watching and performing stand-up comedy, and weekend "male bonding" was the fuel of my last year. Marzieh Derkani, you're one of my favourite people, and thanks for always being there for me. Dorsa Rahmanian, thank you for laughing at my jokes, even when you didn't get them. I miss you! Pouya Bagheri and Shohre Mansouri, your friendship brought me up from one of my deeper downs, for which I'm ever grateful to you two. Bahram Khazaei, thanks for always being there for me, like an older brother. Hamid Hajinezhad, I love you so much and I hope you move away from neoliberal right-wing politics, back to where you truly belong. I've benefited enormously from the camaraderie of the good folks of the Graduate Student Association (GSA), particularly Bradley Knight, Thomas Whiteside, Jim Smith, Steve Brown, Catherine Cheng, Georgia Daly, Emily De Rango, Beornn McCarthy, and of course Andrew Cameron!

Mom and Dad (Haleh Sharifi and Hadi Khatami), for me you've done more than I've deserved, and for that I'm ever grateful. Kasra, you're my only brother, which makes me your only brother too (haha!). Thanks for being such a good sport all these years. It's been very difficult to be away from the three of you over the past decade. No matter what, you always had my back, sent me your love from beyond the oceans, especially during the writing of this very thesis.

Emma Carlsson, you fell into my lap out of the blue and became the light of my life. You're a person of principle. You shared with me a genuine sense of togetherness, never succumbed to the tyranny of distance, and restored my faith in love. You extended my family to Birgitta, Bror, Linnea, Oskar, Sam, and now pipe-Arvid. Thank you for your love and support during the difficult and lonely days of writing this thesis, in the midst of a global pandemic. 


\section{Preface}

The underlying research of this thesis is entirely my original work, including the contributions of my PhD supervisors (as co-authors), other co-author (Dr Keirnan Fowler), and reviewers of my published paper. None of this research has been submitted for any other qualifications, nor was carried out prior to my PhD enrolment.

Chapters 2 to 5 are formatted as journal articles described as below:

1. Chapter 2 (Paper 1 ) is ready for submission as Khatami, S., Peel, M. C., Peterson, T. J., \& Western, A. W. (2020). A Theoretical Framework based on Equifinality for Hypothesis Testing and Modelling Hydrological Systems under Uncertainty

2. Chapter 3 (Paper 2) is published as Khatami, S., Peel, M. C., Peterson, T. J., \& Western, A. W. (2019). Equifinality and flux mapping: A new approach to model evaluation and process representation under uncertainty. Water Resources Research, 55, 8922-8941. https://doi.org/10.1029/2018WR023750

3. Chapter 4 (Paper 3 ) is ready for submission as Khatami, S., Peterson, T. J., Peel, M. C., \& Western, A. W. (2020). Evaluating catchment models as multiple working hypotheses: on the role of error metrics, parameter sampling, model structure, and data information content

4. Chapter 5 (Paper 4) is ready for submission as Khatami, S., Fowler, K., Peel, M. C., Peterson, T. J., \& Western, A. W. (2020). What catchment attributes control runoff generation hypotheses in Australian catchments? 


\section{Table of Contents}

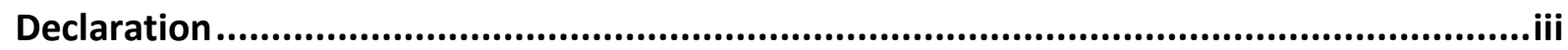

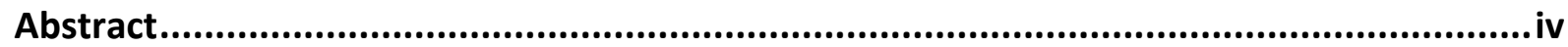

Acknowledgements ................................................................................................... vi

Preface ...................................................................................................................... vii

List of Figures.................................................................................................................

List of Tables................................................................................................................... xii

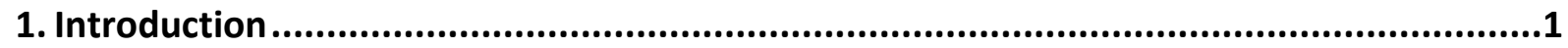

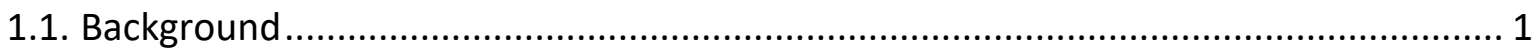

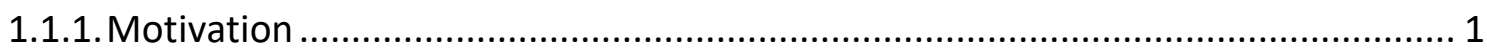

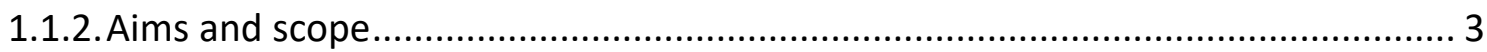

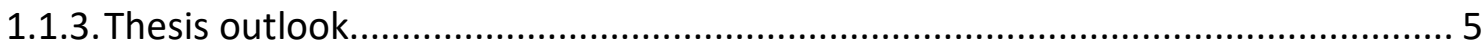

1.2. Evaluating catchment models as hypotheses ....................................................... 5

1.2.1. A brief overview of the state of the art............................................................. 5

1.2.2. Knowledge gaps and research questions: a brief overview.................................. 9

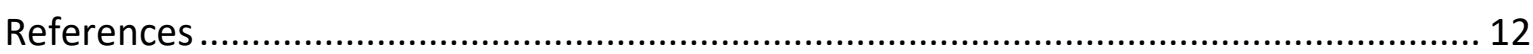

2. Theoretical underpinnings (Paper 1) ...........................................................................21

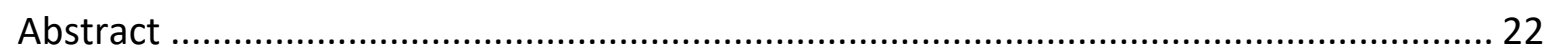

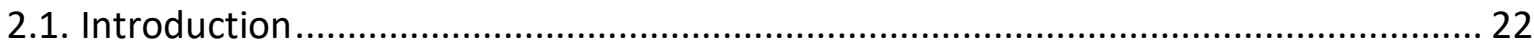

2.2. A panoramic view on equifinality ..................................................................... 24

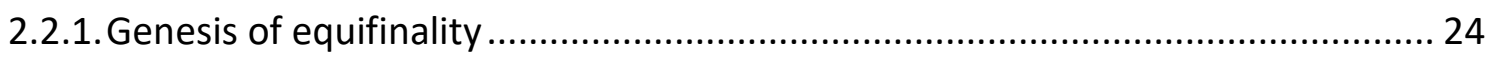

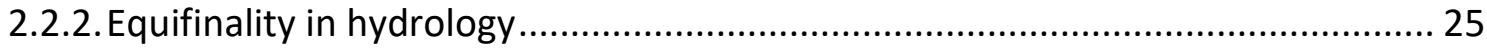

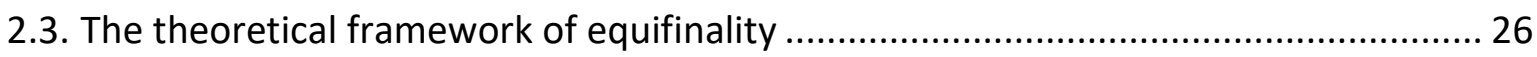

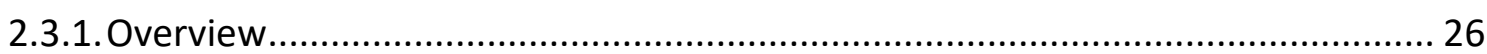

2.3.2. Facets of equifinality: a meta-synthesis ........................................................... 27

2.3.3. Equifinality and knowledge uncertainty: an epistemological account ................. 30

2.3.4. Equifinality and Multiple Working Hypotheses ................................................ 33

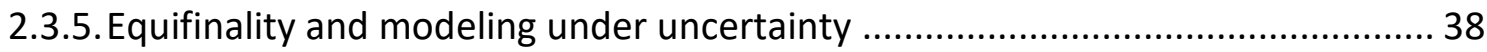

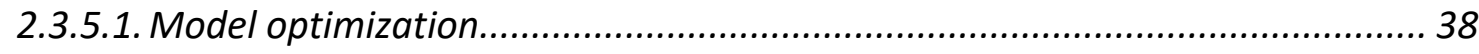

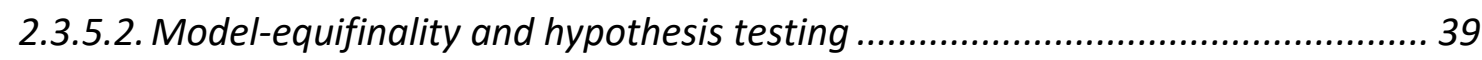

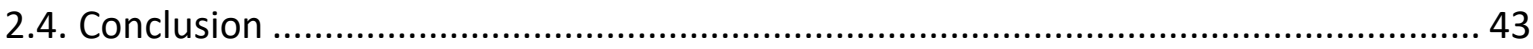

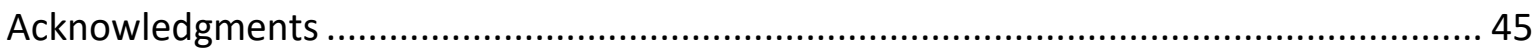

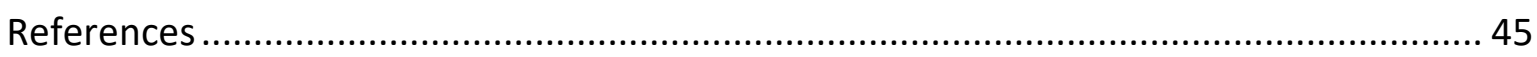

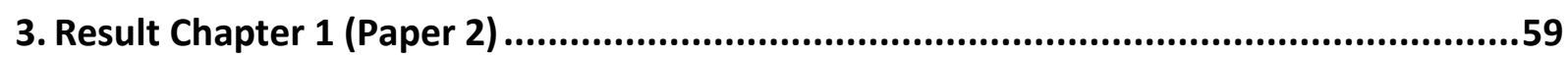

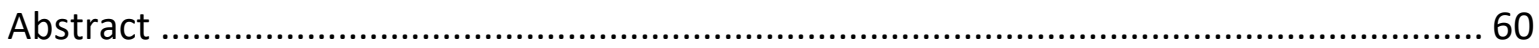


3.1. Introduction 60

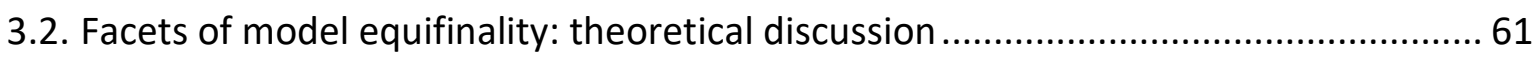

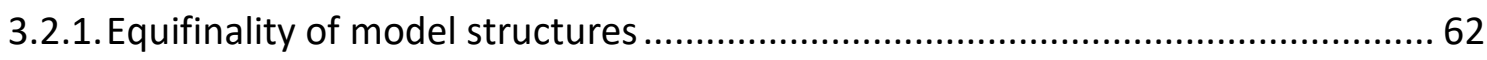

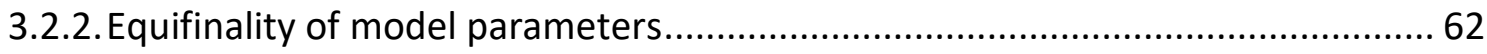

3.2.3. Equifinality of model performance metrics (or objective functions) ....................63

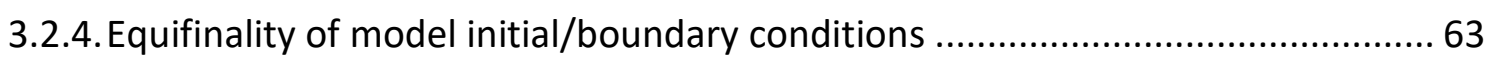

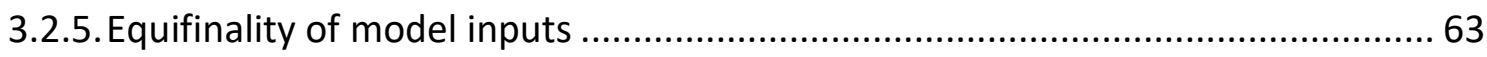

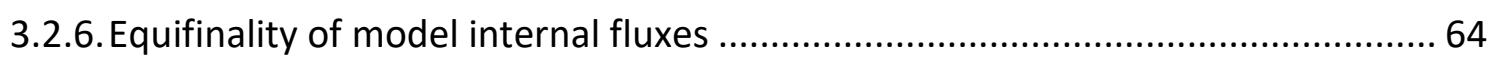

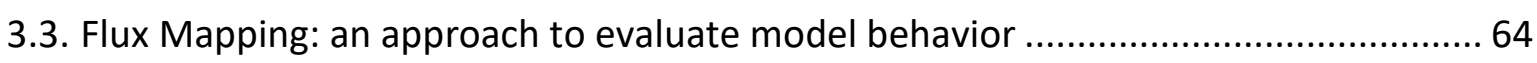

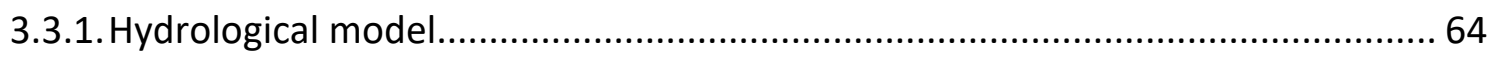

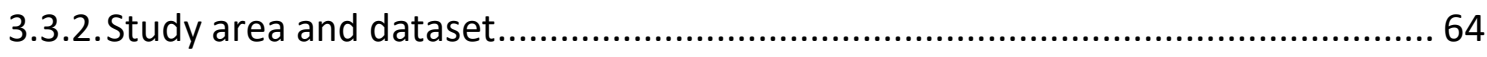

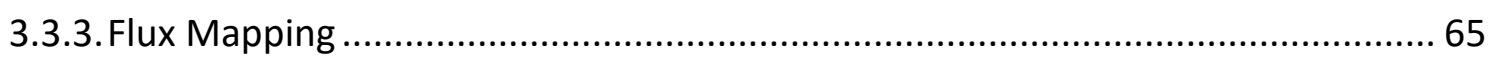

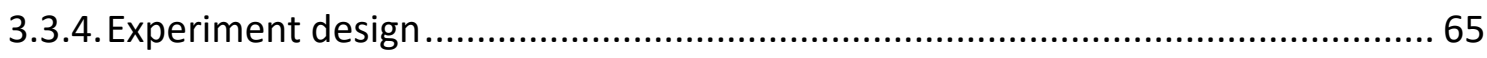

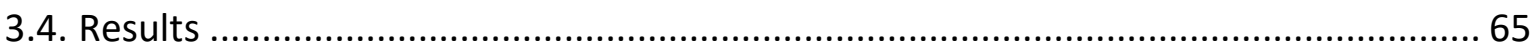

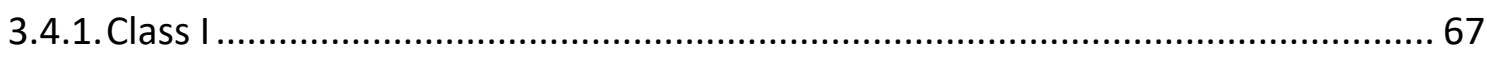

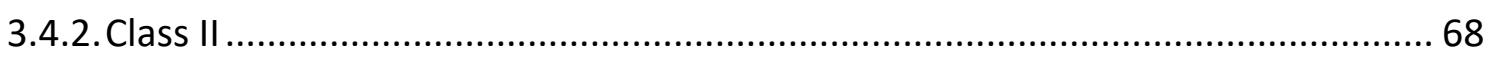

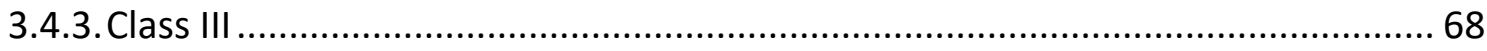

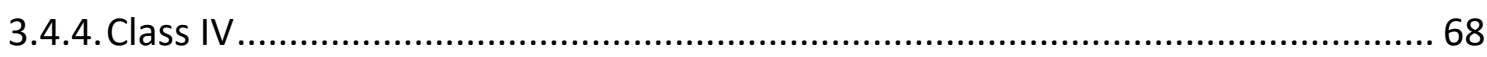

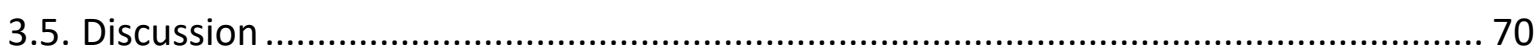

3.5.1. Flux mapping and model evaluation: flux space vs. parameter space ................. 70

3.5.2. Flux mapping, process representation, and multiple working hypotheses......... 72

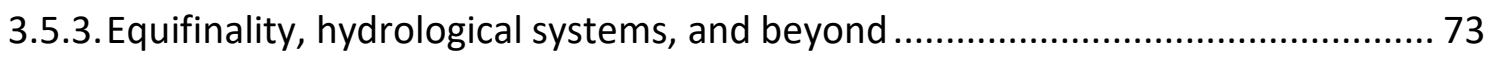

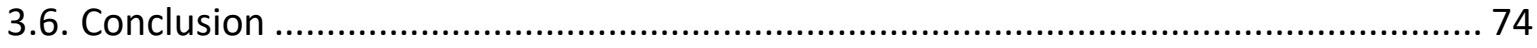

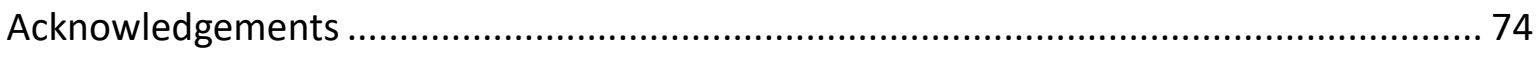

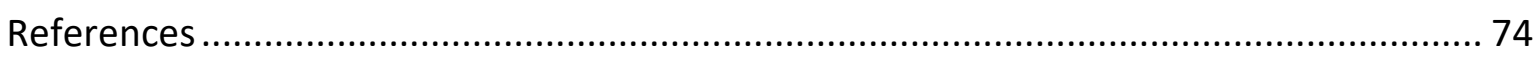

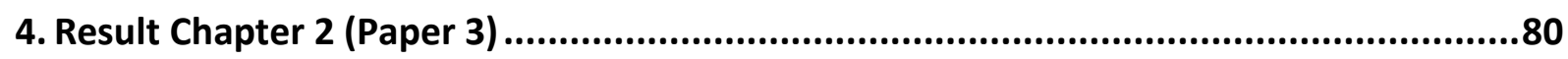

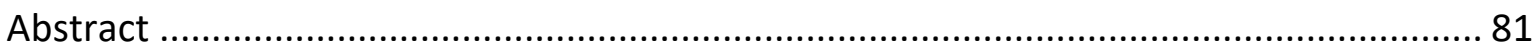

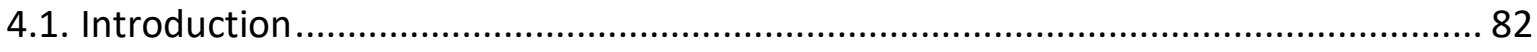

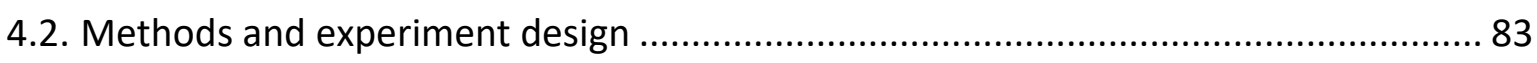

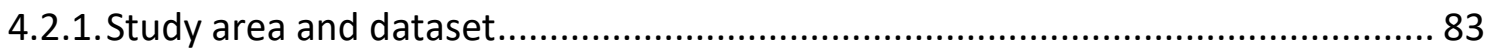

4.2.2. Hydrological models: hypotheses of runoff generation ................................... 84

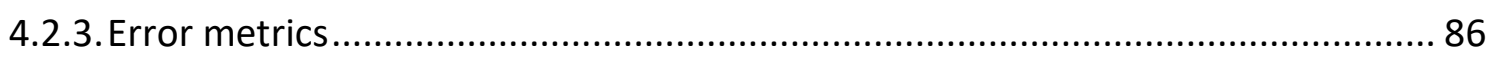

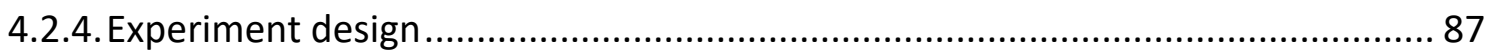

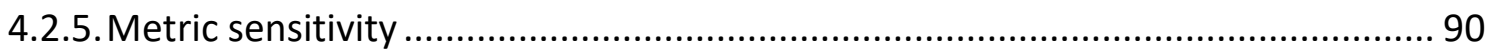

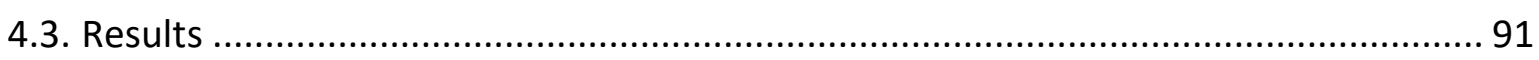

4.3.1. Metric Sensitivity: How do error metrics behave under different error regimes?....

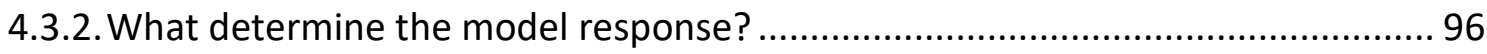

4.3.2.1. Model response based on a single model structure ..................................... 96 
4.3.2.2. Model response based on multiple model structures.................................. 99

4.4. Discussion: evaluating catchment models as hypotheses under uncertainty ............ 103

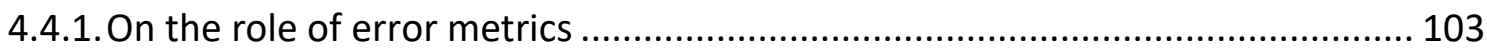

4.4.2. On the role of model structure and process representation............................. 106

4.4.3. On the role of parameter sampling sufficiency................................................ 107

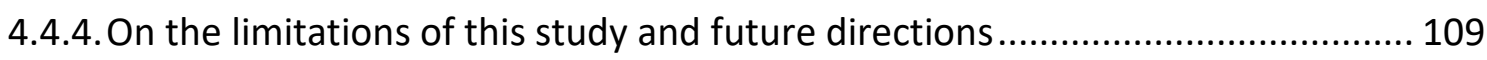

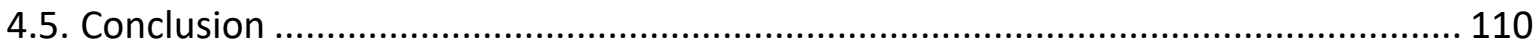

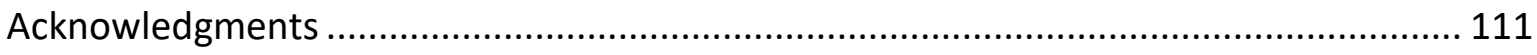

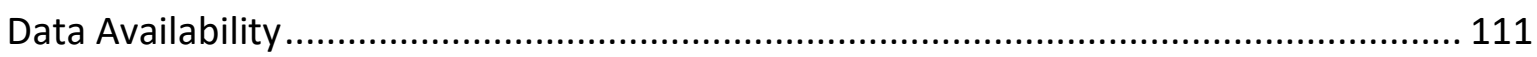

Appendix A: deriving the equation for KGE skill score (KGEss) ................................... 111

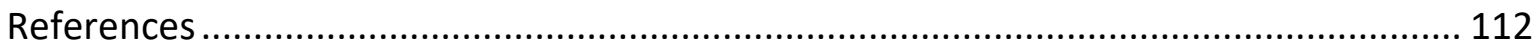

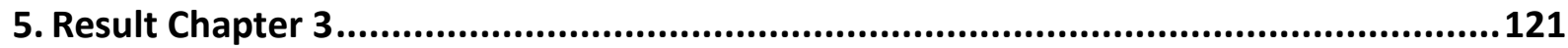

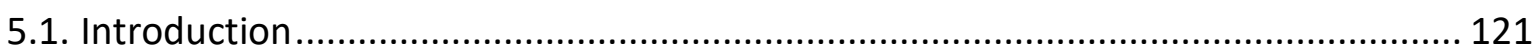

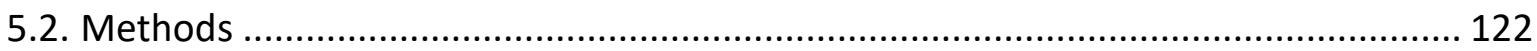

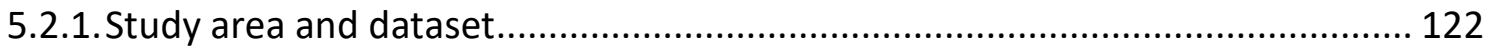

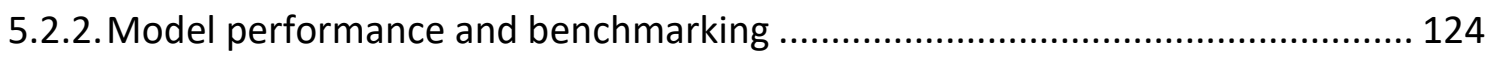

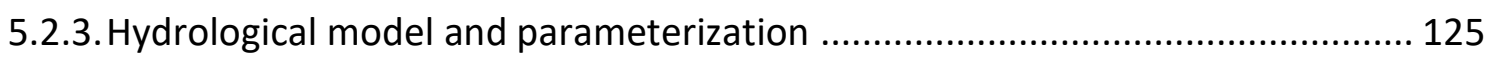

5.2.4. Flux mapping and assessment of runoff generation hypotheses ...................... 126

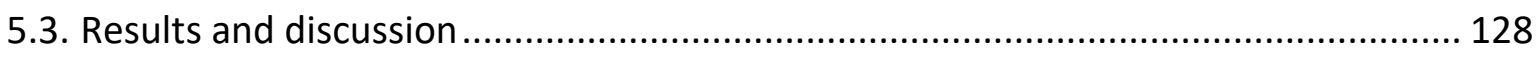

5.3.1.SIMHYD performance across Australian HRS catchments ................................. 128

5.3.2. Runoff generation and model equifinality ................................................... 129

5.3.3. Connectivity between runoff generation hypotheses and catchment attributes ....

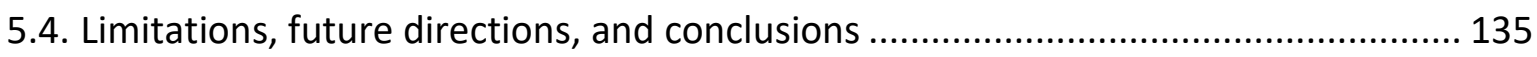

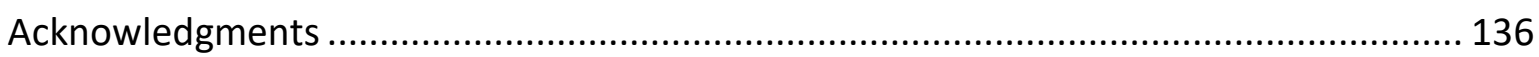

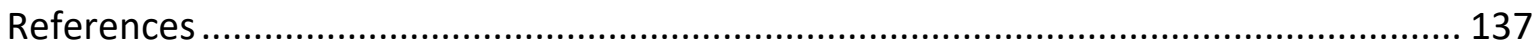

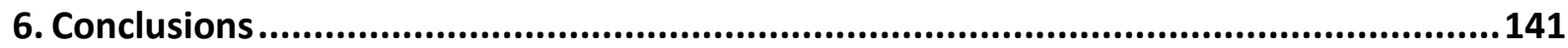

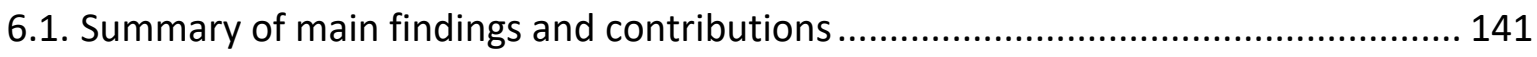

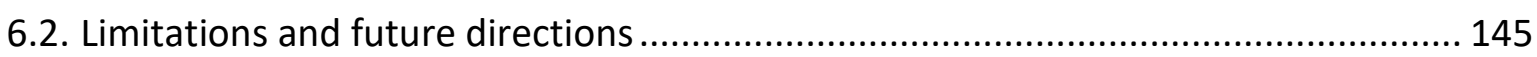

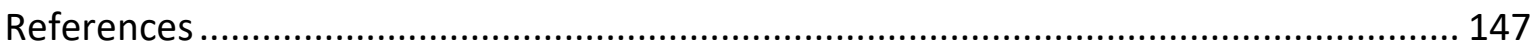

Supporting Information for Chapter 3 (Paper 2) ........................................................ 150

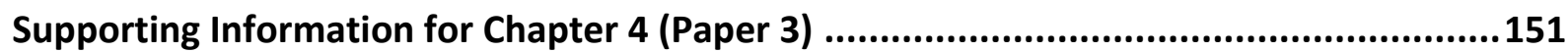




\section{List of Figures}

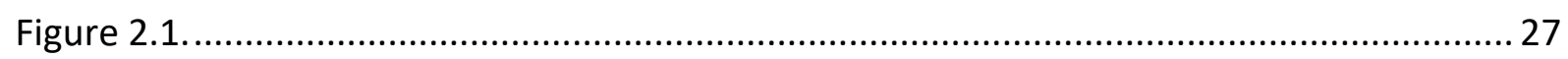

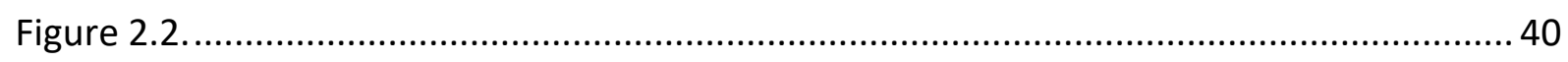

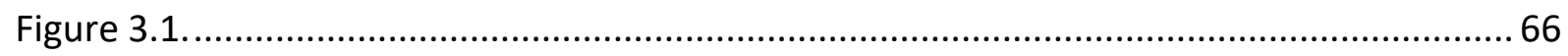

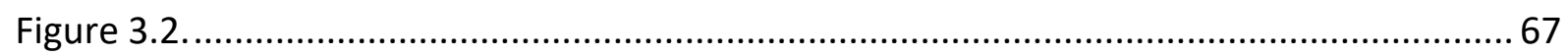

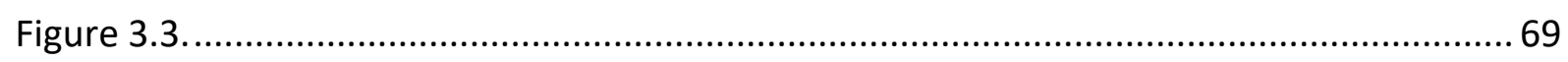

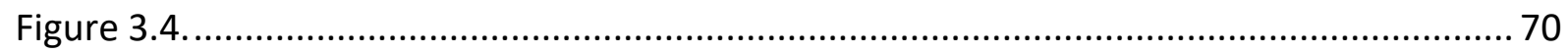

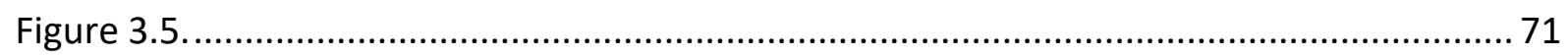

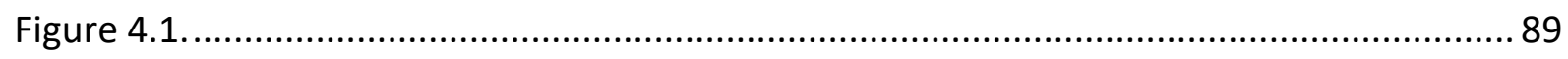

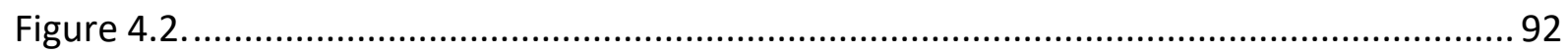

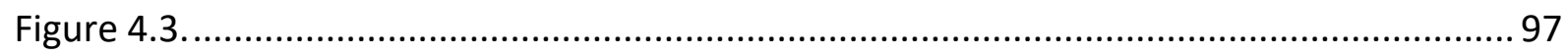

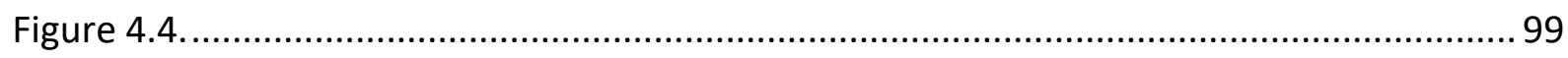

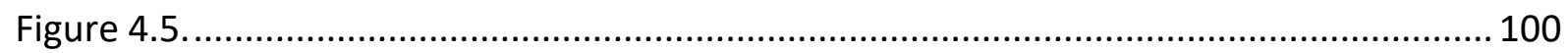

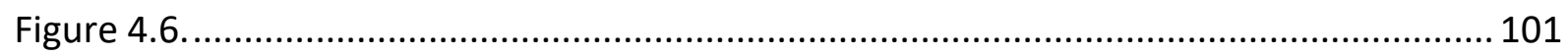

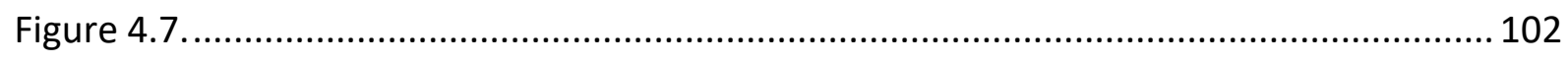

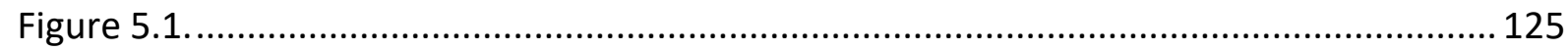

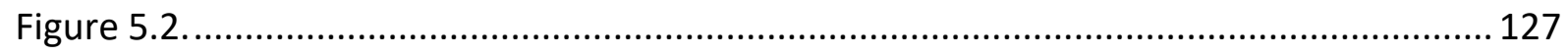

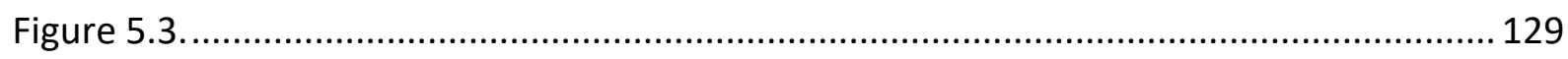

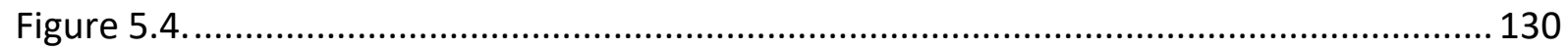

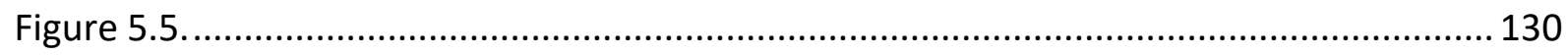

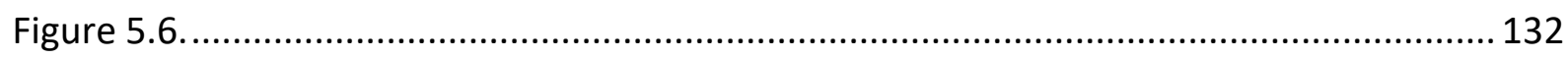

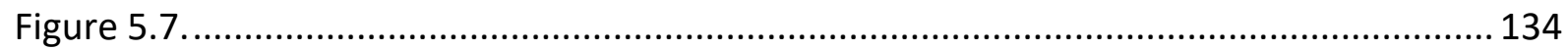




\section{List of Tables}

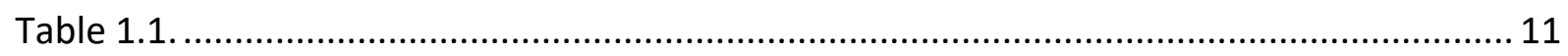

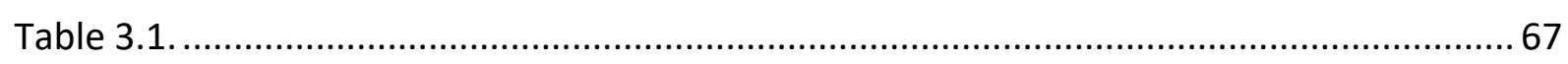

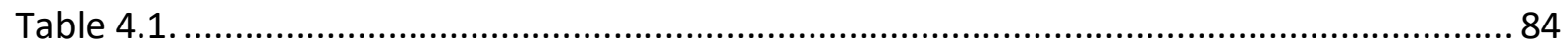

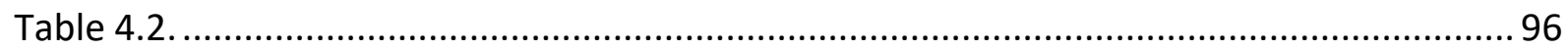

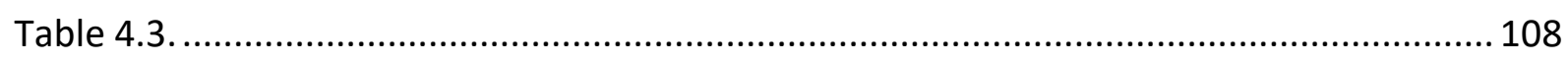

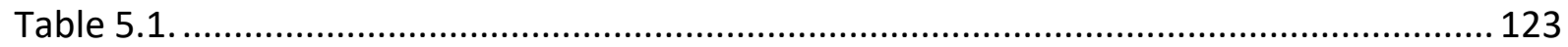

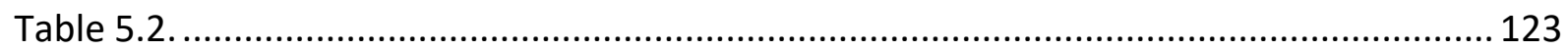




\title{
1. Introduction
}

\author{
"Models are most useful when they are used to challenge existing \\ formulations, rather than to validate or verify them. Any scientist who is \\ asked to use a model to verify or validate a predetermined result should be \\ suspicious." - Oreskes et al. (1994)
}

\subsection{Background}

\subsubsection{Motivation}

A scientific model is generally a hypothesis that represents some aspects of a real-world process. Models are used for three distinct types of model-based inferences, namely explanation, exploration, and extrapolation.

Explanation: models are used for explanatory analysis, to infer explanations about realworld systems through an iterative process of generating, testing, and refining model-based hypotheses. To this end, scientific models are most useful to challenge existing understanding and theories, rather than to validate or verify them (Oreskes et al., 1994).

Exploration: models are used for exploratory analysis, to explore different possibilities within the model space (Moallemi et al., 2020). That is, exploring a range of possible:

- $\quad$ model inputs, i.e. what variables can represent a system?;

- model structures, i.e. how (or in what configurations) those variables can represent the system?;

- model parameters, i.e. how a general model can be specified, e.g. calibrated for a particular catchment and period?; and/or

- model outputs, i.e. what future states are possible given a particular model of the real-world system?. 
Scenario analysis (what-if scenarios) is a common example of exploratory analysis.

Extrapolation: models are used for predictions beyond their calibration domain, whether in time or space; also known as transferability or transposability of models in space or time (Peel \& Blöschl, 2011, and references therein).

In the broadest sense, there are two types of hydrological models namely process-based models (e.g. distributed physics-based models and lumped catchment models) and black-box models (e.g. Artificial Neural Network models). Regardless of their commonalities, spectrum of sub-classes, and whether deterministic or stochastic, each model type takes a different approach to modelling catchment processes. On the one hand, there are process-based models whose primary aim is to represent catchment processes at the spatio-temporal scales of interest. For instance, a lumped daily rainfall-runoff model (in this thesis also referred to as catchment model) simulates runoff by transforming precipitation and evaporative forcing through catchment processes such as interception, evapotranspiration, infiltration, and runoff generating mechanisms (e.g. infiltration excess overland flow and saturation excess overland flow). The underlying connections and interactions of (real-world) catchment processes and stores are simplified and represented as model state variables, stores, and fluxes through the stores. The model adequacy is often evaluated by comparing how closely the simulated runoff matches the observed runoff at the scale of interest. Given the modelling purpose, different aspects of simulated and observed streamflow are evaluated, e.g. timing or magnitude of high/low flows across different time periods. On the other hand, in black-box models less emphasis is placed on catchment processes, and the aim is to numerically relate model inputs to model outputs through empirical relationships. In the case of rainfall-runoff modelling, the aim of a black-box model is to derive some statistical relationships between precipitation (model input) and runoff (model output) that results in the best match between modelled and observed runoff.

Given that catchment models incorporate catchment processes, even though simplified, that could be used for explanatory analysis to formulate and test as Multiple Working Hypotheses (MWH, Chamberlin, 1890) of catchment-scale hydrological processes such as runoff generation. Our understanding improves by modelling as a learning activity where models are treated as hypotheses of the real-world processes. Our understanding is ever-evolving 
yet always remains incomplete and uncertain, and while models may be effective (although simplified) representations of reality, they are forever-unfinished. Due to this symbiotic and never-ending process of learning and modelling, developing frameworks for evaluating conceptual models as hypotheses under uncertainty is - and will always be - a research priority in hydrological sciences (Blöschl et al., 2019) and beyond. Besides its scientific significance, realistic representation of hydrological processes within catchment models has important practical implications, e.g. for runoff projections under climatic changes (Guo et al., 2017).

\subsubsection{Aims and scope}

Scientific models are partial representations of reality (Cartwright, 1983). For instance, a catchment model at best would aggregate catchment processes up to a daily scale at the catchment scale. That is, sub-daily variations and spatial heterogeneity of catchment processes are often not represented within catchment models. While internal variables and stores of catchment models are at best simplified and approximate, and averaged over spatio-temporal scales, they are indicative of catchment behaviour and function. So, embedding internal fluxes within a catchment model provides a parsimonious way for formulating falsifiable hypotheses about catchment processes. Given the above, the overall aim of this thesis is to develop methods and frameworks for evaluating catchment models as hypotheses, with a particular focus on the internal fluxes of the models.

Various components of catchment models could be formulated and evaluated as hypotheses. For instance, Guo et al. (2017) evaluated the representation of evapotranspiration process within three catchment models, and demonstrated that these models are capable of adequately simulating observed runoff despite unrealistic modelled evapotranspiration fluxes. Li et al. (2015) showed that a catchment model can simulate the total observed streamflow well, for various catchments with different characteristics, but through unrealistic modelled runoff components of baseflow and quickflow. The mantra is "getting right answers for the right reasons" (Grayson et al., 1992; Kirchner, 2006; Klemeš, 1986). In the context of catchment models, "the reasons" are model components (fluxes and stores) that represent catchment processes that lead to runoff generation. The focus of this 
research is on the runoff generation components (or hydrograph components) simulated by catchment models, particularly modelled runoff fluxes that sum to the total simulated flow.

In general, there are four main (real-world) runoff generation sources: (1) Infiltration-excess overland flow which occurs when rainfall intensity exceeds the soil infiltrability, also known as Hortonian overland flow (Horton, 1933). (2) Saturation-excess overland flow, also known as Dunnian overland flow (Dunne \& Black, 1970), which occurs under saturated soil conditions, either due to direct rainfall (regardless of its intensity) on saturated soil, or due to the exfiltration (return flow) of a portion of interflow. (3) Subsurface stormflow which is the rapid lateral movement/displacement of subsurface flow under saturated soil conditions (Hewlett \& Hibbert, 1967). (4) Baseflow which is the slow release of water from the catchment store. As Saffarpour et al. (2016) argued, catchment wetness drives both saturation excess overland flow (Western \& Grayson, 1998; Western et al., 2005) and subsurface stormflow (Freer et al., 2002; Tromp van Meerveld \& McDonnell, 2005). Infiltration-excess overland flow is an intensity-based mechanism, and baseflow is a slow (and often continuous) response mechanism. Therefore, the runoff generation sources can be classified into three broad types of mechanisms: intensity-based and wetness-based event responses, and base flow (slow) response.

For this research, I chose two catchment models namely SIMHYD (Chiew et al., 2002; Peel et al., 2000) with 7 parameters, and SACRAMENTO (Burnash, 1995; Burnash et al., 1973) with 15 parameters, as they both simulate streamflow through runoff fluxes that distinctly represent these three types of runoff mechanisms. Both models are daily and lumped at catchment level, with the minimal input requirement of precipitation and potential evapotranspiration daily time series. My study area is a set of 221 Australian catchments, known as Hydrologic Reference Stations (Fowler, 2017; Turner, 2012). To calibrate a model to a particular catchment, an ensemble of working parameter sets will be used, as opposed to calibration to a single parameter set. Ensemble modelling is a way to account for modelling uncertainties. Here, I only account for parameter uncertainty, and do not explicitly account for other sources of modelling uncertainty such as forcing inputs, evaluation data (observed streamflow), and model structural uncertainties. In other words, various sources of modelling uncertainty are assumed to be lumped into model parameter uncertainty. An 
ensemble of catchment models that can adequately simulate runoff could be seen as runoff generation hypotheses (MWH).

Given the above, the overall aim of this research is to evaluate catchment models as $\mathrm{MWH}$, to particularly formulate hypotheses about streamflow simulation based on the runoff generating mechanisms that are embedded in catchment models. Specific research questions that contribute to achieving this overall aim are identified in Section 1.2.2.

\subsubsection{Thesis outlook}

First, in Chapter 2 (Paper 1), I will discuss the theoretical underpinnings of this research. Model evaluation methods are mainly based upon the concept of the equifinality of model structures or parameter sets; i.e. multiple model structures/parameters are equally capable to produce acceptable simulations of catchment processes such as runoff. Arguing that there is more to equifinality than just model structures/parameters, I propose a theoretical framework to conceptualise various facets of equifinality, based on a meta-synthesis of a broad range of literature across geosciences, system theory, and philosophy of science. I distinguish between various facets of equifinality, and discuss their implications for hypothesis testing and modelling of hydrological systems under uncertainty. Second (Chapter 3), building up on the proposed theoretical framework, I develop a new method for evaluation of catchment models based on the equifinality of runoff generating fluxes of catchment models - instead of the convention of model parameters equifinality - to derive MWH of runoff generation at the catchment scale. Third (Chapter 4), I explore the dependency of these MWH on the choice of model structure and parameterisation, error metric, and data information content, across 221 Australian catchments, to disentangle the role of each factor. Finally (Chapter 5), I further explore the dependency of runoff generation hypotheses (derived from catchment models) on catchment characteristics (physiographic, climatic, and streamflow response characteristics). The thesis ends (Chapter 6 ) with a brief discussion of conclusions and limitations of this research, including suggestions for future directions.

\subsection{Evaluating catchment models as hypotheses}

\subsubsection{A brief overview of the state of the art}


Catchment models can be evaluated from at least five main standpoints that are not mutually exclusive, namely performance, sensitivity, uncertainty, information, and realism. Below I briefly explain these standpoints, but since performance and uncertainty are the main focuses of this thesis, I will explain them in more detail:

1) performance: how well observed and modelled series match given some objective functions (or metrics). For instance, a catchment model can be evaluated based on its performance for simulating high flows (Mizukami et al., 2019) or low flows (Garcia et al., 2017; Pushpalatha et al., 2012; Ye et al., 1997), its overall performance (Bennett et al., 2013; Schaefli \& Gupta, 2007), or its performance under changing climate (Coron et al., 2012; Fowler et al., 2018; Vaze et al., 2010). NSE (Nash-Sutcliffe efficiency, Nash \& Sutcliffe, 1970), KGE (Kling-Gupta EfficiencyGupta et al., 2009; Kling et al., 2012), and WIA (Willmott et al., 2012, p. Willmott's refined Index of Agreement) are examples of most commonly used performance metrics. Metrics evaluate model performance against some benchmark (Seibert, 2001). The overall observed mean is the classic benchmark embedded in metrics such as NSE, KGE, and WIA, which is a lower benchmark (Seibert et al., 2018). There are more informative lower benchmarks such as the observed mean flow for every day that better represent seasonality of the flow (Schaefli \& Gupta, 2007). The ideal upper benchmark for these metrics is a perfect match between modelled and observed series, i.e. metric value of 1 . Given the potential errors in calibration/evaluation data, Seibert et al. (2018) argued that models should be evaluated based on a more realistic upper benchmark than a perfect match. They suggested to compare the performance of the model of interest against a benchmark model, i.e. another model calibrated for the study catchment/period which can be a conceptual model (Newman et al., 2017) or data-based model (Nearing et al., 2016). In general, there are three types of objective functions that are used, whether single or multiple, to evaluate catchment models:

a. statistical error metrics: metrics such as RMSE (root mean squared error), coefficient of determination, absolute bias, and percent bias can summarise the model errors statistically. NSE and KGE are essentially a combination of summary statistics like mean, standard deviation, and correlation coefficient. 
Model performance can be evaluated based on either a single or multiple metrics (Davtalab et al., 2017; Efstratiadis \& Koutsoyiannis, 2010; Fowler et al., 2018), whether for a single modelled variable like discharge or multiple variables such as discharge together with a water quality variable e.g. salt loads (Nathan \& Mudgway, 1997) or nitrate loads (Haas et al., 2016);

b. dynamic metrics: are metrics to evaluate how well catchment dynamics are modelled, more explicitly than statistical metrics. Hydrological signatures are quintessential examples of dynamic metrics that summarise particular aspects of catchment variables. For instance, Westerberg and McMillan (2015) discussed various rainfall-runoff signatures to summarise flow distributions (e.g. flow mean signature), flow regime (e.g. flow duration curve signature), rainfall-runoff relationship (e.g. rainfall-runoff ratio signature), or rainfall dynamics (e.g. mean annual precipitation), to name a few. Signatures can be local (e.g. runoff ratio or aridity index) or regional (e.g. annual evapotranspiration) (Kelleher et al., 2017). While using signatures for model evaluation is long-standing in hydrology, it was explicitly formalised as diagnostic evaluation (Gupta et al., 2008; Yilmaz et al., 2008). McMillan et al. (2017) provided guidelines for selecting hydrological signatures.

c. qualitative evaluation: are ways to elicit expert knowledge. The classic example is visual evaluation of the goodness-of-fit between modelled and observed variables (Chiew \& McMahon, 1993). Although qualitative and subjective, expert knowledge can provide valuable insights when further combined with quantitative measures (Crochemore et al., 2015).

2) sensitivity: how sensitive a particular model component (often model output) is to changes in other model components such as model inputs or parameters. In other words, sensitivity analysis (SA) is a way to study the model response surface (Razavi \& Gupta, 2015). There are different types of SA (e.g. local and global SA) each possible through various methods (e.g. variance-based, derivative-based, or Monte Carlo simulations) (Pianosi et al., 2016; Wagener \& Pianosi, 2019). SA could be used for different purposes namely factor prioritisation, factor fixing, and mapping (Pianosi et al., 2016). SA could also be used for understanding model behaviour (Haghnegahdar et al., 2017), such as understanding process simulation using 
catchment models. For instance, Melsen and Guse (2019) studied the sensitivity of the parameters of three catchment models for simulation of hydrological droughts. They demonstrated that parameter sensitivity to drought duration and deficit is influenced by the model structure and varies across different climate types. Pappenberger et al. (2008) argued that different methods of SA lead to different results e.g. different rankings of important model factors, and therefore there is uncertainty inherent in the sensitivity analysis.

3) uncertainty: how model behaviour and predictions are influenced by various sources and types of uncertainties (Beven, 2009, 2016; Montanari, 2007), to name a few:

a. uncertainty of model parameters (Beven \& Binley, 1992; Beven \& Freer, 2001; Duan et al., 2006; Kuczera, 1983),

b. model structural uncertainty (Clark et al., 2008; Yew Gan et al., 1997),

c. uncertainty in model predictions (Papacharalampous et al., 2020a; Papacharalampous et al., 2020b; Uhlenbrook et al., 1999),

d. uncertainty in data (McMillan et al., 2018), also known as disinformation in data (Beven \& Westerberg, 2011); whether as model inputs and forcing data (Beven, 2019; Kavetski et al., 2006a, 2006b) or observed discharge that model outputs are compared to (Beven \& Westerberg, 2011; Kiang et al., 2018; McMahon \& Peel, 2019; Westerberg et al., 2011),

e. uncertainty in hydrological signatures that are used to evaluate model performance (Westerberg \& McMillan, 2015; Westerberg et al., 2016),

f. uncertainty due to subjective modelling decisions (Addor \& Melsen, 2019; Melsen et al., 2019), and

g. uncertainty in process representation (Fenicia et al., 2011; Fenicia et al., 2008; Günther et al., 2019; Kavetski et al., 2011).

Similar to SA, there are various methods for estimating uncertainty analysis (e.g. Bayesian and non-Bayesian methods).

4) information: how models represent (or capture) information and informational relationships of real-world processes. For example, hydrological signatures are used in model evaluations as markers (indicators for minimal representation) of a particular catchment process, based on the information content of its corresponding data/measurements. Information-theoretic methods could also be used to 
understand and characterise process connectivity in models (Bennett et al., 2019), to evaluate model performance based on information-theoretic metrics (Gong et al., 2013; Pechlivanidis et al., 2014), or to develop information-theoretic hypothesis tests to see how well a model can reproduce the information content of the observed data (Nearing et al., 2020).

5) realism: to what extent model internal components and/or outputs are consistent with our understanding of the real-world processes (Antonetti \& Zappa, 2018; Beven, 2000; Euser et al., 2013; Gharari et al., 2014; Wagener, 2003).

The list of examples provided for each type is not exhaustive, rather representative of the spectrum of studies and discussions within the literature. Furthermore, as mentioned earlier these five standpoints are not mutually exclusive, but rather are indicative of emphasis on particular aspects of models.

\subsubsection{Knowledge gaps and research questions: a brief overview}

Ensemble modelling is becoming the established convention to calibrate/evaluate catchment models (Beven, 2009). Instead of using a single model structure or parameter set, modelbased learning is based upon a range of model structures or parameter sets, to account (at least to some extant) for modelling uncertainties. Model ensembles are treated as MWH (Beven, 2012, 2019; Kirchner, 2006), as opposed to models as reality, as theories, or only as operational tools for predictions (Cartwright, 1999; Chamberlin, 1890; Oreskes et al., 1994). This approach of models as MWH (or multi-hypotheses) has been an ongoing topic for research (and debate) within hydrological sciences (Beven, 2012, 2019; Beven et al., 2012; Buytaert \& Beven, 2011; Clark et al., 2011, 2012; Fenicia et al., 2008; Jehn et al., 2018; Kavetski \& Fenicia, 2011).

Ensemble modelling is based upon the concept of equifinality (sometimes referred to with other terms): multiple model structures or multiple parameter sets within a given model structure can equally produce acceptable model outputs (Beck, 1987; Konikow \& Bredehoeft, 1992; Oreskes et al., 1994; Yeh, 1986). For instance, an ensemble of models (structures or parameter sets) can equally reproduce an observed hydrograph (Beven, 2006; Beven \& Binley, 1992; Beven \& Freer, 2001; Gupta \& Sorooshian, 1983; Sorooshian \& Gupta, 1983). This concept of equifinality is widely recognised in hydrological modelling (and 
beyond), and is the cornerstone of most (if not all) methods of model uncertainty analysis (Beven, 2009).

Concepts of equifinality, uncertainty, $\mathrm{MWH}$, and model-based inferences (or multi-model inferences) are interrelated, and have been widely discussed and progressed over the past decades. That said, there is no theoretical framework in the literature of hydrological sciences to elaborate the connection between the aforementioned concepts. While the scope of this thesis is limited to catchment models, these concepts are discussed and developed beyond the domain of hydrological sciences, and have been discussed across a wide range of disciplines namely geosciences, uncertainty, system theory, biology, and philosophy of science. Based on an extensive multi-disciplinary literature review, I concluded that there is more to equifinality than just parameter (or model structural) equifinality.

Within Chapter 2, I present a detailed review of the concept of equifinality and its various facets. I further elaborate the theoretical relationship between equifinality, uncertainty, model-based inferences, and models as $\mathrm{MWH}$. This multi-disciplinary review allowed me to synthesise various notions and discussions of equifinality and other related concepts into a unified theoretical framework. This synthesis advances our understanding of hydrological systems, both real-world systems (i.e. hydrological processes) and conceptual systems (i.e. hydrological models). Given that Chapter 2 provides an extensive review and synthesis of the literature, here I will not discuss the literature any further to avoid repetition.

Table 1.1 presents a concise overview of the main knowledge gaps that I address in this thesis. Each knowledge gap is addressed under a particular Research Question (RQ) and a separate chapter of this thesis. The specifics of each research question and its relevant literature is discussed in more details in the corresponding chapter. 
Table 1.1. A summary of knowledge gaps, research questions (RQ), overall aims and outcomes of this thesis that are addressed in the following chapters. Knowledge Gaps

Research Questions

There is a theoretical disconnect in the literature. Equifinality

(including its various notions in system theory, geomorphology, and modelling), uncertainty, model-based inferences, and the paradigm of Multiple Working Hypotheses are discussed across various disciplines of Earth and environmental sciences. That said, these discussions are scattered across disciplines and can be limited, even though these concepts are interrelated and multifaceted.

There are two main general approaches for characterising the model solution space, which can be combined as well. (1) Response surface (or space) characterises the model performance based on some (single or multiple) objective functions (error metric, signature, etc.) and best parameter sets identified through sampling the parameter space. (2) Likelihood surface (or space) characterises the model uncertainty given some likelihood function and an ensemble of model runs generated from perturbing or sampling some aspects of the model e.g. parameter space, model inputs, or observed model output. Most model evaluation methods are based on assessing the model output (simulated runoff). Model internal fluxes (e.g. runoff fluxes) are often not evaluated, even though they could be insightful for evaluating catchment models as hypotheses.

It is well-established that model output is the result of the interplay of multiple factors namely model structure and parameterisation, objective functions (or error metrics), and data information content. But it is less clear how these factors interact to give rise to a particular model output; i.e. what model internal dynamics underly a given ensemble of acceptable model runs.

Various methods are to developed to numerically characterise/estimate the uncertaintes of model parameters, inputs, and predictions. That said, uncertainteis associated with model internal fluxes and stores are less understood; particularly, the how catchment physical and hydro-climatic attributes control the representation of catchment processes within catchment models.
RQ1) What is equifinality, and its theoretical relationship with uncertainty, model-based inferences, and models as Multiple Working Hypotheses? from catchment models as Multiple Working Hypotheses by accounting for other facets of modelequifinality, particularly equifinality of model internal runoff fluxes.

RQ3) What is the relationship between catchment model simulations (i.e. runoff Multiple Working Hypotheses) and a given set of model structure and parameterisation, error metrics, and data information content?

RQ4) What is the relationship between catchment model simulations (i.e. runoff Multiple Working Hypotheses) and and attributes (physiographic, climatic, and streamflow response) of the simulated catchments?
This chapter is a synthesis of various aspects and relationships between the mentioned concepts, across various disciplines. It suggests a unifying

framework to advance our system-theoretic understanding of hydrological processes (realworld systems) and hydrological models (conceptual systems).

\section{Method Development}

develop a method for constructing a hypothesis space to formulate Multiple Working Hypotheses about runoff generation in catchment models. I demonstrate that an acceptable simulated flow can be the result of different combinations of runoff fluxes embedded in the catchment model (i.e. equifinal runoff fluxes). In other words, I

demonstrate how uncertainty associated with equifinliay model parameter sets propogates through (equifinal) model internal fluxes and give rise to Multiple Working Hypotheses of runoff generation.

\section{Method Application}

The overall aim of this $R Q$ is to demonstrate how equifinal runoff fluxes are generated as the result of the interaction of the mentioned factors. This interaction is characterised through controlled modelling experiments, i.e. changing one of the mentioned factors at a time to evaluate its impact on runoff simulation.

\section{Method Application}

I identify catchment attributes that control the degree of equifinality of model runoff fluxes. Higher degree of flux equifinality implies larger uncertainties associated with the representation of runoff processes at catchment scale, and hence pose a greater challenge for reliable and realistic simulation and prediction of streamflow. The findings of this chapter provides insights into the functional connectivity of catchment attributes and the internal dynamics of model runoff fluxes. 


\section{References}

Addor, N., \& Melsen, L. A. (2019). Legacy, rather than adequacy, drives the selection of hydrological models. Water Resources Research, 55(1), 378-390.

doi:doi:10.1029/2018WR022958

Antonetti, M., \& Zappa, M. (2018). How can expert knowledge increase the realism of conceptual hydrological models? A case study based on the concept of dominant runoff process in the Swiss Pre-Alps. Hydrol. Earth Syst. Sci., 22(8), 4425-4447. doi:10.5194/hess-22$4425-2018$

Beck, M. B. (1987). Water quality modeling: A review of the analysis of uncertainty. Water Resources Research, 23(8), 1393-1442. doi:10.1029/WR023i008p01393

Bennett, A., Nijssen, B., Ou, G., Clark, M., \& Nearing, G. (2019). Quantifying Process Connectivity With Transfer Entropy in Hydrologic Models. Water Resources Research, 55(6), 4613-4629. doi:10.1029/2018wr024555

Bennett, N. D., Croke, B. F. W., Guariso, G., Guillaume, J. H. A., Hamilton, S. H., Jakeman, A. J., et al. (2013). Characterising performance of environmental models. Environmental Modelling \& Software, 40, 1-20. doi:https://doi.org/10.1016/i.envsoft.2012.09.011

Beven, K. (2006). A manifesto for the equifinality thesis. Journal of Hydrology, 320(1-2), 18-36. doi:http://dx.doi.org/10.1016/j.jhydrol.2005.07.007

Beven, K. (2009). Environmental modelling: an uncertain future? : CRC Press.

Beven, K. (2012). Causal models as multiple working hypotheses about environmental processes. Comptes rendus geoscience, 344(2), 77-88.

Beven, K. (2016). Facets of uncertainty: epistemic uncertainty, non-stationarity, likelihood, hypothesis testing, and communication. Hydrological Sciences Journal, 61(9), 1652-1665. doi:10.1080/02626667.2015.1031761

Beven, K. (2019). Towards a methodology for testing models as hypotheses in the inexact sciences. Proceedings of the Royal Society A: Mathematical, Physical and Engineering Sciences, 475(2224), 20180862. doi:doi:10.1098/rspa.2018.0862

Beven, K., \& Binley, A. (1992). The future of distributed models: Model calibration and uncertainty prediction. Hydrological Processes, 6(3), 279-298. doi:10.1002/hyp.3360060305

Beven, K., \& Freer, J. (2001). Equifinality, data assimilation, and uncertainty estimation in mechanistic modelling of complex environmental systems using the GLUE methodology. Journal of Hydrology, 249(1), 11-29.

Beven, K., Smith, P., Westerberg, I., \& Freer, J. (2012). Comment on "Pursuing the method of multiple working hypotheses for hydrological modeling" by P. Clark et al. Water Resources Research, 48(11), W11801. doi:10.1029/2012WR012282 
Beven, K., \& Westerberg, I. (2011). On red herrings and real herrings: disinformation and information in hydrological inference. Hydrological Processes, 25(10), 1676-1680. doi:10.1002/hyp.7963

Beven, K. J. (2000). Uniqueness of place and process representations in hydrological modelling. Hydrol. Earth Syst. Sci., 4(2), 203-213. doi:10.5194/hess-4-203-2000

Blöschl, G., Bierkens, M. F. P., Chambel, A., Cudennec, C., Destouni, G., Fiori, A., et al. (2019). Twenty-three Unsolved Problems in Hydrology (UPH) - a community perspective. Hydrological Sciences Journal. doi:https://doi.org/10.1080/02626667.2019.1620507

Burnash, R. J. C. (1995). The NWS River Forecast System - catchment modeling. In V. P. Singh (Ed.), Computer Models of Watershed Hydrology (pp. 311-366): Highlands Ranch, CO.

Burnash, R. J. C., Ferreal, R. L., \& McGuire, R. A. (1973). A generalized streamflow Simulation System: Conceptual Modeling for Digital Computers. Retrieved from

Buytaert, W., \& Beven, K. (2011). Models as multiple working hypotheses: hydrological simulation of tropical alpine wetlands. Hydrological Processes, 25(11), 1784-1799. doi:10.1002/hyp.7936

Cartwright, N. (1983). How the laws of physics lie. Oxford: Oxford University Press.

Cartwright, N. (1999). The dappled world: A study of the boundaries of science. Cambridge, UK: Cambridge University Press.

Chamberlin, T. C. (1890). The method of multiple working hypotheses. Science, 15, 92-96.

Chiew, F., Peel, M., \& Western, A. (2002). Application and testing of the simple rainfallrunoff model SIMHYD. In V. P. Singh \& D. Frevert (Eds.), Mathematical models of small watershed hydrology and applications (pp. 335-367).

Chiew, F. H. S., \& McMahon, T. A. (1993). Assessing the Adequacy of Catchment Streamflow Yield Estimates. Australian Journal of Soil Research, 31(5), 665-680. doi:10.1071/SR9930665

Clark, M. P., Kavetski, D., \& Fenicia, F. (2011). Pursuing the method of multiple working hypotheses for hydrological modeling. Water Resources Research, 47(9).

Clark, M. P., Kavetski, D., \& Fenicia, F. (2012). Reply to comment by K. Beven et al. on "Pursuing the method of multiple working hypotheses for hydrological modeling". Water Resources Research, 48(11).

Clark, M. P., Slater, A. G., Rupp, D. E., Woods, R. A., Vrugt, J. A., Gupta, H. V., et al. (2008). Framework for Understanding Structural Errors (FUSE): A modular framework to diagnose differences between hydrological models. Water Resources Research, 44(12). doi:doi:10.1029/2007WR006735

Coron, L., Andréassian, V., Perrin, C., Lerat, J., Vaze, J., Bourqui, M., et al. (2012). Crash testing hydrological models in contrasted climate conditions: An experiment on 216 
Australian catchments. Water Resources Research, 48(5), W05552.

doi:10.1029/2011WR011721

Crochemore, L., Perrin, C., Andréassian, V., Ehret, U., Seibert, S. P., Grimaldi, S., et al. (2015). Comparing expert judgement and numerical criteria for hydrograph evaluation. Hydrological Sciences Journal, 60(3), 402-423. doi:10.1080/02626667.2014.903331

Davtalab, R., Mirchi, A., Khatami, S., Gyawali, R., Massah, A., Farajzadeh, M., et al. (2017). Improving Continuous Hydrologic Modeling of Data-Poor River Basins Using Hydrologic Engineering Center's Hydrologic Modeling System: Case Study of Karkheh River Basin. Journal of Hydrologic Engineering, 22(8), 05017011. doi:https://doi.org/10.1061/(ASCE)HE.1943-5584.0001525

Duan, Q., Schaake, J., Andréassian, V., Franks, S., Goteti, G., Gupta, H. V., et al. (2006). Model Parameter Estimation Experiment (MOPEX): An overview of science strategy and major results from the second and third workshops. Journal of Hydrology, 320(1), 3-17. doi:https://doi.org/10.1016/i.jhydrol.2005.07.031

Dunne, T., \& Black, R. D. (1970). Partial Area Contributions to Storm Runoff in a Small New England Watershed. Water Resources Research, 6(5), 1296-1311.

doi:10.1029/WR006i005p01296

Efstratiadis, A., \& Koutsoyiannis, D. (2010). One decade of multi-objective calibration approaches in hydrological modelling: a review. Hydrological Sciences Journal, 55(1), 58-78. doi:10.1080/02626660903526292

Euser, T., Winsemius, H. C., Hrachowitz, M., Fenicia, F., Uhlenbrook, S., \& Savenije, H. H. G. (2013). A framework to assess the realism of model structures using hydrological signatures. Hydrol. Earth Syst. Sci., 17(5), 1893-1912. doi:10.5194/hess-17-1893-2013

Fenicia, F., Kavetski, D., \& Savenije, H. H. G. (2011). Elements of a flexible approach for conceptual hydrological modeling: 1. Motivation and theoretical development. Water Resources Research, 47(11). doi:10.1029/2010wr010174

Fenicia, F., Savenije, H. H. G., Matgen, P., \& Pfister, L. (2008). Understanding catchment behavior through stepwise model concept improvement. Water Resources Research, 44(1). doi:doi:10.1029/2006WR005563

Fowler, K. (2017). Towards improved rainfall-runoff modelling in changing climatic conditions. PhD thesis, University of Melbourne, Department of Infrastructure Engineering. Retrieved from http://hdl.handle.net/11343/208776

Fowler, K., Peel, M., Western, A., \& Zhang, L. (2018). Improved Rainfall-Runoff Calibration for Drying Climate: Choice of Objective Function. Water Resources Research, 54(5), 33923408. doi:doi:10.1029/2017WR022466

Freer, J., McDonnell, J. J., Beven, K. J., Peters, N. E., Burns, D. A., Hooper, R. P., et al. (2002). The role of bedrock topography on subsurface storm flow. Water Resources Research, 38(12), 5-1-5-16. doi:10.1029/2001wr000872 
Garcia, F., Folton, N., \& Oudin, L. (2017). Which objective function to calibrate rainfallrunoff models for low-flow index simulations? Hydrological Sciences Journal, 62(7), 11491166. doi:10.1080/02626667.2017.1308511

Gharari, S., Hrachowitz, M., Fenicia, F., Gao, H., \& Savenije, H. H. G. (2014). Using expert knowledge to increase realism in environmental system models can dramatically reduce the need for calibration. Hydrol. Earth Syst. Sci., 18(12), 4839-4859. doi:10.5194/hess-18-48392014

Gong, W., Gupta, H. V., Yang, D., Sricharan, K., \& Hero, A. O. (2013). Estimating epistemic and aleatory uncertainties during hydrologic modeling: An information theoretic approach. Water Resources Research, 49(4), 2253-2273. doi:10.1002/wrcr.20161

Grayson, R. B., Moore, I. D., \& McMahon, T. A. (1992). Physically based hydrologic modeling: 2. Is the concept realistic? Water Resources Research, 28(10), 2659-2666. doi:10.1029/92WR01259

Günther, D., Marke, T., Essery, R., \& Strasser, U. (2019). Uncertainties in Snowpack Simulations-Assessing the Impact of Model Structure, Parameter Choice, and Forcing Data Error on Point-Scale Energy Balance Snow Model Performance. Water Resources Research, 55(4), 2779-2800. doi:10.1029/2018wr023403

Guo, D., Westra, S., \& Maier, H. R. (2017). Impact of evapotranspiration process representation on runoff projections from conceptual rainfall-runoff models. Water Resources Research, 53(1), 435-454. doi:10.1002/2016WR019627

Gupta, H. V., Kling, H., Yilmaz, K. K., \& Martinez, G. F. (2009). Decomposition of the mean squared error and NSE performance criteria: Implications for improving hydrological modelling. Journal of Hydrology, 377(1-2), 80-91.

doi:http://dx.doi.org/10.1016/i.jhydrol.2009.08.003

Gupta, H. V., Wagener, T., \& Liu, Y. (2008). Reconciling theory with observations: elements of a diagnostic approach to model evaluation. Hydrological Processes, 22(18), 3802-3813. doi:10.1002/hyp.6989

Gupta, V. K., \& Sorooshian, S. (1983). Uniqueness and observability of conceptual rainfallrunoff model parameters: The percolation process examined. Water Resources Research, 19(1), 269-276. doi:10.1029/WR019i001p00269

Haas, M. B., Guse, B., Pfannerstill, M., \& Fohrer, N. (2016). A joined multi-metric calibration of river discharge and nitrate loads with different performance measures. Journal of Hydrology, 536, 534-545. doi:https://doi.org/10.1016/j.jhydrol.2016.03.001

Haghnegahdar, A., Razavi, S., Yassin, F., \& Wheater, H. (2017). Multicriteria sensitivity analysis as a diagnostic tool for understanding model behaviour and characterizing model uncertainty. Hydrological Processes, 31(25), 4462-4476. doi:10.1002/hyp.11358 
Hewlett, J. D., \& Hibbert, A. R. (1967). Factors affecting the response of small watersheds to precipitation in humid areas. In W. E. Sopper \& H. W. Lull (Eds.), Forest Hydrology (pp. 275-291). New York: Pergamon Press.

Horton, R. E. (1933). The Role of infiltration in the hydrologic cycle. Eos, Transactions American Geophysical Union, 14(1), 446-460. doi:10.1029/TR014i001p00446

Jehn, F. U., Breuer, L., Houska, T., Bestian, K., \& Kraft, P. (2018). Incremental model breakdown to assess the multi-hypotheses problem. Hydrol. Earth Syst. Sci., 22(8), 45654581. doi:10.5194/hess-22-4565-2018

Kavetski, D., \& Fenicia, F. (2011). Elements of a flexible approach for conceptual hydrological modeling: 2. Application and experimental insights. Water Resources Research, 47(11). doi:10.1029/2011wr010748

Kavetski, D., Fenicia, F., \& Clark, M. P. (2011). Impact of temporal data resolution on parameter inference and model identification in conceptual hydrological modeling: Insights from an experimental catchment. Water Resources Research, 47(5).

Kavetski, D., Kuczera, G., \& Franks, S. W. (2006a). Bayesian analysis of input uncertainty in hydrological modeling: 1. Theory. Water Resources Research, 42(3), W03407. doi:10.1029/2005WR004368

Kavetski, D., Kuczera, G., \& Franks, S. W. (2006b). Bayesian analysis of input uncertainty in hydrological modeling: 2. Application. Water Resources Research, 42(3), W03408.

doi:10.1029/2005WR004376

Kelleher, C., McGlynn, B., \& Wagener, T. (2017). Characterizing and reducing equifinality by constraining a distributed catchment model with regional signatures, local observations, and process understanding. Hydrol. Earth Syst. Sci., 21(7), 3325-3352. doi:10.5194/hess-213325-2017

Kiang, J. E., Gazoorian, C., McMillan, H., Coxon, G., Le Coz, J., Westerberg, I. K., et al. (2018). A Comparison of Methods for Streamflow Uncertainty Estimation. Water Resources Research, 54(10), 7149-7176. doi:10.1029/2018wr022708

Kirchner, J. W. (2006). Getting the right answers for the right reasons: Linking measurements, analyses, and models to advance the science of hydrology. Water Resources Research, 42(3), W03S04. doi:10.1029/2005WR004362

Klemeš, V. (1986). Dilettantism in hydrology: Transition or destiny? Water Resources Research, 22(9S), 177S-188S. doi:10.1029/WR022i09Sp0177S

Kling, H., Fuchs, M., \& Paulin, M. (2012). Runoff conditions in the upper Danube basin under an ensemble of climate change scenarios. Journal of Hydrology, 424-425, 264-277. doi:https://doi.org/10.1016/i.jhydrol.2012.01.011 
Konikow, L. F., \& Bredehoeft, J. D. (1992). Ground-water models cannot be validated. Advances in Water Resources, 15(1), 75-83. doi:http://dx.doi.org/10.1016/03091708(92)90033-X

Kuczera, G. (1983). Improved parameter inference in catchment models: 1. Evaluating parameter uncertainty. Water Resources Research, 19(5), 1151-1162.

doi:10.1029/WR019i005p01151

Li, L., Lambert, M. F., Maier, H. R., Partington, D., \& Simmons, C. T. (2015). Assessment of the internal dynamics of the Australian Water Balance Model under different calibration regimes. Environmental Modelling \& Software, 66, 57-68.

doi:https://doi.org/10.1016/i.envsoft.2014.12.015

McMahon, T. A., \& Peel, M. C. (2019). Uncertainty in stage-discharge rating curves: application to Australian Hydrologic Reference Stations data. Hydrological Sciences Journal, 64(3), 255-275. doi:10.1080/02626667.2019.1577555

McMillan, H., Westerberg, I., \& Branger, F. (2017). Five guidelines for selecting hydrological signatures. Hydrological Processes, 31(26), 4757-4761. doi:10.1002/hyp.11300

McMillan, H. K., Westerberg, I. K., \& Krueger, T. (2018). Hydrological data uncertainty and its implications. Wiley Interdisciplinary Reviews: Water, 5(6), e1319.

doi:doi:10.1002/wat2.1319

Melsen, L. A., \& Guse, B. (2019). Hydrological Drought Simulations: How Climate and Model Structure Control Parameter Sensitivity. Water Resources Research, 55(12), 1052710547. doi:10.1029/2019wr025230

Melsen, L. A., Teuling, A. J., Torfs, P. J. J. F., Zappa, M., Mizukami, N., Mendoza, P. A., et al. (2019). Subjective modeling decisions can significantly impact the simulation of flood and drought events. Journal of Hydrology, 568, 1093-1104.

doi:https://doi.org/10.1016/i.jhydrol.2018.11.046

Mizukami, N., Rakovec, O., Newman, A. J., Clark, M. P., Wood, A. W., Gupta, H. V., et al. (2019). On the choice of calibration metrics for "high-flow" estimation using hydrologic models. Hydrol. Earth Syst. Sci., 23(6), 2601-2614. doi:10.5194/hess-23-2601-2019

Moallemi, E. A., Kwakkel, J., de Haan, F. J., \& Bryan, B. A. (2020). Exploratory modeling for analyzing coupled human-natural systems under uncertainty. Global Environmental Change, 65, 102186. doi:https://doi.org/10.1016/i.gloenvcha.2020.102186

Montanari, A. (2007). What do we mean by 'uncertainty'? The need for a consistent wording about uncertainty assessment in hydrology. Hydrological Processes, 21(6), 841-845. doi:10.1002/hyp.6623

Nash, J. E., \& Sutcliffe, J. V. (1970). River flow forecasting through conceptual models part I - A discussion of principles. Journal of Hydrology, 10(3), 282-290.

doi:http://dx.doi.org/10.1016/0022-1694(70)90255-6 
Nathan, R. J., \& Mudgway, L. B. (1997). Estimating Salt Loads in High Water Table Areas. II: Regional Salt Loads. Journal of Irrigation and Drainage Engineering, 123(2), 91-99. doi:doi:10.1061/(ASCE)0733-9437(1997)123:2(91)

Nearing, G. S., Mocko, D. M., Peters-Lidard, C. D., Kumar, S. V., \& Xia, Y. (2016). Benchmarking NLDAS-2 Soil Moisture and Evapotranspiration to Separate Uncertainty Contributions. Journal of Hydrometeorology, 17(3), 745-759. doi:10.1175/jhm-d-15-0063.1

Nearing, G. S., Ruddell, B. L., Bennett, A. R., Prieto, C., \& Gupta, H. V. (2020). Does Information Theory Provide a New Paradigm for Earth Science? Hypothesis Testing. Water Resources Research, 56(2), e2019WR024918. doi:10.1029/2019wr024918

Newman, A. J., Mizukami, N., Clark, M. P., Wood, A. W., Nijssen, B., \& Nearing, G. (2017). Benchmarking of a Physically Based Hydrologic Model. Journal of Hydrometeorology, 18(8), 2215-2225. doi:10.1175/jhm-d-16-0284.1

Oreskes, N., Shrader-Frechette, K., \& Belitz, K. (1994). Verification, validation, and confirmation of numerical models in the earth sciences. Science, 263(5147), 641-646.

Papacharalampous, G., Koutsoyiannis, D., \& Montanari, A. (2020a). Quantification of predictive uncertainty in hydrological modelling by harnessing the wisdom of the crowd: Methodology development and investigation using toy models. Advances in Water Resources, 136, 103471. doi:https://doi.org/10.1016/j.advwatres.2019.103471

Papacharalampous, G., Tyralis, H., Koutsoyiannis, D., \& Montanari, A. (2020b). Quantification of predictive uncertainty in hydrological modelling by harnessing the wisdom of the crowd: A large-sample experiment at monthly timescale. Advances in Water Resources, 136, 103470. doi:https://doi.org/10.1016/j.advwatres.2019.103470

Pappenberger, F., Beven, K. J., Ratto, M., \& Matgen, P. (2008). Multi-method global sensitivity analysis of flood inundation models. Advances in Water Resources, 31(1), 1-14. doi:https://doi.org/10.1016/i.advwatres.2007.04.009

Pechlivanidis, I. G., Jackson, B., McMillan, H., \& Gupta, H. (2014). Use of an entropy-based metric in multiobjective calibration to improve model performance. Water Resources Research, 50(10), 8066-8083. doi:doi:10.1002/2013WR014537

Peel, M. C., \& Blöschl, G. (2011). Hydrological modelling in a changing world. Progress in Physical Geography, 35(2), 249-261. doi:10.1177/0309133311402550

Peel, M. C., Chiew, F. H., Western, A. W., \& McMahon, T. A. (2000). Extension of unimpaired monthly streamflow data and regionalisation of parameter values to estimate streamflow in ungauged catchments. Retrieved from Report prepared for the National Land and Water Resources Audit, In Australian Natural Resources Atlas, Pages 37.:

http://people.eng.unimelb.edu.au/mpeel/NLWRA.pdf

Pianosi, F., Beven, K., Freer, J., Hall, J. W., Rougier, J., Stephenson, D. B., et al. (2016). Sensitivity analysis of environmental models: A systematic review with practical workflow. 
Environmental Modelling \& Software, 79, 214-232.

doi:https://doi.org/10.1016/j.envsoft.2016.02.008

Pushpalatha, R., Perrin, C., Moine, N. L., \& Andréassian, V. (2012). A review of efficiency criteria suitable for evaluating low-flow simulations. Journal of Hydrology, 420-421, 171-182. doi:https://doi.org/10.1016/i.jhydrol.2011.11.055

Razavi, S., \& Gupta, H. V. (2015). What do we mean by sensitivity analysis? The need for comprehensive characterization of "global" sensitivity in Earth and Environmental systems models. Water Resources Research, 51(5), 3070-3092. doi:doi:10.1002/2014WR016527

Saffarpour, S., Western, A. W., Adams, R., \& McDonnell, J. J. (2016). Multiple runoff processes and multiple thresholds control agricultural runoff generation. Hydrol. Earth Syst. Sci., 20(11), 4525-4545. doi:10.5194/hess-20-4525-2016

Schaefli, B., \& Gupta, H. V. (2007). Do Nash values have value? Hydrological Processes, 21(15), 2075-2080. doi:10.1002/hyp.6825

Seibert, J. (2001). On the need for benchmarks in hydrological modelling. Hydrological Processes, 15(6), 1063-1064. doi:doi:10.1002/hyp.446

Seibert, J., Vis, M. J. P., Lewis, E., \& van Meerveld, H. J. (2018). Upper and lower benchmarks in hydrological modelling. Hydrological Processes, 32(8), 1120-1125. doi:10.1002/hyp.11476

Sorooshian, S., \& Gupta, V. K. (1983). Automatic calibration of conceptual rainfall-runoff models: The question of parameter observability and uniqueness. Water Resources Research, 19(1), 260-268. doi:10.1029/WR019i001p00260

Tromp van Meerveld, I., \& McDonnell, J. J. (2005). Comment to "Spatial correlation of soil moisture in small catchments and its relationship to dominant spatial hydrological processes, Journal of Hydrology 286: 113-134". Journal of Hydrology, 303(1), 307-312. doi:https://doi.org/10.1016/i.jhydrol.2004.09.002

Turner, M. (2012). Hydrologic Reference Station Selection Guidelines. Retrieved from Melbourne, Australia:

http://www.bom.gov.au/water/hrs/media/static/papers/Selection Guidelines.pdf

Uhlenbrook, S., Seibert, J., Leibundgut, C., \& Rodhe, A. (1999). Prediction uncertainty of conceptual rainfall-runoff models caused by problems in identifying model parameters and structure. Hydrological Sciences Journal, 44(5), 779-797.

Vaze, J., Post, D. A., Chiew, F. H. S., Perraud, J. M., Viney, N. R., \& Teng, J. (2010). Climate non-stationarity - Validity of calibrated rainfall-runoff models for use in climate change studies. Journal of Hydrology, 394(3-4), 447-457.

doi:http://dx.doi.org/10.1016/j.jhydrol.2010.09.018

Wagener, T. (2003). Evaluation of catchment models. Hydrological Processes, 17(16), 3375-3378. doi:10.1002/hyp.5158 
Wagener, T., \& Pianosi, F. (2019). What has Global Sensitivity Analysis ever done for us? A systematic review to support scientific advancement and to inform policy-making in earth system modelling. Earth-Science Reviews, 194, 1-18.

doi:https://doi.org/10.1016/i.earscirev.2019.04.006

Westerberg, I., Guerrero, J. L., Seibert, J., Beven, K. J., \& Halldin, S. (2011). Stage-discharge uncertainty derived with a non-stationary rating curve in the Choluteca River, Honduras. Hydrological Processes, 25(4), 603-613. doi:10.1002/hyp.7848

Westerberg, I. K., \& McMillan, H. K. (2015). Uncertainty in hydrological signatures. Hydrol. Earth Syst. Sci., 19(9), 3951-3968. doi:10.5194/hess-19-3951-2015

Westerberg, I. K., Wagener, T., Coxon, G., McMillan, H. K., Castellarin, A., Montanari, A., et al. (2016). Uncertainty in hydrological signatures for gauged and ungauged catchments. Water Resources Research, 52(3), 1847-1865. doi:doi:10.1002/2015WR017635

Western, A. W., \& Grayson, R. B. (1998). The Tarrawarra Data Set: Soil moisture patterns, soil characteristics, and hydrological flux measurements. Water Resources Research, 34(10), 2765-2768. doi:doi:10.1029/98WR01833

Western, A. W., Zhou, S.-L., Grayson, R. B., McMahon, T. A., Blöschl, G., \& Wilson, D. J. (2005). Reply to comment by Tromp van Meerveld and McDonnell on Spatial correlation of soil moisture in small catchments and its relationship to dominant spatial hydrological processes. Journal of Hydrology, 303(1), 313-315.

doi:https://doi.org/10.1016/j.jhydrol.2004.09.001

Willmott, C. J., Robeson, S. M., \& Matsuura, K. (2012). A refined index of model performance. International Journal of Climatology, 32(13), 2088-2094. doi:10.1002/joc.2419

Ye, W., Bates, B. C., Viney, N. R., Sivapalan, M., \& Jakeman, A. J. (1997). Performance of conceptual rainfall-runoff models in low-yielding ephemeral catchments. Water Resources Research, 33(1), 153-166. doi:doi:10.1029/96WR02840

Yeh, W. W. G. (1986). Review of Parameter Identification Procedures in Groundwater Hydrology: The Inverse Problem. Water Resources Research, 22(2), 95-108. doi:10.1029/WR022i002p00095

Yew Gan, T., Dlamini, E. M., \& Biftu, G. F. (1997). Effects of model complexity and structure, data quality, and objective functions on hydrologic modeling. Journal of Hydrology, 192(1-4), 81-103. doi:http://dx.doi.org/10.1016/S0022-1694(96)03114-9

Yilmaz, K. K., Gupta, H. V., \& Wagener, T. (2008). A process-based diagnostic approach to model evaluation: Application to the NWS distributed hydrologic model. Water Resources Research, 44(9). doi:doi:10.1029/2007WR006716 


\section{Theoretical underpinnings (Paper 1)}

This Chapter, written in American English, is prepared to be submitted to journal WIRES (Wiley Interdisciplinary Reviews) Water.

\section{A Theoretical Framework based on Equifinality for Hypothesis Testing and Modelling Hydrological Systems under Uncertainty}

Sina Khatami ${ }^{1}$, Murray C. Peel ${ }^{1}$, Tim J. Peterson $^{1}$, Andrew W. Western $^{1}$

${ }^{1}$ Department of Infrastructure Engineering, University of Melbourne, Parkville, Victoria, 3010, Australia

Key points:

- We present a theoretical framework that unifies various notions and facets of equifinality across a wide range of Earth and environmental sciences.

- The framework elaborates the relationship between concepts of equifinality, uncertainty, model-based inferences, and the paradigm of Multiple Working Hypotheses.

- This theoretical framework advances our system-theoretic understanding of hydrological processes (real-world systems) and hydrological models (conceptual systems). 
"I can live with doubt and uncertainty and not knowing... I have

approximate answers and possible beliefs, and different degrees of

certainty about different things, but I'm not absolutely sure of anything and there are many things I don't know anything about... I don't have to know an answer, I don't feel frightened by not knowing things, by being lost in a mysterious universe without having any purpose, which is the way it really is, as far as I can tell, possibly. ${ }^{11}$ Richard P. Feynman (1918-1988)

\section{Abstract}

All models are wrong, all data are erroneous, all model evaluations are incomplete, and our knowledge of real-world processes is fallible. Therefore, uncertainty is an inalienable property of any scientific inquiry. At the heart of uncertainty lies the concept of equifinality, i.e. a given finality is equally reachable through distinct developmental pathways (i.e. processes and mechanisms). Equifinality is a characteristic property of open complex systems particularly Earth and environmental systems including hydrological ones. A review of the literature reveals that despite the widespread use of the term, equifinality is mostly used inconsistently and understood/implemented in terms of parameter equifinality/uncertainty. Therefore, in this paper we present a conceptual history of equifinality in science and propose a theoretical framework - based on a meta-synthesis of literature from geosciences, uncertainty, system theory, biology, and philosophy of science - to conceptualize various facets of equifinality and their inter-relationships. Based on this framework, we advocate for scientific inquiry in the sense of plausibility and within the paradigm of Multiple Working Hypotheses (MWH). In the context of modeling under uncertainty, the framework implies using and evaluating models as plausible multihypotheses, particularly when dealing with open complex systems.

\subsection{Introduction}

\footnotetext{
${ }^{1}$ from BBC Horizon Series 18 Episode 9 "Feynman, The Pleasure of Finding Things Out" aired on 23 November 1981
} 
Blöschl et al. (2019) provided a blueprint of a set of "23 Unsolved Problems in Hydrology" to better direct the future research efforts of the hydrological sciences community. With regards to hydrological modeling, while the progress of the community over the past decades was acknowledged, the desire for a more coherent framework for modeling under uncertainty was emphasized. Here we outline an overarching framework to conceptualize equifinality, and to advance the ongoing debate on the theoretical underpinnings of conceptual modeling under uncertainty (Beven, 2002, 2019; Clark et al., 2011; Clark et al., 2016; Hrachowitz \& Clark, 2017; Khatami et al., 2019; Nearing et al., 2016), which is applicable to any domain of Earth and environmental sciences.

We reviewed a large body of literature from geosciences, uncertainty, system theory, biology, and philosophy of science. Based on our review, we argue that the Earth and environmental modeling community understands and implements equifinality predominantly in terms of model structural and parameter uncertainty (Khatami et al., 2019), and equifinality itself is lacking an explicit and coherent conceptualization. Within the literature, equifinality is so deeply entangled with parameter uncertainty that the two are often conflated. Despite progress in the area of uncertainty, equifinality is an unknown known, i.e. a known that is overlooked and not properly understood. Although the interconnection between uncertainty and equifinality cannot be ignored, in this paper we argue that equifinality-like uncertainty-is a separate and distinct concept with multiple facets, and there is more to equifinality than just parameter uncertainty. Our review reveals that the term equifinality has been used frequently and widely, but in many cases inconsistently and without acknowledgement of the various aspects of equifinality, which can lead to both ambiguity and methodological fallacies. To elaborate this deficiency, we first present a concise conceptual history of equifinality (section 2.2.1). This helps to shed light on the current gap(s) in conceptualization and implementation of equifinality in the hydrological sciences, where the concept of equifinality received considerable attention (section 2.2.2). Building on that, we develop a theoretical framework to conceptualize three facets of equifinality namely process-equifinality, model-equifinality and explanationequifinality (section 2.3.2). Distinct aspects of equifinality have not previously been characterized clearly within a coherent framework. We further render an epistemological account to elaborate the relationship of equifinality and knowledge uncertainty (section 
2.3.3), and discuss the implications of our framework for scientific inquiry and hypothesis testing (section 2.3.4) as well as modeling under uncertainty (section 2.3.5).

In essence, we advocate for scientific inquiry, including modeling under uncertainty, only in the sense of plausibility, using abductive reasoning and within the paradigm of Multiple Working Hypotheses (MWH, Chamberlin, 1890). Our framework is generalizable to any domain that deals with understanding and modeling open complex systems under uncertainty (Döll \& Romero-Lankao, 2017; Ghanem et al., 2017; Khazaei et al., 2019a; Maier et al., 2016; Moallemi et al., 2018; Moallemi \& Köhler, 2019; Moallemi \& Malekpour, 2017).

\subsection{A panoramic view on equifinality}

\subsubsection{Genesis of equifinality}

The notion of equifinality was first introduced by Hans Driesch, a German biologist and philosopher. Driesch identified equifinality as a developmental principle describing a situation when developing organisms of the same species could reach the same finality/endpoint either (a) from different initial conditions, and/or (b) through different developmental pathways (Driesch, 1908, pp. 159-162). He presented examples of different types of equifinality, such as (a) and (b) above, in the context of the restitution of biological organisms, and referred to this as the problem of the "Equifinality of Restitutions". Driesch's notion of equifinality has become an axiom of Developmental Systems Theory-a theoretical perspective on biological development, heredity, and evolution (Gottlieb, 2003, p. 4).

Later, von Bertalanffy (1968) demonstrated that the principle of equifinality is a characteristic property of any open system. A system is open when "there is import and export and, therefore, change of the components" (von Bertalanffy, 1950). In other words, an open system (e.g. the living organisms discussed earlier by Driesch) is interacting with its environments, and its behavior depends upon this interaction, which might be exchanges of material, energy, or information. On the other hand, von Bertalanffy (1968, p. 40) argued that a closed system is not influenced by the external environment, so its final state is "unequivocally determined by the initial conditions". For open systems, however, similar final states may be equally reached through different pathways and/or from different initial conditions. von Bertalanffy (1968, pp. 32-33 \& 39-41) further argued that conventional 
physics and physical chemistry (e.g. classical laws of thermodynamics), hitherto, deal with closed systems, and are not necessarily applicable to open systems. Therefore, generalized models, principles, and laws are required that are independent from the type and nature of the system. He postulated the new discipline/paradigm of General Systems Theory (GST), which aims to formulate and derive universal principles, such as the principle of equifinality, that are valid for systems in general (von Bertalanffy, 1968, pp. 32-33).

"General formulations", such as the principle of equifinality are nonetheless not enough to provide "explanation" for specific phenomena as they are open to "system-theoretical interpretations" (von Bertalanffy, 1968, pp. 32-36). That is, such general formulations lack explanatory value unless special conditions are considered (von Bertalanffy, 1968, p. 133), and specified in the context of the system under study to be able to meaningfully interpret such generalized principles. Although the principle of equifinality is extendable to any field of Earth and environmental sciences that deals with open complex systems, in the next section we focus our discussion on hydrological systems.

\subsubsection{Equifinality in hydrology}

Inspired by von Bertalanffy's GST, Beven (1975, p. 14) presented the first use of the term equifinality in the domain of hydrological modeling. Later, Beven (1993) proposed a concept of equifinality for model evaluation and uncertainty analysis. Based on his suggested concept, the operational definition of equifinality is that different model structures and/or parameter sets (i.e. equal pathways) are equally capable of reproducing a given observed behavior. For example, in the case of rainfall-runoff modeling, for a given criterion of reproducibility (e.g. an objective function), a number of rainfall-runoff models (i.e. distributed or lumped, process-based or data-based, etc. such as TOPMODEL, HBV, Sacramento, etc.) and/or various parameter sets might be able to equally reproduce a particular observed runoff hydrograph. This operational definition of equifinality is closely related to structural and parameter uncertainty, and is the cornerstone of sensitivity and uncertainty estimation frameworks such as generalized sensitivity (Hornberger \& Spear, 1981, nowadays referred to as Regional Sensitivity Analysis) and GLUE (Generalized Likelihood Uncertainty Estimation, (Beven \& Binley, 1992; Beven \& Binley, 2014)). 
In hydrology, or any other domain of Earth and environmental sciences, the concept of system could refer to both real-world processes as well as their corresponding models. The real-world hydrological cycle including catchment processes are quintessential examples of open systems as they exchange energy and mass with their surrounding environment (including ecosystem and human activities). Humans also understand and conceptually represent this cycle as an open system. Having said that, we acknowledge that there are different understandings of the water cycle (Abbott et al., 2019), and one may conceptualize the hydrological cycle as an ad hoc closed system to only consider the transfer and transformation of water within the cycle itself (Dooge, 1968). Models of hydrological processes (mathematical and computer-based), are also open systems given their datadriven nature (exchange of information with their environment, i.e. user/modeler).

Within the framework of GST and given that both real-world hydrological processes and their models can be characterized as open systems, the GST framework implies that equifinality is a characteristic of each of these systems. That said, given the fundamental (ontological) differences between these systems, each requires specific contextualization. In the next section, we formulate a theoretical framework that introduces and conceptualizes process-equifinality, and model-equifinality as discrete system-theoretical interpretations of the principle of equifinality within the context of the real-world and conceptual systems accordingly. We further introduce another facet of equifinality, namely explanationequifinality, and discuss the relations and implications of these facets for scientific inquiry.

\subsection{The theoretical framework of equifinality}

\subsubsection{Overview}

In this section, we broaden our discussion by presenting a theoretical framework to disambiguate equifinality and characterize its various facets (summarized in Figure 2.1). The framework is based upon a meta-synthesis of geosciences, uncertainty, system theory, and philosophy of science literature, and applicable to any domain of Earth and environmental sciences. First, some semantic hygiene is essential, i.e. what do we mean by equifinality? To this end, we first characterize three main facets of equifinality namely process-equifinality, model-equifinality, and explanation-equifinality. We then outline an epistemological account 
to discuss the relationship of equifinality and knowledge uncertainty, and further discuss the implication of the framework for hypothesis testing under uncertainty.

\subsubsection{Facets of equifinality: a meta-synthesis}

Earth and environmental systems-whether real-world e.g. catchment systems, or conceptual i.e. scientific models-are open systems. Therefore, the principle of equifinality applies to each and should be interpreted separately (see Figure 2.1).

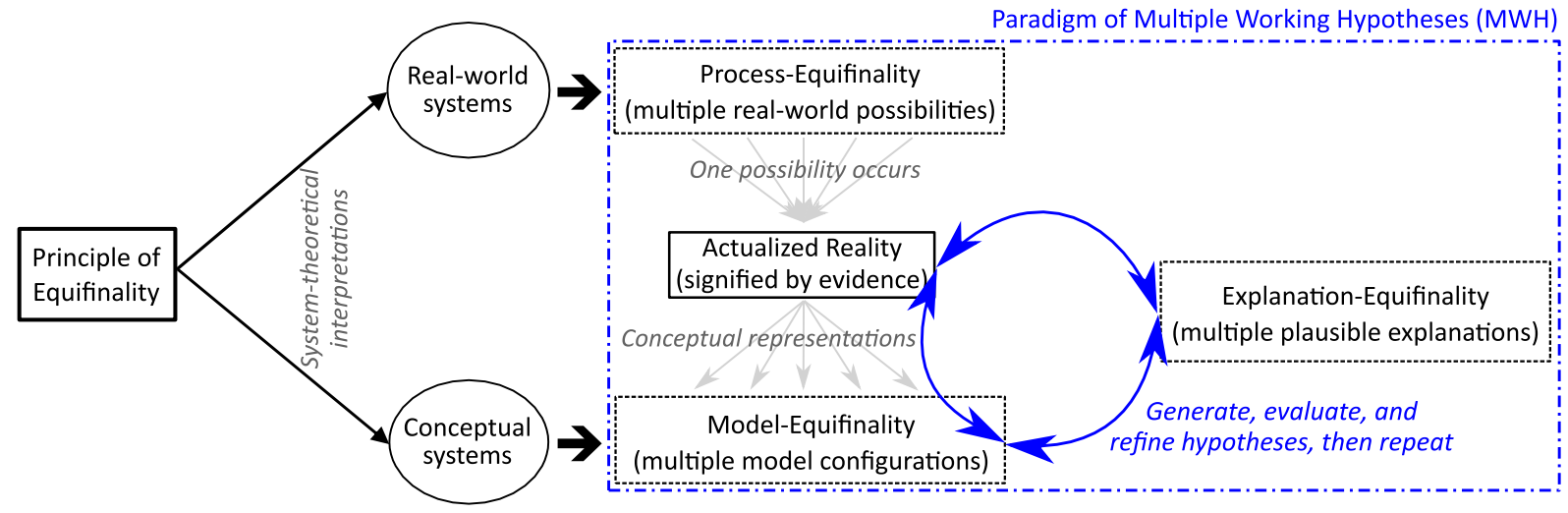

Figure 2.1. The schematic overview of the theoretical framework of various facets of equifinality and their relation to the paradigm of Multiple Working Hypotheses (MWH).

Reality takes a single (unique) developmental pathway as it occurs, which we term actualized reality. That said, before it occurs, there are multiple possibilities of developmental pathways to give rise to a given phenomenon from certain initial conditions. In the language of set theory, actual reality is a member of a set of possibilities. Various combinations and sequencing of processes, mechanisms, and events at a given scale can equally lead to a given real-world phenomenon (finality), which we term processequifinality. For instance, a certain runoff event (hydrograph) can be achieved equally via different combinations of distinct runoff generating mechanisms, e.g. infiltration-excess and saturation-excess, and/or distinct runoff sources, e.g. surface/overland flow, interflow, and/or baseflow. Therefore, process-equifinality is a case-specific and scale dependent characteristic of the real world itself independent of our epistemology (knowledge of the real world). Driesch's observation of organism development, discussed in section 2.2.1, was an example of process-equifinality. Process-equifinality should not be conflated with the 
debate around whether the real world is fully deterministic or has some inherent stochasticity. A given phenomenon (endpoint) could be actualized through multiple combinations of different processes/mechanisms (pathways), regardless of the underlying nature of each pathway (deterministic or stochastic).

Within conceptual systems such as hydrological models, the equifinality principle implies that there are many acceptable models for representing a given observed phenomenon, which we term model-equifinality (refer to Frigg and Hartmann (2018) for an overview of scientific models). In other words, model-equifinality implies that there are always multiple plausible representations/models of a real world phenomenon (refer to Frigg and Nguyen (2018) for further discussion on scientific representation). Khatami et al. (2019) provided a detailed account of various facets of model-equifinality itself. Here it is important to discuss four points about models. First, there are different types of models. In Earth and environmental sciences, it is useful to make a distinction between process-based and databased models. Process-based models (also known as conceptual or physically-based) are primarily based upon our understanding of the real-world processes, while data-based models (also known as black-box) like machine learning models are mainly based on the data themselves (see Beven and Young (2013) argument against using the term physically-based). Here by models we refer to various modeling configurations e.g. different model structure/parameters, inputs, initial and boundary conditions, and objective functions for process-based models, or different numerical schemes for data-based models. Second, while no model is true, each brings out and approximate particular aspects of a real-world phenomenon. Yet, no single model can represent all aspects, and hence cannot serve all purposes (Cartwright, 1983, p. 11). For instance, data-based models represent a relationship between some assumed start and end points of a given process; e.g. for the rainfall-runoff process they develop statistical relationships between rainfall data (and/or other inputs) and flow time series. On the other hand, process-based models are developed to reproduce the underlying processes and mechanisms, e.g. to simulate rainfall-runoff events based on vegetation and soil moisture dynamics of the catchment. Data-based models are better fits for prediction purposes as they almost always outperform their process-based counterparts, while process-based models are preferred to represent the internal behavior and complexity of a system. Third, given that both types of models are data-driven, a plausible model 
requires input data adequacy (both in terms of quality and quantity). Fourth, an ensemble of plausible models can be generated by different parameter sets either within a given model structure (also called model runs, parameterizations, or realizations) or multiple model structures. Note that the demarcation line between model structure and model parameter sets is blurry, the two are intertwined (Khatami et al., 2019). In this paper, we use the term model in the broadest sense, i.e. each parameter set generates a distinct model structure, unless specified otherwise. Plausible models are also referred to as working, acceptable, behavioral, or fit-for-purpose within the literature.

Within scientific inquiry we aim to understand the real world. A scientific hypothesis offers a tentative explanation for a given phenomenon. Scientific models including hydrological ones are primarily hypotheses or hypothesis testing tools (Beven et al., 2012; Buytaert \& Beven, 2011; Clark et al., 2011, 2012; Clark et al., 2015b; Grayson et al., 1992a, 1992b; Jehn et al., 2018; Khatami et al., 2019; Krueger et al., 2010), to which their operational purposes as predictive tools is secondary (Beven, 1989; Kirchner, 2006; Klemeš, 1986b). Within the paradigm of $\mathrm{MWH}$ and through a never-ending process, hypotheses are generated, evaluated, revised/refined, and further evaluated. While exact characterization/representation of reality is impossible in almost all scientific disciplines (Helmer \& Rescher, 1959), the goal of scientific inquiry (including modeling) is to approximate reality. In other words, to provide explanations in the sense of plausibility, i.e. possible approximations of some aspects of a real-world phenomenon at the scale of interest, not truth. One test for a model as a plausible hypothesis is to examine the credibility of its prediction(s), although the applicability of this test varies by context and domain; e.g. it is different in hydrology than geology. Simply put, scientific explanations can be inferred based on some framework or model of explanations (see Woodward (2017) for further discussion). For a given real-world phenomenon there are typically multiple plausible (alternative or competing) explanations, which we term explanation-equifinality. Different scientists perceive and explain a given phenomenon differently given their background, judgements, assumptions, etc. Further, as Beven (2015) argued, looking backwards into the past, it is not possible to capture the full history and details of events and mechanisms that led to a given phenomenon, and hence we end up with an "equifinality of explanation[s]". 
Although he made this case within the context of geomorphology (landform organization), it is applicable to explaining any real-world phenomenon.

We acknowledge that Beven (2006; 2009, p. 271) alluded to various notions of equifinality (i.e. the principle, process-, and model-equifinality) as different "usage" of the term. As argued before, a coherent theoretical framework to conceptualize equifinality and its facets was missing. As shown in Figure 2.1, process- and model-equifinality are derived from the same principle of equifinality as distinct system-theoretical interpretations given the nature of the system that the principle is applied to. In other words, an ontological distinction has to be made between the real-world processes and their conceptual representations (models). Such ontological distinction has crucial epistemological implications that we discuss further within the next sections.

\subsubsection{Equifinality and knowledge uncertainty: an epistemological account}

"Known knowns", "known unknowns", and "unknown knowns" are widely recognized as three facets of epistemic or knowledge uncertainty. Nonetheless, this characterization is inadequate. We argue that knowledge uncertainty can be due to:

- approximate knowns i.e. our knowns are only approximations-simplified, idealized, and aggregated;

- unknowns due to limited knowledge (i.e. limited data, theories, models, etc. or lack thereof) that may be reduced/eliminated by acquiring more knowledge. Unknowns might be identifiable (known unknowns) or not (unknown unknowns);

- unknowables i.e. unknowns that are inherently unknowable e.g. inaccessible complexities at a particular scale, and historical or future boundary conditions. It is captured in the maxim "ignoramus et ignorabimus" i.e. "we do not know and will not know" (Du Bois-Reymond, 1872), which denotes our epistemological finitude (i.e. unavoidable limits of our knowledge and hence inherently limited knowledge); or

- unknown knowns are the knowns that are treated as unknowns, i.e. the knowns that we have overlooked, forgotten, or ignored. For instance, tacit assumptions that are crucial to an analysis but we overpass them without testing, e.g. assuming that catchment behavior always recovers after a disturbance like drought (Peterson et al., 2009). Unarticulated presuppositions that we pretend to be unaware of (Zizek, 2004; 
Žižek, 2006). Knowns that are forgotten and hence have become unknown (Davis \& Erlanson, 2013; Hann, 2011). Subjective beliefs and prejudices e.g. in model selection (Addor \& Melsen, 2019; Heymann \& Dalmedico, 2019; Melsen et al., 2019). Unconscious biases in experiment design, e.g. complete exclusion of women from clinical trials in the 1990s in US (Schiebinger, 1999, pp. 114-117), or in the general practice of science (Holmes et al., 2008; Oreskes, 1996; Popp et al., 2019). Equifinality is a quintessential example of unknown knowns; batches of knowns scattered across literature without a coherent understanding, which we address in this paper.

Process-equifinality is an inherent characteristic of the real world (of ontological nature) and model- and explanation-equifinality are due to our limited knowledge of the world (of epistemic nature). The majority of equifinality discussion within the literature revolves around model-equifinality, while there are very few instances of explicit discussion of process-equifinality in the geosciences literature. Here we discuss those instances. The classic example is the account of equifinality in geomorphic processes influenced by GST (Chorley, 1962), "that similar landforms might arise as a result of quite different sets of processes and histories" (Beven, 2006). It is an example of process-equifinality, although the term process-equifinality is not used. In the context of glacial geomorphology and using the term "form equifinality", Möller and Dowling (2018) demonstrated the equifinality of the shape of subglacial landforms using field examples; that different and unrelated processes in various physical settings, on their own or in combination, can lead to landforms with very similar morphology such as a glaciogenic landform pattern. Based on such examples of process-equifinality, they argued against the quest for a single process theory (i.e. a single formational mechanism, or a single causal explanation) that can explain the formation of all similar landforms. Zimmer and McGlynn (2017) also discussed their observations of processequifinality of different runoff generating mechanisms, and its implications for seasonal stream biogeochemistry patterns. Weiler and McDonnell (2004) used the term processequifinality in referring to a comparable notion discussing the possibility of "multiple process responses" producing similar hillslope hydrographs (see a similar discussion by Grayson et al. (1992a)). Hellebrand et al. (2011) also used the term, but in a slightly different way, to describe various processes in different catchments that resulted in the same values of runoff characteristics; in other words, catchments with similar behavior but different characteristics (Ley et al., 2011). We also found a few other allusions (Benn \& Lukas, 2006; Shen et al., 
2018): process-equifinality implies that model evaluations and improvements are inconclusive even if the model may " $f i t$ " the data.

Acknowledging Beven's concept of equifinality (Beven, 1993; Beven \& Freer, 2001) in hydrological modeling (i.e. model-equifinality), Savenije (2001) argued that hydrological laws or relations are derived essentially as laws of averaging (see Cartwright $(1983,1999)$ for an in-depth critical account on the notion of "laws of nature"). The parameters of these relationships are also a function of the averaging level, e.g. primarily a function of the catchment size. Therefore, empirical hydrological relations-such as Muskingum's method, Manning's equation, dispersion equations, and even Darcy's law-have meaning only at the scale they are derived. In other words, through the process of averaging, we zoom out over time and space, also called aggregation (Kirchner, 2016), and the world becomes more regular and predictable for us. Aggregation is a mechanism or basis to approximate reality, which gives rise to explanation- or model-equifinality as the details of developmental pathways are averaged and thereby simplified (for further discussion on (dis)aggregation see Beven, 1996). For a given phenomenon, we construct different models for different purposes and based on alternative theoretical treatments (e.g. different assumptions and equations). In the context of model evaluation, Oreskes and Belitz (2001) referred to (modellequifinality as a form of non-uniqueness, and argued that "conceptual models can be underdetermined by available evidence, causing an empirically adequate model to break down when applied to a problem other than the one for which it was built". These allusions to various aspects of equifinality are scattered and hence the current discussion within the literature is disjointed. That said, they all do suggest that model- and explanation-equifinality are scale-dependent, and largely due to epistemic uncertainty.

As we reduce the dimension of any structure of information, e.g. times series, to handle its complexity we are prone to equifinality. Put differently, in the process of simplifying complexities equifinality rises due to aggregating information content. Whether investigating past events (looking backward) or predicting future events (looking forward), in almost all our (scientific) inquiries we reduce the complexity of the study phenomenon. For instance, by making simplifying assumptions at a given scale. In other words, in our inquiries we are often dealing with less knowns/knowables than unknowns/unknowables, and to handle the unknowns we often make simplifying assumptions. So, our inquiries are ill-posed 
(ill-conditioned) even when simplified, and hence the equifinality of plausible models and explanations is inherent. The choice of a simplifying assumption, scientific model, analysis approach, or an explanation is made from a number of competing alternatives, based on the scientist's reasoning given their preferences, beliefs, and interpretations. Despite an idealist account of the scientific method, reasoning is not a process in abstraction or vacuum, but it is conducted within a socio-political paradigm (Ginsberg, 2011; Mirowski, 2011; Saltelli, 2016; Takacs, 2003), and "reason is... the slave of the passions" (Hume, 1739, p. 415). This implies a fundamental epistemic limitation, and hence knowledge uncertainty, to our scientific inquiries including understanding and modeling Earth and environmental systems (see Cartwright (1999) re boundaries of science). Given our epistemological finitude, it is very difficult (if possible at all) to draw a sharp dividing line between knowledge and uncertainty. We can only hope that as we acquire more knowledge we constrain our knowledge uncertainty by conditioning it on the new observations, which themselves are also inference- and theory-laden (Mayo, 1996, p. 21; Oreskes et al., 1994). Therefore, inexactness and uncertainty are inalienable to our scientific inquiries particularly in domains such as geosciences.

In summary, given the incomplete and finite nature of our knowledge, we always end up with multiple approximations, i.e. an ensemble of plausible models and explanations for a given phenomenon at a particular scale. One may ignore some or all alterative explanations/models in favor of one or some particular ones. Regardless of the reasons, this ignorance will increase the uncertainties and bring with itself higher risks of unforeseen surprises. The principle of equifinality provides the theoretical grounds for the aptness of the MWH paradigm for scientific inquiry.

\subsubsection{Equifinality and Multiple Working Hypotheses}

Scientific hypotheses/explanations are formulated through different types of logical reasoning, namely deduction, induction and abduction. At each step of reasoning, an inference is made, i.e. moving from a (set of) premise(s) to a (set of) logical consequence(s). Logical empiricists (originally known as logical positivists) believed that the aim of science is to discover and establish generalizations (or "laws of nature") based on deductive logic and verificationism (Creath, 2017). The notions of generalizations and laws of nature has been 
heavily criticized by various logicians and philosophers of sciences (Cartwright, 1983, 1999; Cartwright et al., 1996; Godfrey-Smith, 2003; Hanson, 1958). Hanson (1958), among others, argued that the logic of scientific discovery is most commonly based on abduction (Devitt, 1997; Godfrey-Smith, 2003, p. 43; Magnani, 2011, pp. 1-2; Sarkar \& Pfeifer, 2006). Historically, abduction (or retroduction) was coined by Charles Sanders Peirce, founder of the philosophical tradition of pragmatism, and referred to a form of explanatory reasoning for generating hypotheses (Peirce, 1934). In the modern sense, abduction is an explanatory reasoning for also justifying hypotheses, also called "inference to the best explanation" (Baker, 2017; Douven, 2017), and the basis of the logic of scientific discovery (Hanson, 1958). Through abduction, we are inferring a hypothesis about a particular phenomenon to explain the data, as opposed to inferring to a generalization (Godfrey-Smith, 2003, p. 43). That is, inference from observations (a set of data) to hypotheses that formulate processes and mechanisms to plausibly explain the observations. Abductive inference is also called explanatory induction, theoretical induction, theoretical inference, and explanatory inference (Godfrey-Smith, 2003, p. 43). It runs backwards from an effect to a cause and is data-driven (Oh, 2011). Within the paradigm of $\mathrm{MWH}$, abduction leads to a series of plausible explanations. We emphasize that abductive reasoning and explanation is not a guide to truth-“what has explanatory power to do with truth?" (Cartwright, 1983, p. 4; Van Fraassen, 1980). Rather, abductive reasoning is a defensible approach of scientific inquiry to approximate reality in the face of uncertainties.

Now suppose there is a list of all plausible hypotheses, i.e. the entire hypothesis space. The goal is to refine the list by rejecting the unrealistic/implausible hypotheses (i.e. inconsistent with available evidence and knowledge) and/or to generate (or refine) the more plausible ones. To this end, within the paradigm of $\mathrm{MWH}$, a (non-exhaustive) set of plausible hypotheses will be tested against each other and available evidence. The aim of scientific inquiry is not to ask which of these hypotheses is true. We know a priori that all hypotheses are wrong in the strict sense, i.e. not exactly true, in almost all scientific disciplines (Helmer $\&$ Rescher, 1959). Given our epistemological finitude, we can barely formulate and/or discover the true hypothesis. But the goal is to formulate hypotheses that approximate reality, specifically the aspects that are of interest given some acceptability criteria, auxiliary hypotheses, and simplifying assumptions. So, we continuously refine, and possibly constrain, 
the hypothesis space to improve the approximations. To demonstrate the MWH framework, we discuss a hydrological example. We aim to improve our understanding of some catchment processes. We often begin from a highly detailed, although qualitative, understanding of the processes (Seibert \& McDonnell, 2002); what Beven (2012) calls perceptual models and Gupta et al. (2012) calls perceptual-conceptual models as our perceptual and conceptual models are interdependent. Then, we try to bring this understanding to the conceptual level, i.e. to conceptualize our perceptual understanding in terms of mathematical and computer-based models (Beven (2012) calls the computer code, of a given conceptual model, procedural model that can be implemented in different ways as Knoben et al. (2019) demonstrated). Both perceptual and conceptual models are non-unique and incomplete: (a) there will always be an ensemble of equifinal plausible models; and (b) no matter how comprehensive an ensemble is claimed to be, it can never span the entire hypothesis space especially due to our epistemological finitude. By collecting new information and testing our models, we attempt to improve model realism i.e. refining the hypothesis space. Model realism means both internal consistency, i.e. real-world processes represented within the model are consistent with one another and with our understanding of those processes, and external relevance, i.e. the model is relevant for the application and fits the purpose to the extent possible. To constrain and improve the realism of a model ensemble we may use multiple sources of hard and soft data/information (Pool et al., 2019; Seibert \& McDonnell, 2002; Winsemius et al., 2009), various performance metrics and/or diagnostic signatures (Addor et al., 2018; Davtalab et al., 2017; Fowler et al., 2018; Jehn et al., 2019; Kelleher et al., 2017; Pool et al., 2018), define some limits of acceptability (Beven, 2019; Blazkova \& Beven, 2009; Schaefli, 2016), elicit expert knowledge (Gharari et al., 2014; Hrachowitz et al., 2014), or apply various methods of uncertainty (Beven, 2019; Beven \& Binley, 2014; Kavetski et al., 2006a, 2006b; Vrugt \& Beven, 2018) and sensitivity analysis (Gupta \& Razavi, 2018; Haghnegahdar et al., 2017; Kelleher et al., 2015; Pappenberger et al., 2008; Sheikholeslami \& Razavi, 2017), information theoretic analyses (Bennett et al., 2019; Gong et al., 2013; Goodwell \& Kumar, 2017; Nearing \& Gupta, 2015), or process-based model evaluation (Beven, 2019; Khatami et al., 2019; Melsen et al., 2016). Through an iterative and revisionary process, we continuously generate/refine plausible models (hypotheses) to better approximate reality, while improving our approximate understanding 
of the real-world processes. In other words, we continuously refine and constrain explanation- and model-equifinality.

While we use and improve our knowledge in generating and refining plausible hypotheses/models, we should note that our knowledge of the real world is also approximate-uncertain and incomplete. Even where we have a lot of data and enormous field and modeling experience, our knowledge is still conditional on the inference-laden (Oreskes et al., 1994) and erroneous (non-error-free) nature of data (Beven \& Smith, 2015; Beven \& Westerberg, 2011; Fisher, 2008, p. 496; McMahon \& Peel, 2019; Western et al., 2005), data uncertainty whether epistemic (Beven, 2019; Beven et al., 2011) or measurement accuracy (Beven \& Young, 2013) or commensurability error (Beven, 2009, p. 42), limited observations even at the scales of interest (Hall \& Anderson, 2002), indeterminacy (Rotmans \& van Asselt, 2001), our subjective assessments and interpretations (Madani \& Khatami, 2015; Melsen et al., 2019), assumptions about the stability of the system and feedbacks (Peterson \& Western, 2014; Peterson et al., 2014), etc. So, it is indeed possible to falsely reject some of the plausible hypotheses (false negative error). Further, each hypothesis itself comprises of a bundle of auxiliary hypotheses. That is, any hypothesis is formulated together with a set of tacit assumptions and other hypotheses e.g. about various aspects of the underlying mechanisms and/or interacting processes of the study phenomenon. These auxiliary hypotheses are another example of unknown knowns: they are often overlooked or even impossible to test in isolation. Thus, it is possible to falsely accept some of the hypotheses that are comprised of faulty or wrong auxiliary hypotheses (false positive error); the locus classicus is "getting right answers-or better say plausible answers or approximations-for the wrong reasons" (Grayson et al., 1992b; Kirchner, 2006; Klemeš, 1986a). On top of all this, there is no guarantee that one can ever acquire the list of all plausible hypotheses. So, we often cannot fully determine the range and merit of plausible hypotheses including their auxiliary hypotheses. Some of these challenges, particularly the impossibility of testing hypotheses in isolation, have also been discussed within the philosophy of sciences, known as the problem of underdetermination of scientific theory by evidence or Duhem-Quine Thesis; which is a longstanding and still lively debate. While the underdetermination problem may pose challenges to hypothesis testing, the debate is unsettled with no overall consensus to what extent and in what contexts these challenges 
(and their implications) hinder our scientific inquiries. Stanford (2017) provided an overview of this debate. Although this debate has some relevance to our theoretical framework, we will not further discuss it in the present paper to avoid any oversimplification or mischaracterization given the nuances and subtleties of this debate.

In addition to the above difficulties in generating and refining plausible hypotheses, the next question is whether it is meaningful and justifiable to assign probabilities to the plausible hypotheses. In model evaluation and uncertainty analysis it is common to assign some measure of likelihood to each of the acceptable models within an ensemble. That said, it is very difficult to justify assigning probability to a set of plausible hypotheses, unless under strong assumptions and ideal conditions. We do not have sufficient knowledge of the nature of the population nor the sample of hypotheses to be able to draw reasonable and reliable probabilistic conclusions. In addition to the aforementioned limitations of probabilistic approaches in handling MWH under uncertainty, there are numerous examples of their drawback within the geosciences literature. Numerous studies (e.g. Beven, 2013; Beven, 2016; Beven et al., 2011; Beven, 2018; Di Baldassarre et al., 2015; Khatami et al., 2019; Nearing et al., 2016) discussed the limitations and challenges of probabilistic characterization of uncertainties, particularly of epistemic nature. Hall and Anderson (2002) argued that the most interesting hydrological problems are where the phenomenon of interest and the available observations are either not directly relevant, not precisely measured or not available at all, or have a low degree of repeatability e.g. extreme floods or droughts. Given that such problems are not of random variability nor stationary nature, Hall and Anderson (2002) argued that applying/developing non-probabilistic approaches (e.g. random set theory, fuzzy theory, Walley's theory of imprecise probabilities) could be more appropriate. Schär et al. (2016) demonstrated how the commonly used methodology of percentile-based assessment of climate trends and change projections can lead to misleading results. Whetton et al. (2016) also argued that probabilistic interpretation and representation of climate ensembles are potentially misleading as uncertainties cannot be well-captured by the climate model ensembles. Further, much of human reasoning and judgment is possibilistic rather than probabilistic (Hall \& Anderson, 2002). Moreover, some forms of information or aspects of the study system might be vague rather than random, e.g. sandy soil. Such cases can be investigated more appropriately using possibilistic approaches 
like fuzzy logic (Bárdossy et al., 1990; Jacquin \& Shamseldin, 2007; Khazaei \& Hosseini, 2015; Schulz \& Huwe, 1997; Schulz et al., 1999; Shrestha et al., 2007). In light of the above, we argue against probabilistic handling and interpretation of plausible hypotheses/models.

\subsubsection{Equifinality and modeling under uncertainty}

\subsubsection{Model optimization}

Process-equifinality, considering the scale, is an inevitable property of real-world phenomena. Similarly, explanation- and model-equifinality are unavoidable due to knowledge uncertainty. In the context of modeling, our presented theoreticalepistemological framework implies that the notion of a single true model of the real world is only a myth and wishful thinking, whether for historical simulation or future prediction. That is, the false promise of developing an ultimate model to represent a complex, open and ever-evolving system (e.g. catchment). The idea of a single model structure and/or parameter set-also referred to as the optimal, best, effective, etc. model/parameter set-is false and flawed, even within a process-based model. Needless to mention that all hydrological models-regardless of their complexity even if claimed to be physically-basedare, at best, only partial representations of real-world systems (Beven, 1989; Grayson et al., 1992b); in this sense of partial representations, hydrological models are no exceptions to other scientific models (Cartwright, 1999). To eliminate model-equifinality would require a perfect modeling setup at the scale of interest. That is, a true model including complete knowledge of the detailed characteristics of the constituent real-world phenomenon: material properties e.g. soil (Western \& Grayson, 1998; Western et al., 2002), biological processes e.g. vegetation dynamics (Peel, 2009; Peel et al., 2010), complex dynamics both within and between natural and human systems (Barnett et al., 2008; Falkenmark, 1977; Haddeland et al., 2014; Khazaei et al., 2019b; Madani et al., 2014; Peterson \& Western, 2014; Peterson et al., 2012, 2014; Wine \& Davison, 2019), boundary conditions (Staudinger et al., 2019), etc. Such detailed characteristics may essentially be unknowable (Beven, 2009, p. 34; Cartwright, 1999), or unquantifiable even if knowable. Even if we aim to include the aforementioned interrelated processes based on an interdisciplinary Earth System Science approach (Clark et al., 2015a; Fan et al., 2019), still that will not lead to developing a true model given all the arguments we discussed in this paper. The non-existence of an ultimate true model, both its theoretical and applied considerations, have been widely discussed 
within the modeling literature since the 1970s (Beven, 1975; Box, 1976; Box, 1979; Gelb, 1974; Lewis \& Nir, 1978; Schweppe, 1973) and 1980s (Beck, 1987; Beven, 1987; Gupta \& Sorooshian, 1983; Sorooshian \& Gupta, 1983); although other terminology may have been used like uniqueness, identifiability, etc. Despite these arguments for moving from the optimization paradigm (which we call unicorn modeling) to the more reasonable paradigm of ensemble modeling to account for uncertainties, there remains part of the community assuming and searching for the unicorn model or parameter set.

Theoretically, only well-defined mathematical problems can be optimized. Even those may not be optimized against multiple objectives. As discussed, real-world phenomena are complex dynamical systems that even their best models are only approximations with inevitable model residuals. In other words, these models are simplifications of idealizations of the study phenomenon, and are ill-defined/ill-posed as they have less knowns than unknowns. Not to mention that real-world systems can never be represented conclusively with mathematical models; only partially, at a particular scale, and under strong assumptions. So, a model cannot be optimized in the theoretical sense of the term. Therefore, it is fundamental to generate model ensembles and evaluate their associated uncertainties in some way. That said, we acknowledge that a modeler may have to choose a single model due to practical restrictions, for such a case global search schemes are used. Global search routines are also useful to gain preliminary insights into model behavior. For instance, Khatami et al. (2019) used Shuffled Complex Evolution scheme (Duan et al., 1992) to tentatively assess how suitable a particular model structure is for a given catchment given some objective functions (they referred to this as pre-calibration). Moreover, guided search algorithms, that are the basis of most optimization schemes, are efficient ways of sampling the parameter space compared to their alternative random searches such as Latin Hypercube Sampling (Tolson \& Shoemaker, 2008). Although, it is possible that these guided search methods overlook some important regions of the model space (Beven \& Binley, 2014).

\subsubsection{Model-equifinality and hypothesis testing}

To date, almost all discussions around equifinality in the literature are around modelequifinality; in fact, model parameter equifinality. Khatami et al. (2019) discussed other facets of model-equifinality than parameter equifinality; namely equifinality of model 
structures (and model approaches), performance metrics, initial/boundary conditions, inputs, and internal fluxes. A crucial question is the relationship between model-equifinality and reality (both actualized reality and process-equifinality): is there a correspondence between model-equifinality and process-equifinality?

Process-equifinality vs. model-equifinality

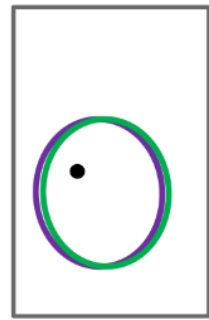

(a)

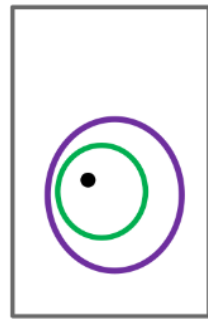

ii

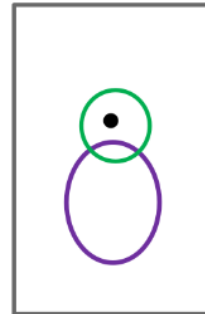

iii

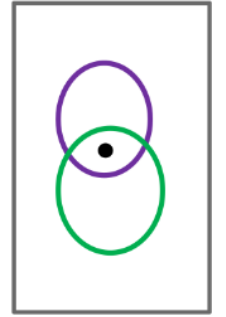

iv

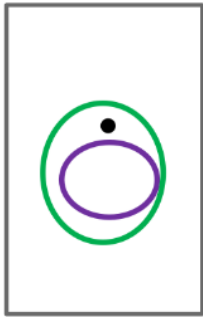

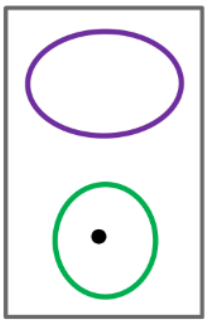

vi

Process-equifinality vs. model-equifinality (multiple model structures)

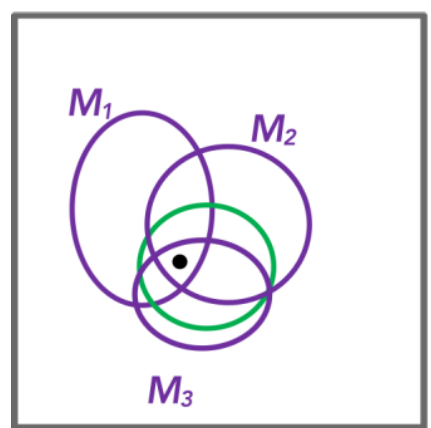

i

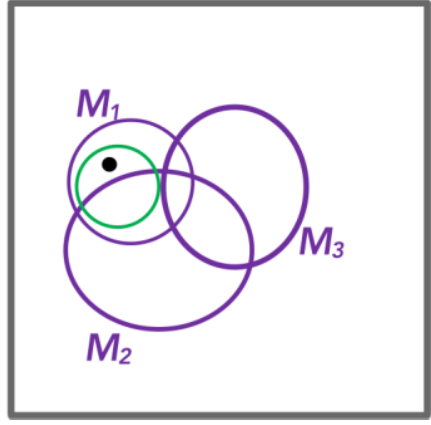

ii

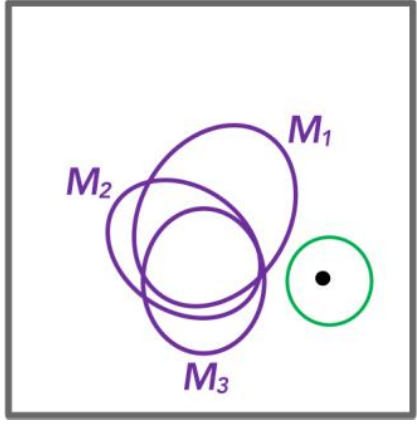

iii

(b)

Figure 2.2. The conceptual relationship between model-equifinality and process-equifinality in the cases of (a) a single model structure and (b) multiple model structures represented as $M_{1}, M_{2}$ and $M_{3}$. The grey box defines the hypothesis space and the black dot represents the actualized reality. Figure a-i illustrates the ideal case when the model-equifinality corresponds to the total process-equifinality, i.e. approximates the real-world possibilities and actualized reality. The size of the ovals (and grey boxes) on the Venn diagrams is arbitrary but implies that the degree of process- and model-equifinality can vary from one case to another. The characteristics of the black dot, size and content of the hypothesis space (including model- and processequifinality) change as our knowledge improves.

The actualized reality (black dot in Figure 2.2 ) always occurs as a certain case within the larger set of real-world possibilities, i.e. actualized reality is necessarily embedded in process-equifinality (green ovals in Figure 2.2). The grey box in Figure 2.2 represents the overall set of all plausible hypotheses, i.e. the hypothesis space, which encompasses 
process-equifinality and hence actualized reality; only in the sense of plausibility and not truth (as discussed earlier). The purple oval represents model-equifinality, i.e. an ensemble of acceptable model runs within a given model structure. Figure $2.2 \mathrm{a}-i$ is an ideal case where equifinal model runs capture/reproduce the process-equifinality and hence actualized reality. In the case of Figure 2.2a-ii, model-equifinality plausibly captures all the processequifinality and hence actualized reality. However, the model ensemble includes additional non-process-equifinality, represented as the area within the purple oval and outside the green oval, which we term implausible model-equifinality. While model-equifinality in both cases of Figures 2.2a-iii and 2.2a-iv produces implausible model-equifinality, actualized reality is captured in the latter case. Figures 2.2a-iii shows that even though a model ensemble may reasonably represent our understanding of some real-world processes, it does not necessarily approximate the actualized reality for the particular study case. So, the model is rejected as unfit for the purpose given the available data and assumed acceptability metrics. In the case of Figure 2.2a-v, although there is no implausible model-equifinality, the model's process-representation is not thorough enough to approximate the actualized reality. This is an interesting case where model structure includes/represents realistic process understanding, but-for whatever reason-the model ensemble does not approximate what actually happened for the particular case at hand. That is, even a highly competent process-based model may be unfit for a given case/purpose. The worst case is where the ensemble lacks any plausible process representation (Figure 2.2a-vi) and hence fails to approximate the actualized reality.

Figure $2.2 \mathrm{~b}$ demonstrates the extension of the above discussion to the case of multiple model structures. Each model structure $M_{1}, M_{2}$, and $M_{3}$ represents a different set of model ensembles (see the discussion by Khatami et al. (2019) on the ambiguity of distinction between model structure and parameter sets). Figure $2.2 \mathrm{~b}-i$ is a case where all three model structures collectively capture all the process-equifinality. As for Figure $2.2 b$-ii, modelequifinality of a single model structure $\left(M_{1}\right)$ fully captures the process-equifinality and hence the actualized reality; while none of the other two model structures $\left(M_{2}\right.$ and $\left.M_{3}\right)$ approximates the actualized reality, even though $\mathrm{M}_{2}$ partially represents some plausible real-world processes. In other words, the ensemble of model runs generated within model structure $M_{1}$ adequately approximated the observed reality, while the collective ensembles 
of model structures $M_{2}$ and $M_{3}$ failed to do so, although some process understanding is embedded in model structure $\mathrm{M}_{2}$. In Figure $2.2 \mathrm{~b}$-iii, none of the model structures represent the process-equifinality and hence the actualized reality. So, using numerous model structures does not necessarily guarantee fit-for-purpose or a plausible representation of the real-world processes, just as using a single model structure is not necessarily inadequate. For a demonstration of the aforementioned cases, see different instances of conceptual hydrological modeling under changing climates by Fowler et al. (2016).

So, conceptual models must be evaluated for each case separately, no matter how completely process understanding is embedded within the model components. For example, even a competent process-based hydrological model may fail to adequately represent/approximate the rainfall-runoff events in some catchments even if high-quality data are adequately provided, while it would adequately do so in other catchments. So, if a conceptual model was evaluated as adequate in a range of catchments, its adequacy for another catchment cannot be assumed by extension and must be investigated separately (see a similar discussion of "uniqueness of place" by Beven (2000)). This is crucial particularly when a large sample of catchments and model structures are used. Regardless of the number and complexity of the model structures utilized and their (dis)agreement, implausible model runs signify implausible hypotheses that could be due to characteristics of the input data (errors, uncertainty and/or insufficient information content), inadequate model process-representation at the scale of modeling, over-parameterization (i.e. model output adequately fits the observations but generated through unrealistic model process representations), unrealistic modeling assumptions, etc. Model (im)plausibility/(in)adequacy, potential sources of uncertainty, and avenues for constraining implausible model-equifinality should be examined for each modeling case specifically. Theoretically, such implausible model-equifinality should be identified and refined through iterations of MWH framework. It should again be emphasized that the aforementioned conceptual relationships between reality, process-, and model-equifinality should be understood only in the sense of plausibility at a given scale and for some criteria of model acceptability. Further, our understanding of each of these ingredients is evolving. With each iteration of hypothesis generating/testing, some of the hypotheses that were known as plausible will be identified as implausible and hence rejected, some hypotheses will remain 
or be refined to be plausible, or new hypotheses may be generated. Meanwhile our knowledge grows as well.

\subsection{Conclusion}

All models are wrong, all data are erroneous, all model evaluations are incomplete, and our knowledge of the real-world processes is fallible. Therefore, uncertainty is an inalienable property of scientific inquiry and overshadows our decision making. Despite these limitations, models are useful, data contain vital information, our knowledge is insightful particularly for decision making under uncertainty. It is in fact the tension between these two poles of scientific inquiry, i.e. dialectics, that drives the learning progress. Although uncertainty is deeply interconnected and intertwined with equifinality, the two are not equivalent. We discussed that despite the widespread use of the term equifinality in the geosciences literature, it is mostly understood as model structure or parameter equifinality, without a broader characterization of the various aspects of equifinality. We demonstrated that the concept of equifinality was originally developed to explain a real-world phenomenon. It was then formulated as a general property of any open complex system, whether real-world or conceptual. We developed an overarching theoretical framework to coherently conceptualize three main facets of equifinality, namely:

- process-equifinality: real-world possibilities than can equally lead to a given phenomenon before it occurs. A feature of the real world itself independent of our knowledge of the real world;

- model-equifinality: various models can plausibly represent a real-world phenomenon for a particular purpose and given some underlying assumptions and conditional on our knowledge uncertainty; and

- explanation-equifinality: various plausible explanations for a given phenomenon can be inferred conditional on our knowledge uncertainty.

Knowledge uncertainty implies partial and approximate understanding of real-world phenomena at best. Equifinality implies both the possibility of multiple real-world processes/mechanisms to give rise to a given phenomenon, as well as non-unique scientific theories, explanations, and hypotheses (including models) to approximate/represent the given phenomenon. Therefore, regardless of the context and purpose, it is fundamental to 
always develop multiple working hypotheses or plausible model ensembles that adequately fit the purpose. How the ensemble is generated and analyzed are technical questions. A model ensemble can be a result of a single or multiple model structures, based on one or a vector of model error metrics, based on some threshold or limits of acceptability, etc. The plausible model ensembles can be used for various analyses such as sensitivity, uncertainty, information theoretic, etc. Given the limits and challenges of hypothesis testing and due to various types and sources of uncertainty, we argued against probabilistic treatment of hypotheses (including model ensembles).

Besides its theoretical contribution, our framework also has important practical implications in Earth and environmental modelling. For instance, our Flux Mapping method (Khatami et al., 2019) is an application of this framework for process-based model evaluation, which provides new insights into model process-representation that are not apparent from conventional model uncertainty evaluations, such as dotty plots and parameter statistical distributions. Flux map of equifinal models characterizes the uncertainty of model runoff generating mechanisms and pathways. Runoff pathways have important implications for water quality response (Lintern et al., 2018), environmental flow assessment (Arthington, 2012), and low-flow or high-flow analyses. In decision making under uncertainty where models are used as the basis of policies and decisions, it is important to acknowledge the approximate nature and widespread range of models with even conflicting results, and hence the uncertainties and risks associated with the model outputs - notwithstanding other factors than models that are influencing decision making. The bottom line is that we should always base our inquiries on an ensemble of plausible hypotheses/models, and not the false hope of a unicorn model, no matter how elegant the model structure is or claimed to be optimized.

In light of the above, we advocate for abductive reasoning, whether for generating or justifying hypotheses, within the paradigm of $\mathrm{MWH}$. That is, to infer multiple plausible approximations, where each approximation covers some aspects of reality at the scale of interest and given some assumptions. Equifinality and knowledge uncertainty are the sine qua nons (i.e. the essential and indispensable) conditions underlying any scientific inquiry. That is, hypothesis testing and modeling is only meaningful in the sense of plausibility and within the paradigm of $\mathrm{MWH}$. In the throes of uncertainty, scientific method is our best 
attempt to be reasonable, to maintain "the pessimism of the intellect, and optimism of the will"' (attributed to Antonio Gramsci, Letter from Prison, 19 December 1929).

\section{Acknowledgments}

We would like to acknowledge constructive feedback by Martyn Clark, Andrew Binley, Hoshin Gupta, and Grey Nearing on earlier versions of this manuscript. Sina Khatami is also grateful to Keith Beven and Keirnan Fowler for multiple discussions that helped better shape the ideas of this paper.

The authors gratefully acknowledge the support of the University of Melbourne and Australian Government in carrying out this research; Sina Khatami supported by Melbourne International Research and Fee Remission Scholarships (MIRS and MIFRS), Murray Peel the recipient of an Australian Research Council Future Fellowship (FT120100130), and Tim Peterson jointly funded by Australian Research Council Linkage Project LP130100958, Bureau of Meteorology (Australia), Department of Environment, Land, Water and Planning (Vic., Australia), Department of Economic Development, Jobs, Transport and Resources (Vic., Australia) and Power and Water Corporation (N.T., Australia).

No data or model were used in this manuscript.

\section{References}

Abbott, B. W., Bishop, K., Zarnetske, J. P., Minaudo, C., Chapin, F. S., Krause, S., et al. (2019). Human domination of the global water cycle absent from depictions and perceptions. Nature Geoscience, 12(7), 533-540. doi:10.1038/s41561-019-0374-y

Addor, N., \& Melsen, L. A. (2019). Legacy, rather than adequacy, drives the selection of hydrological models. Water Resources Research, 55(1), 378-390.

doi:doi:10.1029/2018WR022958

Addor, N., Nearing, G., Prieto, C., Newman, A. J., Le Vine, N., \& Clark, M. P. (2018). A Ranking of Hydrological Signatures Based on Their Predictability in Space. Water Resources Research. doi:doi:10.1029/2018WR022606

Arthington, A. H. (2012). Environmental Flows: Saving Rivers in the Third Millennium. London: University of California Press.

Baker, V. R. (2017). Debates-Hypothesis testing in hydrology: Pursuing certainty versus pursuing uberty. Water Resources Research, 53(3), 1770-1778. doi:10.1002/2016wr020078 
Bárdossy, A., Bogardi, I., \& Duckstein, L. (1990). Fuzzy regression in hydrology. Water Resources Research, 26(7), 1497-1508. doi:10.1029/WR026i007p01497

Barnett, T. P., Pierce, D. W., Hidalgo, H. G., Bonfils, C., Santer, B. D., Das, T., et al. (2008). Human-induced changes in the hydrology of the western United States. Science, 319(5866), 1080-1083.

Beck, M. B. (1987). Water quality modeling: A review of the analysis of uncertainty. Water Resources Research, 23(8), 1393-1442. doi:10.1029/WR023i008p01393

Benn, D. I., \& Lukas, S. (2006). Younger Dryas glacial landsystems in North West Scotland: an assessment of modern analogues and palaeoclimatic implications. Quaternary Science Reviews, 25(17), 2390-2408. doi:https://doi.org/10.1016/i.quascirev.2006.02.015

Bennett, A., Nijssen, B., Ou, G., Clark, M., \& Nearing, G. (2019). Quantifying Process Connectivity With Transfer Entropy in Hydrologic Models. Water Resources Research, 55(6), 4613-4629. doi:10.1029/2018wr024555

Beven, K. (1975). A deterministic, spatially distributed model of catchment hydrology. University of East Anglia.

Beven, K. (1989). Changing ideas in hydrology - The case of physically-based models. Journal of Hydrology, 105(1), 157-172. doi:https://doi.org/10.1016/0022-1694(89)90101-7

Beven, K. (1993). Prophecy, reality and uncertainty in distributed hydrological modelling. Advances in Water Resources, 16(1), 41-51. doi:http://dx.doi.org/10.1016/03091708(93)90028-E

Beven, K. (1996). The limits of splitting: Hydrology. Science of The Total Environment, 183(1), 89-97. doi:https://doi.org/10.1016/0048-9697(95)04964-9

Beven, K. (2002). Towards a coherent philosophy for modelling the environment. Proceedings of the Royal Society of London. Series A: Mathematical, Physical and Engineering Sciences, 458(2026), 2465-2484. doi:10.1098/rspa.2002.0986

Beven, K. (2006). A manifesto for the equifinality thesis. Journal of Hydrology, 320(1-2), 18-36. doi:http://dx.doi.org/10.1016/j.jhydrol.2005.07.007

Beven, K. (2009). Environmental modelling: an uncertain future? : CRC Press.

Beven, K. (2012). Rainfall-runoff modelling: the primer (2nd ed.). Chicheseter, UK: John Wiley \& Sons, Ltd.

Beven, K. (2013). So how much of your error is epistemic? Lessons from Japan and Italy. Hydrological Processes, 27(11), 1677-1680. doi:10.1002/hyp.9648

Beven, K. (2015). What we see now: Event-persistence and the predictability of hydroeco-geomorphological systems. Ecological Modelling, 298(0), 4-15. doi:http://dx.doi.org/10.1016/j.ecolmodel.2014.07.019 
Beven, K. (2016). Facets of uncertainty: epistemic uncertainty, non-stationarity, likelihood, hypothesis testing, and communication. Hydrological Sciences Journal, 61(9), 1652-1665. doi:10.1080/02626667.2015.1031761

Beven, K. (2019). Towards a methodology for testing models as hypotheses in the inexact sciences. Proceedings of the Royal Society A: Mathematical, Physical and Engineering Sciences, 475(2224), 20180862. doi:doi:10.1098/rspa.2018.0862

Beven, K., \& Binley, A. (1992). The future of distributed models: Model calibration and uncertainty prediction. Hydrological Processes, 6(3), 279-298. doi:10.1002/hyp.3360060305

Beven, K., \& Binley, A. (2014). GLUE: 20 years on. Hydrological Processes, 28(24), 58975918. doi:10.1002/hyp.10082

Beven, K., \& Freer, J. (2001). Equifinality, data assimilation, and uncertainty estimation in mechanistic modelling of complex environmental systems using the GLUE methodology. Journal of Hydrology, 249(1), 11-29.

Beven, K., \& Smith, P. (2015). Concepts of Information Content and Likelihood in Parameter Calibration for Hydrological Simulation Models. Journal of Hydrologic Engineering, 20(1), A4014010. doi:10.1061/(ASCE)HE.1943-5584.0000991

Beven, K., Smith, P., Westerberg, I., \& Freer, J. (2012). Comment on "Pursuing the method of multiple working hypotheses for hydrological modeling" by P. Clark et al. Water Resources Research, 48(11), W11801. doi:10.1029/2012WR012282

Beven, K., Smith, P. J., \& Wood, A. (2011). On the colour and spin of epistemic error (and what we might do about it). Hydrol. Earth Syst. Sci., 15(10), 3123-3133. doi:10.5194/hess-153123-2011

Beven, K., \& Westerberg, I. (2011). On red herrings and real herrings: disinformation and information in hydrological inference. Hydrological Processes, 25(10), 1676-1680. doi:10.1002/hyp.7963

Beven, K., \& Young, P. (2013). A guide to good practice in modeling semantics for authors and referees. Water Resources Research, 49(8), 5092-5098.

Beven, K. J. (1987). Towards a new paradigm in hydrology. In J. C. Rodda \& N. C. Matalas (Eds.), Water for the future: hydrology in perspective, Rome Symposium (Vol. IAHS Publ. No. 164, pp. 393-403). London, UK: International Association of Hydrological Sciences.

Beven, K. J. (2000). Uniqueness of place and process representations in hydrological modelling. Hydrol. Earth Syst. Sci., 4(2), 203-213. doi:10.5194/hess-4-203-2000

Beven, K. J. (2018). On hypothesis testing in hydrology: Why falsification of models is still a really good idea. Wiley Interdisciplinary Reviews: Water, 5(3), e1278. doi:10.1002/wat2.1278

Blazkova, S., \& Beven, K. (2009). A limits of acceptability approach to model evaluation and uncertainty estimation in flood frequency estimation by continuous simulation: Skalka 
catchment, Czech Republic. Water Resources Research, 45(12), W00B16. doi:10.1029/2007WR006726

Blöschl, G., Bierkens, M. F. P., Chambel, A., Cudennec, C., Destouni, G., Fiori, A., et al. (2019). Twenty-three Unsolved Problems in Hydrology (UPH) - a community perspective. Hydrological Sciences Journal. doi:https://doi.org/10.1080/02626667.2019.1620507

Box, G. E. P. (1976). Science and Statistics. Journal of the American Statistical Association, 71(356), 791-799. doi:10.1080/01621459.1976.10480949

Box, G. E. P. (1979). Robustness in the Strategy of Scientific Model Building. In R. R. Launer \& G. N. Wilkinson (Eds.), Robustness in Statistics (pp. 201-236): Academic Press.

Buytaert, W., \& Beven, K. (2011). Models as multiple working hypotheses: hydrological simulation of tropical alpine wetlands. Hydrological Processes, 25(11), 1784-1799. doi:10.1002/hyp.7936

Cartwright, N. (1983). How the laws of physics lie. Oxford: Oxford University Press.

Cartwright, N. (1999). The dappled world: A study of the boundaries of science. Cambridge, UK: Cambridge University Press.

Cartwright, N., Cat, J., Uebel, T. E., \& Fleck, L. (1996). Otto Neurath: Philosophy between science and politics. Cambridge: Cambridge University Press.

Chamberlin, T. C. (1890). The method of multiple working hypotheses. Science, 15, 92-96.

Chorley, R. J. (1962). Geomorphology and general systems theory (500B). Retrieved from http://pubs.er.usgs.gov/publication/pp500B

\section{https://pubs.usgs.gov/pp/0500b/report.pdf}

Clark, M. P., Fan, Y., Lawrence, D. M., Adam, J. C., Bolster, D., Gochis, D. J., et al. (2015a). Improving the representation of hydrologic processes in Earth System Models. Water Resources Research, 51(8), 5929-5956. doi:doi:10.1002/2015WR017096

Clark, M. P., Kavetski, D., \& Fenicia, F. (2011). Pursuing the method of multiple working hypotheses for hydrological modeling. Water Resources Research, 47(9).

Clark, M. P., Kavetski, D., \& Fenicia, F. (2012). Reply to comment by K. Beven et al. on "Pursuing the method of multiple working hypotheses for hydrological modeling". Water Resources Research, 48(11).

Clark, M. P., Nijssen, B., Lundquist, J. D., Kavetski, D., Rupp, D. E., Woods, R. A., et al. (2015b). A unified approach for process-based hydrologic modeling: 1. Modeling concept. Water Resources Research, 51(4), 2498-2514. doi:doi:10.1002/2015WR017198

Clark, M. P., Schaefli, B., Schymanski, S. J., Samaniego, L., Luce, C. H., Jackson, B. M., et al. (2016). Improving the theoretical underpinnings of process-based hydrologic models. Water Resources Research, 52(3), 2350-2365. doi:doi:10.1002/2015WR017910 
Creath, R. (2017). Logical Empiricism. In E. N. Zalta (Ed.), The Stanford Encyclopedia of Philosophy.

Davis, B. J., \& Erlanson, D. A. (2013). Learning from our mistakes: The 'unknown knowns' in fragment screening. Bioorganic \& Medicinal Chemistry Letters, 23(10), 2844-2852. doi:https://doi.org/10.1016/j.bmcl.2013.03.028

Davtalab, R., Mirchi, A., Khatami, S., Gyawali, R., Massah, A., Farajzadeh, M., et al. (2017). Improving Continuous Hydrologic Modeling of Data-Poor River Basins Using Hydrologic Engineering Center's Hydrologic Modeling System: Case Study of Karkheh River Basin. Journal of Hydrologic Engineering, 22(8), 05017011. doi:https://doi.org/10.1061/(ASCE)HE.1943-5584.0001525

Devitt, M. (1997). Realism and truth. Cambridge: Princeton University Press.

Di Baldassarre, G., Brandimarte, L., \& Beven, K. (2015). The seventh facet of uncertainty: wrong assumptions, unknowns and surprises in the dynamics of human-water systems. Hydrological Sciences Journal, 61(9), 1748-1758. doi:10.1080/02626667.2015.1091460

Döll, P., \& Romero-Lankao, P. (2017). How to embrace uncertainty in participatory climate change risk management-A roadmap. Earth's Future, 5(1), 18-36.

doi:doi:10.1002/2016EF000411

Dooge, J. C. I. (1968). The hydrologic cycle as a closed system. International Association of Scientific Hydrology. Bulletin, 13(1), 58-68. doi:10.1080/02626666809493568

Douven, I. (2017). Abduction. In E. N. Zalta (Ed.), The Stanford Encyclopedia of Philosophy.

Driesch, H. (1908). The science and philosophy of the organisms. London: Black.

Du Bois-Reymond, E. H. (1872). Über die grenzen des naturerkennens. Leipzig: Von Veit \& Com.

Duan, Q., Sorooshian, S., \& Gupta, V. (1992). Effective and efficient global optimization for conceptual rainfall-runoff models. Water Resources Research, 28(4), 1015-1031. doi:10.1029/91WR02985

Falkenmark, M. (1977). Water and Mankind: A Complex System of Mutual Interaction. Ambio, 6(1), 3-9.

Fan, Y., Clark, M., Lawrence, D. M., Swenson, S., Band, L. E., Brantley, S. L., et al. (2019). Hillslope Hydrology in Global Change Research and Earth System Modeling. Water Resources Research, 55(2), 1737-1772. doi:10.1029/2018wr023903

Fisher, P. B. (2008). Uncertainty and Error. In K. K. Kemp (Ed.), Encyclopedia of Geographic Information Science (pp. 493-497). Thousand Oaks, California.

Fowler, K., Peel, M., Western, A., \& Zhang, L. (2018). Improved Rainfall-Runoff Calibration for Drying Climate: Choice of Objective Function. Water Resources Research, 54(5), 33923408. doi:doi:10.1029/2017WR022466 
Fowler, K. J. A., Peel, M. C., Western, A. W., Zhang, L., \& Peterson, T. J. (2016). Simulating runoff under changing climatic conditions: Revisiting an apparent deficiency of conceptual rainfall-runoff models. Water Resources Research, 52(3), 1820-1846.

doi:10.1002/2015WR018068

Frigg, R., \& Hartmann, S. (2018). Models in Science. In E. N. Zalta (Ed.), The Stanford Encyclopedia of Philosophy.

Frigg, R., \& Nguyen, J. (2018). Scientific Representation. In E. N. Zalta (Ed.), The Stanford Encyclopedia of Philosophy.

Gelb, A. (1974). Applied optimal estimation. Cambridge, MA: MIT press.

Ghanem, R., Higdon, D., \& Owhadi, H. (2017). Handbook of uncertainty quantification: Springer.

Gharari, S., Hrachowitz, M., Fenicia, F., Gao, H., \& Savenije, H. H. G. (2014). Using expert knowledge to increase realism in environmental system models can dramatically reduce the need for calibration. Hydrol. Earth Syst. Sci., 18(12), 4839-4859. doi:10.5194/hess-18-48392014

Ginsberg, B. (2011). The fall of the faculty: The Rise of the All-Administrative University and Why it Matters New York, US: Oxford University Press.

Godfrey-Smith, P. (2003). Theory and reality: An introduction to the philosophy of science. Chicago: University of Chicago Press.

Gong, W., Gupta, H. V., Yang, D., Sricharan, K., \& Hero, A. O. (2013). Estimating epistemic and aleatory uncertainties during hydrologic modeling: An information theoretic approach. Water Resources Research, 49(4), 2253-2273. doi:10.1002/wrcr.20161

Goodwell, A. E., \& Kumar, P. (2017). Temporal information partitioning: Characterizing synergy, uniqueness, and redundancy in interacting environmental variables. Water Resources Research, 53(7), 5920-5942. doi:10.1002/2016wr020216

Gottlieb, G. (2003). Probabilistic epigenesis of development. In J. Valsiner \& K. Connolly (Eds.), Handbook of developmental psychology (pp. 3-17). London, UK: SAGE Publications Ltd.

Grayson, R. B., Moore, I. D., \& McMahon, T. A. (1992a). Physically based hydrologic modeling: 1. A terrain-based model for investigative purposes. Water Resources Research, 28(10), 2639-2658. doi:10.1029/92WR01258

Grayson, R. B., Moore, I. D., \& McMahon, T. A. (1992b). Physically based hydrologic modeling: 2. Is the concept realistic? Water Resources Research, 28(10), 2659-2666. doi:10.1029/92WR01259

Gupta, H., Clark, M. P., Vrugt, J. A., Abramowitz, G., \& Ye, M. (2012). Towards a comprehensive assessment of model structural adequacy. Water Resources Research, 48(8). doi:doi:10.1029/2011WR011044 
Gupta, H. V., \& Razavi, S. (2018). Revisiting the Basis of Sensitivity Analysis for Dynamical Earth System Models. Water Resources Research. doi:doi:10.1029/2018WR022668

Gupta, V. K., \& Sorooshian, S. (1983). Uniqueness and observability of conceptual rainfallrunoff model parameters: The percolation process examined. Water Resources Research, 19(1), 269-276. doi:10.1029/WR019i001p00269

Haddeland, I., Heinke, J., Biemans, H., Eisner, S., Flörke, M., Hanasaki, N., et al. (2014). Global water resources affected by human interventions and climate change. Proceedings of the National Academy of Sciences, 111(9), 3251-3256. doi:10.1073/pnas.1222475110

Haghnegahdar, A., Razavi, S., Yassin, F., \& Wheater, H. (2017). Multicriteria sensitivity analysis as a diagnostic tool for understanding model behaviour and characterizing model uncertainty. Hydrological Processes, 31(25), 4462-4476. doi:10.1002/hyp.11358

Hall, J., \& Anderson, M. (2002). Handling uncertainty in extreme or unrepeatable hydrological processes - the need for an alternative paradigm. Hydrological Processes, 16(9), 1867-1870. doi:10.1002/hyp.5026

Hann, M. M. (2011). Molecular obesity, potency and other addictions in drug discovery. MedChemComm, 2(5), 349-355. doi:10.1039/C1MD00017A

Hanson, N. R. (1958). Patterns of discovery: An inquiry into the conceptual foundations of science. New York, USA: Cambridge University Press.

Hellebrand, H., Müller, C., Matgen, P., Fenicia, F., \& Savenije, H. (2011). A process proof test for model concepts: Modelling the meso-scale. Physics and Chemistry of the Earth, Parts A/B/C, 36(1-4), 42-53. doi:http://dx.doi.org/10.1016/i.pce.2010.07.019

Helmer, O., \& Rescher, N. (1959). On the Epistemology of the Inexact Sciences. Management Science, 6(1), 25-52.

Heymann, M., \& Dalmedico, A. D. (2019). Epistemology and Politics in Earth System Modeling: Historical Perspectives. Journal of Advances in Modeling Earth Systems. doi:10.1029/2018ms001526

Holmes, M. A., O'Connell, S., Frey, C., \& Ongley, L. (2008). Gender imbalance in US geoscience academia. Nature Geoscience, 1, 79. doi:10.1038/ngeo113

Hornberger, G. M., \& Spear, R. C. (1981). An approach to the preliminary analysis of environmental systems. Journal of Environmental Management, 12, 7-18.

Hrachowitz, M., \& Clark, M. P. (2017). HESS Opinions: The complementary merits of competing modelling philosophies in hydrology. Hydrol. Earth Syst. Sci., 21(8), 3953-3973. doi:10.5194/hess-21-3953-2017

Hrachowitz, M., Fovet, O., Ruiz, L., Euser, T., Gharari, S., Nijzink, R., et al. (2014). Process consistency in models: The importance of system signatures, expert knowledge, and process complexity. Water Resources Research, 50(9), 7445-7469. doi:10.1002/2014WR015484 
Hume, D. (1739). A treatise of human nature. London.

Jacquin, A. P., \& Shamseldin, A. Y. (2007). Development of a possibilistic method for the evaluation of predictive uncertainty in rainfall-runoff modeling. Water Resources Research, 43(4), W04425. doi:10.1029/2006WR005072

Jehn, F. U., Breuer, L., Houska, T., Bestian, K., \& Kraft, P. (2018). Incremental model breakdown to assess the multi-hypotheses problem. Hydrol. Earth Syst. Sci., 22(8), 45654581. doi:10.5194/hess-22-4565-2018

Jehn, F. U., Chamorro, A., Houska, T., \& Breuer, L. (2019). Trade-offs between parameter constraints and model realism: a case study. Scientific Reports, 9(1), 10729.

doi:10.1038/s41598-019-46963-6

Kavetski, D., Kuczera, G., \& Franks, S. W. (2006a). Bayesian analysis of input uncertainty in hydrological modeling: 1. Theory. Water Resources Research, 42(3), W03407.

doi:10.1029/2005WR004368

Kavetski, D., Kuczera, G., \& Franks, S. W. (2006b). Bayesian analysis of input uncertainty in hydrological modeling: 2. Application. Water Resources Research, 42(3), W03408. doi:10.1029/2005WR004376

Kelleher, C., McGlynn, B., \& Wagener, T. (2017). Characterizing and reducing equifinality by constraining a distributed catchment model with regional signatures, local observations, and process understanding. Hydrol. Earth Syst. Sci., 21(7), 3325-3352. doi:10.5194/hess-213325-2017

Kelleher, C., Wagener, T., \& McGlynn, B. (2015). Model-based analysis of the influence of catchment properties on hydrologic partitioning across five mountain headwater subcatchments. Water Resources Research, 51(6), 4109-4136.

doi:doi:10.1002/2014WR016147

Khatami, S., Peel, M. C., Peterson, T. J., \& Western, A. W. (2019). Equifinality and Flux Mapping: a new approach to model evaluation and process representation under uncertainty. Water Resources Research. doi:https://doi.org/10.1029/2018WR023750

Khazaei, B., Anderson, E. J., Klump, J. V., \& Bravo, H. R. (2019a). Development of Hydrodynamic and Sediment Transport Model for Green Bay, Lake Michigan World Environmental and Water Resources Congress 2019 (pp. 68-82).

Khazaei, B., \& Hosseini, S. M. (2015). Improving the performance of water balance equation using fuzzy logic approach. Journal of Hydrology, 524(Supplement C), 538-548. doi:https://doi.org/10.1016/i.jhydrol.2015.02.047

Khazaei, B., Khatami, S., Alemohammad, S. H., Rashidi, L., Wu, C., Madani, K., et al. (2019b). Climatic or regionally induced by humans? Tracing hydro-climatic and land-use changes to better understand the Lake Urmia tragedy. Journal of Hydrology, 569, 203-217. doi:https://doi.org/10.1016/i.jhydrol.2018.12.004 
Kirchner, J. W. (2006). Getting the right answers for the right reasons: Linking measurements, analyses, and models to advance the science of hydrology. Water Resources Research, 42(3), W03S04. doi:10.1029/2005WR004362

Kirchner, J. W. (2016). Aggregation in environmental systems - Part 1: Seasonal tracer cycles quantify young water fractions, but not mean transit times, in spatially heterogeneous catchments. Hydrol. Earth Syst. Sci., 20(1), 279-297. doi:10.5194/hess-20-279-2016

Klemeš, V. (1986a). Dilettantism in hydrology: Transition or destiny? Water Resources Research, 22(9S), 177S-188S. doi:10.1029/WR022i09Sp0177S

Klemeš, V. (1986b). Operational testing of hydrological simulation models. Hydrological Sciences Journal, 31(1), 13-24. doi:10.1080/02626668609491024

Knoben, W. J. M., Freer, J. E., Fowler, K. J. A., Peel, M. C., \& Woods, R. A. (2019). Modular Assessment of Rainfall-Runoff Models Toolbox (MARRMoT) v1.2: an open-source, extendable framework providing implementations of 46 conceptual hydrologic models as continuous state-space formulations. Geosci. Model Dev., 12(6), 2463-2480.

doi:10.5194/gmd-12-2463-2019

Krueger, T., Freer, J., Quinton, J. N., Macleod, C. J. A., Bilotta, G. S., Brazier, R. E., et al. (2010). Ensemble evaluation of hydrological model hypotheses. Water Resources Research, 46(7). doi:10.1029/2009wr007845

Lewis, S., \& Nir, A. (1978). A study of parameter estimation procedures of a model for lake phosphorus dynamics. Ecological Modelling, 4(2), 99-117. doi:https://doi.org/10.1016/0304$\underline{3800(78) 90002-9}$

Ley, R., Casper, M. C., Hellebrand, H., \& Merz, R. (2011). Catchment classification by runoff behaviour with self-organizing maps (SOM). Hydrol. Earth Syst. Sci., 15(9), 2947-2962. doi:10.5194/hess-15-2947-2011

Lintern, A., Webb, J. A., Ryu, D., Liu, S., Bende-Michl, U., Waters, D., et al. (2018). Key factors influencing differences in stream water quality across space. Wiley Interdisciplinary Reviews: Water, 5(1), e1260. doi:10.1002/wat2.1260

Madani, K., Hooshyar, M., Khatami, S., Alaeipour, A., \& Moeini, A. (2014, 5-8 Oct. 2014). Nash-reinforcement learning (N-RL) for developing coordination strategies in nontransferable utility games. Paper presented at the 2014 IEEE International Conference on Systems, Man, and Cybernetics (SMC).

Madani, K., \& Khatami, S. (2015). Water for Energy: Inconsistent Assessment Standards and Inability to Judge Properly. Current Sustainable/Renewable Energy Reports, 2(1), 10-16. doi:https://doi.org/10.1007/s40518-014-0022-5

Magnani, L. (2011). Abduction, reason, and science: Process of discovery and explanation. New York: Springer Science. 
Maier, H. R., Guillaume, J. H. A., van Delden, H., Riddell, G. A., Haasnoot, M., \& Kwakkel, J. H. (2016). An uncertain future, deep uncertainty, scenarios, robustness and adaptation: How do they fit together? Environmental Modelling \& Software, 81, 154-164.

doi:https://doi.org/10.1016/i.envsoft.2016.03.014

Mayo, D. G. (1996). Error and the growth of experimental knowledge: University of Chicago Press.

McMahon, T. A., \& Peel, M. C. (2019). Uncertainty in stage-discharge rating curves: application to Australian Hydrologic Reference Stations data. Hydrological Sciences Journal, 64(3), 255-275. doi:10.1080/02626667.2019.1577555

Melsen, L. A., Teuling, A. J., Torfs, P. J. J. F., Uijlenhoet, R., Mizukami, N., \& Clark, M. P. (2016). HESS Opinions: The need for process-based evaluation of large-domain hyperresolution models. Hydrol. Earth Syst. Sci., 20(3), 1069-1079. doi:10.5194/hess-20-1069-2016

Melsen, L. A., Teuling, A. J., Torfs, P. J. J. F., Zappa, M., Mizukami, N., Mendoza, P. A., et al. (2019). Subjective modeling decisions can significantly impact the simulation of flood and drought events. Journal of Hydrology, 568, 1093-1104.

doi:https://doi.org/10.1016/i.jhydrol.2018.11.046

Mirowski, P. (2011). Science-mart: Privatizing American Science. Cambridge, UK: Harvard University Press.

Moallemi, E. A., Elsawah, S., \& Ryan, M. J. (2018). Model-based multi-objective decision making under deep uncertainty from a multi-method design lens. Simulation Modelling Practice and Theory, 84, 232-250. doi:https://doi.org/10.1016/i.simpat.2018.02.009

Moallemi, E. A., \& Köhler, J. (2019). Coping with uncertainties of sustainability transitions using exploratory modelling: The case of the MATISSE model and the UK's mobility sector. Environmental Innovation and Societal Transitions. doi:https://doi.org/10.1016/i.eist.2019.03.005

Moallemi, E. A., \& Malekpour, S. (2017). A participatory exploratory modelling approach for long-term planning in energy transitions. Energy Research \& Social Science. doi:https://doi.org/10.1016/j.erss.2017.10.022

Möller, P., \& Dowling, T. P. F. (2018). Equifinality in glacial geomorphology: instability theory examined via ribbed moraine and drumlins in Sweden. GFF, 140(2), 106-135. doi:10.1080/11035897.2018.1441903

Nearing, G. S., \& Gupta, H. V. (2015). The quantity and quality of information in hydrologic models. Water Resources Research, 51(1), 524-538. doi:10.1002/2014WR015895

Nearing, G. S., Tian, Y., Gupta, H. V., Clark, M. P., Harrison, K. W., \& Weijs, S. V. (2016). A philosophical basis for hydrological uncertainty. Hydrological Sciences Journal, 61(9), 16661678. doi:10.1080/02626667.2016.1183009 
Oh, P. S. (2011). Characteristics of abductive inquiry in earth science: An undergraduate case study. Science Education, 95(3), 409-430. doi:10.1002/sce.20424

Oreskes, N. (1996). Objectivity or Heroism? On the Invisibility of Women in Science. Osiris, 11(1), 87-113. doi:10.1086/368756

Oreskes, N., \& Belitz, K. (2001). Philosophical Issues in Model Assessment. In M. G. Anderson \& P. D. Bates (Eds.), Model Validation: Perspectives in Hydrological Science (pp. 2341). London: John Wiley and Sons Ltd.

Oreskes, N., Shrader-Frechette, K., \& Belitz, K. (1994). Verification, validation, and confirmation of numerical models in the earth sciences. Science, 263(5147), 641-646.

Pappenberger, F., Beven, K. J., Ratto, M., \& Matgen, P. (2008). Multi-method global sensitivity analysis of flood inundation models. Advances in Water Resources, 31(1), 1-14. doi:https://doi.org/10.1016/j.advwatres.2007.04.009

Peel, M. C. (2009). Hydrology: catchment vegetation and runoff. Progress in Physical Geography: Earth and Environment, 33(6), 837-844. doi:10.1177/0309133309350122

Peel, M. C., McMahon, T. A., \& Finlayson, B. L. (2010). Vegetation impact on mean annual evapotranspiration at a global catchment scale. Water Resources Research, 46(9). doi:10.1029/2009wr008233

Peirce, C. S. (1934). Collected papers of charles sanders peirce: The Belknap Press of Harvard University Press.

Peterson, T. J., Argent, R. M., Western, A. W., \& Chiew, F. H. S. (2009). Multiple stable states in hydrological models: An ecohydrological investigation. Water Resources Research, 45(3). doi:10.1029/2008wr006886

Peterson, T. J., \& Western, A. W. (2014). Multiple hydrological attractors under stochastic daily forcing: 1. Can multiple attractors exist? Water Resources Research, 50(4), 2993-3009. doi:10.1002/2012WR013003

Peterson, T. J., Western, A. W., \& Argent, R. M. (2012). Analytical methods for ecosystem resilience: A hydrological investigation. Water Resources Research, 48(10). doi:10.1029/2012wr012150

Peterson, T. J., Western, A. W., \& Argent, R. M. (2014). Multiple hydrological attractors under stochastic daily forcing: 2. Can multiple attractors emerge? Water Resources Research, 50(4), 3010-3029. doi:10.1002/2012WR013004

Pool, S., Vis, M., \& Seibert, J. (2018). Evaluating model performance: towards a nonparametric variant of the Kling-Gupta efficiency. Hydrological Sciences Journal, 63(13-14), 1941-1953. doi:10.1080/02626667.2018.1552002

Pool, S., Viviroli, D., \& Seibert, J. (2019). Value of a Limited Number of Discharge Observations for Improving Regionalization: A Large-Sample Study Across the United States. Water Resources Research, 55(1), 363-377. doi:doi:10.1029/2018WR023855 
Popp, A., Lutz, S., Khatami, S., van Emmerik, T., \& Knoben, W. J. M. (2019). A global survey on the perceptions and impacts of gender inequality in the Earth and space sciences. Earth and Space Science. doi:https://doi.org/10.1029/2019EA000706

Rotmans, J., \& van Asselt, M. A. (2001). Uncertainty in Integrated Assessment Modelling: A Labyrinthic Path. Integrated Assessment, 2(2), 43-55. doi:10.1023/A:1011588816469

Saltelli, A. (2016). Young statistician, you shall live in adventurous times. Significance, 13(6), 38-41. doi:doi:10.1111/j.1740-9713.2016.00983.x

Sarkar, S., \& Pfeifer, J. (2006). The philosophy of science: An encyclopedia. New York: Routledge.

Savenije, H. H. G. (2001). Equifinality, a blessing in disguise? Hydrological Processes, 15(14), 2835-2838. doi:10.1002/hyp.494

Schaefli, B. (2016). Snow hydrology signatures for model identification within a limits-ofacceptability approach. Hydrological Processes, 30(22), 4019-4035. doi:10.1002/hyp.10972

Schär, C., Ban, N., Fischer, E. M., Rajczak, J., Schmidli, J., Frei, C., et al. (2016). Percentile indices for assessing changes in heavy precipitation events. Climatic Change, 137(1), 201216. doi:10.1007/s10584-016-1669-2

Schiebinger, L. (1999). Has feminism changed science? Cambridge, MA: Harvard University Press.

Schulz, K., \& Huwe, B. (1997). Water flow modeling in the unsaturated zone with imprecise parameters using a fuzzy approach. Journal of Hydrology, 201(1), 211-229. doi:https://doi.org/10.1016/S0022-1694(97)00038-3

Schulz, K., Huwe, B., \& Peiffer, S. (1999). Parameter uncertainty in chemical equilibrium calculations using fuzzy set theory. Journal of Hydrology, 217(1), 119-134.

doi:https://doi.org/10.1016/S0022-1694(99)00016-5

Schweppe, F. C. (1973). Uncertain dynamic systems. Englewood Cliffs, N.J.: Prentice-Hall.

Seibert, J., \& McDonnell, J. J. (2002). On the dialog between experimentalist and modeler in catchment hydrology: Use of soft data for multicriteria model calibration. Water Resources Research, 38(11), 23-21-23-14. doi:10.1029/2001WR000978

Sheikholeslami, R., \& Razavi, S. (2017). Progressive Latin Hypercube Sampling: An efficient approach for robust sampling-based analysis of environmental models. Environmental Modelling \& Software, 93, 109-126. doi:https://doi.org/10.1016/i.envsoft.2017.03.010

Shen, C., Laloy, E., Elshorbagy, A., Albert, A., Bales, J., Chang, F. J., et al. (2018). HESS Opinions: Incubating deep-learning-powered hydrologic science advances as a community. Hydrol. Earth Syst. Sci., 22(11), 5639-5656. doi:10.5194/hess-22-5639-2018 
Shrestha, R. R., Bárdossy, A., \& Nestmann, F. (2007). Analysis and propagation of uncertainties due to the stage-discharge relationship: a fuzzy set approach. Hydrological Sciences Journal, 52(4), 595-610. doi:10.1623/hysj.52.4.595

Sorooshian, S., \& Gupta, V. K. (1983). Automatic calibration of conceptual rainfall-runoff models: The question of parameter observability and uniqueness. Water Resources Research, 19(1), 260-268. doi:10.1029/WR019i001p00260

Stanford, K. (2017). Underdetermination of Scientific Theory. In E. N. Zalta (Ed.), The Stanford Encyclopedia of Philosophy.

Staudinger, M., Stoelzle, M., Cochand, F., Seibert, J., Weiler, M., \& Hunkeler, D. (2019). Your work is my boundary condition!: Challenges and approaches for a closer collaboration between hydrologists and hydrogeologists. Journal of Hydrology, 571, 235-243. doi:https://doi.org/10.1016/j.jhydrol.2019.01.058

Takacs, D. (2003). How Does Your Positionality Bias Your Epistemology? Thought \& Action, 27.

Tolson, B. A., \& Shoemaker, C. A. (2008). Efficient prediction uncertainty approximation in the calibration of environmental simulation models. Water Resources Research, 44(4). doi:10.1029/2007wr005869

Van Fraassen, B. C. (1980). The scientific image: Oxford University Press.

von Bertalanffy, L. (1950). The theory of open systems in physics and biology. Science, 111(2872), 23-29.

von Bertalanffy, L. (1968). General system theory: Foundations, development, applications. New York: Braziller.

Vrugt, J. A., \& Beven, K. J. (2018). Embracing equifinality with efficiency: Limits of Acceptability sampling using the DREAM(LOA) algorithm. Journal of Hydrology, 559, 954-971. doi:https://doi.org/10.1016/j.jhydrol.2018.02.026

Weiler, M., \& McDonnell, J. (2004). Virtual experiments: a new approach for improving process conceptualization in hillslope hydrology. Journal of Hydrology, 285(1-4), 3-18. doi:http://dx.doi.org/10.1016/S0022-1694(03)00271-3

Western, A. W., \& Grayson, R. B. (1998). The Tarrawarra Data Set: Soil moisture patterns, soil characteristics, and hydrological flux measurements. Water Resources Research, 34(10), 2765-2768. doi:doi:10.1029/98WR01833

Western, A. W., Grayson, R. B., \& Blöschl, G. (2002). Scaling of Soil Moisture: A Hydrologic Perspective. Annual Review of Earth and Planetary Sciences, 30(1), 149-180.

doi:10.1146/annurev.earth.30.091201.140434

Western, A. W., Grayson, R. B., \& Costelloe, J. F. (2005). Principles of Hydrological Measurements. In M. G. Anderson \& J. J. McDonnell (Eds.), Encyclopedia of hydrological sciences. Chichester, England: John Wiley \& Sons, Ltd. 
Whetton, P. H., Grose, M. R., \& Hennessy, K. J. (2016). A short history of the future: Australian climate projections 1987-2015. Climate Services, 2-3(Supplement C), 1-14. doi:https://doi.org/10.1016/i.cliser.2016.06.001

Wine, M. L., \& Davison, J. H. (2019). Untangling global change impacts on hydrological processes: Resisting climatization. Hydrological Processes, 33(15), 2148-2155. doi:10.1002/hyp.13483

Winsemius, H. C., Schaefli, B., Montanari, A., \& Savenije, H. H. G. (2009). On the calibration of hydrological models in ungauged basins: $A$ framework for integrating hard and soft hydrological information. Water Resources Research, 45(12).

doi:doi:10.1029/2009WR007706

Woodward, J. (2017). Scientific Explanation. In E. N. Zalta (Ed.), The Stanford Encyclopedia of Philosophy.

Zimmer, M. A., \& McGlynn, B. L. (2017). Ephemeral and intermittent runoff generation processes in a low relief, highly weathered catchment. Water Resources Research, 53(8), 7055-7077. doi:10.1002/2016wr019742

Zizek, S. (2004). Iraq's False Promises. Foreign Policy(140), 43-49. doi:10.2307/4147518

Žižek, S. (2006). Philosophy, the "unknown knowns," and the public use of reason. Topoi, 25(1), 137-142. doi:10.1007/s11245-006-0021-2 


\section{Result Chapter 1 (Paper 2)}

This Chapter is published (citation below) and included in this thesis with the permission of the publisher John Wiley and Sons.

Khatami, S., Peel, M. C., Peterson, T. J., \& Western, A.

W. (2019). Equifinality and flux mapping: A new approach to model

evaluation and process representation under uncertainty. Water Resources

Research, 55, 8922-8941. https://doi.org/10.1029/2018WR023750 


\section{Water Resources Research}

\section{RESEARCH ARTICLE \\ 10.1029/2018WR023750}

Key Points:

- We characterized different facets of model equifinality and discussed them within the context of conceptual hydrological modeling

- We introduced the new model evaluation method of Flux Mapping to explore model behavior, particularly process representation

Even within a very narrow margin of model error/performance, different modes of model response (i.e., internal flux dynamics) can be equally active

Supporting Information:

- Supporting Information S1

Correspondence to:

S. Khatami,

sina.khatami@unimelb.edu.au

Citation:

Khatami, S., Peel, M. C., Peterson, T. J., \& Western, A. W. (2019). Equifinality and flux mapping: A new approach to model evaluation and process representation under uncertainty. Water Resources Research, 55, 8922-8941. https://doi.org/10.1029/ 2018WR023750

Received 23 JUL 2018 Accepted 18 JUN 2019 Accepted article online 26 JUN 2019 Published online 12 NOV 2019 (c)2019. American Geophysical Union. All Rights Reserved.

\section{Equifinality and Flux Mapping: A New Approach to Model Evaluation and Process Representation Under Uncertainty}

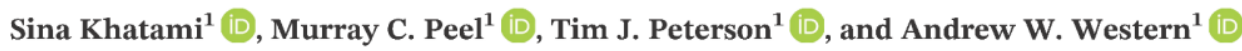 \\ ${ }^{1}$ Department of Infrastructure Engineering, University of Melbourne, Parkville, Victoria, Australia
}

\begin{abstract}
Uncertainty analysis is an integral part of any scientific modeling, particularly within the domain of hydrological sciences given the various types and sources of uncertainty. At the center of uncertainty rests the concept of equifinality, that is, reaching a given endpoint (finality) through different pathways. The operational definition of equifinality in hydrological modeling is that various model structures and/or parameter sets (i.e., equal pathways) are equally capable of reproducing a similar (not necessarily identical) hydrological outcome (i.e., finality). Here we argue that there is more to model equifinality than model structures/parameters, that is, other model components can give rise to model equifinality and/or could be used to explore equifinality within model space. We identified six facets of model equifinality, namely, model structure, parameters, performance metrics, initial and boundary conditions, inputs, and internal fluxes. Focusing on model internal fluxes, we developed a methodology called flux mapping that has fundamental implications in understanding and evaluating model process representation within the paradigm of multiple working hypotheses. To illustrate this, we examine the equifinality of runoff fluxes of a conceptual rainfall-runoff model for a number of different Australian catchments. We demonstrate how flux maps can give new insights into the model behavior that cannot be captured by conventional model evaluation methods. We discuss the advantages of flux space, as a subspace of the model space not usually examined, over parameter space. We further discuss the utility of flux mapping in hypothesis generation and testing, extendable to any field of scientific modeling of open complex systems under uncertainty.
\end{abstract}

\section{Introduction}

Understanding, modeling, and predicting hydrological systems-realistically and viably-is the Holy Grail of hydrological sciences. There are barriers in this quest, particularly in a world undergoing rapid and largescale changes (Peel \& Blöschl, 2011). Among numerous difficulties with modeling and prediction of realworld hydrological processes are the issues of scale (Blöschl \& Sivapalan, 1995) and commensurability (Beven, 2012b, p. 245) between observed and modeled variables; dependency upon the quantity (Boughton, 2007) and quality (Beven \& Westerberg, 2011; Yew Gan et al., 1997) of available data and their information content (Nearing \& Gupta, 2015); model complexity (Perrin et al., 2001; Yew Gan et al., 1997); the chaotic nature of many hydrological processes (Khatami, 2013a, 2013b; Sivakumar, 2000; Sivakumar et al., 2001); modeling hydrological responses to change (Schaefli et al., 2011) and resilience to disturbance (Peterson et al., 2014; Peterson \& Western, 2014); numerical daemons of conceptual hydrological modeling (Clark \& Kavetski, 2010; Kavetski \& Clark, 2011); and the ill conditionedness or ill posedness of environmental models (Beck, 1987; Yeh, 1986). The latter is also referred to as equifinality (Beck, 2002; Beven, 2006; Ebel \& Loague, 2006; Kelleher et al., 2017).

Beven (1975), p. 14) first used the term equifinality in the domain of hydrological modeling. Later, Beven (1993) proposed a concept of equifinality for model evaluation and uncertainty analysis. Based on his suggested concept, the operational definition of equifinality is that different model structures and/or parameter sets (i.e., equal pathways) are equally capable of reproducing a similar (not necessarily identical) hydrological outcome (i.e., finality). For example, in the case of rainfall-runoff modeling, for a given criterion of reproducibility (e.g., an objective function), a number of rainfall-runoff models (i.e., distributed or lumped, and process based or black box such as TOPMODEL, HBV, and Sacramento) and/or various parameter sets might be able to equally reproduce a particular observed runoff. This operational definition of equifinality 
is closely related to structural and parameter uncertainty and is the cornerstone of sensitivity and uncertainty estimation frameworks such as generalized sensitivity (Hornberger \& Spear, 1981) and generalized likelihood uncertainty estimation (Beven \& Binley, 1992).

In this paper we argue that equifinality-like uncertainty-is a multifaceted concept, and various model components other than model structure and parameters could also give rise to model equifinality. We first, briefly outline various facets of model equifinality (section 2), namely, equifinality of model structures and/or parameters, objective functions (or model performance metrics), model initial/boundary conditions, model inputs, and model internal fluxes. We should mention that there are other facets of equifinality than model equifinality that we discussed under a comprehensive theoretical framework of scientific inquiry and modeling of hydrological systems under uncertainty. While facets of model equifinality are not mutually exclusive and in fact are intertwined, each facet underscores a particular aspect (subspace) of the overall model space. We develop a new model evaluation scheme, called flux mapping (section 3), to examine the degree of equifinality of model internal fluxes and to explore and characterize model process representation. Using a modeling experiment (section 3.4), we demonstrate how flux mapping - analyzing model equifinality through the lens of model internal fluxes instead of model parameters-provides new insights into model internal behavior and process representation, which cannot be (easily) captured/characterized using conventional model evaluation schemes (e.g., objective functions, dotty plots, and parameter distributions; sections 4 and 5.1). In other words, reprojecting model behavior (e.g., response surface) from parameter space to the flux space can give new insights into model internal behavior that are not inferable from parameter space. To this end, we showcase and discuss the results of flux mapping for a number of Australian catchments (section 4).

Flux mapping is an approach to generate and explore multiple working hypotheses (MWH) based on model internal behavior and process representation. Chamberlin (1890) argued for the paradigm of MWH in scientific inquiries as this paradigm is more robust to reduce bias (i.e., assure impartiality) toward a particular hypothesis for explaining a given phenomenon. Theoretically, to explain real-world processes, $\mathrm{MWH}$ is a never-ending process within which hypotheses, that is, a set of plausible explanations of real-world phenomenon, are generated, evaluated, revised/refined, and further evaluated with the hope that our refined hypotheses converge toward an approximation of the actual reality. The value and significance of pursuing MWH in hydrological modeling is discussed in the literature (Beven, 2012a; Beven et al., 2012; Buytaert \& Beven, 2011; Clark et al., 2011, 2012). We further discuss the utility and exploratory power of flux mapping in hypothesis forming/testing and process understanding (section 5.2). Flux mapping is extendable beyond hydrological modeling to any field of scientific modeling dealing with conceptual modeling of open complex systems under uncertainty.

\section{Facets of Model Equifinality: Theoretical Discussion}

Throughout the hydrological literature when the term equifinality is used, it is predominantly referring to model equifinality; different model structures and/or parameter sets could produce a similar outcome given some available (uncertain) observations and a particular (incomplete) metric of acceptability (e.g., model performance above a subjective value of one/multiple objective functions). So model equifinality is conditional on the model configuration, performance metric(s), and the information content of the data used. Beven (1975), p. 14) was the first to use the term equifinality in hydrology, and later Beven (1993) discussed its implication in hydrological modeling in terms of multiple acceptable model structures and/or parameter sets as a preferred alternative to the notion of a single optimum parameter set. There also has been other studies that referred to model equifinality using other terms such as ambiguity, identifiability, empirical equivalence, nonuniqueness, underdetermination or indeterminacy, and system convergence (e.g., Beck, 1987; Bethke, 1992; Carrera \& Neuman, 1986; Gupta \& Sorooshian, 1983; Hornberger \& Spear, 1981; Konikow \& Bredehoeft, 1992; Oreskes et al., 1994; Quine, 1975; Sorooshian \& Gupta, 1983; Yeh, 1986).

The question of model equifinality is often reduced to model parameter equifinality as parameter uncertainty expressed in probabilistic terms (i.e., parameter distribution), although there are other studies that attempted to take other sources of uncertainty into account such as model inputs (e.g., Blazkova \& Beven, 2009; Haydon \& Deletic, 2009; Kavetski et al., 2006; Liu et al., 2009; Vrugt et al., 2008) or structural uncertainty (Ajami et al., 2007; Bulygina \& Gupta, 2009, 2010, 2011; Butts et al., 2004; Renard et al., 2010). In 
this section, we make the case that there is more to model equifinality than parameter uncertainty (distribution) by characterizing six different, yet interconnected, facets of model equifinality.

\subsection{Equifinality of Model Structures}

Multiple model structures with different degrees of complexity (i.e., number of model parameters, fluxes, and/or other components) that are almost equally capable of reproducing a hydrologic behavior (e.g., discharge hydrograph) could be seen as MWH, with each model structure representing catchment behavior differently and hence equifinality of model structures. Various hydrological modeling frameworks have been developed arguably based on this very facet of model equifinality, whether or not this facet was explicitly acknowledged, including, but not limited to, SUMMA (Clark et al., 2015a; Clark et al., 2015b), FUSE (Clark et al., 2008), and SUPERFLEX (Fenicia et al., 2011; Kavetski \& Fenicia, 2011). Evaluating the realism of model structures (process representation) is fundamentally difficult, regardless of the number of models utilized and their (dis)agreement, as not all catchment internal processes are known or observed even at the scale of interest. Developing/choosing the model structure is majorly dependent upon the personal judgments and preferences of modelers (Addor \& Melsen, 2019; Holländer et al., 2009) and influenced by politics (Heymann \& Dalmedico, 2019). Thus, there is a "problem of decidability" (Beven, 2006) between feasible representations of the real world, that is, which conceptual model fits better to our perceptual model. In fact, the choice of model structure, like other subjective decisions in modeling, for example, the choice of objective function (Crochemore et al., 2015; discussed below), is often an act of will (i.e., modeler's personal or institutional preference) rather than rationality/objectivity (i.e., model adequacy or fit for purpose). For instance, Addor and Melsen (2019) demonstrated that in most cases that they investigated, the affiliation of the first author was a clear predictor of model selection, while the role model adequacy given the research objectives was less clear.

It is worth mentioning that model-structure-equifinality could be seen as a special case of equifinality of modeling approaches. Different modeling approaches, such as a top-down versus bottom-up, process-based versus black box, and distributed versus lumped, may lead to similar results in a given modeling case.

\subsection{Equifinality of Model Parameters}

This is the most widely studied facet of equifinality in hydrology (Arsenault \& Brissette, 2014; Beven \& Binley, 2014; Kelleher et al., 2015; Kelleher et al., 2017; Kirchner, 2016; Tang \& Zhuang, 2008; Teweldebrhan et al., 2018; Vrugt \& Beven, 2018). The operational definition of equifinality in hydrological literature is in fact parameter equifinality. Equifinal parameters are uncertain. Within the hydrological literature parameter equifinality and uncertainty are treated similarly and interchangeably. In simple terms, parameter uncertainty means that there is no certain/true parameter set and it is conventionally represented probabilistically as parameter distributions (commonly presented as marginal distributions). There are multiple acceptable/working parameter sets, that is, equifinal parameters, within the larger set of all uncertain parameters. Parameter uncertainty is generally addressed by searching for multiple acceptable parameter sets (e.g., set theoretic approaches and Monte Carlo experiments) given single/multiple measures of model performance. There are different ways to address parameter uncertainty, for example, Bayesian approach where different degrees of belief are assigned to the sampled parameter sets and approaches where parameter sets below a certain threshold of acceptability or outside particular limits of acceptability are rejected (e.g., generalized likelihood uncertainty estimation; Beven, 2009; Vrugt \& Beven, 2018). Regardless of the approach, parameter uncertainty is typically then expressed in terms of likelihood, that is, a parameter distribution.

In the above, parameter equifinality is determined based on the model performance-that is, the value of objective (or likelihood) function(s)—and the physical significance/plausibility of the so-called equifinal/behavioral parameter sets is often not examined, while, typically expressed probabilistically, parameter equifinality could be represented in other nonprobabilistic forms (see section 4 for more details). It should be further noted that it is difficult to draw a sharp dividing line between model structure and parameter equifinality, as the two are intertwined. Model structures (e.g., equations of model fluxes and storages) can be dependent upon the parameter values (driven by the input data), and parameter values change the function of a model component, sometimes drastically. For instance, for the SIMHYD model used in this study (see Figure 5a), parameter INSC (interception store capacity) can vary between 0 and 20. INSC $=0$ 
means the interception storage of the model is nonexistent and hence a significant change in process description/representation within the model structure. Similarly, $K$ (baseflow recession parameter) can vary between 0 and $1 . K=0$ means a nonexistent flux otherwise a linear flux equation with slopes decreasing from 1 (i.e., $K=1$ ) asymptotic to the $x$ axis (horizontal line at 0 ) as $K \rightarrow 0$. That is, each of these parameter values leads to an effectively different model structure.

\subsection{Equifinality of Model Performance Metrics (or Objective Functions)}

Objective functions-both their choice and function-are integral parts of the modeling process. For instance, the model output or response surface is the product of the interplay between model structure, parameters, objective function, data information content, and modeler's decisions. Objective functions characterize the model performance as an aggregated measure of the matching between modeled and observed; either as metrics of model residuals (Bennett et al., 2013; Davtalab et al., 2017; Fowler et al., 2018; Murphy, 1988) or as signatures of similarity (Addor et al., 2018; Fowler et al., 2016; Gupta et al., 2008; Kelleher et al., 2017; Pfannerstill et al., 2014; Sawicz et al., 2014; Schaefli, 2016; Yilmaz et al., 2008); whether a scalar metric/variable (single criterion) or a vector of metrics/variables (i.e., multiple criteria/multivariable; Efstratiadis \& Koutsoyiannis, 2010; Gupta et al., 1998; Stisen et al., 2018); and whether aggregated or distributed (Koch et al., 2016; Koch et al., 2017). Performance metrics reduce the complex behavior of a systemoften the integrated response of the catchment system, that is, discharge-from a higher dimension (e.g., a time series) to a single, or a few, point values; thus information loss is inevitable (Gong et al., 2013; Gupta \& Nearing, 2014; Nearing \& Gupta, 2015). Such aggregations, similar to the averaging process discussed by Savenije (2001), give rise to equifinality. That is, a similar model error (i.e., distance between the model output and observed behavior, e.g., discharge hydrograph) could be the result of different objective functions with different mathematical structures. Although it is possible to improve metrics, for example, by benchmarking (Schaefli \& Gupta, 2007; Seibert, 2001) or reformulation (Chiew et al., 1993; Gupta et al., 2009; Legates \& McCabe, 1999; Pool et al., 2018; Willmott et al., 2012), all metrics (whether single/vector or error-based/signature) have limitations and deficiencies (Pushpalatha et al., 2012; Santos et al., 2018; Westerberg et al., 2016; Westerberg \& McMillan, 2015). The problem of metric equifinality will not be eliminated by developing more sophisticated metrics. There is no ultimate (set of) objective function(s), as all metrics are "underdetermined" (i.e., "do not describe unique error characteristics, even when many of them are used collectively" (Tian et al., 2016)). Tian et al. (2016) demonstrated how identical values of conventional metrics and their derivatives-for example, bias, correlation coefficient, and mean square errorcan be achieved from vastly different time series.

\subsection{Equifinality of Model Initial/Boundary Conditions}

Given the unknowability of historical/future initial and boundary conditions in almost all cases (epistemic uncertainty), they are a source of model equifinality. That is, different initial/boundary conditions can lead to similar results. Ebel and Loague (2006) simulated five scenarios of different initial/boundary conditions (e.g., soil water content and permeability characteristic functions) for a distributed model of an experimental catchment, with NSE (Nash-Sutcliffe model efficiency (Nash \& Sutcliffe, 1970) values between 0.66 to 0.82 for the discharge. That is, different initial/boundary conditions could lead to reasonably acceptable model performance for the discharge. To see through this "fog of equifinality" of models' discharge performances, they further compared the simulated and observed pressure head at three locations and found that the associated NSE values were all negative except for the scenario with discharge NSE of 0.76 . They attempted to constrain the model equifinality and improve the model realism by looking at variables other than discharge, that is, introducing additional information. There can be many other realistic scenarios with different initial/boundary conditions (Pappenberger et al., 2006), and these scenarios may fail to simulate other catchment processes if new data are introduced.

\subsection{Equifinality of Model Inputs}

Different input variables with varying degrees of information content (i.e., different types, quantities, and qualities of inputs) could lead to similar model outcome, for example, equifinality of model predictions from different stochastic realizations of the input data (Zin, 2002) such as rainfall input (Ehlers et al., 2018). Newman et al. (2015) developed an ensemble of gridded observation-based daily precipitation and temperature for 1980-2012 for the contiguous United States, which could be used to account for uncertainty of 
gridded product and model forcing, as well as exploring the equifinality of model inputs. As another example, Oudin et al. (2005) investigated the use of different potential evapotranspiration (PET) inputs to four different rainfall-runoff models and found no systematic improvements in the calibrated model performance when using daily temporally varying PET instead of seasonal mean PET. This instance of model input equifinality may also be related to the insensitivity of the model (process representation) to input information content.

\subsection{Equifinality of Model Internal Fluxes}

Various combinations of model internal fluxes can lead to similar model output. Interception, evapotranspiration (ET), and runoff fluxes are examples of internal fluxes in the case of a conceptual rainfall-runoff model. These fluxes are essentially representations of real-world processes, for example, model runoff fluxes mimic catchment runoff generation mechanisms. Also, under a given model conditioning, that is, available data and model performance metrics, different routines for calculating internal fluxes (e.g., interception) can be equifinal. Grayson et al. (1992) demonstrated that a given observed hydrograph could be equally reproduced through Hortonian overland flow or saturated area runoff with very different distributed flow characteristics. Physical significance is a distinct characteristic of flux equifinality, over other facets of model equifinality like parameter equifinality, which is desirable for generating/testing hypotheses.

It should be noted that these six facets of model equifinality are not mutually exclusive, as different model components are intertwined as discussed above. That said, each facet accentuates a particular aspect (subspace) of the overall model space. That is, each facet (or their combinations) could be utilized as a way of generating model simulations or to investigate an ensemble of model runs in terms of MWH. In the next section, we demonstrate how replacing the emphasis from the equifinality of model parameters to model internal fluxes gives new insights into model behavior and to generate $\mathrm{MWH}$, even if only model parameters are perturbed.

\section{Flux Mapping: An Approach to Evaluate Model Behavior}

In this section we develop a method called flux mapping for evaluating model behavior, based on the concept of model internal flux equifinality. We demonstrate that the new tool of flux maps can give new insights into model behavior that are not inferable from conventional model evaluation tools of dotty plots (i.e., projection of points on a model response or likelihood surface onto a single parameter axis (Beven, 2006)) or statistical parameter distributions.

\subsection{Hydrological Model}

For this study, we chose SIMHYD, a lumped conceptual daily rainfall-runoff model (Chiew et al., 2002; Peel et al., 2000). It has seven parameters, takes precipitation and areal PET (APET) as inputs, and generates streamflow as the output. SIMHYD incorporates runoff generating mechanisms, namely, infiltration excess (INFexc), interflow and saturation excess overland flows (INT \& SATexc), and baseflow (BAS; Figure 5a). With three runoff generating mechanisms it is a suitable choice to examine the equifinality of internal (runoff) fluxes.

\subsection{Study Area and Data Set}

The Australian Network of Hydrologic Reference Stations (HRS) is a set of 222 catchments (http://www. bom.gov.au/water/hrs/) with minimal land use disturbances and water resource development and relatively high-quality data (Turner, 2012, p. 6) composed of daily time series of observed streamflow (Q). Fowler et al. (2016) calculated areal average precipitation $(P)$ from Australian Water Availability Project (www.bom.gov. $\mathrm{au} / \mathrm{jsp} / \mathrm{awap} /$ ) daily 5-km grids (Jones et al., 2009) and also estimated APET at the catchment centroid using Morton's Wet Environment method (Morton, 1983) using gridded estimates of Jeffrey et al., 2001; see Fowler et al., 2016, for further details of data set preparation).

The modeling experiment (flux mapping) is conducted on a subset of HRS catchments with a high level of SIMHYD performance, here defined as NSE $\geq 0.75$. To select them, SIMHYD was first calibrated to all HRS sites over their total streamflow record, using the global optimization algorithm of Shuffled Complex Evolution (Duan et al., 1992). For each case, the Shuffled Complex Evolution routine was repeated 20 times to ensure consistency in the calibration results. The highest NSE value from the 20 repeats for each 
catchment-model pair was selected as the upper bound of possible model performance (hereinafter SCENSE). A subset of the top 53 catchments, $0.75 \leq$ NSE $\leq 0.88$, were selected. It should be stressed that this precalibration step is not a part of the modeling experiment and only serves to find the upper bound of model performance as a rough measure of sampling sufficiency (explained in the following section).

\subsection{Flux Mapping}

Figure 1a presents a conceptual example indicating that a model (here SIMHYD) can simulate an observed hydrograph through different combinations of model internal fluxes (here proportions of model runoff fluxes), leading to similar NSE values $(0.803 \leq \mathrm{NSE} \leq 0.825)$ at a given catchment. It clearly shows that the value of the objective function is not a reliable measure of model internal behavior. For a large ensemble of model runs, equifinal fluxes can be summarized and visualized based on the percentage of their (volumetric) contribution to the total simulated $Q$ on a plot we name a flux map. Figure $1 \mathrm{~b}$ is a conceptual example of flux map and is used to inspect the runoff flux space, a subset of the model flux space, of SIMHYD model by mapping the three runoff fluxes (i.e., INFexc, INT \& SATexc, and BAS) for three equifinal model runs demonstrated on Figure 1a.

A flux map is a ternary plot where each dimension represents a model runoff flux, and each model run is projected as a single point based on the proportions of its equifinal runoff fluxes to the total simulated $Q$. The cloud pattern can vary from very constrained (Figures 3a, one flux is dominating the simulation of total $Q$ ), through intermediated cases (Figures $3 \mathrm{~b}$ and $3 \mathrm{c}$, two fluxes are codominating the simulation of total $Q$ with possibly small contribution of the third flux), up to filling the entire plausible flux space (i.e., the entire triangle, Figures $3 \mathrm{~d}$ and 4). Thus, the point cloud on the flux maps is an expression of the model flux equifinality; filling a larger space on the flux map indicates higher degrees of model flux equifinality. In the case of two fluxes, the plausible flux space would shrink to a line showing the interplay between the contribution of either flux. In case of more than three fluxes, the flux map can be simply presented as a series of two-bytwo scatterplots.

\subsection{Experiment Design}

The flux space of each catchment model is explored using simulations of $10^{6}$ parameter sets sampled from a uniform parameter (prior) distribution using Latin Hypercube Sampling (LHS). The sample size was determined by comparing the difference between SCE-NSE (the best NSE value from 20 repeats of precalibration) and the highest NSE value from the LHS ensemble (hereinafter Ensemble-NSE) at a few trial catchments. Selecting $10^{6}$ samples generally led to the Ensemble-NSE being within 3\% of the SCE-NSE, suggesting that $10^{6}$ samples was sufficient to adequately explore the parameter space and the consequent flux space. It should be mentioned that for higher-dimensional parameter spaces, LHS or random sampling are very inefficient and often insufficient; efficient searching/sampling strategies should be used instead such as dynamically dimensioned search (Tolson \& Shoemaker, 2008).

To track the emerging pattern of the point cloud of the flux maps, model runs are evaluated against a set of thresholds of equifinality/acceptability, defined as SCE-NSE $\times\{0.99,0.98,0.97,0.96,0.95,0.90,0.85,0.80\}$, that is, gradually relaxing the threshold-hereinafter referred to as thresholding. Equifinal model runs above a given threshold are considered as acceptable and the rest as unacceptable.

\section{Results}

The overall model performance in the example catchments is $0.75 \leq$ SCE-NSE $\leq 0.80$ and for the extreme case is SCE-NSE $=0.82$. Yet as shown in Figures 3 and 4 the flux maps are vastly different. We chose four classes of general flux map behavior (Classes I to IV), within the 53 catchments studied, for further discussion. For each class, we present flux maps of an example catchment for the strict $(0.95 \times$ SCE-NSE $)$ and relaxed $(0.85 \times$ SCE-NSE) thresholds (Figures 3 and 4$)$, color coded based on the corresponding Ensemble-NSE values. For Class IV, an additional example of an extreme case is also presented (Figure 4). Flux maps of other thresholds are presented in the supporting information (Table S1) to demonstrate the emerging pattern of the flux maps. Also, the corresponding two-by-two flux maps of Figures 3 and 4 are available (see Khatami et al., 2017). To the extent possible, the four examples have similar hydrological characteristics, namely, catchment area of $125-170 \mathrm{~km}^{2}$, mean annual $950-1353 \mathrm{~mm}$, mean annual $Q=$ 162-335 mm, mean annual APET $=1,222-1,532 \mathrm{~mm}$, and annual runoff coefficient $0.17-0.25$. The 


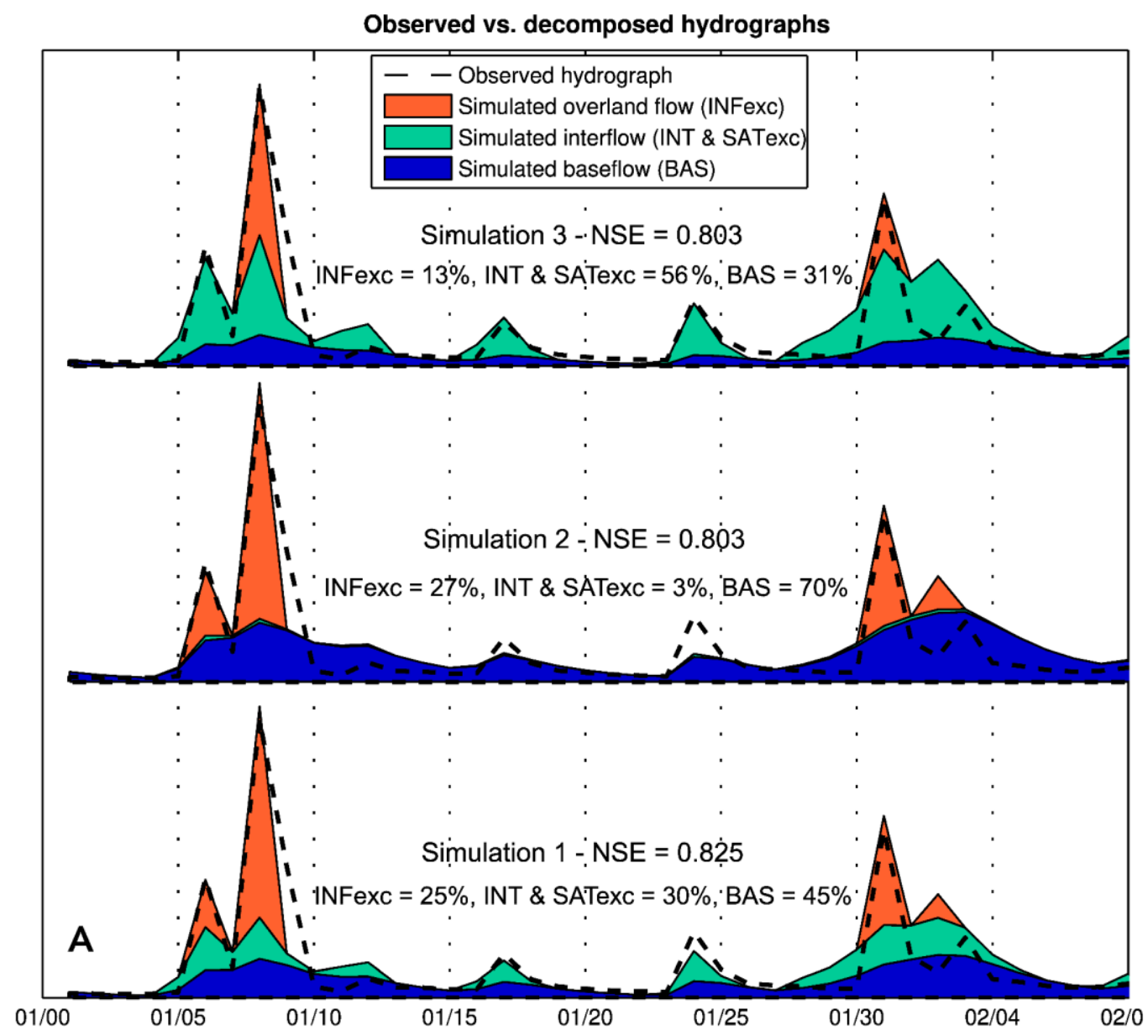

Flux Map of SIMHYD runoff fluxes for 3 simulation examples

B

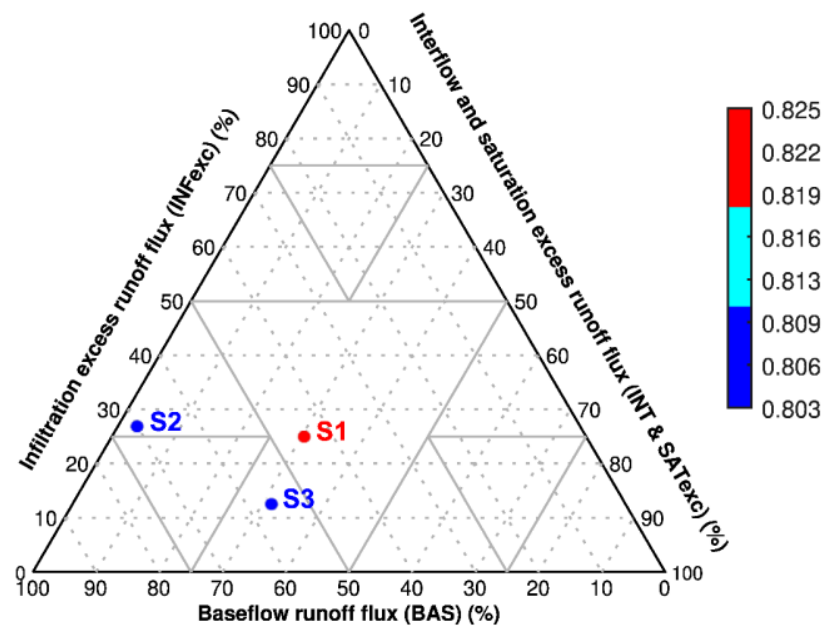

Figure 1. (a) Three simulations (S1-S3) of an observed hydrograph through different combinations of runoff generating mechanisms (volumetric contribution to the total simulated runoff) summarized on a flux map (b), color coded based on the simulation performance (NSE value). The triangle $(B)$ represents the plausible flux space for a model with three runoff fluxes. NSE $=$ Nash-Sutcliffe model efficiency. 


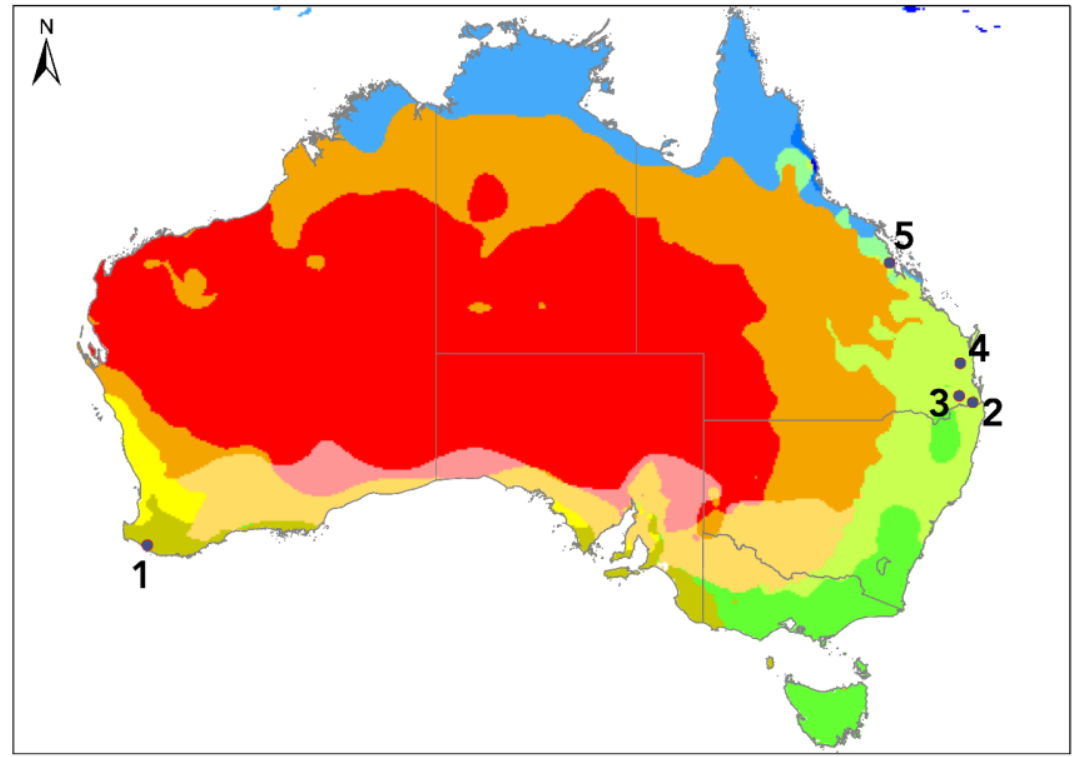

Figure 2. Map of the Australian example catchments for the modeling experiment of flux mapping. The color scheme is based on the Köppen-Geiger climate classification by Peel et al. (2007).

extreme case of Class IV flux maps is quite similar to the other four examples except for a smaller catchment area, $83 \mathrm{~km}^{2}$, and a higher runoff coefficient of 0.44 . Figure 2 presents the location of example catchments based on the Köppen-Geiger climate classification (Peel et al., 2007), and catchment summaries are presented in Table 1. Specific simulation characteristics of each example are mentioned in the corresponding figure caption.

\subsection{Class I}

The point cloud on the flux map in Figures $3 a 1$ and $3 a 2$ is very constrained indicating a very low degree of flux equifinality, a baseflow-dominant runoff simulation, having zero infiltration excess runoff and a low saturation excess runoff in the simulations. For the strict threshold (Figure 3a1) there are 252 equifinal model runs, which all exhibit a very narrow range of possible flux contributions to total simulated $Q$. As the equifinality threshold lowers to the relaxed threshold (Figure 3a2) the number of equifinal runs increases, yet the general pattern of the flux map remains, i.e., predominantly baseflow oriented, with the possibility of up to $20 \%$ contribution from INT \& SATexc.

Table 1

Catchments Summaries of the Examples Presented in Modeling Experiments

\begin{tabular}{|c|c|c|c|c|c|c|c|c|}
\hline \multirow[b]{2}{*}{$\begin{array}{l}\text { Catchment } \\
\text { no. }\end{array}$} & \multirow[b]{2}{*}{$\begin{array}{l}\text { Corresponding } \\
\text { figures (class) }\end{array}$} & \multicolumn{7}{|c|}{ Catchment } \\
\hline & & Name & Location & $\begin{array}{l}\text { Area } \\
\left(\mathrm{km}^{2}\right)\end{array}$ & $\begin{array}{l}\text { Mean annual } \\
\text { total } P(\mathrm{~mm})\end{array}$ & $\begin{array}{l}\text { Mean annual } \\
\text { total } Q(\mathrm{~mm})\end{array}$ & $\begin{array}{l}\text { Mean annual } \\
\text { APET }(\mathrm{mm})\end{array}$ & $\begin{array}{l}\text { Annual } \\
\text { runoff ratio }\end{array}$ \\
\hline 1 & $\begin{array}{l}\text { Figures } 3 a 1 \\
\quad \& 3 a 2(\mathrm{I})\end{array}$ & $\begin{array}{c}\text { Dombakup Brook at } \\
\text { Malimup Track }\end{array}$ & $\begin{array}{l}\text { Western Australia } \\
\left(115.98^{\circ} \mathrm{E} 34.58^{\circ} \mathrm{S}\right)\end{array}$ & 125.09 & $1,130.99$ & 232.63 & $1,222.41$ & 0.21 \\
\hline 2 & $\begin{array}{l}\text { Figures 3b1 } \\
\qquad \& 3 b 2(\mathrm{II})\end{array}$ & $\begin{array}{l}\text { Albert River at } \\
\text { Lumeah }\end{array}$ & $\begin{array}{c}\text { Queensland } \\
\left(153.05^{\circ} \mathrm{E} 28.05^{\circ} \mathrm{S}\right)\end{array}$ & 167.39 & $1,353.61$ & 335.14 & $1,451.17$ & 0.25 \\
\hline 3 & $\begin{array}{l}\text { Figures } 3 \mathrm{c} 1 \\
\qquad \& 3 \mathrm{c} 2 \text { (III) }\end{array}$ & $\begin{array}{l}\text { Bremer River } \\
\text { at Adams Bridge }\end{array}$ & $\begin{array}{c}\text { Queensland } \\
\left(152.51^{\circ} \mathrm{E} 27.83^{\circ} \mathrm{S}\right)\end{array}$ & 126.09 & 951.07 & 162.19 & $1,506.55$ & 0.17 \\
\hline 4 & $\begin{array}{l}\text { Figures } 3 \mathrm{~d} 1 \\
\quad \& 3 \mathrm{~d} 2(\mathrm{IV})\end{array}$ & $\begin{array}{l}\text { Kandanga Creek } \\
\text { at Hygait }\end{array}$ & $\begin{array}{c}\text { Queensland } \\
\left(152.65^{\circ} \mathrm{E} 26.39^{\circ} \mathrm{S}\right)\end{array}$ & 170.78 & $1,135.18$ & 277.98 & $1,532.49$ & 0.24 \\
\hline 5 & $\begin{array}{l}\text { Figures } 4 a, 4 b, \\
\quad \& 4 c(I V)\end{array}$ & $\begin{array}{l}\text { Carmila Creek } \\
\text { at Carmila }\end{array}$ & $\begin{array}{l}\text { Queensland }\left(149.399^{\circ}\right. \\
\left.\text { E } 21.915^{\circ} \mathrm{S}\right)\end{array}$ & 83.8 & 1,275 & 538 & 1,736 & 0.42 \\
\hline
\end{tabular}


Model runs with similar flux contributions but distinct flux dynamics (e.g., magnitude, shape, and sequencing of events) would be mapped as identical points on the flux map. Therefore, even a very constrained flux map might be unfolded to a number of model runs with distinct dynamics yet similar volumetric contribution of the fluxes. In other words, flux maps are in fact underestimating the flux equifinality.

\subsection{Class II}

The flux map for this class (Figures $3 \mathrm{~b} 1$ and $3 \mathrm{~b} 2$ ) is mainly constrained around a line that corresponds to the complementary possible contributions of the BAS and INT \& SATexc runoff fluxes. The range of the line varies depending on the thresholding. For the strict threshold (Figure 3b1), the baseflow contribution to total runoff volume is around $45-90 \%$, and as the threshold relaxes (Figure 3b2), baseflow contributes 15-100\% to the total simulated flow. SIMHYD exhibits less than $5 \%$ contribution from INFexc at the relaxed threshold.

It should be noted that in producing flux maps, model runs with different performance but similar flux contributions are plotted on top of each other, with higher performing points (toward red) plotted on top. So, the marginal distributions of flux maps are also provided (supporting information Table S1). Regardless of the threshold, even the highest performing points (i.e., red ones in the cloud) are moderately spread across the two contributing fluxes. Color coding and marginal distributions of flux maps are not suggested as a way for identifying optimal or high likelihood regions on the flux maps. One cannot infer that model runs with higher performance values (red points on the flux maps) are more realistic. Model performance-particularly assessed in a scalar sense-is a weak, unreliable, and unrealistic measure for model evaluation, as model process representation cannot be measured with a single (or few) value(s) of performance metrics (for further details also see the discussion on hydrological signatures (Addor et al., 2018; Euser et al., 2013; Gupta et al., 2008; Kelleher et al., 2017; Schaefli, 2016; Yilmaz et al., 2008)). As demonstrated by Ebel and Loague (2006) and Seibert and McDonnell (2002) in detail, strict interpretation of objective functions is misleading, as model runs with slightly lower values of NSE might have better process representation than the higher ones. Model performance does not imply realism and may be a numerical artifact given various sources of uncertainty. Insufficient knowledge of catchment processes (e.g., runoff-generating mechanisms and the details of the sequencing of different storm and runoff events) makes it difficult to assign likelihood to model runs. Marginal distributions (Table S1) and color coding of the flux maps only serve a demonstrative purpose (the spread of equifinal fluxes on the flux map) and not a prescriptive one (necessarily indicating the realism of model runs). All the cloud points are equifinal by definition, that is, possible flux contributions given the modeling setup and equifinality threshold, unless/until additional data are used to reject or constrain them, which argues against a probability- or likelihood-based interpretation of the flux maps.

\subsection{Class III}

This class (Figures 3c1 and c2) is an extension of Class II to three active fluxes, that is, all three runoff fluxes can make noticeable contributions to simulating the observed flow, albeit with INFexc being smaller than the other two. For the strict case of acceptability (Figure 3c1), $0.74 \leq$ Ensemble-NSE $\leq 0.78$, there exists an extreme model run with almost 95\% contribution form INT \& SATexc and another with almost $80 \%$ contribution from BAS. INFexc contributes up to around 15\%. For the relaxed threshold (Figure 3c2), the range of all fluxes increases, most notably INFexc, which is the least constrained (being $<15 \%$ at the strict threshold). For both cases of thresholding, particularly for the relaxed one, the flux contribution of high-performing model runs (red points) are widely spread on the flux map, indicating a high degree of flux equifinality even for the highest performing model runs.

\subsection{Class IV}

This class (Figures 3d) is an extension of Class III, that is, all three fluxes can vary widely. Even for the strict threshold, there are 1,270 acceptable model runs with a moderately wide range ( $\geq 50 \%$ variation) of possible flux contributions as shown in Figure 3d1 (compare this case with Figure 3b1). A key difference to the other classes is that INFexc is as variable as the other fluxes. In the case of the relaxed threshold, the cloud fills almost the entire space of the flux map (lower triangle), signifying a very high degree of flux equifinality. All three runoff fluxes vary around at least $90 \%$ of flux contributions. In other words, almost any combination of runoff flux (volumetric) contribution could lead to a similar model performance-all flux combinations are plausible/feasible. 
Class I
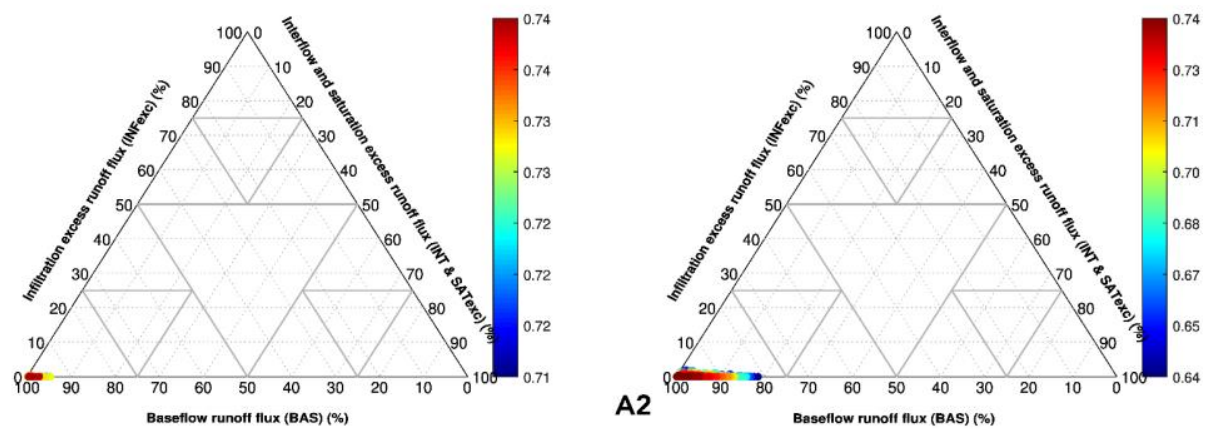

Class II
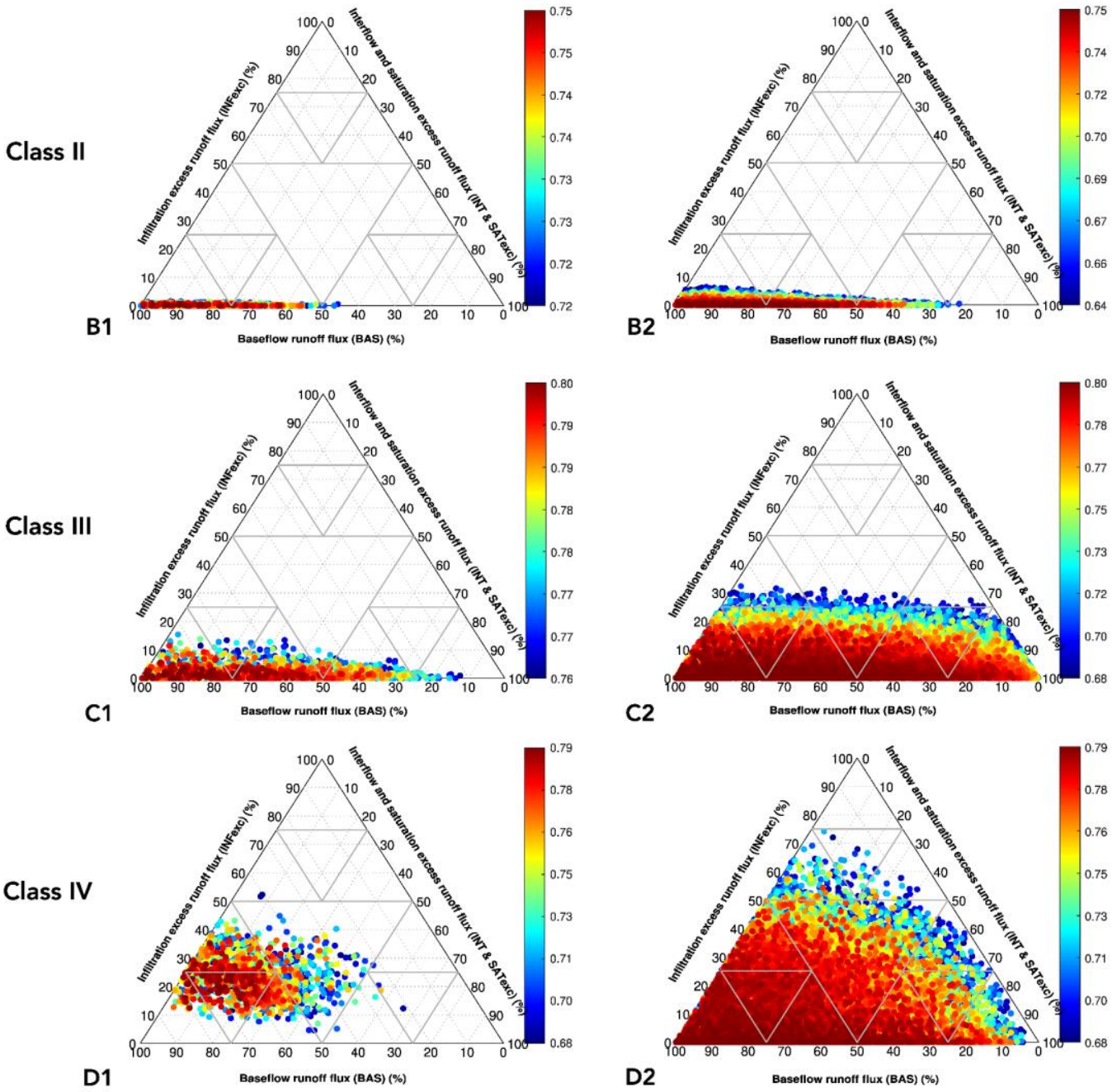

Figure 3. This figure represents how different model internal behavior, represented on flux maps, can emerge within a certain range of model performance. Flux maps for four different Australian catchments (catchments 1-4 on Table 1) for two different thresholding; each row presents a different catchment with strict threshold on the first column and relaxed threshold on the second column. Color bar represents the model performance in terms of Nash-Sutcliffe model efficiency value. (a) Class I flux maps for strict threshold $(0.95 \times$ SCE-NSE $=0.71 \leq$ Ensemble-NSE $=0.75 \leq$ SCE-NSE $=0.75)$ with 252 equifinal simulations (a1) and relaxed threshold $(0.85 \times$ SCE-NSE $=0.64 \leq$ Ensemble-NSE $\leq$ SCE-NSE) with 3,036 equifinal simulations (a2). (b) Class II flux maps for strict threshold $(0.95 \times$ $\mathrm{SCE}-\mathrm{NSE}=0.71 \leq$ Ensemble-NSE $=0.75 \leq \mathrm{SCE}-\mathrm{NSE}=0.75)$ with 592 equifinal simulations $(\mathrm{b} 1)$ and relaxed threshold $(0.85 \times \mathrm{SCE}-\mathrm{NSE}=0.64 \leq$ Ensemble-NSE $\leq$ SCE-NSE) with 8,476 equifinal simulations (b2). (c) Class III flux maps for strict threshold ( $0.95 \times$ SCE-NSE $=0.74 \leq$ Ensemble-NSE $=0.78 \leq$ SCE-NSE $=0.78)$ with 3,644 equifinal simulations (c1) and relaxed threshold $(0.85 \times$ SCE-NSE $=0.66 \leq$ Ensemble-NSE $\leq$ SCE-NSE) with 47,702 equifinal simulations (c2). (d) Class IV flux maps for strict threshold $(0.95 \times$ SCE-NSE $=0.71 \leq$ Ensemble-NSE $=0.75 \leq$ SCE-NSE $=0.75)$ with 1,270 equifinal simulations $(\mathrm{d} 1)$ and relaxed threshold $(0.85 \times$ SCE-NSE $=0.64 \leq$ Ensemble-NSE $\leq$ SCE-NSE) with 65,126 equifinal simulations $(\mathrm{d} 2)$. Catchment summaries are presented in Table 1. 

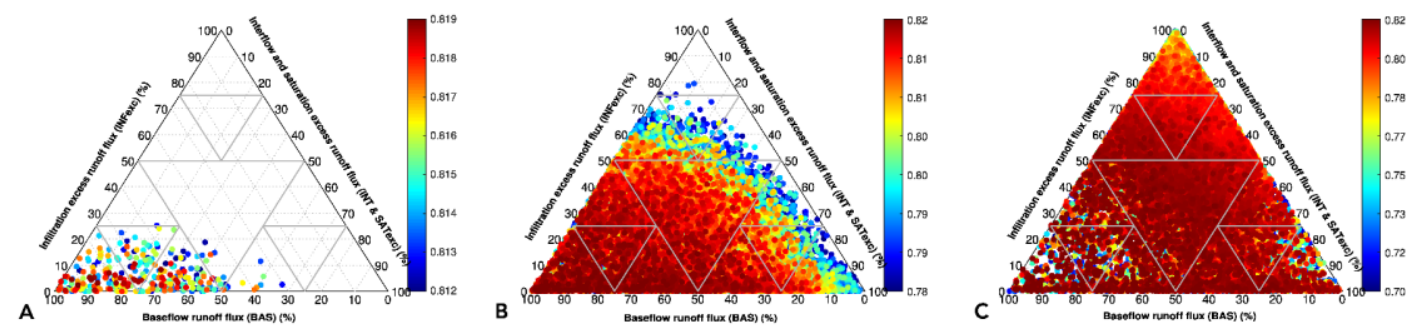

Figure 4. Class IV flux maps for very strict threshold $(0.99 \times$ SCE-NSE $=0.80 \leq$ Ensemble-NSE $=0.80 \leq$ SCE-NSE) with 287 equifinal simulations $(a)$, strict threshold $(0.95 \times$ SCE-NSE $=0.77 \leq$ Ensemble-NSE $\leq$ SCE-NSE) with 69,090 equifinal simulations $(b)$, and relaxed threshold $(0.85 \times$ SCE-NSE $=0.69 \leq$ Ensemble-NSE $\leq$ SCE-NSE) with 49,591 equifinal simulations only from $10^{5}$ simulations (c). Catchment summaries are presented in Table 1.

To further illustrate Class IV, Figure 4 presents an extreme case. Even for a threshold as strict as $0.99 \times$ SCENSE and as few as 287 equifinal runs (which is close to the number of equifinal runs in the case of strict thresholding in Class I with a constrained flux map, Figure 3a1), acceptable fluxes are remarkably scattered-occupying about $25 \%$ of the flux map plane, shown in Figure $4 a$. Even within $1 \%$ of SCE-NSE, significant differences in the dynamics of model runoff fluxes emerge. The flux map is almost space filled even for the strict threshold, with more than 69,000 equifinal model runs (Figure 4b). This shows an extraordinary degree of flux equifinality compared with previous cases. For such a degree of flux equifinality, even $10^{5}$ thousand model runs were enough to achieve a space-filling flux map at the relaxed threshold (Figure 4c). Given that the SCE-NSE for this catchment is higher than the previous cases (0.81), one cannot simply associate the flux equifinality with the model performance.

\section{Discussion}

\subsection{Flux Mapping and Model Evaluation: Flux Space Versus Parameter Space}

A striking dimension of the results is the wide range of model internal dynamics that emerges from a similar level of model performance for catchments with a reasonably constrained range of physiographic characteristics, regardless of the thresholding and number of equifinal model runs. The different patterns/degrees of flux equifinality range from very constrained to almost space-filling flux maps. Such new insights into model behavior that flux mapping provides cannot (easily) be characterized by common model evaluation tools, like dotty plots and parameter distributions. The dotty plot is a tool to visualize model parameter equifinality and (in)sensitivity, and the statistical distribution of parameter values (commonly presented as marginal distributions) is a probability-based tool for expressing model parameter uncertainty. While dotty plots and parameter distributions are useful tools, they do not sufficiently characterize the model behavior, particularly its internal dynamics and process representation; hence, the flux map is a valuable complement to these tools. For instance, the differences in model behaviors for the aforementioned cases I-IV are not discernible from the marginal distribution of model parameters (Figure 5) nor the dotty plots (supporting information Table S1).

Figure 5 presents the marginal distributions of model parameters corresponding to the example catchments in Figure 3. Comparing Figures 3 and 5 shows that despite vastly different flux maps, the marginal distributions of the influencing parameters can be similar, and therefore, it would be difficult to translate the changes in distribution into flux dynamics. For instance, parameter distributions of both Classes III and IV (Figure 5b) are almost identical except for parameter SUB, which controls the INT \& SATexc flux, while Figure 3 clearly shows that there are profound differences between the flux maps of these classes.

To explore more complex interactions of model parameters and their implication on model fluxes, we discuss further a few more cases. While given the model structure, some parameters are not influencing the partitioning of runoff fluxes (e.g., $K$ only determines the timing of the baseflow reservoir); other parameters are strongly related to flux partitioning. For instance, both INSC and COEFF influence infiltration excess runoff, but INSC is almost identical across all cases hence not informative, and COEFF is very similar between Classes I, III, and IV. When parameter SUB, as a control of INT \& SATexc flux, is highly constrained (Class I) the BAS flux is also constrained, and as the SUB marginal distribution becomes more uniform (toward Class IV) the BAS flux becomes less constrained. That said, while BAS flux is 


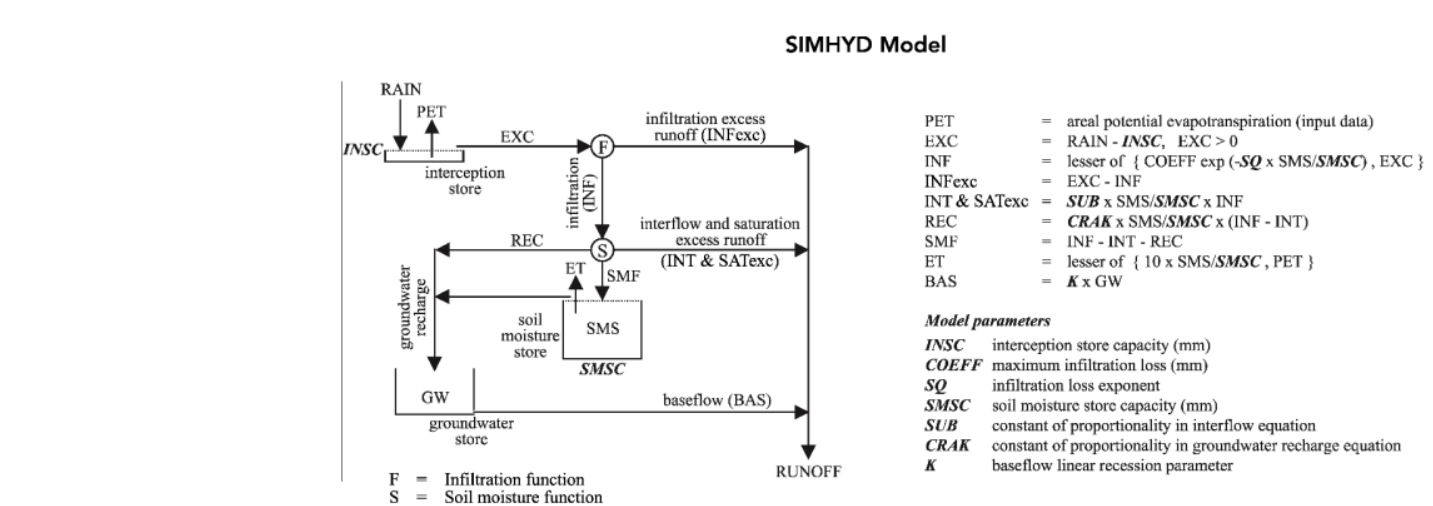

A
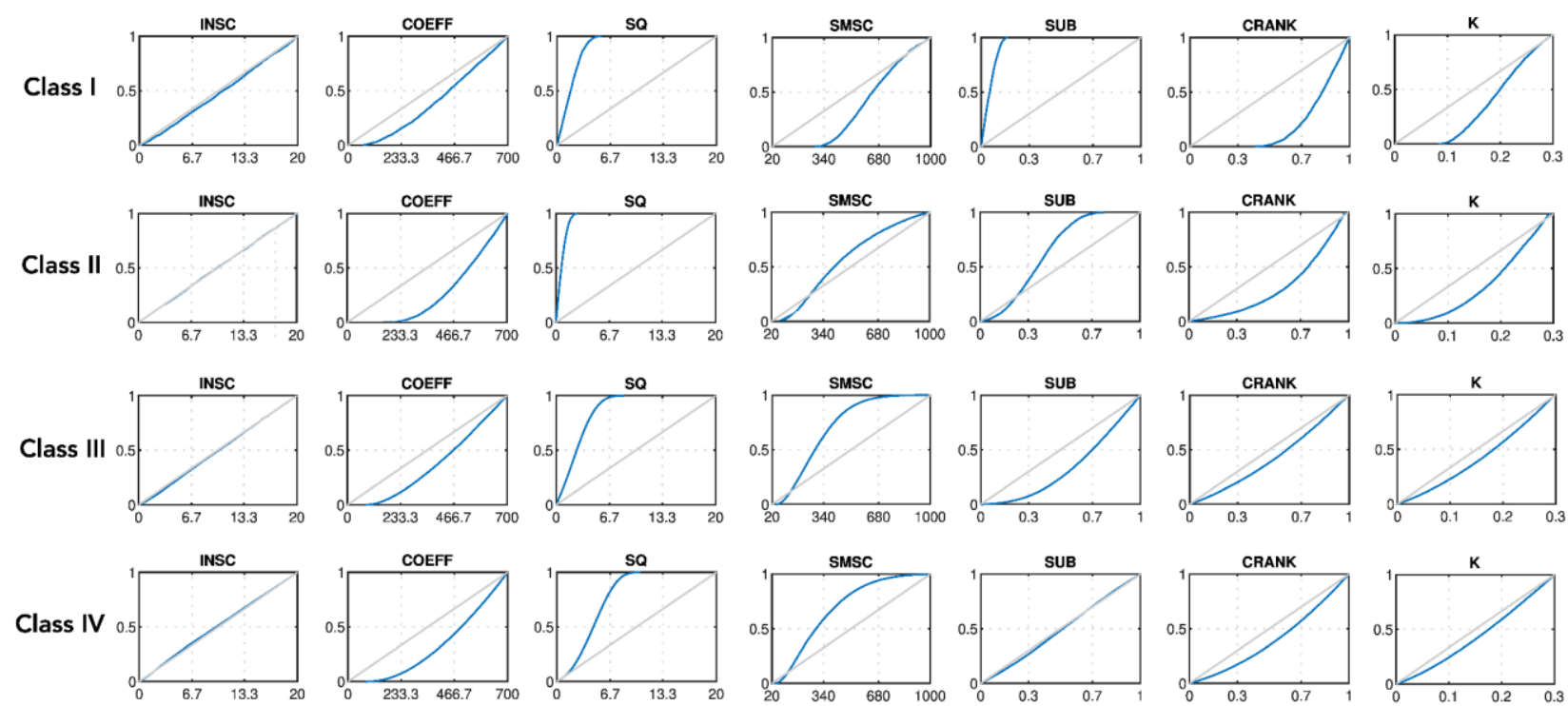

B

Figure 5. (a) Schematic illustration of the SIMHYD model structure together with the description of the model's internal fluxes and parameters (derived from Peel et al., 2000). (b) Marginal (cumulative) distribution of model parameters (gray is the prior, and blue is the posterior distributions) corresponding to the Classes I-IV flux maps (excluding the extreme case of Class IV) in section 4 , for the relaxed threshold $(0.85 \times$ SCE-NSE).

(almost) equally variable for both Classes III and IV (varying between 0 and 100\%), the corresponding marginal distributions of SUB parameter are different. This is due to the strong interaction of influencing parameters, as model fluxes are usually controlled by more than one parameter. The bottom line is, given the often complex and nonlinear interaction between model parameters, even in the case of influencing parameters, it is still very difficult to evaluate the impact of parameter distributions or their changes from one case (e.g., catchment and model structure) to another on flux dynamics (partitioning/contributions) in particular and model process representation in general. Hence, it is difficult-if not impossible-to infer model internal dynamics from parameter marginal distributions and/or their changes. It is instead much easier to map the model behavior into the flux space, that is, flux mapping. In technical terms, flux mapping is a nonlinear transformation of the model response surface from the parameter space into the flux space. Within parameter uncertainty estimation methods, modeling uncertainties - the interplay between data information content, modeling framework and model structure, performance metrics, and modeler's decisions/understanding-are lumped into and evaluated within the parameter space. Flux mapping can illustrate the impact of modeling uncertainties, regardless of the source and nature, on model internal behavior and process representation. 
In this study, flux maps could be interpreted as a new visualization of parameter equifinality within the model flux space. Although in this study we only perturbed model parameters to explore the dynamics of internal fluxes, other model components could be taken into account (e.g., using an ensemble of model inputs or various scenarios of boundary conditions, as discussed in section 2) to generate an ensemble of model runs. No matter how the ensemble of model runs is produced, we could use flux maps (i.e., the particular facet of model internal fluxes of model equifinality) to explore, summarize, and visualize model internal behavior. It should also be mentioned that the overall pattern of the point cloud of flux maps is independent of the thresholding, the number of acceptable model runs, and/or how constrained the parameter distributions are. Flux maps of each modeling example for different thresholdings are presented in Table S1. The bottom line is that equifinal model fluxes, compared to equifinal model parameters, provide a more insightful basis to generate and explore MWH based on model process representation.

Furthermore, runoff flux space has lower dimensions than parameter space. For instance, in the case of SIMHYD, visualizing and investigating a 3-D runoff flux space instead of a 7-D parameter space is more convenient. Moreover, flux mapping is extendable to any combination of model fluxes. It is particularly of interest for fluxes of physical significance such as actual evaporation. Although in this work model realizations are the product of perturbing model parameters, other components of the model could also be used for generating flux maps, for example, model inputs and/or input/boundary conditions.

\subsection{Flux Mapping, Process Representation, and Multiple Working Hypotheses}

Flux space also has the advantage over parameter space of being (more) physically meaningful/relatable. Modeling uncertainties in general, and parameter uncertainty in particular, are the result of various types/sources of uncertainties. However, placing the emphasis only on parameter distributions, that is, uncertainty estimation as if all uncertainties are aleatory (due to variability and randomness; Beven, 2016), neglects the crucial role of epistemic uncertainties. But, within the flux mapping approach, we deal with and can pose questions of an epistemic nature. For instance, the flux map of Class I (Figures 3a1 and 3a2) indicates a baseflow-dominant system, a hypothesis to be further tested across multiple model structures and/or performance metrics (error/efficiency metrics and hydrological signatures). To see whether different modeling setups (given modeler's judgments/decisions) are in (dis)agreement with each other and to what extent and eventually pose an essential question of conceptual modeling, that is, how well model output (and internal behavior) corresponds to catchment response (and its internal processes). In other words, changing the emphasis of model equifinality from model parameters to fluxes enables us to develop MWH that are process-based and testable both across different model-based hypotheses as well as our understanding of real-world catchment processes. It should be noted that defining the flux space-that is, selecting a subset of the model's entire flux space for flux mapping - is closely related to the model structure and nature of the hypotheses of interest, that is, what processes are represented in the model or meant to be examined.

The importance of independent estimates of catchment internal fluxes/storages and their exploitation as diagnostic tools has been discussed in the literature (for further details see Clark et al., 2011). However, evaluating model behavior in terms of their internal fluxes-model flux equifinality - has received little attention compared with parameter equifinality, although it can be a valuable source of insight. For instance, Guo et al. (2017) presented an example of evaluating the relative realism of ET process representation within three conceptual rainfall-runoff models by comparing the simulated actual ET (AET) with measurements. They observed some unrealistic behavior in the simulated AET. Given that ET process representation can have significant impacts on the sensitivity of runoff projections under climatic changes, assessing the realism of model AET flux is essential. Li et al. (2015) also demonstrated that while a conceptual model can generally simulate the total observed streamflow well for various catchments with different characteristics, it may fail to match the observed baseflow and quickflow fluxes. Such unrealistic internal model behavior/dynamics are not easily discernible from model performance solely or parameter distributions (if at all) but are crucial for rejecting unfit model runs, improving the model realism and reducing model structural and prediction uncertainties.

Furthermore, if additional measurements are available, such as flow path information (baseflow measurements/estimates), the conflicting modeling scenarios (as MWH) could then be evaluated in terms 
of their process representation. That is, which of the so-called equifinal fluxes should be rejected as not physically plausible/significant (less realistic) and which of them could be seen as plausible working hypotheses. Therefore, the curious follow-up question would be to investigate the relationship between catchment characteristics and flux map patterns: which catchment characteristics are controlling/determining flux maps? For instance, other hydrologic variables such as filed data on surface runoff measurement and soil moisture (Western \& Grayson, 1998), water quality, for example, salt load (Nathan \& Mudgway, 1997), and isotopes (Beria et al., 2018; Kendall \& McDonnell, 1998) may provide diagnostic information about the sources of dominant flow processes that could be used to further evaluate/constrain model fluxes. Also, integrating hard and soft data (Winsemius et al., 2009) and diagnostic approaches (e.g., hydrological signatures) could provide valuable sources of information to understand the interplay between flux maps and catchment dynamics particularly dominant processes. While knowledge about dominant processes within the catchment system is a major control for developing/improving models (Seibert \& McDonnell, 2002), the modeler's personal judgment and experience is crucial in deciding the dominant processes (Holländer et al., 2009). So combining hydrologic signatures with expert knowledge of mechanisms and processes of real-world catchment systems, that is, expert elicitation, we can improve model realism and process representation by imposing relative model parameter/flux constraints (Euser et al., 2013; Fenicia et al., 2014; Gharari et al., 2014; Hrachowitz et al., 2014).

We can also further assess how modifying different model components (e.g., interception, evaporation, and soil water routines) can influence and hopefully improve the flux map pattern. Therefore, flux mapping has an exploratory power to evaluate the impact of modeling uncertainties on model behavior and to explore model capacity for process representation, at least partly and in a lumped way. This can pave the way to go beyond only evaluating model performance (i.e., model capability for yielding a high value of some error metrics), possibly together with some estimation of parameter uncertainties, based on only the model output. We emphasize that flux mapping alone cannot improve model realism, and additional information is required for refining models. Also, flux mapping provides explanatory opportunities to postulate hypotheses of possible explanations of real-world processes (e.g., catchment processes and their changes) based on the (internal) behavior of their corresponding conceptual models under all modeling uncertainties. The relationship between different modes of model process representation (i.e., model equifinality) and catchment internal processes is a crucial question and remains an open one, which can only be addressed by bridging the gap between modeling and experimental hydrology (Seibert \& McDonnell, 2002). That said, various catchment internal processes are unknown or unknowable (knowledge uncertainty). There are myriad (ever evolving and dynamic) flow paths in any real catchment that we cannot expect conceptual models to represent them. Such epistemic uncertainties and hence modeling limitations may be a contributing factor to model equifinality. It is unclear to what extent a projected flux equifinality resembles the plausible hypotheses of internal processes of a given catchment and to what extent it is a modeling artifact due to modeling uncertainties, for instance, to what extent a constrained or space-filling flux map is due to catchment characteristics or due to modeling setup. What occurred in reality in a particular period would be mapped to a single unknown true point on the flux map. Model equifinality, for example, flux equifinality, results in a point cloud that necessarily does not encompass the true point (i.e., reality). What we can hope for is to refine our hypotheses to approximate reality by improving model realism - by improving model structures, evaluation schemes, and data quality and accounting for their uncertainties-and hence reducing knowledge uncertainty.

\subsection{Equifinality, Hydrological Systems, and Beyond}

The theoretical framework presented, and its implications for model evaluation (going beyond model output and accounting for model behavior under modeling uncertainties) and hypothesis generating, could be further extended to other domains (Blöschl et al., 2019). It could also be used to improve understanding/modeling in data-poor catchments/regions (Davtalab et al., 2017) and in regional generalization (also known as regionalization or prediction in ungauged basins; Peel et al., 2000; Reichl et al., 2006). Moreover, although the proposed theoretical framework and flux mapping method are mainly discussed within the context of hydrological systems, it can be further extended to any field of scientific modeling concerned with understanding/modeling open complex systems in the face of uncertainties. Real-world processes and their perceptual and conceptual models are all open systems and hence give rise to 


\section{Acknowledgments}

The authors gratefully acknowledge the support of the University of Melbourne and Australian Government in carrying out this research. Sina Khatami is supported by Melbourne International Research and Fee Remission Scholarships (MIRS and MIFRS), Murray Peel is the recipient of an Australian Research Council Future Fellowship (FT120100130), and Tim Peterson jointly funded by Australian Research Council Linkage Project LP130100958, Bureau of Meteorology (Australia), Department of Environment, Land, Water and Planning (Vic., Australia), Department of Economic Development, Jobs, Transport and Resources (Vic., Australia), and Power and Water Corporation (N.T., Australia). The authors would also like to acknowledge the rigorous yet delightful review process that helped to significantly improve the manuscript by sincerely thanking Andrew Binley for suggesting the use of ternary plots reviewing the first draft of the manuscript, as well as the encouraging and constructive reviews of Hoshin Gupta, Grey Nearing, and two anonymous reviewers. Sina Khatami is extremely grateful to Keith Beven for selflessly giving his time to teaching the excellent course of "Uncertainty in

Environmental Modelling," as well as Sven Halldin for administrating it at Department of Earth Sciences at

Uppsala University. He is also sincerely thankful to Keirnan Fowler for preparing and sharing the entire rainfallrunoff data set of this study and his occasional feedback throughout the evolution of this work as well as the manuscript. Streamflow data used in this project are from the Australian Bureau of Meteorology's (BOM) Hydrologic Reference Station project website (www.bom.gov.au/hrs) Rainfall data are from the Australian Water Availability Project (AWAP) project (www.bom.gov.au/jsp/awap/). Potential evapotranspiration data are from the SILO project (www.longpaddock.qld.gov.au/silo/). equifinality. Therefore, it is important to go beyond evaluating only the (equifinality of) model output and account for model fluxes (or other facets of model equifinality) as well, particularly physically meaningful fluxes of conceptual models that may be used in, for example, data assimilation (Alvarez-Garreton et al., 2014; Teweldebrhan et al., 2018) and flood forecasting (Alvarez-Garreton et al., 2015), catchment classification (Kelleher et al., 2015; Knoben et al., 2018; Sawicz et al., 2014), sociohydrological systems (Di Baldassarre et al., 2015; Khazaei et al., 2019; van Emmerik et al., 2014; Westerberg et al., 2017), environmental (Chowdhury et al., 2016) and ecological systems (Luo et al., 2009), natural hazard and risk assessment (Beven et al., 2017), decision making under uncertainty (Madani \& Lund, 2011; Maier et al., 2016), agentbased modeling (Billari et al., 2006; Madani et al., 2014), sustainability transitions (de Haan et al., 2016; Moallemi \& Köhler, 2019) and exploratory modeling (Kwakkel \& Pruyt, 2013; Moallemi et al., 2017; Moallemi \& Malekpour, 2017) under deep uncertainty (Haasnoot et al., 2013; Maier et al., 2016; Moallemi et al., 2018), demand modeling/forecasting in energy (van Ruijven et al., 2010), and traffic (Flyvbjerg et al., 2006; Saberi et al., 2018) and network design (Chen et al., 2011).

\section{Conclusion}

We outlined different facets of model equifinality in the context of hydrological modeling. We developed a novel model evaluation scheme, flux mapping, based on a particular facet of model equifinality, namely, model internal fluxes. We demonstrated how flux mapping can give new insights into model behavior that cannot be inferred from conventional evaluation methods. That is, even within a very narrow margin of model error/performance, different modes of model response, that is, internal runoff generating fluxes of the model, can be equally active. In other words, different dynamics of model internal fluxes can equally reproduce a given observed hydrograph within a narrow margin of model error. Flux mapping can be extended to any field of scientific modeling dealing with conceptual modeling of open complex systems under uncertainty. We argued that equifinality plays a central role in scientific modeling, particularly within the paradigm of $\mathrm{MWH}$.

\section{References}

Addor, N., \& Melsen, L. A. (2019). Legacy, rather than adequacy, drives the selection of hydrological models. Water Resources Research, 55 , 378-390. https://doi.org/10.1029/2018WR022958

Addor, N., Nearing, G., Prieto, C., Newman, A. J., Le Vine, N., \& Clark, M. P. (2018). A ranking of hydrological signatures based on their predictability in space. Water Resources Research, 54, 8792-8812. https://doi.org/10.1029/2018WR022606

Ajami, N. K., Duan, Q., \& Sorooshian, S. (2007). An integrated hydrologic Bayesian multimodel combination framework: Confronting input, parameter, and model structural uncertainty in hydrologic prediction. Water Resources Research, 43, W01403. https://doi.org/ 10.1029/2005WR004745

Alvarez-Garreton, C., Ryu, D., Western, A. W., Crow, W. T., \& Robertson, D. E. (2014). The impacts of assimilating satellite soil moisture into a rainfall-runoff model in a semi-arid catchment. Journal of Hydrology, 519, 2763-2774. https://doi.org/10.1016/j. jhydrol.2014.07.041

Alvarez-Garreton, C., Ryu, D., Western, A. W., Su, C. H., Crow, W. T., Robertson, D. E., \& Leahy, C. (2015). Improving operational flood ensemble prediction by the assimilation of satellite soil moisture: comparison between lumped and semi-distributed schemes. Hydrology and Earth System Sciences, 19(4), 1659-1676. https://doi.org/10.5194/hess-19-1659-2015

Arsenault, R., \& Brissette, F. P. (2014). Continuous streamflow prediction in ungauged basins: The effects of equifinality and parameter set selection on uncertainty in regionalization approaches. Water Resources Research, 50, 6135-6153. https://doi.org/10.1002/ 2013WR014898

di Baldassarre, G., Viglione, A., Carr, G., Kuil, L., Yan, K., Brandimarte, L., \& Blöschl, G. (2015). Debates-Perspectives on socio-hydrology: Capturing feedbacks between physical and social processes. Water Resources Research, 51, 4770-4781. https://doi.org/10.1002/ 2014WR016416

Beck, M. B. (1987). Water quality modeling: A review of the analysis of uncertainty. Water resources research, 23(8), 1393-1442. https://doi. org/10.1029/WR023i008p01393

Beck, M. B. (2002). Environmental foresight and models: A manifesto. Oxford: Elsevier.

Bennett, N. D., Croke, B. F. W., Guariso, G., Guillaume, J. H. A., Hamilton, S. H., Jakeman, A. J., et al. (2013). Characterising performance of environmental models. Environmental Modelling \& Software, 40, 1-20. https://doi.org/10.1016/j.envsoft.2012.09.011

Beria, H., Larsen, J. R., Ceperley, N. C., Michelon, A., Vennemann, T., \& Schaefli, B. (2018). Understanding snow hydrological processes through the lens of stable water isotopes. Wiley Interdisciplinary Reviews: Water, 5(6), e1311. https://doi.org/10.1002/ wat2.1311

Bethke, C. M. (1992). The question of uniqueness in geochemical modeling. Geochimica et Cosmochimica Acta, 56(12), 4315-4320. https:// doi.org/10.1016/0016-7037(92)90274-M

Beven, K. (1975). A deterministic, spatially distributed model of catchment hydrology. University of East Anglia,

Beven, K. (1993). Prophecy, reality and uncertainty in distributed hydrological modelling. Advances in Water Resources, 16(1), 41-51. https://doi.org/10.1016/0309-1708(93)90028-E

Beven, K. (2006). A manifesto for the equifinality thesis. Journal of Hydrology, 320(1-2), 18-36. https://doi.org/10.1016/j. jhydrol.2005.07.007 
Beven, K. (2009). Environmental modelling: An uncertain future? CRC Press.

Beven, K. (2012a). Causal models as multiple working hypotheses about environmental processes. Comptes rendus geoscience, 344(2), 77-88. https://doi.org/10.1016/j.crte.2012.01.005

Beven, K. (2012b). Rainfall-runoff modelling: The primer, (2nd ed.). Chicheseter, UK: John Wiley \& Sons, Ltd. https://doi.org/10.1002/ 9781119951001

Beven, K. (2016). Facets of uncertainty: Epistemic uncertainty, non-stationarity, likelihood, hypothesis testing, and communication. Hydrological Sciences Journal, 61(9), 1652-1665. https://doi.org/10.1080/02626667.2015.1031761

Beven, K., \& Binley, A. (1992). The future of distributed models: Model calibration and uncertainty prediction. Hydrological Processes, 6(3), 279-298. https://doi.org/10.1002/hyp.3360060305

Beven, K., \& Binley, A. (2014). GLUE: 20 years on. Hydrological Processes, 28(24), 5897-5918. https://doi.org/10.1002/hyp.10082

Beven, K., Smith, P., Westerberg, I., \& Freer, J. (2012). Comment on "Pursuing the method of multiple working hypotheses for hydrological modeling" by P. Clark et al. Water Resources Research, 48, W11801. https://doi.org/10.1029/2012WR012282

Beven, K., \& Westerberg, I. (2011). On red herrings and real herrings: Disinformation and information in hydrological inference. Hydrological Processes, 25(10), 1676-1680. https://doi.org/10.1002/hyp.7963

Beven, K. J., Aspinall, W. P., Bates, P. D., Borgomeo, E., Goda, K., Hall, J. W., et al. (2017). Epistemic uncertainties and natural hazard risk assessment. 2. What should constitute good practice? Natural Hazards and Earth System Sciences, 2017, 1-25. https://doi.org/10.5194/ nhess-2017-251

Billari, F. C., Fent, T., Prskawetz, A., \& Scheffran, J. (2006). Agent-based computational modelling: Applications in demography, social, economic and environmental sciences. Physica-Verlag Heidelberg.

Blazkova, S., \& Beven, K. (2009). A limits of acceptability approach to model evaluation and uncertainty estimation in flood frequency estimation by continuous simulation: Skalka catchment, Czech Republic. Water Resources Research, 45, W00B16. https://doi.org/ $10.1029 / 2007$ WR006726

Blöschl, G., Bierkens, M. F. P., Chambel, A., Cudennec, C., Destouni, G., Fiori, A., et al. (2019). Twenty-three Unsolved Problems in Hydrology (UPH)—A community perspective. Hydrological Sciences Journal. https://doi.org/10.1080/02626667.2019.1620507

Blöschl, G., \& Sivapalan, M. (1995). Scale issues in hydrological modelling: A review. Hydrological Processes, 9(3-4), 251-290. https://doi. org/10.1002/hyp.3360090305

Boughton, W. C. (2007). Effect of data length on rainfall-runoff modelling. Environmental Modelling \& Software, 22(3), 406-413. https:// doi.org/10.1016/j.envsoft.2006.01.001

Bulygina, N., \& Gupta, H. (2009). Estimating the uncertain mathematical structure of a water balance model via Bayesian data assimilation. Water Resources Research, 45, W00B13. https://doi.org/10.1029/2007WR006749

Bulygina, N., \& Gupta, H. (2010). How Bayesian data assimilation can be used to estimate the mathematical structure of a model. Stochastic Environmental Research and Risk Assessment, 24(6), 925-937. https://doi.org/10.1007/s00477-010-0387-y

Bulygina, N., \& Gupta, H. (2011). Correcting the mathematical structure of a hydrological model via Bayesian data assimilation. Water Resources Research, 47, W05514. https://doi.org/10.1029/2010WR009614

Butts, M. B., Payne, J. T., Kristensen, M., \& Madsen, H. (2004). An evaluation of the impact of model structure on hydrological modelling uncertainty for streamflow simulation. Journal of Hydrology, 298(1-4), 242-266. https://doi.org/10.1016/j.jhydrol.2004.03.042

Buytaert, W., \& Beven, K. (2011). Models as multiple working hypotheses: Hydrological simulation of tropical alpine wetlands. Hydrological Processes, 25(11), 1784-1799. https://doi.org/10.1002/hyp.7936

Carrera, J., \& Neuman, S. P. (1986). Estimation of aquifer parameters under transient and steady state conditions: 1. Maximum likelihood method incorporating prior information. Water Resources Research, 22(2), 199-210. https://doi.org/10.1029/WR022i002p00199

Chamberlin, T. C. (1890). The method of multiple working hypotheses. Science, 15, 92-96.

Chen, A., Zhou, Z., Chootinan, P., Ryu, S., Yang, C., \& Wong, S. C. (2011). Transport network design problem under uncertainty: A review and new developments. Transport Reviews, 31(6), 743-768. https://doi.org/10.1080/01441647.2011.589539

Chiew, F., Peel, M., \& Western, A. (2002). Application and testing of the simple rainfall-runoff model SIMHYD. In V. P. Singh \& D. Frevert (Eds.), Mathematical models of small watershed hydrology and applications (pp. 335-367). Water Resources Pub.

Chiew, F. H. S., Stewardson, M. J., \& McMahon, T. A. (1993). Comparison of six rainfall-runoff modelling approaches. Journal of Hydrology, 147(1-4), 1-36. https://doi.org/10.1016/0022-1694(93)90073-I

Chowdhury, R. B., Moore, G. A., Weatherley, A. J., \& Arora, M. (2016). A novel substance flow analysis model for analysing multi-year phosphorus flow at the regional scale. Science of The Total Environment, 572, 1269-1280. https://doi.org/10.1016/j.scitotenv.2015.10.055

Clark, M. P., \& Kavetski, D. (2010). Ancient numerical daemons of conceptual hydrological modeling: 1. Fidelity and efficiency of time stepping schemes. Water Resources Research, 46, W10510. https://doi.org/10.1029/2009WR008894

Clark, M. P., Kavetski, D., \& Fenicia, F. (2011). Pursuing the method of multiple working hypotheses for hydrological modeling. Water Resources Research, 47, W09301. https://doi.org/10.1029/2010WR009827

Clark, M. P., Kavetski, D., \& Fenicia, F. (2012). Reply to comment by K. Beven et al. on "Pursuing the method of multiple working hypotheses for hydrological modeling". Water Resources Research, 48, W11802. https://doi.org/10.1029/2012WR012547

Clark, M. P., Nijssen, B., Lundquist, J. D., Kavetski, D., Rupp, D. E., Woods, R. A., et al. (2015a). A unified approach for process-based hydrologic modeling: 1. Modeling concept. Water Resources Research, 51, 2498-2514. https://doi.org/10.1002/2015WR017198

Clark, M. P., Nijssen, B., Lundquist, J. D., Kavetski, D., Rupp, D. E., Woods, R. A., et al. (2015b). A unified approach for process-based hydrologic modeling: 2. Model implementation and case studies. Water resources research, 51, 2515-2542. https://doi.org/10.1002/ 2015 wr017200

Clark, M. P., Slater, A. G., Rupp, D. E., Woods, R. A., Vrugt, J. A., Gupta, H. V., et al. (2008). Framework for Understanding Structural Errors (FUSE): A modular framework to diagnose differences between hydrological models. Water Resources Research, 44, W00B02. https://doi.org/10.1029/2007WR006735

Crochemore, L., Perrin, C., Andréassian, V., Ehret, U., Seibert, S. P., Grimaldi, S., et al. (2015). Comparing expert judgement and numerica criteria for hydrograph evaluation. Hydrological Sciences Journal, 6O(3), 402-423. https://doi.org/10.1080/02626667.2014.903331

Davtalab, R., Mirchi, A., Khatami, S., Gyawali, R., Massah, A., Farajzadeh, M., \& Madani, K. (2017). Improving continuous hydrologic modeling of data-poor river basins using hydrologic engineering center's hydrologic modeling system: Case study of Karkheh River basin. Journal of Hydrologic Engineering, 22(8). https://doi.org/10.1061/(ASCE)HE.1943-5584.0001525

Duan, Q., Sorooshian, S., \& Gupta, V. (1992). Effective and efficient global optimization for conceptual rainfall-runoff models. Water Resources Research, 28(4), 1015-1031. https://doi.org/10.1029/91WR02985

Ebel, B. A., \& Loague, K. (2006). Physics-based hydrologic-response simulation: Seeing through the fog of equifinality. Hydrological Processes, 20(13), 2887-2900. https://doi.org/10.1002/hyp.6388 
Efstratiadis, A., \& Koutsoyiannis, D. (2010). One decade of multi-objective calibration approaches in hydrological modelling: A review. Hydrological Sciences Journal, 55(1), 58-78. https://doi.org/10.1080/02626660903526292

Ehlers, L. B., Sonnenborg, T. O., \& Refsgaard, J. C. (2018). Observational and predictive uncertainties for multiple variables in a spatially distributed hydrological model. Hydrological Processes. https://doi.org/10.1002/hyp.13367

van Emmerik, T. H. M., Li, Z., Sivapalan, M., Pande, S., Kandasamy, J., Savenije, H. H. G., et al. (2014). Socio-hydrologic modeling to understand and mediate the competition for water between agriculture development and environmental health: Murrumbidgee River basin, Australia. Hydrology and Earth System Sciences, 18(10), 4239-4259. https://doi.org/10.5194/hess-18-4239-2014

Euser, T., Winsemius, H. C., Hrachowitz, M., Fenicia, F., Uhlenbrook, S., \& Savenije, H. H. G. (2013). A framework to assess the realism of model structures using hydrological signatures. Hydrology and Earth System Sciences, 17(5), 1893-1912. https://doi.org/10.5194/hess-171893-2013

Fenicia, F., Kavetski, D., \& Savenije, H. H. G. (2011). Elements of a flexible approach for conceptual hydrological modeling: 1. Motivation and theoretical development. Water Resources Research, 47, W11510. https://doi.org/10.1029/2010wr010174

Fenicia, F., Kavetski, D., Savenije, H. H. G., Clark, M. P., Schoups, G., Pfister, L., \& Freer, J. (2014). Catchment properties, function, and conceptual model representation: Is there a correspondence? Hydrological Processes, 28(4), 2451-2467. https://doi.org/10.1002/hyp.9726

Flyvbjerg, B., Skamris Holm, M. K., \& Buhl, S. L. (2006). Inaccuracy in traffic forecasts. Transport Reviews, 26(1), 1-24. https://doi.org/ $10.1080 / 01441640500124779$

Fowler, K., Peel, M., Western, A., \& Zhang, L. (2018). Improved rainfall-runoff calibration for drying climate: Choice of objective function. Water Resources Research, 54, 3392-3408. https://doi.org/10.1029/2017WR022466

Fowler, K. J. A., Peel, M. C., Western, A. W., Zhang, L., \& Peterson, T. J. (2016). Simulating runoff under changing climatic conditions: Revisiting an apparent deficiency of conceptual rainfall-runoff models. Water Resources Research, 52, 1820-1846. https://doi.org/ 10.1002/2015WR018068

Gharari, S., Hrachowitz, M., Fenicia, F., Gao, H., \& Savenije, H. H. G. (2014). Using expert knowledge to increase realism in environmental system models can dramatically reduce the need for calibration. Hydrology and Earth System Sciences, 18(12), 4839-4859. https://doi. org/10.5194/hess-18-4839-2014

Gong, W., Gupta, H. V., Yang, D., Sricharan, K., \& Hero, A. O. (2013). Estimating epistemic and aleatory uncertainties during hydrologic modeling: An information theoretic approach. Water Resources Research, 49, 2253-2273. https://doi.org/10.1002/wrcr.20161

Grayson, R. B., Moore, I. D., \& McMahon, T. A. (1992). Physically based hydrologic modeling: 1. A terrain-based model for investigative purposes. Water Resources Research, 28(10), 2639-2658. https://doi.org/10.1029/92WR01258

Guo, D., Westra, S., \& Maier, H. R. (2017). Impact of evapotranspiration process representation on runoff projections from conceptual rainfall-runoff models. Water Resources Research, 53, 435-454. https://doi.org/10.1002/2016WR019627

Gupta, H. V., Kling, H., Yilmaz, K. K., \& Martinez, G. F. (2009). Decomposition of the mean squared error and NSE performance criteria: Implications for improving hydrological modelling. Journal of Hydrology, 377(1-2), 80-91. https://doi.org/10.1016/j. jhydrol.2009.08.003

Gupta, H. V., \& Nearing, G. S. (2014). Debates-The future of hydrological sciences: A (common) path forward? Using models and data to learn: A systems theoretic perspective on the future of hydrological science. Water Resources Research, 50, 5351-5359. https://doi.org/ $10.1002 / 2013$ WR015096

Gupta, H. V., Sorooshian, S., \& Yapo, P. O. (1998). Toward improved calibration of hydrologic models: Multiple and noncommensurable measures of information. Water Resources Research, 34(4), 751-763. https://doi.org/10.1029/97WR03495

Gupta, H. V., Wagener, T., \& Liu, Y. (2008). Reconciling theory with observations: Elements of a diagnostic approach to model evaluation. Hydrological Processes, 22(18), 3802-3813. https://doi.org/10.1002/hyp.6989

Gupta, V. K., \& Sorooshian, S. (1983). Uniqueness and observability of conceptual rainfall-runoff model parameters: The percolation process examined. Water resources research, 19(1), 269-276. https://doi.org/10.1029/WR019i001p00269

de Haan, F. J., Rogers, B. C., Brown, R. R., \& Deletic, A. (2016). Many roads to Rome: The emergence of pathways from patterns of change through exploratory modelling of sustainability transitions. Environmental Modelling \& Software, 85, 279-292. https://doi.org/10.1016/j. envsoft.2016.05.019

Haasnoot, M., Kwakkel, J. H., Walker, W. E., \& ter Maat, J. (2013). Dynamic adaptive policy pathways: A method for crafting robust decisions for a deeply uncertain world. Global Environmental Change, 23(2), 485-498. https://doi.org/10.1016/j.gloenvcha.2012.12.006

Haydon, S., \& Deletic, A. (2009). Model output uncertainty of a coupled pathogen indicator-hydrologic catchment model due to input data uncertainty. Environmental Modelling \& Software, 24(3), 322-328. https://doi.org/10.1016/j.envsoft.2008.09.004

Heymann, M., \& Dalmedico, A. D. (2019). Epistemology and politics in Earth system modeling: Historical perspectives. Journal of Advances in Modeling Earth Systems. https://doi.org/10.1029/2018ms001526

Holländer, H. M., Blume, T., Bormann, H., Buytaert, W., Chirico, G. B., Exbrayat, J. F., et al. (2009). Comparative predictions of discharge from an artificial catchment (Chicken Creek) using sparse data. Hydrology and Earth System Sciences, 13(11), 2069-2094. https://doi.org/ 10.5194/hess-13-2069-2009

Hornberger, G. M., \& Spear, R. C. (1981). An approach to the preliminary analysis of environmental systems. Journal of Environmental Management, 12, 7-18.

Hrachowitz, M., Fovet, O., Ruiz, L., Euser, T., Gharari, S., Nijzink, R., et al. (2014). Process consistency in models: The importance of system signatures, expert knowledge, and process complexity. Water Resources Research, 50, 7445-7469. https://doi.org/10.1002/ 2014WR015484

Jeffrey, S. J., Carter, J. O., Moodie, K. B., \& Beswick, A. R. (2001). Using spatial interpolation to construct a comprehensive archive of Australian climate data. Environmental Modelling \& Software, 16(4), 309-330. https://doi.org/10.1016/S1364-8152(01)00008-1

Jones, D. A., Wang, W., \& Fawcett, R. (2009). High-quality spatial climate data-sets for Australia. Australian Meteorological and Oceanographic Journal, 58(04), 233-248. https://doi.org/10.22499/2.5804.003

Kavetski, D., \& Clark, M. P. (2011). Numerical troubles in conceptual hydrology: Approximations, absurdities and impact on hypothesis testing. Hydrological Processes, 25(4), 661-670. https://doi.org/10.1002/hyp.7899

Kavetski, D., \& Fenicia, F. (2011). Elements of a flexible approach for conceptual hydrological modeling: 2. Application and experimental insights. Water Resources Research, 47, W11511. https://doi.org/10.1029/2011wr010748

Kavetski, D., Kuczera, G., \& Franks, S. W. (2006). Bayesian analysis of input uncertainty in hydrological modeling: 1. Theory. Water Resources Research, 42, W03407. https://doi.org/10.1029/2005WR004368

Kelleher, C., McGlynn, B., \& Wagener, T. (2017). Characterizing and reducing equifinality by constraining a distributed catchment model with regional signatures, local observations, and process understanding. Hydrology and Earth System Sciences, 21(7), 3325-3352. https:// doi.org/10.5194/hess-21-3325-2017 
Kelleher, C., Wagener, T., \& McGlynn, B. (2015). Model-based analysis of the influence of catchment properties on hydrologic partitioning across five mountain headwater subcatchments. Water Resources Research, 51, 4109-4136. https://doi.org/10.1002/2014WR016147 Kendall, C., \& McDonnell, J. J. (1998). Isotope Tracers In Catchment Hydrology. Amsterdam: Elsevier.

Khatami, S. (2013a). Evidence of low-dimensional determinism in short time series of solute transport. Retrieved from Lund, Sweden: https://lup.lub.lu.se/search/publication/4139566

Khatami, S. (2013b). Nonlinear chaotic and trend analyses of water level at Urmia Lake, Iran. M.Sc. Thesis report: TVVR 13/5012, ISSN:1101-9824, Lund: Lund University, Retrieved from https://lup.lub.lu.se/search/publication/4253926

Khatami, S., Peel, M., Peterson, T., \& Western, A. (2017). Equifinality and process-based modelling. Paper presented at the AGU Fall Meeting, New Orleans, LA.

Khazaei, B., Khatami, S., Alemohammad, S. H., Rashidi, L., Wu, C., Madani, K., et al. (2019). Climatic or regionally induced by humans? Tracing hydro-climatic and land-use changes to better understand the Lake Urmia tragedy. Journal of Hydrology, 569, 203-217. https:// doi.org/10.1016/j.jhydrol.2018.12.004

Kirchner, J. W. (2016). Aggregation in environmental systems-Part 2: Catchment mean transit times and young water fractions under hydrologic nonstationarity. Hydrology and Earth System Sciences, 20(1), 299-328. https://doi.org/10.5194/hess-20-299-2016

Knoben, W. J. M., Woods, R. A., \& Freer, J. E. (2018). A quantitative hydrological climate classification evaluated with independent streamflow data. Water Resources Research, 54, 5088-5109. https://doi.org/10.1029/2018WR022913

Koch, J., Mendiguren, G., Mariethoz, G., \& Stisen, S. (2017). Spatial sensitivity analysis of simulated land surface patterns in a catchment model using a set of innovative spatial performance metrics. Journal of Hydrometeorology, 18(4), 1121-1142. https://doi.org/10.1175/ jhm-d-16-0148.1

Koch, J., Siemann, A., Stisen, S., \& Sheffield, J. (2016). Spatial validation of large-scale land surface models against monthly land surface temperature patterns using innovative performance metrics. Journal of Geophysical Research: Atmospheres, 121, 5430-5452. https://doi. org/10.1002/2015JD024482

Konikow, L. F., \& Bredehoeft, J. D. (1992). Ground-water models cannot be validated. Advances in Water Resources, 15(1), 75-83. https:// doi.org/10.1016/0309-1708(92)90033-X

Kwakkel, J. H., \& Pruyt, E. (2013). Exploratory modeling and analysis, an approach for model-based foresight under deep uncertainty. Technological Forecasting and Social Change, 80(3), 419-431. https://doi.org/10.1016/j.techfore.2012.10.005

Legates, D. R., \& McCabe, G. J. (1999). Evaluating the use of "goodness-of-fit" measures in hydrologic and hydroclimatic model validation. Water Resources Research, 35(1), 233-241. https://doi.org/10.1029/1998WR900018

Li, L., Lambert, M. F., Maier, H. R., Partington, D., \& Simmons, C. T. (2015). Assessment of the internal dynamics of the Australian Water Balance Model under different calibration regimes. Environmental Modelling \& Software, 66, 57-68. https://doi.org/10.1016/j. envsoft.2014.12.015

Liu, Y., Freer, J., Beven, K., \& Matgen, P. (2009). Towards a limits of acceptability approach to the calibration of hydrological models: Extending observation error. Journal of Hydrology, 367(1-2), 93-103. https://doi.org/10.1016/j.jhydrol.2009.01.016

Luo, Y., Weng, E., Wu, X., Gao, C., Zhou, X., \& Zhang, L. (2009). Parameter identifiability, constraint, and equifinality in data assimilation with ecosystem models. Ecological Applications, 19(3), 571-574. https://doi.org/10.1890/08-0561.1

Madani, K., Hooshyar, M., Khatami, S., Alaeipour, A., \& Moeini, A. (2014, 5-8 Oct. 2014). Nash-reinforcement learning (N-RL) for developing coordination strategies in non-transferable utility games. Paper presented at the 2014 IEEE International Conference on Systems, Man, and Cybernetics (SMC). https://doi.org/10.1109/SMC.2014.6974336

Madani, K., \& Lund, J. R. (2011). A Monte-Carlo game theoretic approach for multi-criteria decision making under uncertainty. Advances in water resources, 34(5), 607-616. https://doi.org/10.1016/j.advwatres.2011.02.009

Maier, H. R., Guillaume, J. H. A., van Delden, H., Riddell, G. A., Haasnoot, M., \& Kwakkel, J. H. (2016). An uncertain future, deep uncertainty, scenarios, robustness and adaptation: How do they fit together? Environmental Modelling \& Software, 81, 154-164. https:// doi.org/10.1016/j.envsoft.2016.03.014

Moallemi, E. A., de Haan, F., Kwakkel, J., \& Aye, L. (2017). Narrative-informed exploratory analysis of energy transition pathways: A case study of India's electricity sector. Energy Policy, 110, 271-287. https://doi.org/10.1016/j.enpol.2017.08.019

Moallemi, E. A., Elsawah, S., \& Ryan, M. J. (2018). Model-based multi-objective decision making under deep uncertainty from a multimethod design lens. Simulation Modelling Practice and Theory, 84, 232-250. https://doi.org/10.1016/j.simpat.2018.02.009

Moallemi, E. A., \& Köhler, J. (2019). Coping with uncertainties of sustainability transitions using exploratory modelling: The case of the MATISSE model and the UK's mobility sector. Environmental Innovation and Societal Transitions.. https://doi.org/10.1016/j. eist.2019.03.005

Moallemi, E. A., \& Malekpour, S. (2017). A participatory exploratory modelling approach for long-term planning in energy transitions. Energy Research \& Social Science., 35, 205-216. https://doi.org/10.1016/j.erss.2017.10.022

Morton, F. I. (1983). Operational estimates of areal evapotranspiration and their significance to the science and practice of hydrology. Journal of Hydrology, 66(1), 1-76. https://doi.org/10.1016/0022-1694(83)90177-4

Murphy, A. H. (1988). Skill scores based on the mean square error and their relationships to the correlation coefficient. Monthly Weather Review, 116(12), 2417-2424. https://doi.org/10.1175/1520-0493(1988)116<2417:ssbotm >2.0.co;2

Nash, J. E., \& Sutcliffe, J. V. (1970). River flow forecasting through conceptual models part I-A discussion of principles. Journal of Hydrology, 10(3), 282-290. https://doi.org/10.1016/0022-1694(70)90255-6

Nathan, R. J., \& Mudgway, L. B. (1997). Estimating salt loads in high water table areas. II: Regional salt loads. Journal of Irrigation and Drainage Engineering, 123(2), 91-99. https://doi.org/10.1061/(ASCE)0733-9437(1997)123:2(91)

Nearing, G. S., \& Gupta, H. V. (2015). The quantity and quality of information in hydrologic models. Water Resources Research, 51, 524-538. https://doi.org/10.1002/2014WR015895

Newman, A. J., Clark, M. P., Craig, J., Nijssen, B., Wood, A., Gutmann, E., et al. (2015). Gridded ensemble precipitation and temperature estimates for the contiguous United States. Journal of Hydrometeorology, 16(6), 2481-2500. https://doi.org/10.1175/jhm-d-150026.1

Oreskes, N., Shrader-Frechette, K., \& Belitz, K. (1994). Verification, validation, and confirmation of numerical models in the earth sciences. Science, 263(5147), 641-646.

Oudin, L., Michel, C., \& Anctil, F. (2005). Which potential evapotranspiration input for a lumped rainfall-runoff model?: Part 1-Can rainfall-runoff models effectively handle detailed potential evapotranspiration inputs? Journal of Hydrology, 303(1-4), 275-289. https:// doi.org/10.1016/j.jhydrol.2004.08.025 
Pappenberger, F., Matgen, P., Beven, K. J., Henry, J.-B., Pfister, L., \& Fraipont, P. (2006). Influence of uncertain boundary conditions and model structure on flood inundation predictions. Advances in Water Resources, 29(10), 1430-1449. https://doi.org/10.1016/j. advwatres.2005.11.012

Peel, M. C., \& Blöschl, G. (2011). Hydrological modelling in a changing world. Progress in Physical Geography, 35(2), 249-261. https://doi. org/10.1177/0309133311402550

Peel, M. C., Chiew, F. H., Western, A. W., \& McMahon, T. A. (2000). Extension of unimpaired monthly streamflow data and regionalisation of parameter values to estimate streamflow in ungauged catchments. Retrieved from Report prepared for the National Land and Water Resources Audit, In Australian Natural Resources Atlas, Pages 37.: http://people.eng.unimelb.edu.au/mpeel/NLWRA.pdf

Peel, M. C., Finlayson, B. L., \& McMahon, T. A. (2007). Updated world map of the Köppen-Geiger climate classification. Hydrology and Earth System Sciences, 11(5), 1633-1644. https://doi.org/10.5194/hess-11-1633-2007

Perrin, C., Michel, C., \& Andréassian, V. (2001). Does a large number of parameters enhance model performance? Comparative assessment of common catchment model structures on 429 catchments. Journal of Hydrology, 242(3-4), 275-301. https://doi.org/10.1016/S00221694(00)00393-0

Peterson, T. J., \& Western, A. W. (2014). Multiple hydrological attractors under stochastic daily forcing: 1. Can multiple attractors exist? Water Resources Research, 50, 2993-3009. https://doi.org/10.1002/2012WR013003

Peterson, T. J., Western, A. W., \& Argent, R. M. (2014). Multiple hydrological attractors under stochastic daily forcing: 2. Can multiple attractors emerge? Water Resources Research, 50, 3010-3029. https://doi.org/10.1002/2012WR013004

Pfannerstill, M., Guse, B., \& Fohrer, N. (2014). Smart low flow signature metrics for an improved overall performance evaluation of hydrological models. Journal of Hydrology, 510, 447-458. https://doi.org/10.1016/j.jhydrol.2013.12.044

Pool, S., Vis, M., \& Seibert, J. (2018). Evaluating model performance: Towards a non-parametric variant of the Kling-Gupta efficiency. Hydrological Sciences Journal, 63(13-14), 1941-1953. https://doi.org/10.1080/02626667.2018.1552002

Pushpalatha, R., Perrin, C., Moine, N. L., \& Andréassian, V. (2012). A review of efficiency criteria suitable for evaluating low-flow simulations. Journal of Hydrology, 420-421, 171-182. https://doi.org/10.1016/j.jhydrol.2011.11.055

Quine, W. V. (1975). On empirically equivalent systems of the world. Erkenntnis, 9(3), 313-328. https://doi.org/10.1007/BF00178004

Reichl, J., Chiew, F. H., \& Western, A. (2006). Model averaging, equifinality and uncertainty estimation in the modelling of ungauged catchments. Paper presented at the 3rd International Congress on Environmental Modelling and Software (iEMSs), BURLINGTON, VERMONT.

Renard, B., Kavetski, D., Kuczera, G., Thyer, M., \& Franks, S. W. (2010). Understanding predictive uncertainty in hydrologic modeling: The challenge of identifying input and structural errors. Water Resources Research, 46, W05521. https://doi.org/10.1029/ 2009WR008328

van Ruijven, B., de Vries, B., van Vuuren, D. P., \& van der Sluijs, J. P. (2010). A global model for residential energy use: Uncertainty in calibration to regional data. Energy, 35(1), 269-282. https://doi.org/10.1016/j.energy.2009.09.019

Saberi, M., Rashidi, T. H., Ghasri, M., \& Ewe, K. (2018). A complex network methodology for travel demand model evaluation and validation. Networks and Spatial Economics., 18(4), 1051-1073. https://doi.org/10.1007/s11067-018-9397-y

Santos, L., Thirel, G., \& Perrin, C. (2018). Technical note: Pitfalls in using log-transformed flows within the KGE criterion. Hydrology and Earth System Sciences, 22(8), 4583-4591. https://doi.org/10.5194/hess-22-4583-2018

Savenije, H. H. G. (2001). Equifinality, a blessing in disguise? Hydrological Processes, 15(14), 2835-2838. https://doi.org/10.1002/hyp.494

Sawicz, K. A., Kelleher, C., Wagener, T., Troch, P., Sivapalan, M., \& Carrillo, G. (2014). Characterizing hydrologic change through catchment classification. Hydrology and Earth System Sciences, 18(1), 273-285. https://doi.org/10.5194/hess-18-273-2014

Schaefli, B. (2016). Snow hydrology signatures for model identification within a limits-of-acceptability approach. Hydrological Processes, 30(22), 4019-4035. https://doi.org/10.1002/hyp.10972

Schaefli, B., \& Gupta, H. V. (2007). Do Nash values have value? Hydrological Processes, 21(15), 2075-2080. https://doi.org/10.1002/hyp.6825

Schaefli, B., Harman, C. J., Sivapalan, M., \& Schymanski, S. J. (2011). HESS Opinions: Hydrologic predictions in a changing environment: Behavioral modeling. Hydrology and Earth System Sciences, 15(2), 635-646. https://doi.org/10.5194/hess-15-635-2011

Seibert, J. (2001). On the need for benchmarks in hydrological modelling. Hydrological Processes, 15(6), 1063-1064. https://doi.org/10.1002/ hyp. 446

Seibert, J., \& McDonnell, J. J. (2002). On the dialog between experimentalist and modeler in catchment hydrology: Use of soft data for multicriteria model calibration. Water Resources Research, 38(11), 1241. https://doi.org/10.1029/2001WR000978

Sivakumar, B. (2000). Chaos theory in hydrology: Important issues and interpretations. Journal of Hydrology, 227(1-4), 1-20. https://doi. org/10.1016/S0022-1694(99)00186-9

Sivakumar, B., Berndtsson, R., Olsson, J., \& Jinno, K. (2001). Evidence of chaos in the rainfall-runoff process. Hydrological Sciences Journal, 46(1), 131-145. https://doi.org/10.1080/02626660109492805

Sorooshian, S., \& Gupta, V. K. (1983). Automatic calibration of conceptual rainfall-runoff models: The question of parameter observability and uniqueness. Water resources research, 19(1), 260-268. https://doi.org/10.1029/WR019i001p00260

Stisen, S., Koch, J., Sonnenborg, T. O., Refsgaard, J. C., Bircher, S., Ringgaard, R., \& Jensen, K. H. (2018). Moving beyond run-off calibration -Multivariable optimization of a surface-subsurface-atmosphere model. Hydrological Processes, 32(17), 2654-2668. https://doi.org/ 10.1002/hyp.13177

Tang, J., \& Zhuang, Q. (2008). Equifinality in parameterization of process-based biogeochemistry models: A significant uncertainty source to the estimation of regional carbon dynamics. Journal of Geophysical Research, 113, G04010. https://doi.org/10.1029/2008JG000757

Teweldebrhan, A., Burkhart, J., Schuler, T., \& Xu, C.-Y. (2018). Improving the informational value of MODIS fractional snow cover area using fuzzy logic based ensemble smoother data assimilation frameworks. Remote Sensing, 11(1), 28. https://doi.org/10.3390/ rs 11010028

Teweldebrhan, A. T., Burkhart, J. F., \& Schuler, T. V. (2018). Parameter uncertainty analysis for an operational hydrological model using residual-based and limits of acceptability approaches. Hydrology and Earth System Sciences, 22(9), 5021-5039. https://doi.org/10.5194/ hess-22-5021-2018

Tian, Y., Nearing, G. S., Peters-Lidard, C. D., Harrison, K. W., \& Tang, L. (2016). Performance metrics, error modeling, and uncertainty quantification. Monthly Weather Review, 144(2), 607-613. https://doi.org/10.1175/mwr-d-15-0087.1

Tolson, B. A., \& Shoemaker, C. A. (2008). Efficient prediction uncertainty approximation in the calibration of environmental simulation models. Water Resources Research, 44, W04411. https://doi.org/10.1029/2007wr005869

Turner, M. (2012). Hydrologic reference station selection guidelines. Australia: Retrieved from Melbourne. http://www.bom.gov.au/water/ hrs/media/static/papers/Selection_Guidelines.pdf 
Vrugt, J. A., \& Beven, K. J. (2018). Embracing equifinality with efficiency: Limits of Acceptability sampling using the DREAM (LOA) algorithm. Journal of Hydrology, 559, 954-971. https://doi.org/10.1016/j.jhydrol.2018.02.026

Vrugt, J. A., ter Braak, C. J. F., Clark, M. P., Hyman, J. M., \& Robinson, B. A. (2008). Treatment of input uncertainty in hydrologic modeling: Doing hydrology backward with Markov chain Monte Carlo simulation. Water Resources Research, 44, W00B09. https://doi.org/10.1029/ 2007WR006720

Westerberg, I. K., Di Baldassarre, G., Beven, K. J., Coxon, G., \& Krueger, T. (2017). Perceptual models of uncertainty for socio-hydrologica systems: A flood risk change example. Hydrological Sciences Journal, 62(11), 1705-1713. https://doi.org/10.1080/02626667.2017.1356926

Westerberg, I. K., \& McMillan, H. K. (2015). Uncertainty in hydrological signatures. Hydrology and Earth System Sciences, 19(9), 3951-3968 https://doi.org/10.5194/hess-19-3951-2015

Westerberg, I. K., Wagener, T., Coxon, G., McMillan, H. K., Castellarin, A., Montanari, A., \& Freer, J. (2016). Uncertainty in hydrologica signatures for gauged and ungauged catchments. Water Resources Research, 52, 1847-1865. https://doi.org/10.1002/2015WR017635

Western, A. W., \& Grayson, R. B. (1998). The Tarrawarra data set: Soil moisture patterns, soil characteristics, and hydrological flux measurements. Water Resources Research, 34(10), 2765-2768. https://doi.org/10.1029/98WR01833

Willmott, C. J., Robeson, S. M., \& Matsuura, K. (2012). A refined index of model performance. International Journal of Climatology, 32(13), 2088-2094. https://doi.org/10.1002/joc.2419

Winsemius, H. C., Schaefli, B., Montanari, A., \& Savenije, H. H. G. (2009). On the calibration of hydrological models in ungauged basins: A framework for integrating hard and soft hydrological information. Water Resources Research, 45, W12422. https://doi.org/10.1029/ 2009WR007706

Yeh, W. W. G. (1986). Review of parameter identification procedures in groundwater hydrology: The inverse problem. Water resources research, 22(2), 95-108. https://doi.org/10.1029/WR022i002p00095

Yew Gan, T., Dlamini, E. M., \& Biftu, G. F. (1997). Effects of model complexity and structure, data quality, and objective functions on hydrologic modeling. Journal of Hydrology, 192(1-4), 81-103. https://doi.org/10.1016/S0022-1694(96)03114-9

Yilmaz, K. K., Gupta, H. V., \& Wagener, T. (2008). A process-based diagnostic approach to model evaluation: Application to the NWS distributed hydrologic model. Water Resources Research, 44, W09417. https://doi.org/10.1029/2007WR006716

Zin, I. (2002). Incertitudes et ambiguïté dans la modélisation hydrologique. (Thèse de Doctorat), Grenoble, France. 


\title{
4. Result Chapter 2 (Paper 3)
}

This Chapter, written in American English, is prepared to be submitted to journal Water Resources Research.

\section{Evaluating catchment models as multiple working hypotheses: on the role of error metrics, parameter sampling, model structure, and data information content}

\author{
Sina Khatami ${ }^{1}$, Tim J. Peterson ${ }^{1,2}$, Murray C. Peel ${ }^{1}$, Andrew W. Western ${ }^{1}$ \\ ${ }^{1}$ Department of Infrastructure Engineering, University of Melbourne, Parkville, Victoria, \\ 3010, Australia \\ ${ }^{2}$ Department of Civil Engineering, Monash University, Clayton, Victoria, Australia
}

Key points:

- KGEss is a more reliable metric than NSE and WIA, due to its mathematical structure.

- The choice of error metric - other things being equal - changes how model performance, parameter sampling sufficiency, and/or model hypotheses are measured.

- Relying on large samples of parameter space, without considering the model solution space, is a major source of uncertainty. 


\section{Abstract}

Hydrological models are conventionally evaluated in terms of their response surface or likelihood surface constructed within the model parameter space. To evaluate models as hypotheses, we developed the method of Flux Mapping to construct a hypothesis space based on model process representation. Here we defined the hypothesis space based on dominant runoff generating mechanisms, and acceptable model runs are defined as total simulated flow with similar (and minimal) model error simulated by distinct combinations of runoff components. In each modeling case, the hypothesis space is the result of an interplay of factors: model structure; parameter sampling; choice of error metric; and data information content. The aim of this study is to disentangle the role of each factor in this interplay. We used two model structures (SACRAMENTO and SIMHYD), two parameter sampling approaches (Latin Hypercube Sampling of the parameter space and guided-search of the solution space), three widely used error metrics (Nash-Sutcliffe Efficiency - NSE, KlingGupta Efficiency skill score - KGEss, and Willmott's refined Index of Agreement - WIA), and hydrological data from a range of Australian catchments. First, we characterized how the three error metrics behave under different error types and error magnitudes independent of any modeling. We then conducted a series of controlled experiments to unpack the role of each factor in runoff generation hypotheses. We show that KGEss is a more reliable error metric compared to NSE and WIA for model evaluation. We further demonstrate that only changing the error metric - while other factors remain constant - can change the model solution space and hence vary model performance, parameter sampling sufficiency, and/or the flux map. In other words, sampling sufficiency is not just a function a parameter space and sample size, but also the error metric and forcing data that determine the model solution space. We show how unreliable error metrics and insufficient parameter sampling impact the runoff generation hypotheses (flux maps), or any model-based inferences for that matter.

Keywords: model evaluation, model error, uncertainty, sensitivity, hypothesis testing, computational hydrology 


\subsection{Introduction}

The summum bonum (i.e. ultimate goal) of earth and environmental sciences, including hydrology, is to improve process understanding and prediction. Models are developed and improved by incorporating our understanding of real-world processes into them, and our understanding improves by modeling as a learning activity where models are treated as hypotheses of the real-world processes. Our understanding is ever-evolving, yet always remains incomplete and uncertain. While models are simplified representations of reality, they are most useful when used to challenge existing understanding (Oreskes et al., 1994). Due to this symbiotic and never-ending process of learning and modeling, developing frameworks for evaluating models as hypotheses under uncertainty is - and will always be - a research priority in hydrological sciences (Blöschl et al., 2019) and beyond.

Models can be evaluated from different standpoints. For instance, a response space (or surface) can be formed based on model parameters given some error metrics (Sorooshian \& Gupta, 1983), or a likelihood space based on distributions of model parameters given some likelihood functions as a measure of model parameter uncertainty/sensitivity (Beven \& Binley, 1992; Hornberger \& Spear, 1981). Treating models as hypotheses, we developed a method to construct a hypothesis space based on equifinal model internal runoff fluxes that amount to the total simulated flow, called Flux Mapping (Khatami et al., 2019). The principle of equifinality implies that we should implement and evaluate models as multiple working hypotheses $(\mathrm{MWH})$, which underpins the current paradigm of hydrological modeling (Beven, 2012; Buytaert \& Beven, 2011; Clark et al., 2011a; Jehn et al., 2018; Krueger et al., 2010). A catchment model, including its internal fluxes and stores, is a simplified and approximate representation of catchment dynamics, averaged over spatio-temporal units. So, the internal runoff fluxes of hydrological models are indicative of catchment scale behavior for runoff generation, and hence provides a parsimonious way for testing and falsifying our knowledge of their corresponding catchment processes. In light of the above, the premise of this study is evaluating model runoff fluxes under uncertainty as MWH about catchment behavior/function namely runoff generation. It is a truism that model output is the result of the interplay between model structure and parameterization, data information content, and objective functions (or error metrics). The overall aim of this study is to unpack and demonstrate salient points of this interplay, which impact model-based inferences. We 
specifically address: how the error metric values change under different types or magnitudes of errors? What role does the error metric play in parameter sampling sufficiency? How error metric and/or parameter sampling influence model performance and process representation? To this end, we designed a series of controlled experiments to disentangle the role of each factor on the model output.

In the following sections we outline the dataset of 221 Australian catchments, runoff generation within the two hydrological models (section 4.2.2), three error metrics for model evaluation (section 4.2.3), and design of ensemble modeling experiments (section 4.2.4). A key contribution of this work is disentangling the role of error metrics, specifically their mathematical structure, in model evaluation and hypothesis formation. To this end, we conducted a one-factor-at-a-time sensitivity analysis on the mathematical structure of the three aforementioned error metrics (section 4.2.5), to demonstrate how each metric functions under different error types and magnitudes independent of any hydrological modeling (section 4.3.1). To the best of our knowledge a formal metric sensitivity analysis has not been done previously. Our results (section 4.3) show that some limitations in model evaluation and hypothesis testing are partly due to inherent characteristics of error metrics embedded in their mathematical structure - independent of model structure and parameterization, parameter sampling sufficiency, and forcing data. Such characteristics of error metrics may impede a reliable model evaluation, and thus give rise to misleading hypotheses. Finally, we discuss our findings including some of the limitations of this work that can be addressed in future studies (section 4.4).

\subsection{Methods and experiment design}

\subsubsection{Study area and dataset}

The study area is a subset of 221 catchments, called the Australian Network of Hydrologic Reference Stations (HRS), provided by the Bureau of Meteorology (http://www.bom.gov.au/water/hrs/). Overall, the HRS catchments have relatively highquality data with minimal land-use disturbance or water resources development over the period of record (Turner, 2012, p. 6). In addition to the daily time series of observed streamflow of HRS catchments, Fowler et al. (2016) estimated the daily catchment average precipitation and daily Morton's areal potential evapotranspiration (APET) at the catchment 
centroid. For further details on data preparation refer to Fowler et al. (2016). We limited our presented results (section 4.3) to a number of catchments that illustrate the impact of different modeling factors (i.e. model structure and parameterization, parameter sampling sufficiency, error metric, and forcing data) on flux maps (i.e. runoff generation hypotheses). A summary of catchment characteristics is presented in Table 4.1. Since it is not the aim of this study to evaluate the correspondence between catchment characteristics and model behavior, we do not further discuss catchment characteristics. Given that the aim of this study is to treat models as hypotheses (and not to calibrate models for predictions), we used the entire record of forcing data to calibrate/evaluate models.

Table 4.1. Summary of the study catchments used in modelling experiments and presented in the results section.

\begin{tabular}{|c|c|c|c|c|c|c|c|c|}
\hline $\begin{array}{l}\text { Catchment } \\
\text { No. }\end{array}$ & $\begin{array}{c}\text { Corresponding } \\
\text { figures }\end{array}$ & Name & Location & $\begin{array}{l}\text { Area } \\
\left(\mathrm{km}^{2}\right)\end{array}$ & $\begin{array}{c}\text { Mean } \\
\text { annual } \\
\text { precipitation } \\
\text { (mm) }\end{array}$ & $\begin{array}{c}\text { Mean } \\
\text { annual } \\
\text { streamflow } \\
(\mathrm{mm})\end{array}$ & $\begin{array}{l}\text { Mean } \\
\text { annual } \\
\text { APET } \\
\text { (mm) }\end{array}$ & $\begin{array}{c}\text { Annual } \\
\text { runoff } \\
\text { ratio }\end{array}$ \\
\hline 1 & Figure 4.3 & $\begin{array}{l}\text { Suggan } \\
\text { Buggan } \\
\text { River at } \\
\text { Suggan } \\
\text { Buggan }\end{array}$ & Victoria & 364.5 & 975.9 & 136.0 & 1088.5 & 0.14 \\
\hline 2 & Figure 4.3 & $\begin{array}{l}\text { Emu Creek } \\
\text { at Emu Vale }\end{array}$ & Queensland & 153.8 & 996.2 & 99.2 & 1408.8 & 0.10 \\
\hline 3 & Figure 4.3 & $\begin{array}{l}\text { Currambene } \\
\text { Creek at } \\
\text { Falls Creek }\end{array}$ & $\begin{array}{l}\text { New South } \\
\text { Wales }\end{array}$ & 93.5 & 1075.1 & 202.5 & 1241.1 & 0.19 \\
\hline 4 & Figure 4.4 & $\begin{array}{l}\text { Wide Bay } \\
\text { Creek at } \\
\text { Kilkivan }\end{array}$ & Queensland & 352.3 & 945.0 & 147.3 & 1518.8 & 0.16 \\
\hline 5 & Figure 4.5 & $\begin{array}{l}\text { Kandanga } \\
\text { Creek at } \\
\text { Hygait }\end{array}$ & Queensland & 170.8 & 1135.2 & 278.0 & 1532.5 & 0.24 \\
\hline 6 & Figure 4.6 & $\begin{array}{l}\text { Normanby } \\
\text { River at } \\
\text { Battle Camp }\end{array}$ & Queensland & 2314 & 1533.6 & 364.4 & 1865.1 & 0.24 \\
\hline 7 & Figure 4.7 & $\begin{array}{l}\text { Elizabeth } \\
\text { Creek at } \\
\text { Mount } \\
\text { Surprise }\end{array}$ & Queensland & 459.2 & 806.8 & 88.5 & 1641.9 & 0.11 \\
\hline
\end{tabular}

\subsubsection{Hydrological models: hypotheses of runoff generation}


As hypotheses for runoff generation, a hydrological model may entail runoff generation mechanisms, whether at local or catchment scales, based on distinct catchment processes. In general, there are four main runoff generation mechanisms/sources which can be embedded within catchment models: (1) Infiltration-excess overland flow, which occurs when rainfall intensity exceeds the soil infiltrability, also known as Hortonian overland flow (Horton, 1933). (2) Saturation-excess overland flow, also known as Dunnian overland flow (Dunne \& Black, 1970), which occurs under saturated soil conditions, either due to direct rainfall (regardless of its intensity) on saturated soil, or due to the exfiltration (return flow) of a portion of interflow. (3) Subsurface stormflow, which is the rapid lateral movement/displacement of subsurface flow under saturated soil conditions (Hewlett \& Hibbert, 1967). (4) Baseflow, which is the slow response or slow release of water from the catchment store.

For this study, we chose two conceptual hydrological models namely SIMHYD (Chiew et al., 2002; Peel et al., 2000) with 7 parameters, and SACRAMENTO (Burnash, 1995; Burnash et al., 1973) with 15 parameters. Despite their conceptual differences, these two are comparable process-based models for runoff generation, in that they simulate runoff through distinct runoff generating mechanisms. Total simulated flow in SIMHYD is the sum of three runoff fluxes representing different mechanisms of streamflow: (1) infiltration excess overland flow, (2) interflow and saturation excess overland flow, and (3) baseflow from a slow response reservoir. Details of SIMHYD and its runoff fluxes are explained in the literature (Chiew et al., 2002; Khatami et al., 2019; Peel et al., 2000). SACRAMENTO simulates runoff through five runoff fluxes: (1) runoff from permanently impervious areas (i.e. infiltration excess runoff), (2) direct runoff from additional impervious areas due to saturated conditions (a type of saturation excess runoff), (3) surface runoff when the Upper Zone Free Water storage is full (i.e. saturated conditions) and the precipitation intensity exceeds the rate of percolation and interflow, (4) interflow due to the lateral drainage of the Upper Zone Free Water storage, and (5) baseflow which is composed of primary and supplemental baseflow.

As Saffarpour et al. (2016) argued, catchment wetness drives both saturation excess overland flow (Western \& Grayson, 1998; Western et al., 2005) and subsurface stormflow (Freer et al., 2002; Tromp van Meerveld \& McDonnell, 2005). Infiltration-excess overland 
flow is an intensity-based mechanism, and baseflow is a slow (and often continuous) response, compared with event hydrograph timescales. Therefore, the runoff fluxes of these models can be classified into three groups or modes of model response, namely intensitybased, wetness-based, and slow response. Here we treat model output as a hypothesis indicating how runoff is simulated through these three modes of runoff generation for each modeling example. The flux map is a hypothesis space that summarizes an ensemble of acceptable/behavioral model runs based on their modes of model response (details in section 4.2.4).

\subsubsection{Error metrics}

We use three error metrics namely NSE (equation 1), skill score variant of KGE (KGEsS, equation 2), and WIA (equation 3). Each metric quantifies some aspects of the (dis)similarity or distance between a target variable (e.g. observed streamflow time series, $O_{i}$ for $i=$ $1, \ldots, n$ datapoints) and a test variable (e.g. modeled streamflow time series, $M_{i}$ ). NSE is based on least square errors, whereas WIA is built upon absolute errors (Willmott et al., 2012). Decomposing NSE, Murphy (1988) showed that NSE characterizes the distance between two variables (or time series) as an obfuscated function of their corresponding summary statistics: mean, standard deviation, and Pearson's linear correlation coefficient (CC). Refining the intrinsic redundancies within NSE, Gupta et al. (2009) developed KGE to systematically account for the three error terms of bias, variability, and correlation of two time series. In other words, KGE is inherently a multiple-criteria metric based on the Pareto set (or non-dominant solutions) approach (Gupta et al., 1998). Gupta et al. (2009) originally used standard deviation to account for the variability error. It was later substituted by the coefficient of variation to reduce the cross-correlation between bias and variability terms (Kling et al., 2012), which is the KGE variant that we used in this study (Equation 2.1).

$$
\begin{aligned}
& N S E=1-\frac{\sum_{i=1}^{n}\left(M_{i}-O_{i}\right)^{2}}{\sum_{i=1}^{n}\left(O_{i}-\bar{O}\right)^{2}} ;-\infty \leq N S E \leq 1 \\
& K G E_{S S}=1-\frac{1-K G E}{\sqrt{2}}=;-\infty \leq K G E_{S S} \leq 1 \\
& K G E=1-\sqrt{\left(1-\frac{\bar{M}}{\bar{O}}\right)^{2}+\left(1-\frac{M_{c v}}{O_{c v}}\right)^{2}+(1-C C)^{2}}
\end{aligned}
$$


WIA $=\left\{\begin{array}{l}1-\frac{\sum_{i=1}^{n}\left|M_{i}-O_{i}\right|}{2 \cdot \sum_{i=1}^{n}\left|O_{i}-\bar{O}\right|}, \text { when } \sum_{i=1}^{n}\left|M_{i}-O_{i}\right|<2 \cdot \sum_{i=1}^{n}\left|O_{i}-\bar{O}\right| \\ \frac{2 \cdot \sum_{i=1}^{n}\left|O_{i}-\bar{O}\right|}{\sum_{i=1}^{n}\left|M_{i}-O_{i}\right|}-1, \text { when } \sum_{i=1}^{n}\left|M_{i}-O_{i}\right|>2 \cdot \sum_{i=1}^{n}\left|O_{i}-\bar{O}\right|\end{array} ;-1 \leq\right.$ WIA $\leq 1$

(Equation 3)

where $\bar{M}$ is the mean of the modeled series, and $M_{c v}$ and $O_{c v}$ are the coefficient of variation for the modeled and observed series respectively. All three are efficiency metrics, i.e. they assign a dimensionless scalar value to indicate the distance between the observed and modeled series. A perfect match would result in a metric value of 1 , and as the modeled series diverge from the observed series the metric value decreases. NSE and WIA are inherently benchmarked against the mean of the observed series, $\bar{O}$. That is, the metric value is zero when the test (or modeled) series comprises of the overall mean of the target variable for every data point. Unlike NSE and WIA, KGE (both original and modified versions) is not benchmarked (Knoben et al., 2019). To benchmark KGE, here we developed the skill score version of KGE (KGEss, see Appendix A). Skill score is a common measure of the relative accuracy (or skill) of a forecast against a given reference/benchmark, e.g. NSE is essentially a skill score of mean squared error benchmarked against the observed mean (Murphy, 1988). KGE-based skill scores have been used previously for assessing the performance of hydrological models (Towner et al., 2019) and streamflow forecasts (Hirpa et al., 2018) benchmarked against some reference model/forecast. Here, we benchmarked KGE against observed mean to improve the comparability between the values of the metrics.

It should be mentioned that each metric characterizes some aspects of the distance between target and test variables, while no single metric can characterize all aspects (Khatami et al., 2019). We will further discuss this by cross comparing these three metrics in sections 4.3 .1 and 4.4.1.

\subsubsection{Experiment design}

As shown on Figure 4.1, the experiment design has three main steps as follow:

Step 1: to setup the modelling experiments. To sample the parameter space, we generated two sets of Latin Hypercube Samples (LHS) of model parameter sets: 1 million LHS for SIMHYD, and 1.2 million for SACRAMENTO. These two sets of LHS parameter sets are used consistently for all modeling experiments, i.e. parameter sets do not vary across catchments 
and error metrics. Given the higher number of parameters in SACRAMENTO, we decided to use an additional 200,000 LHS parameter sets for SACRAMENTO. This is a subjective decision and does not guarantee sampling sufficiency, which varies by the choice of error metric, data information content, and model structure. The forcing data to the hydrological models are precipitation and evapotranspiration as explained in section 4.2.1, and the error metrics are NSE, KGEss, and WIA as explained in section 4.2.3.

Step 2: to run each hydrological model using two different parameterization approaches. (1) Random global search of the parameter space using the LHS parameter sets, resulting in an ensemble of model runs. (2) Guided global search of the solution space using Shuffled Complex Evolution (SCE, (Duan et al., 1992)) resulting in a single model run with the highest error metric value achievable. Due to inherent randomness in search routines like SCE, it is a common practice to repeat the search multiple times (Peterson \& Fulton, 2019; Peterson \& Western, 2014). Here, each modeling example was repeated 10 times for each error metric. The highest metric value among the 10 repeats (hereafter SCE-HMV) was chosen as the indicator of the guided search efficacy and a benchmark for the solution space, and the highest metric value of the model ensemble (hereafter Ensemble-HMV) as the indicator of the LHS effectiveness.

Step 3: to evaluate the model runs. As shown on Figure 4.1, model evaluation has three parts: (i) evaluating the sampling sufficiency, (ii) refining the LHS ensemble to define acceptable model runs, and (iii) flux mapping.

(i) Assessing the sample sufficiency by comparing Ensemble-HMV and SCE-HMV, i.e. comparing the best of the two worlds that accounted for both parameter space (based on the feasible range of parameter values) and solution space (based on the model performance given the model parametrization, error metric, and forcing data). We defined that a sampling is insufficient if for a given error metric | Ensemble-HMV - SCE-HMV | > 0.01. This is a relative test of sampling sufficiency where the sampling approach with the smaller indicator is certainly inadequate, while we cannot be certain about the adequacy of the other approach.

(ii) Refining the original LHS ensemble based on some criterion of model acceptability. For each error metric, the highest metric value $(\mathrm{HMV}=\max \{$ Ensemble-HMV, SCE-HMV\}) 
achievable is an upper benchmark (Seibert et al., 2018) of the model performance (or solution space), regardless of the sampling strategy. This allows us to separate the influence of acceptability threshold from parameter sampling sufficiency on flux maps (i.e. model's runoff generation). The acceptability threshold is an arbitrary distance from the HMV for a given metric. For example, for the error metric KGEss we can apply a strict threshold of 0.03 (acceptability threshold $=H M V_{K G E s S}-0.03$ ), or a more relaxed threshold of 0.10 (acceptability threshold $=H M V_{K G E S S}-0.10$ ). A model run is defined acceptable if its corresponding metric value is above the acceptability threshold. While it is hard to objectively justify the choice of a threshold, we previously showed that the overall pattern of NSE-based flux maps is independent of the acceptability threshold (Khatami et al., 2019). Although it is clear that relaxing the threshold allows the acceptance of a larger number of model runs and relatively expands the flux map point cloud. We will further discuss the differences between these three error metrics and their impact on sampling sufficiency and model process-representation in section 4.3.2, using a variety of thresholds for different modeling examples.

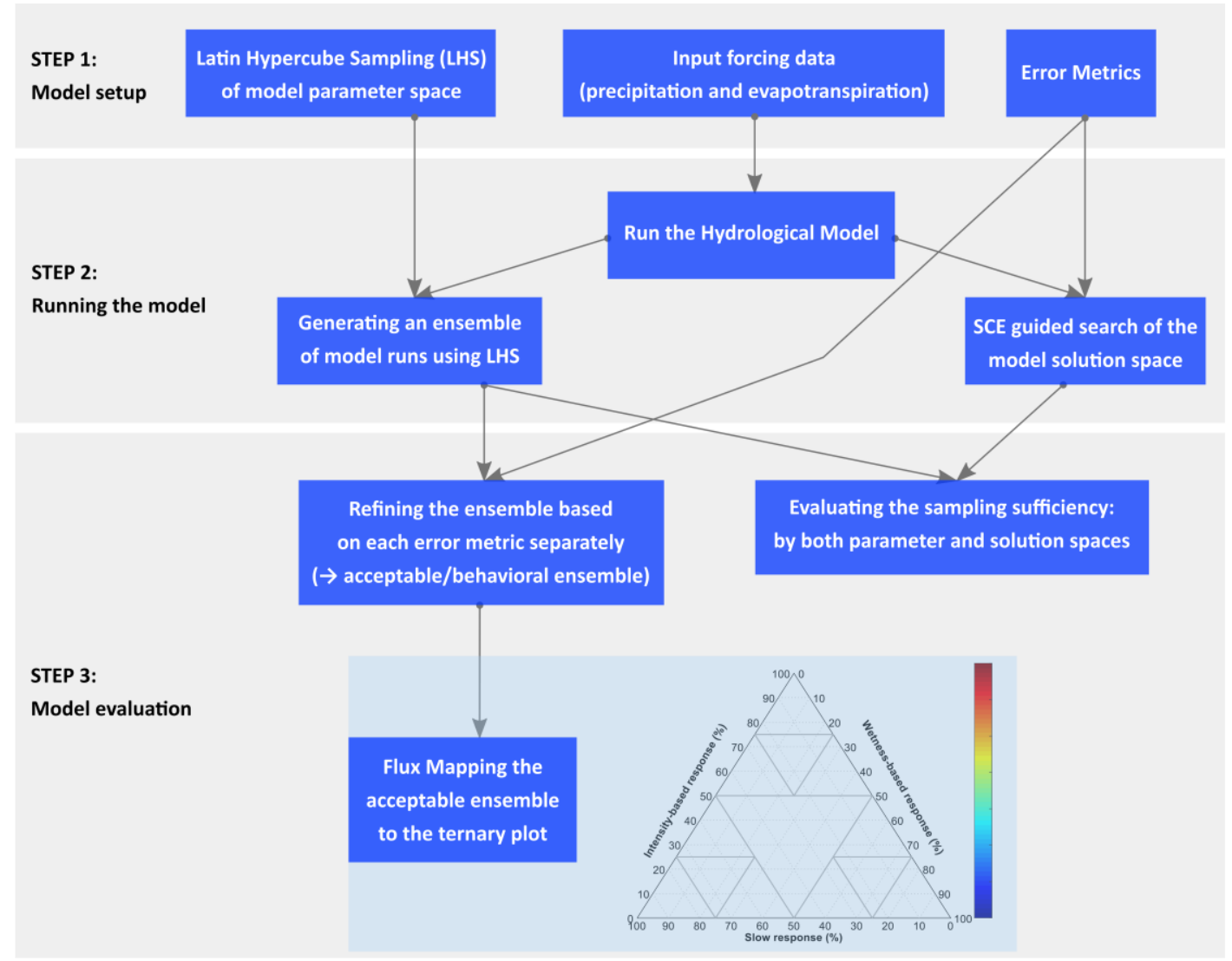

Figure 4.1. Schematic illustration of the modeling experiment design. The result of each experiment is to characterize the model response with a flux map. 
(iii) Flux mapping the acceptable model runs to characterize how each model run simulates runoff generation (Khatami et al., 2019). Model parameters are often the only source of uncertainty that is accounted for, i.e. all sources of modeling uncertainty are implicitly lumped into the parameter uncertainty, although uncertainty sources such as model input (Kavetski et al., 2006; Khazaei \& Hosseini, 2015; Moallemi et al., 2018; Papacharalampous et al., 2020a; Papacharalampous et al., 2020b; Vrugt et al., 2008), observed data (McMahon \& Peel, 2019; Westerberg et al., 2016), and model structural uncertainty (Clark et al., 2015; Fenicia et al., 2011) can be accounted for more explicitly. Even when only parameter uncertainty is accounted for, flux mapping characterizes how uncertainty propagates from parameter space to flux space and hence the impact on model process-representation and MWH (Khatami et al., 2019). Each model run is represented as a point on the flux map (the ternary plot in Figure 4.1) based on the percentage of the volumetric contribution of each model runoff flux and color-coded by its performance (i.e. the error metric value). The upper value of the color bar is the Ensemble-HMV, and the lowest value is HMV - acceptability threshold. The flux map (triangle) is comprised of 4 smaller triangles, based on which the acceptable ensemble could be further classified as: (1) Slow response (or baseflow) dominated model response if more than $50 \%$ of the simulated runoff is produced by slow/baseflow response, i.e. the bigger bottom left triangle within the flux map. (2) Wetness dominated model response if more than $50 \%$ of the simulated runoff is produced by wetness-based runoff fluxes of the model, i.e. the bigger bottom right triangle within the flux map. (3) Intensity dominated response when more than $50 \%$ of the total simulated runoff is generated by intensity-based fluxes, i.e. the bigger upper triangle within the flux map. (4) No dominant mode when a model run is summarized into a point within the central triangle of the flux map. So, the flux map represents the relative dominance of different modes of model response that we defined in section 4.2.2.

It should be mentioned that as we used the SCE routine only for the global search of the parameter space (and not model calibration), its corresponding parameter set is not used in flux mapping.

\subsubsection{Metric sensitivity}


Here, we demonstrate how NSE, KGEss, and WIA function under three different error regimes namely bias errors $\left(e_{B}\right)$, variability errors $\left(e_{V}\right)$, and correlation errors $\left(e_{C}\right)$. To this end, we took an arbitrary observed flow series, which includes multiple sequence of high and low flows, with 45 data points $\left(O_{i}, i=1,2, \ldots, 45\right)$, and conducted a one-factor-at-a-time sensitivity analysis (Pianosi et al., 2016) on each metric itself. In 20 steps $(k=1,2, \ldots, 20)$, we incrementally corrupted the observed series under each error type (see the example of step 1 in Figure S1 in Supporting Information for Chapter 4). For bias errors, we corrupt the observed series to form a biased series (Series $B$ ), which is generated by adding a bias equal to $5 \%$ of the average of the original observed series, $\bar{O}$, at each step: $\overline{B^{k}}=(1+k \cdot 0.05) \times$ $\bar{O}$, while standard deviation and Pearson's linear CC with the original series were kept constant: $B_{\text {std }}^{k}=O_{\text {std }}$ and $\operatorname{corr}_{P}\left(B^{k}, O\right)=1$. In other words, increasing bias by $5 \%$ at each step under ceteris paribus (other factors held constant) assumption, i.e. standard deviation and CC unchanged. The residuals of series $B$ and $O$ represent bias errors, and the added bias at step 20 equals the mean of the original series $\left(e_{B}^{20}=\overline{B^{20}}-\bar{O}=\bar{O}\right)$. For variability errors, we corrupt the observed series to form Series $V$, which is generated by increasing the standard deviation of the original series by $5 \%$ at each step: $V_{\text {std }}^{k}=(1+k \cdot 0.05) \times O_{\text {std }}$, under ceteris paribus assumption: $\overline{V^{k}}=\bar{O}$ and $\operatorname{corr}_{P}\left(V^{k}, O\right)=1$. The residuals of series $V$ and $O$ represent variability errors, which is twice the standard deviation of the original series at step $20\left(V_{s t d}^{20}=2 \cdot O_{s t d}\right)$. For correlation errors, we corrupt the observed series to form Series $C$, which is generated by decreasing Pearson's linear CC between the original and corrupted series by 0.05 at each step: $\operatorname{corr}_{p}\left(C^{k}, O\right)=1-k \times 0.05$, under ceteris paribus assumption: $\overline{C^{k}}=\bar{O}$ and $C_{s t d}^{k}=O_{s t d}$. The CC between the original series and the corrupted series at step 20 equals 0 . The residuals of series $C$ and $O$ represent correlation errors, and $\operatorname{corr}_{p}\left(C^{20}, O\right)=0$. The original series and the three corrupted series are provided in Table S1 in Supporting Information for Chapter 4.

\subsection{Results}

\subsubsection{Metric Sensitivity: How do error metrics behave under different error regimes?}

Comparing the corrupted series $B, V$, and $C$ with the original series $O$, Figures 4.2a-c show how the values of the three metrics degrade from their ideal value of 1 (step 0 ) under each 
error type. To further demonstrate the underlying mechanisms of the three error regimes, we also present the residuals for each error type and step (Figures $4.2 d-f$ ). For all error types, the original series remains uncorrupted at step 0 , and hence the residuals for all data points (dark purple dots on Figures $4.2 \mathrm{~d}$-f) are 0, i.e. $B^{0}=V^{0}=C^{0}=0$. Increasing the bias errors, enlarges the residuals homoscedastically (Figure $4.2 \mathrm{~d}$ ). That is, the magnitude of residuals increases while the variance of residuals remains constant; the zero slope of the linear lines highlighting the residuals at each step indicates this homoscedasticity. On the other hand, both variability and correlation errors generate heteroscedastic residuals (Figures 4.2e-f), but each exhibits a different type of heteroscedasticity. Variability errors lead to uniform (or linear) heteroscedasticity, indicated by a uniform increase in the slope of the highlighted lines in Figure 4.2e. Correlation errors, however, give rise to non-uniform (or non-linear) heteroscedasticity, indicated by a non-uniform expansion of the plain in which residuals lie (highlighted plains in Figure 4.2f). In short, bias errors are homoscedastic, variability errors are uniformly heteroscedastic, and correlation errors are non-uniformly heteroscedastic. It is worth mentioning that introducing correlation errors generates data points with negative values. While a negative flow is unrealistic, it does not matter for this particular sensitivity analysis.

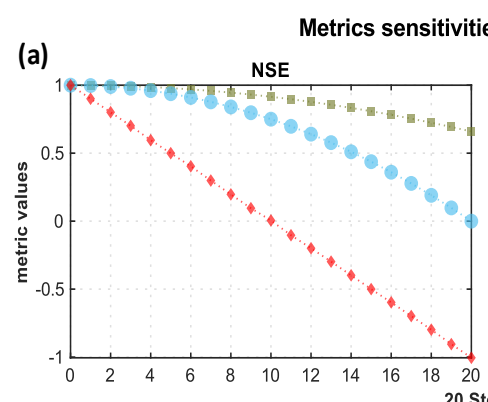

(b)

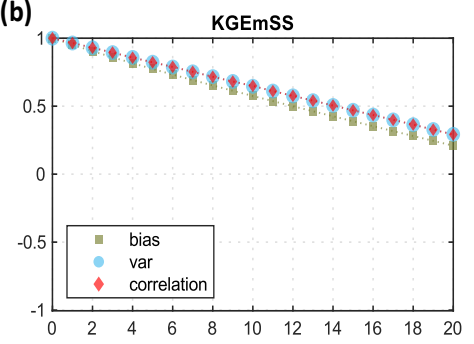

(e)

(d) Residuals after change in bias

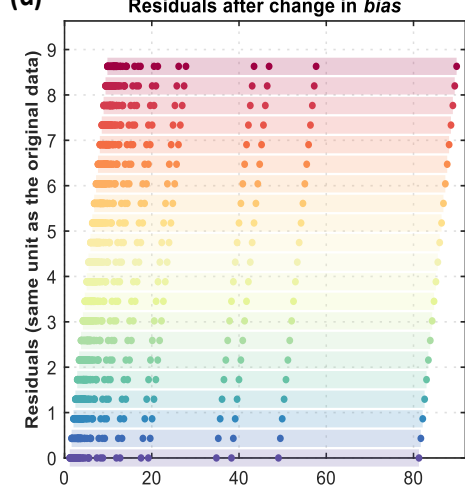

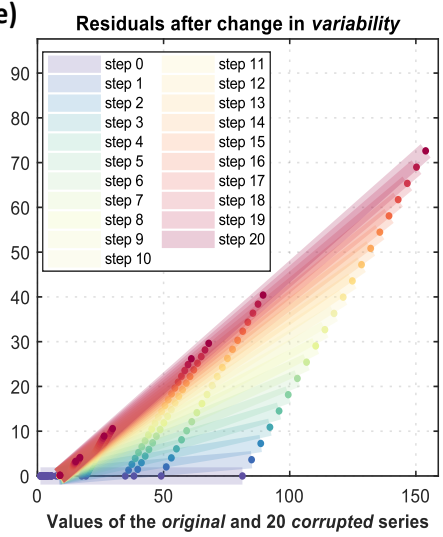

(c)

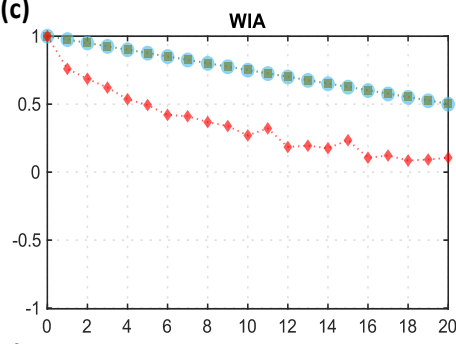

(f) Residuals after change in correlation

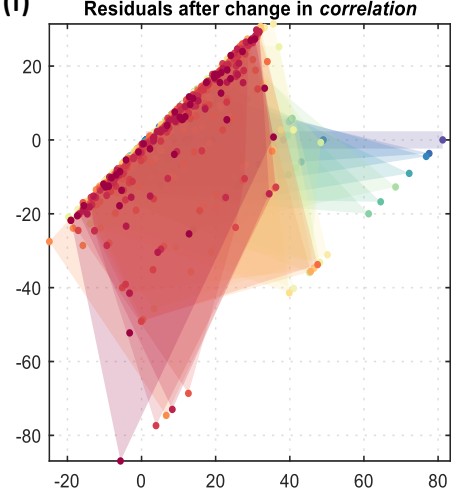

Figure 4.2. Sensitivity of efficiency metrics NSE, KGEss, and WIA in response to bias, variability, and correlation errors in $\mathbf{2 0}$ steps (a-c); the residuals of corrupted series for each error type and step (d-f). At step 0 , corrupted series equals the original series $\left(B^{0}=V^{0}=C^{0}=O\right)$. 
As shown in Figure 4.2a, NSE changes in a remarkably different way under the three error regimes, which arguably obscure the interpretability of NSE values. First, NSE exhibits varying degrees of sensitivity to different error regimes. At any given step, NSE is least sensitive to bias errors and most sensitive to correlation errors. The NSE's degradation line under bias errors (the line through green squares) has the smallest gradient of the three degradation lines. NSE values barely change for the first 5 steps, while KGEss and WIA values degrade more rapidly and linearly under bias errors. NSE is more sensitive to variability errors compared to bias errors, i.e. the degradation line of variability errors (the line through blue circles) has a steeper gradient. NSE is most sensitive to correlation errors as its degradation line under correlation errors (line through red diamonds) has the steepest slope between the three degradation lines. Due to this characteristic, for instance NSE $=0.80$ can almost equally represent bias errors at step 16, variability errors at step 10, or correlation errors at step 3. In other words, a high NSE value does not equally represent the magnitude of the different type of errors. An NSE of 0.8 could contain a high bias, a medium variability error, or a small correlation error. This unequal sensitivity to different error types makes interpreting errors via NSE unreliable.

Second, NSE is less sensitive to bias and variability errors at higher NSE values (i.e. smaller error magnitudes) than lower values. This is due to the exponential decay of degradation lines of bias and variability errors, unlike the linear degradation line for correlation errors. In other words, although the magnitude of error is consistent across the error regimes and all 20 steps, NSE degrades inconsistently from one step to another for bias and variability errors (although consistently for correlation errors). For instance, a decrease in NSE values from $1.00 \rightarrow 0.90$ corresponds to larger bias or variability errors, than a decrease from $0.60 \rightarrow$ 0.50. This characteristic obscures the interpretability and cross-comparison of NSE values across different ranges of itself. As we get closer to 1, it becomes harder to distinguish between models, whether comparing various model structures or parameter sets within a given model. Also, improving the performance of a given model, for example, from NSE: 0.50 $\rightarrow 0.60$ is not comparable to NSE: $0.70 \rightarrow 0.80$. Due to this characteristic, a model can be accepted falsely (i.e. a false positive error) based on higher NSE values despite non-trivial bias or variability errors. 
Third, comparing the three metrics, NSE is the least sensitive metric to bias errors and most sensitive to correlation errors at any given step (except for smaller correlation errors where WIA and NSE are not easily comparable due to irregular decay of WIA as shown on Figure 4.2c). This characteristic has important implications for cross comparing these metrics. While NSE may result in a high metric value despite relatively high bias errors, KGEss and WIA would yield lower values. On the other hand, NSE can generate lower values than KGEss and WIA under identical correlation errors. In other words, a model may be falsely rejected (i.e. a false negative error) because of lower NSE values due to NSE's over-sensitivity to correlation errors. While both KGEss and WIA consistently degrade under bias and variability errors, WIA degrades at a lower rate (compare the slopes of green squares and blue dots on Figures 4.2b-c). This implies that when comparing WIA and KGEss values under similar bias or variability errors, WIA will result in higher values due to its mathematical structure regardless of the actual performance of a model. The same comments apply to NSE and KGEss under correlation errors (compare the slopes of red diamonds in Figures 4.2a-b). So, using pre-determined metric values (despite recommendations such as NSE $=0.75$ implying good model performance (Moriasi et al., 2007)) or cross-comparing metric values is not a reliable approach for evaluating model performance or improvement. We further demonstrate in section 4.3.2 that model performance and error metric value do not necessarily correspond.

Due to these three characteristics, achieving high NSE values does not necessarily imply smaller residuals, and hence does not imply a good model structure or performance (i.e. a false positive error). It could simply be due to the insensitivity of NSE to bias or variability errors at higher NSE values. On the other hand, a lower NSE value does not necessarily indicate a poor model structure or performance, as it can be due to the higher sensitivity of NSE to correlation errors (i.e. a false negative). In other words, NSE is an unreliable metric to evaluate model structure and characterize the model performance because of the inconsistent sensitivity of NSE to different error types and magnitudes, which is due to its mathematical structure and independent of the model structure or performance. NSE values are a result of complicated interactions between multiple bias, variability, and correlation terms inherent to the NSE function (see the NSE decomposition by Murphy (1988) and Gupta et al. (2009)). The problematic interaction between these components of NSE 
motivated the development of KGE, within which bias, variability, and correlation errors are separately and systematically accounted for.

Given its mathematical structure, KGEss functions consistently across all magnitudes (i.e. steps) of the three error types (Figure 4.2b). In other words, KGEss is equally sensitive to bias, variability, and correlation errors. The small difference between the degradation lines of bias errors and the other two errors is due to the variability term of KGEss being based on the coefficient of variation, which is a function of both standard deviation and bias. So, while standard deviation was kept constant under bias errors, the coefficient of variation (the variability term of KGEss) changes due to change in bias. Similar to KGEss, WIA functions consistently for different magnitudes of bias and variability errors (Figure 4.2c). But unlike KGEss, its degradation has an irregular (and somewhat exponential) decay under correlation errors. Although similar to KGEss, WIA degradation lines are linear across the steps, and WIA is less sensitive to both bias and variability errors than KGEss. In other words, even a small change in the decimals of WIA value indicates a relatively larger error, compared with the other metrics. This is due to WIA's mathematical structure being bounded at -1 for lower values, compared to the lower bound of NSE and KGEss being $-\infty$. Such a narrow range of WIA values results in compact intervals and misleading interpretations if decimals are rounded. In this example, WIA $=0.75$ may correspond to almost $50 \%$ increase in bias errors $\left(e_{B}=\sim 1.5 \times O_{\text {mean }}\right)$, while KGEss $=0.75$ can be due to about $25 \%$ increase in bias errors. In summary, under the hypothetical conditions of this analysis: for similar bias errors, at each step NSE > WIA > KGEss; for smaller variability errors NSE > WIA > KGEss, and for larger variability errors WIA > KGEsS> NSE; for correlation errors KGEsS > WIA and KGEsS > NSE, whereas for higher correlation errors KGESS > WIA > NSE, and for smaller correlation errors WIA and NSE are not easily comparable due to the irregular decay of WIA. Metric values for the degenerate cases (i.e. step 20) under each error regime are presented in Table 4.2. As shown, KGEss is the most consistent metric in terms of its sensitivity to different error regimes. While it is hard to generalize particularly beyond these three error types, it can be inferred that there would be a more controlled trade-off between these error regimes under KGEss than the other metrics, which is due to its mathematical structure, and hence KGEss provides more reliable insights into model performance. That said, KGEss has its own limitations that we will discuss in section 4.4.1. Regardless of the limitations of error metrics, 
we argue that even a reliable error metric is not a sufficient condition for characterizing the model response.

Table 4.2. Metrics values for the degenerate cases (i.e. step 20) of each error type based on the original series mean $\left(O_{\text {mean }}\right)$, standard deviation $\left(O_{\text {std }}\right)$, and Pearson's correlation between the original and corrupted series at step $20\left(C C_{p}^{20}\right)$.

\begin{tabular}{llll}
\hline At step 20 & NSE & KGEss & WIA \\
\hline Bias errors $=O_{\text {mean }}$ & 0.66 & 0.21 & 0.50 \\
Variability errors $=2 \times O_{\text {std }}$ & 0.00 & 0.30 & 0.50 \\
Correlation errors: $C C_{p}^{20}=0$ & -1.00 & 0.30 & 0.11 \\
\hline
\end{tabular}

\subsubsection{What determine the model response?}

Here we demonstrate salient points of the interplay between model structure and parameterization, parameter sampling sufficiency, choice of error metric, and data information content. To this end, we conduct controlled experiments, i.e. varying one factor at a time while holding other factors constant (ceteris paribus assumption) to the extent possible, to disentangle the interplay of these factor. For each example, the model flux map is used to characterize the model response in terms of runoff generation. First (section 4.3.2.1), we examine the interplay of these factors for a single model SIMHYD, i.e. the model structure is unchanged. We then (section 4.3.2.2) examine the interplay of these factors considering both SIMHYD and SACRAMENTO, i.e. varying the model structure. For all examples the parameter sampling is controlled by using the same LHS parameter sets (1 M for SIMHYD and 1.2 M for SACRAMENTO) for all modelling experiments. For each catchment the data information content is controlled, i.e. the hydrological data (period, resolution, etc.) are the same. Details of each experiment are described accordingly.

\subsubsection{Model response based on a single model structure}

Figure 4.3 shows 9 different modeling examples: flux maps for 3 different catchments (each row) using SIMHYD with 3 error metrics (each column). For these 9 examples parameter sampling is considered sufficient as | Ensemble-HMV - SCE-HMV | $\leq 0.01$. So, the HMV is within \pm 0.01 of the upper bound value of the color bar. For all examples the acceptability threshold is $H M V-0.10$ (lower bound value of the color bar), and the model structure and parameterization is controlled i.e. SIMHYD with the same 1 M LHS parameter sets. For each 
row the data information content is also controlled (i.e. same catchment) and only the error metric varies, while for each column the error metric is controlled and the data information content across the three catchments varies. As shown on each row, for a given catchment and model parameterization, the choice of error metric can change the flux map in some examples (Figures 4.3a-c and 4.3d-f), while in some examples the choice of error metric is not as important (Figures 4.3h and 4.3i). On the other hand, the flux maps for two given catchments (\#2 and \#3) can be very different for some error metrics (NSE as in Figures 4.3d and $4.3 \mathrm{~g}$, and KGEss as in Figures 4.3e and 4.3h) and quite similar for another metric (WIA, as in Figures $4.3 f$ and $4.3 i)$. In other words, the interplay between the error metric and data information content for a given model structure and parameterization, can radically change the model response and hence the model's representation of runoff generation. So, when models are used to formulate hypotheses about catchment response, the hydrological (dis)similarity between two catchments can be radically changed by the choice of error metric - even under the same model structure and parameterization with sufficient parameter sampling.

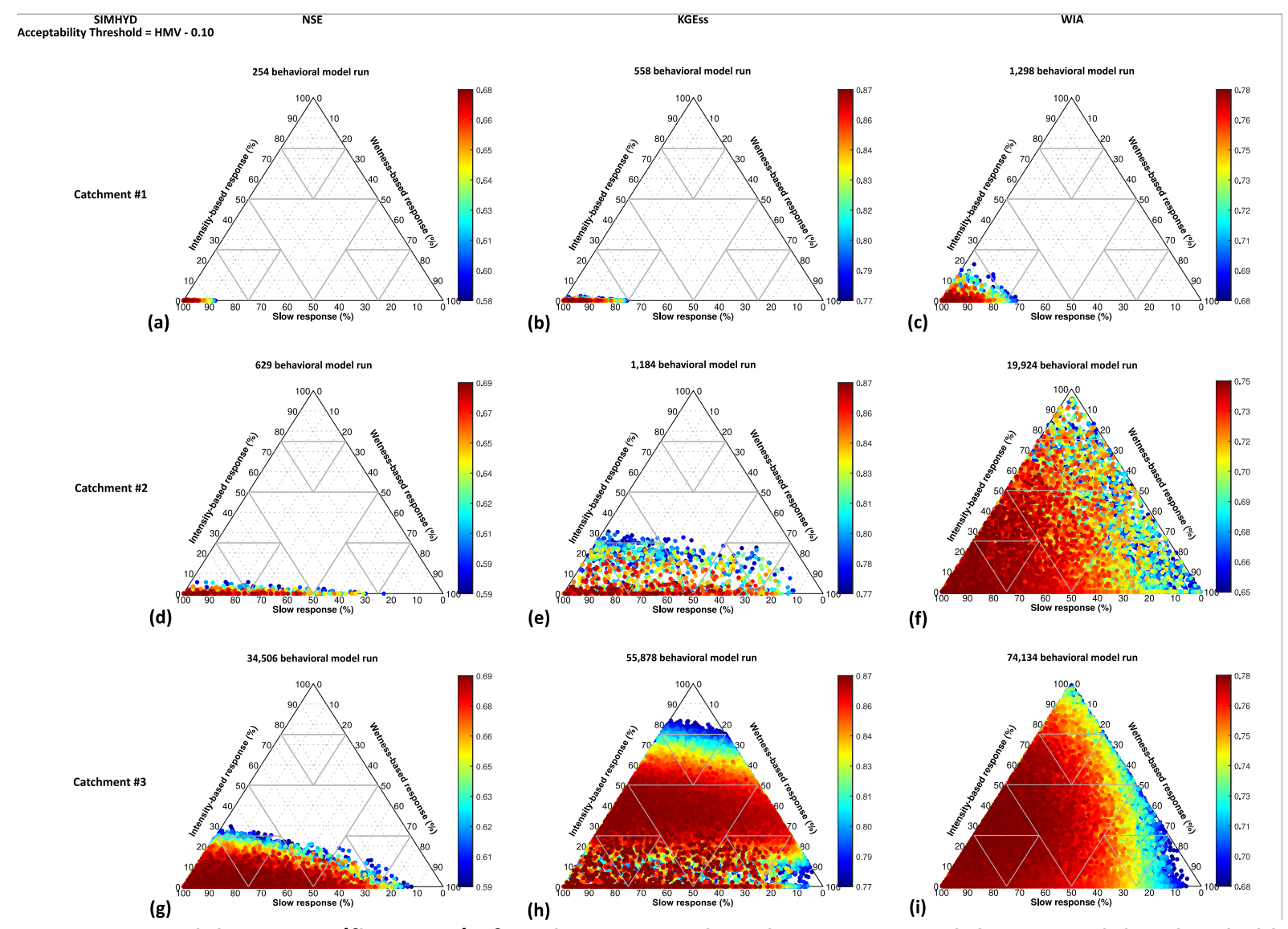

Figure 4.3. Model response (flux maps) of catchments \#1-3 based on SIMHYD and the acceptability threshold of $\mathrm{HMV}-\mathbf{0 . 1 0}$ for all error metrics. For all modeling examples parameter sampling is considered sufficient. 
Given the behavior of error metrics at different intervals of their values (established in section 4.3.1), a given threshold would lead to a different number of acceptable runs under each error metric. Yet, as we discussed before (Khatami et al., 2019), the point cloud pattern of a flux map - and hence the model response - is not strictly dependent upon the number of acceptable model runs. The three examples of Figures $4.3 \mathrm{f}, 4.3 \mathrm{~h}$ and $4.3 \mathrm{i}$ are space-filled flux maps with varying acceptable ensemble sizes from $\sim 20,000$ to $\sim 74,000$ model runs. A flux map can be space-filled with fewer acceptable model runs (Figure 4.3f, 20,000 model runs), while another flux map can be constrained with more acceptable runs (Figure 4.3g, $\sim 35,000$ model runs).

In a different set of experiments (Figure 4.4) we gradually relax the acceptability threshold across the three metrics, under a ceteris paribus assumption (the catchment (\#4), model structure and parameterization are unchanged). For each error metric (each column in Figure 4.4), the HMV is determined (HMV = $\max \{$ Ensemble-HMV, SCE-HMV $\})$, and the acceptability threshold relaxes in three steps from HMV - 0.03 to HMV -0.06 and HMV 0.09. As shown in Figure 4.4, the choice of error metric - even when other factors remain constant - can change the sampling sufficiency, which in turn can impact the flux map. For NSE ( $1^{\text {st }}$ column in Figure 4.4), the 1 million LHS parameter sets are not sufficient as SCE-NSE - Ensemble-NSE $\approx 0.03$; while for KGEss ( $2^{\text {nd }}$ column in Figure 4.4) the SCE guided search is inadequate as Ensemble-KGEss - SCE-KGEss $\approx 0.02$. So, for NSE the guided search and for KGEss the LHS was the better sampling approach for finding parameter sets with the highest metric values. The sampling sufficiency is considered sufficient for WIA ( $3^{\text {rd }}$ column in Figure 4.4), which is at least partly due to compact intervals of WIA values as this metric is bounded (as explained in section 4.3.1). For the strict threshold ( $1^{\text {st }}$ row in Figure 4.4), no model run is accepted under NSE (Figure 4.4a), whereas there are acceptable model runs under both KGEss and WIA (Figures 4.4b-c) but with different flux maps. So, given the choice of error metric, a set of LHS parameter sets not only may be (in)sufficient even for a model with only 7 parameters, but also can generate similar or distinct runoff generation hypotheses regardless of the sampling sufficiency. Given the degree of sampling insufficiency, all model runs may be rejected (i.e. no working hypotheses); not because of model structural inadequacy, but because of sampling insufficiency due to the choice of error metric (all other factors being held constant). 


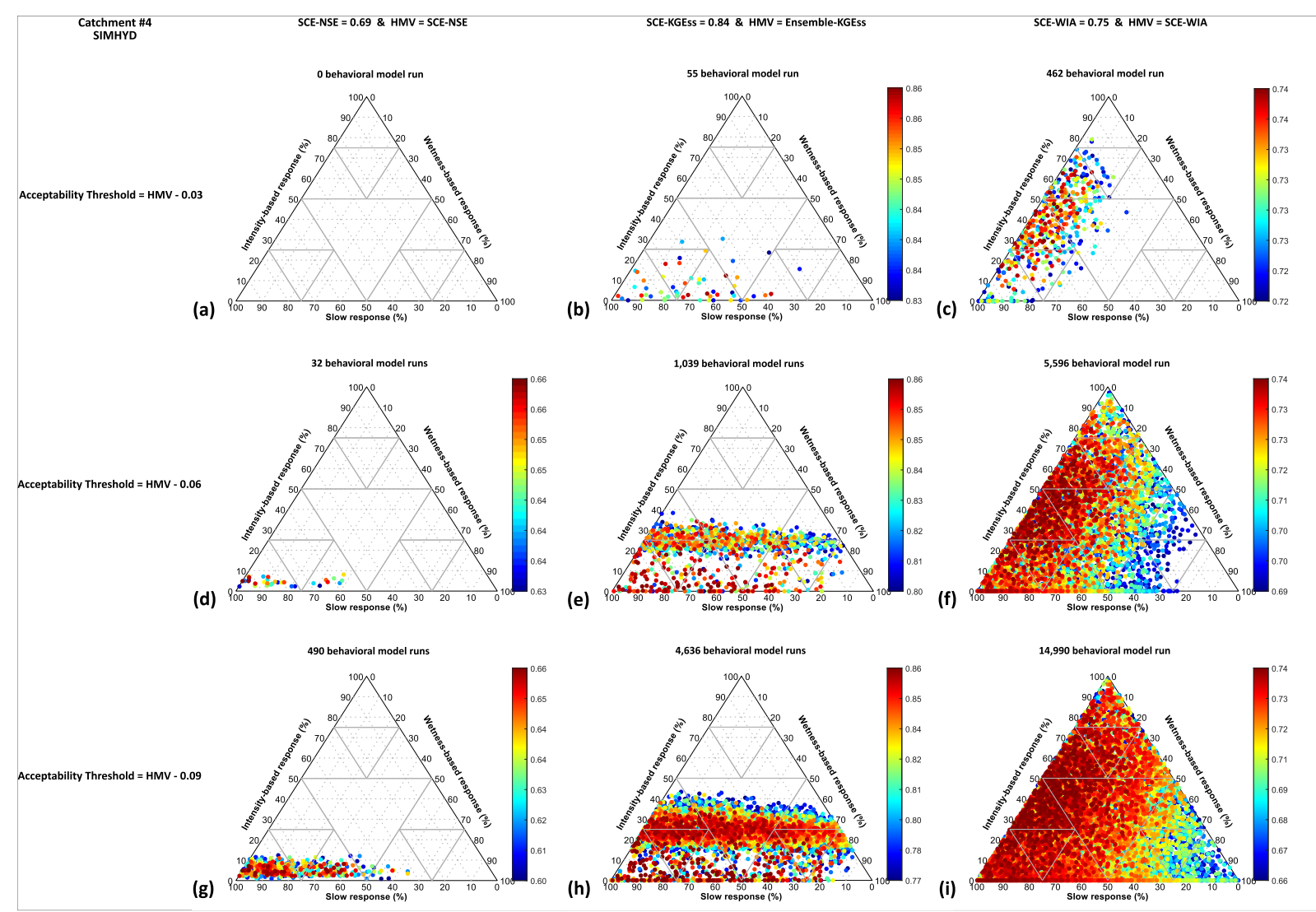

Figure 4.4. Model response (flux maps) of catchment \#4 based on SIMHYD for the three error metrics (each column) with varying acceptability threshold (each row). Sampling sufficiency changes based on the choice of error metric: it is considered as sufficient for WIA, but insufficient for NSE and KGEss. For each error metric, HMV signals which parameter sampling (SCE or ensemble) was better i.e. found a parameter set with the highest metric value.

\subsubsection{Model response based on multiple model structures}

All the six modeling examples presented in Figure 4.5 are sufficiently sampled. The metric values for SIMHYD and SACRAMENTO are relatively similar under each error metric, yet the SIMHYD flux map is remarkably different from its corresponding SACRAMENTO flux map. For all error metrics, the SACRAMENTO intensity-based response is almost similarly constrained around $25 \%$ (Figures $4.5 \mathrm{~d}-\mathrm{f}$ ). This is due to the fact that the intensity-based response in SACRAMENTO is determined as a fixed portion of the input rainfall by a constant parameter value, and hence there is not a wide range of variability for this flux. In SIMHYD, however, the runoff fluxes can interact widely. For SIMHYD each error metric gives rise to a different set of runoff generating hypotheses under the same model parameterization with sufficient parameter sampling (Figure 4.5a-c). For SACRAMENTO, on the other hand, the flux maps under the three error metrics are quite similar. For almost identical model performance under KGESS, SACRAMENTO gave rise to mostly wetness-dominated and slow response 
hypotheses, while SIMHYD resulted in a space-filled flux map i.e. any combination of model runoff fluxes is plausible to simulate the catchment response. So, while SIMHYD is a simpler model (smaller number of parameters, store, and fluxes), it exhibits a wider range of runoff generation hypotheses for catchment \#5 even within a narrow range of (high) KGEss values.

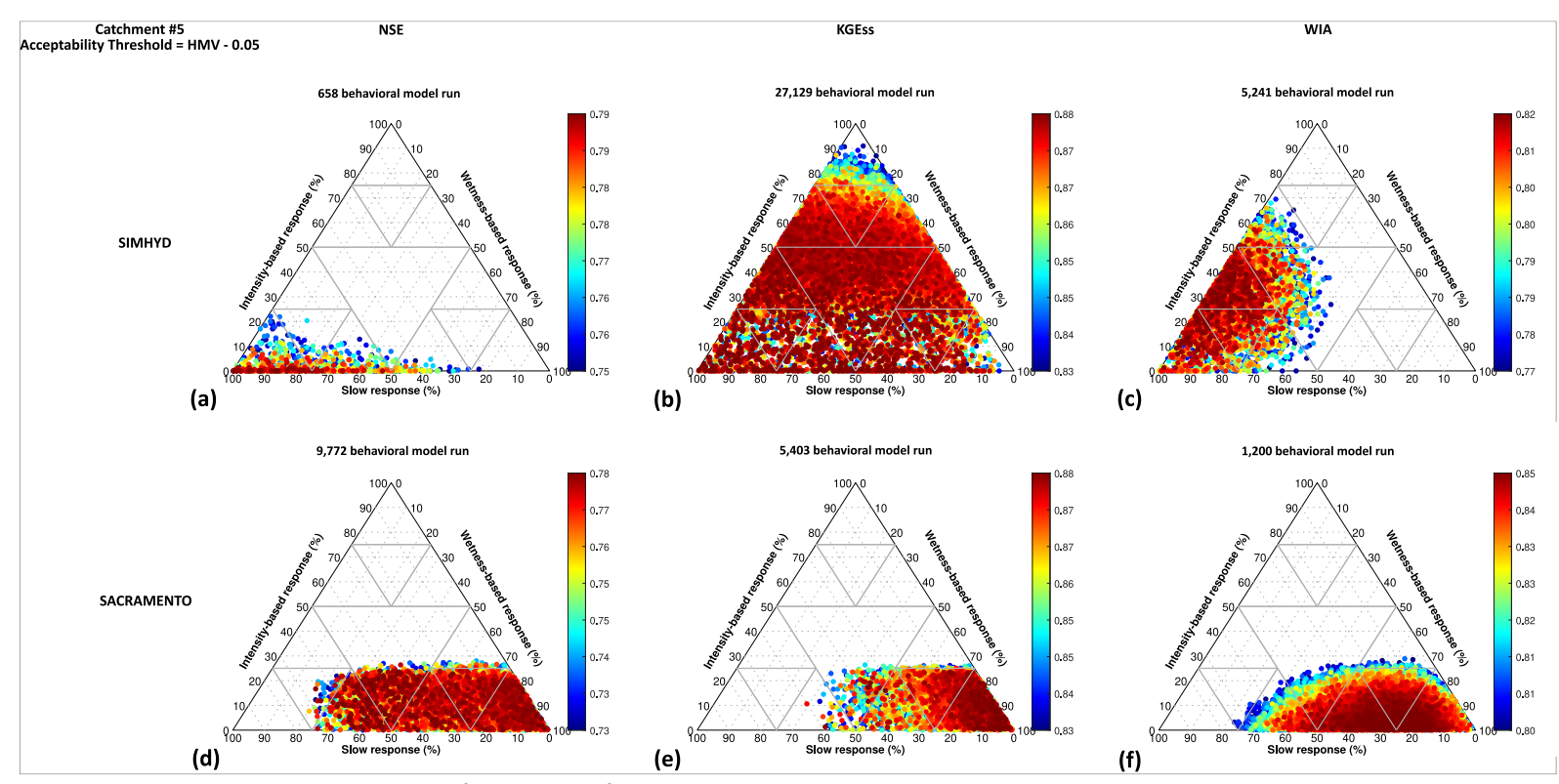

Figure 4.5. Model response (flux maps) of catchment \#5 based on SIMHYD and SACRAMENTO, and the acceptability threshold of HMV $-\mathbf{0 . 0 5}$ for all error metrics. For all modeling examples parameter sampling is considered sufficient.

Although the 1.2 million SACRAMENTO LHS parameter sets were sufficient for catchment \#5 under all error metrics (Figure 4.5d-f), they are insufficient for catchment \#6 under NSE and KGEss (Figure 4.6d-e). This sampling insufficiency undermines both (A) model performance and (B) process representation. For catchment \#6 and KGEss (Figures 4.6b and 6e): (A) the LHS ensemble misleadingly indicates a big difference between the performance of these two model structures (Ensemble-KGEsS ${ }^{\text {SIMHYD }}=0.80$ and Ensemble-KGEss ${ }^{\text {SACRAMENTO }}=0.69$ ), against the SCE guided search indicating a relatively similar performance (SCE-KGESS ${ }^{\text {SIMHYD }}=$ 0.81 and SCE-KGESSSACRAMENTO $=0.77$ ). (B) Sampling insufficiency deflates the number of acceptable model runs under KGEss (only 4 even for a relaxed threshold, Figure 4.6e) resulting in a deficient flux map. 


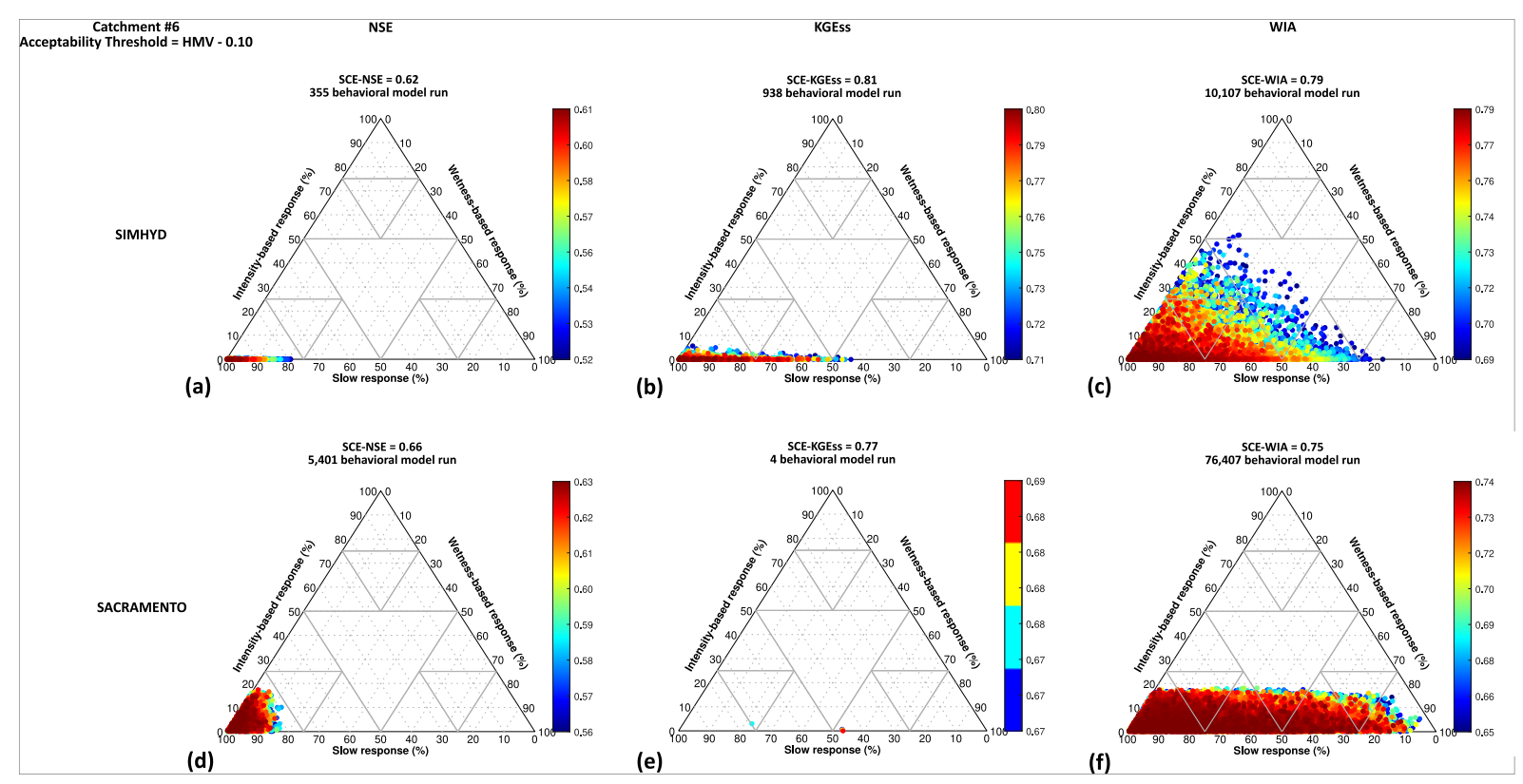

Figure 4.6. Model response (flux maps) of catchment \#6 based on SIMHYD and SACRAMENTO, and the acceptability threshold of HMV $\mathbf{- 0 . 1 0}$ for all error metrics. While for all SIMHYD examples parameter sampling is sufficient, it is not sufficient for SACRAMENTO under NSE and KGEss.

In catchment \#6 and irrespective of sampling strategy, NSE suggests a better performance of SACRAMENTO in this catchment, while KGEss favors SIMHYD. That said, both models have equally high performance for catchment \#7 under KGEss (KGEss = 0.92, Figures 4.7b and 7e) with sufficient parameter sampling. In a case like catchment \#7, we can reliably compare the model structures and their processes representation (model flux maps) to formulate MWH about catchment response; because other factors are adequately checked i.e. equally high model performance and sufficient parameter sampling for a reliable error metric (KGEss) across all model structures. For catchment \#7 and KGEss, the main distinction between these two models is that SIMHYD flux map indicates a catchment response with no significant intensity-based runoff generation, while SACRAMENTO suggests intensity-based response as large as $40 \%$ of the total flow. Such competing hypotheses can further be evaluated using additional data/knowledge about the catchment response. 


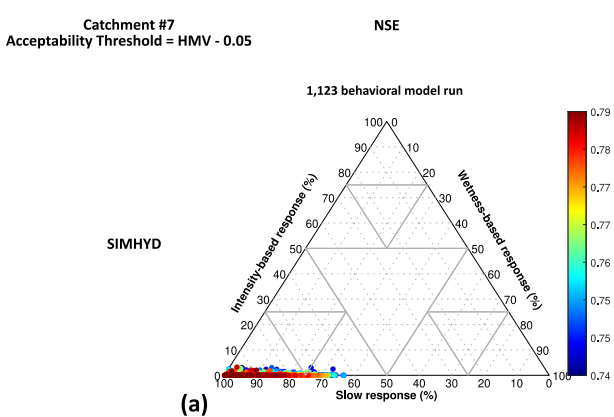

(a)

(b)
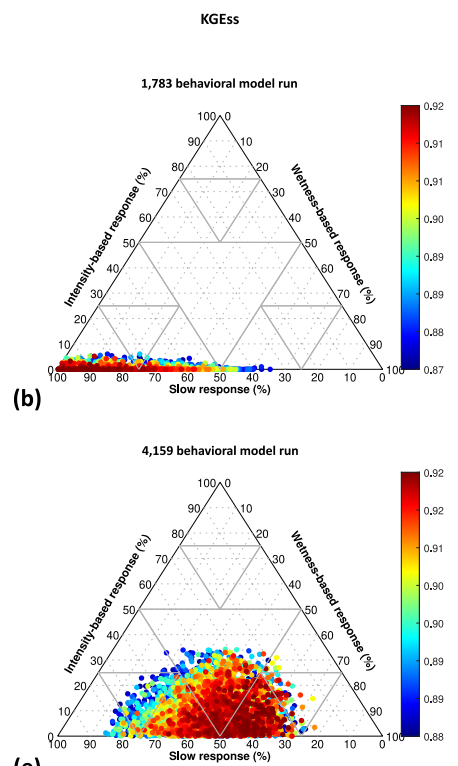

(d)

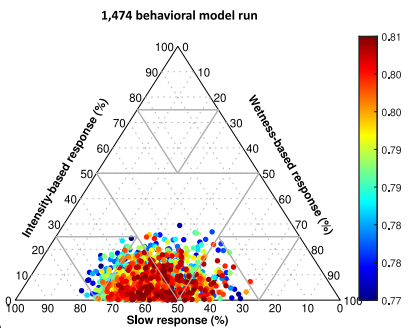

(e)

(c)
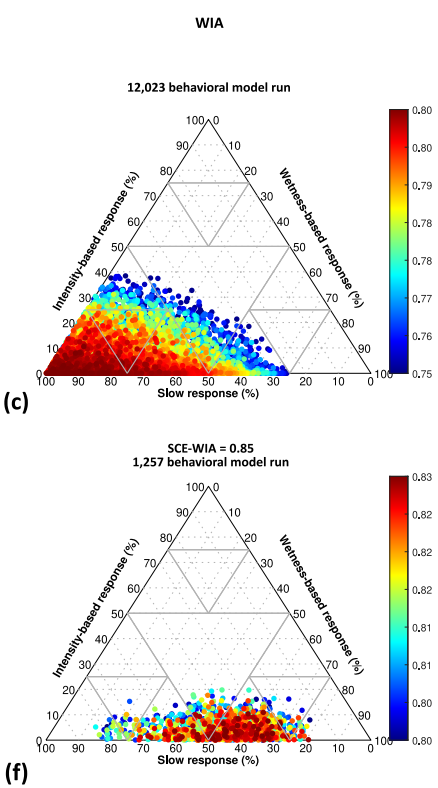

(f)

Figure 4.7. Model response (flux maps) of catchment \#7 based on SIMHYD and SACRAMENTO, and the acceptability threshold of HMV - 0.05 for all error metrics. Parameter sampling is only insufficient under WIA and SACRAMENTO.

Based on analyzing 221 Australian catchments, we could not derive any systematic relationship between the error metric, number of acceptable model runs, sampling sufficiency, and size/type of the flux map point cloud across these two model structures (results not presented here). Examples of the range of interplay between these factors have been presented in Figures 4.3-4.7, from which we note some features. Firstly, Figures 4.3-4.4 shows that for a given error metric and under sufficient sampling, the flux map is independent of the HMV (i.e. model performance), acceptability threshold, or number of acceptable runs (also see Khatami et al., 2019). Secondly, the number of acceptable model runs is independent of the choice of error metric. Given that WIA intervals are very compact (bounded between +1 and -1 ), a certain range of WIA values can represent relatively larger errors and hence result in a higher number of acceptable model runs compared with NSE and KGEss; that said, this characteristic of WIA can be cancelled out by other factors and thus lead to a smaller number of acceptable model runs (e.g. compare Figures 4.5 and 4.7). The same comment applies to the impact of WIA on the size of the flux map point cloud (e.g. compare Figures $4.3 \mathrm{i}$ and $4.7 \mathrm{f}$ with comparable acceptable runs but different catchments and model structures). Thirdly, the number of acceptable runs is also not a function of the model structure, i.e. higher model dimensionality does not necessarily imply more flexibility in the model space and hence does not lead to more acceptable runs. With similar metric 
values, SIMHYD under KGEss (Figure 4.5b) has about five times more acceptable runs than its corresponding SACRAMENTO example (Figure 4.5e) (also compare Figures $4.5 \mathrm{~d}$-f and $4.6 \mathrm{~d}$-f for SACRAMENTO flux maps of two catchments under different acceptability thresholds, sampling sufficiency, number of acceptable model runs across the three metrics).

\subsection{Discussion: evaluating catchment models as hypotheses under uncertainty}

The model output and hence the generated $\mathrm{MWH}$ are the result of an interplay between model structure and parameterization, parameter sampling sufficiency, error metric, and data information content. As shown in section 4.3, this interplay is complex and unique to each case. That said, each factor can be controlled/improved to enhance model evaluation and hypotheses formulation. We further discuss a few points about each factor:

\subsubsection{On the role of error metrics}

A robust error metric is a necessary condition for reliable model evaluation. We conducted a one-at-a-time sensitivity analysis on the metrics NSE, KGEss, and WIA to characterize their behavior under well-defined error regimes, independent of any modeling. Willmott et al. (2015) opined that the interpretation of WIA is often more straightforward than NSE, and our sensitivity analysis is consistent with this: unlike NSE, WIA behaves consistently under bias and variability errors (Figures $4.2 \mathrm{a}$ and $4.2 \mathrm{c}$ ). That said, we demonstrated that WIA's behavior hinders its interpretation in at least three ways: (a) WIA is more sensitive to correlation errors than bias and variability errors, (b) WIA's sensitivity to correlation errors is inconsistent across different intervals of WIA values, and (c) WIA intervals are very compact as it is bounded by \pm 1 , hence WIA values degrade at a slower rate. We further discuss three major points about using error metrics for characterizing model performance:

(i) NSE is a misleading error metric and the modeling community should abandon it. There are perceptions about the meaning of NSE values, e.g. NSE $\geq 0.5$ indicates acceptable model performance (Davtalab et al., 2017; Moriasi et al., 2007) or acceptable parameter sets (Freer et al., 1996; Lane et al., 2019), the NSE = 0.6 as a threshold for acceptable model runs (Choi \& Beven, 2007), NSE $\geq 0.75$ indicates good model performance (Moriasi et al., 2007), etc. Despite such widespread perceptions and based on a systematic sensitivity analysis of the 
NSE function, we demonstrated that NSE does not consistently represent different error types and magnitudes (Figure 4.2a and Table 4.2). As discussed, evaluating model performance based on higher NSE values may lead to false positives (e.g. accepting model runs and parameter sets despite large bias errors under-represented by higher NSE), or false negatives due to lower NSE values (e.g. rejecting models with small correlation errors exaggerated by NSE). Therefore, NSE is an unreliable metric to assess model prediction accuracy, benchmark model performance, or search the model solution space. From a process representation standpoint, given that NSE penalizes error regimes inconsistently, the solution space constructed based on NSE is unreliable due to its mathematical structure, even for a sufficient/representative parameter sample, regardless of data information content and the competence of the model structure. Shortcomings are inherent to models, and subjective decisions are inherent to various modeling decisions (Melsen et al., 2019; Moallemi et al., 2020a; Zare et al., 2020), including the choice of error metrics. That said, modelers can make better decisions. We believe that our study provides further evidence that NSE is inherently defective for model evaluation, and modelers and practitioners should instead use more reliable metrics such as KGEss, and ultimately aim to develop even better metrics.

(ii) Cross-comparing error metrics is inherently problematic. Error metrics behave differently under a given error type/magnitude due to differences in mathematical structure (Figures 4.2a-c and Table 4.2). So, it is inherently inappropriate to cross compare the values of different error metrics, unless their values are standardized to be compatible. For example, supposing that parameter set $A$ gives NSE $=0.7$, and parameter set $B$ gives KGEss $=0.60$ for a given model, can we infer that the model performs better using parameter set $A$ ? No. We can only cross compare A and B when they are both assessed with the same error metric. The same point also applies to cross comparison of various model structures using different error metrics.

(iii) KGEss is a better metric than NSE and WIA, but it is not without its own flaws. KGEss unlike the other two metrics - responds consistently to at least three types of bias, variability, and correlation errors. So, KGEss values can be interpreted more judiciously, and we recommend using KGEss for single-metric evaluations. Furthermore, if parameter space is sufficiently sampled, the model solution space (i.e. acceptable parameter sets) and 
hypothesis space (e.g. runoff generation flux maps) derived based on KGEss are relatively more reliable, as they are at least independent of how KGEss behaves under different error types and magnitudes. However, the interaction between error terms within KGEss is not apparent in its final value. For instance, KGEss $=0.8$ could equally be the result of various combinations of error terms e.g. with smaller or larger bias terms (a type of modelequifinality, see details in Khatami et al. (2019)). Yet, the tradeoff of the three error terms is relatively restrained/controlled under the mathematical structure of KGEss.

A major limitation of KGEss is that it does not explicitly account for the heteroscedasticity of model residuals, which is a general issue with almost all error metrics. Residual heteroscedasticity implies modeling inadequacy (i.e. potential to improve modeling setup), because there is information in the residuals (rather than residuals of random errors) that is not captured by the model structure and parameterization. This can be due to a combination of model structure and parameterization, error metrics, parameter sampling (in)sufficiency, and the fact that data themselves are not error free and their errors may propagate to the model outputs. While the issue of heteroscedasticity is long recognized (Sorooshian \& Dracup, 1980), it is not explicitly accounted for in KGE nor WIA (or other metrics based on absolute error (Legates \& McCabe, 1999)). Despite numerous reviews and comparisons of error metrics (Bennett et al., 2013; Crochemore et al., 2015; Gueymard, 2014; Krause et al., 2005; Moriasi et al., 2007), it is not clear what role the mathematical structure of error metrics particularly play in giving rise to heteroscedastic residuals. Two general approaches to address residual heteroscedasticity have been studied. (i) To indirectly account for heteroscedasticity by transforming flow series using transformations (Mclnerney et al., 2017) such as Box-Cox (Box \& Cox, 1964; Yeo \& Johnson, 2000), inverse function (Pushpalatha et al., 2012), or $n^{\text {th }}$ root functions (Chiew et al., 1993; Chiew et al., 1995), to put more emphasis on low flows and hence harness the heteroscedasticity of model residuals. While inverse function offers some improvements, particularly better results than logarithmic transformations, it has its own limitations (e.g. when flows become close to zero) for the estimation of the water balance, physical interpretation of error terms, and model calibration (Santos et al., 2018). (ii) There are also approaches to directly account for heteroscedasticity, which also have their own limitations. For example, Evin et al. (2014) 
proposed postprocessing model parameters for heteroscedasticity and autocorrelation but their approach works poorly in ephemeral catchments.

Given the above, there is room to further improve KGEss by developing a new error term to account for residuals heteroscedasticity or develop new error metrics, which is an important theoretical quest with significant practical implications for practitioners. In doing so, a few points should be considered:

- Redundant error terms should not be embedded in an error metric.

- Error metric should function consistently across different error types/magnitudes.

- Error metric should behave consistently across different periods of high and low flows.

- There is no ultimate metric, no matter how elegant a metric would be, it can only characterize certain (and not all) aspects of model-observation (dis)similarity. Therefore, it is essential to only use/interpret metrics that are fit for purpose.

\subsubsection{On the role of model structure and process representation}

In addition to error metric, model structure also influence the runoff generation hypotheses. For instance, as shown in Figures $4.5 \mathrm{~d}$-f, the intensity-based response of SACRAMENTO is similar across the three error metrics; while SIMHYD (Figures 4.5a-c) results in distinct flux maps and varying degrees of intensity-based response for each error metric. Because the partitioning of input rainfall into intensity-based runoff flux is determined by a constant model parameter in SACRAMENTO. That is, the SACRAMENTO model structure constrains the intensity-based runoff generation in these cases. That said, Figures 4 .7e-f show that SACRAMENTO results in different flux maps, with almost twice as much intensity-based response under KGEss than WIA, in a different catchment. Whereas, SIMHYD allows for four times as much intensity-based response under WIA than KGEss, in the same catchment. So, the model structure plays a role in how model fluxes, and hence hypothesis of catchment processes, are allowed to behave for a given catchment and error metric. Undoubtedly, the representation of runoff generation mechanisms in these hydrological models are simplifications of real-world processes. Runoff generation varies in time (e.g. due to seasonality or land-use changes) and space (due to catchment heterogeneity), and often a mix of these processes causes runoff (Saffarpour et al., 2016). Particularly as we are using lumped daily models treating a catchment as a single spatial unit, heterogeneity and sub- 
daily variations of these processes are overlooked and aggregated into daily catchment averages. Despite such simplifications and other sources/types of modeling uncertainties, a conceptual model and its internal dynamics can still be indicative of different (dominant) catchment processes (Dunn et al., 2008; Guo et al., 2017; Lerat et al., 2012). Given that processes such as runoff generation are incorporated into conceptual models at least partly with the aim of improving realism, thus these internal components should be evaluated in addition to the final model output.

Use of process-based models for evaluating runoff generation mechanisms has been previously studied. For example, Grayson et al. (1992) compared the representation of different runoff generation mechanisms in a process-based model across a few Australian and north American catchments. Buchanan et al. (2018) characterized the predominance of infiltration-excess and saturation-excess runoff across the contiguous United States. With flux mapping, we formalize a hypothesis space based on different modes of model runoff fluxes (Khatami et al., 2019), that is useful for formulating and comparing MWH for runoff generation (catchment response) across different catchments, periods, and model structures. Treating models as hypotheses, modeling would be a learning activity to formulate alternative/competing hypotheses. Testing hypotheses against catchment behavior and attributes using field data (Clark et al., 2011b; Seibert \& McDonnell, 2002; Winsemius et al., 2009) is the avenue towards evaluating the plausibility of these hypotheses, and to further improving model realism (Gharari et al., 2014; Hrachowitz et al., 2014; Wagener, 2003).

\subsubsection{On the role of parameter sampling sufficiency}

Sufficient parameter sampling is a necessary condition for reliable evaluation of models as $M W H$. Sampling insufficiency undermines both model performance and process representation, as demonstrated in the results (Figures 4.4, 4.6 and 4.7). A representative sample of the parameter space can be achieved either by guided search routines and/or large random samples. While we acknowledge that various methods have been developed to sample the parameters more effectively and efficiently (Asadzadeh \& Tolson, 2013; Sheikholeslami \& Razavi, 2017; Tolson \& Shoemaker, 2007; Vrugt \& Beven, 2018), we adopted two of the most widely used sampling strategies in hydrological modeling: large LHS 
to sample the parameter space and SCE to benchmark the solution space. We compared these two strategies against one another in each modeling case, i.e. compare \{ EnsembleHMV, SCE-HMV \}, as a test of relative sampling sufficiency.

An overview of our results across all 221 catchments show that large samples of parameter space were better only in $4 \%$ (or less) of cases (compare row 1 and 2 of Table 4.3), than the SCE search. This implies that it is a better approach to search the model solution space to either sample behavioral/acceptable parameter sets or benchmark the model performance. A geometry-based strategy like LHS aims to sample different regions of the parameter space more evenly than a random sample, yet LHS samples may even fail to be geometrically representative due to their inherent randomness (Goel et al., 2008), let alone sufficient for the model solution space (Tolson \& Shoemaker, 2008). Relying on large samples of the parameter space, without considering the model solution space, is a major source of uncertainty for model evaluation and hypothesis formulation. Particularly, for higher model dimensionality (SACRAMENTO), the risk of relying only on large samples of the parameter space increases (the percentage of equal cases drops, e.g. from $52 \%$ to $34 \%$ for KGEss, Table 4.3). It is worth mentioning that in addition to model performance, WIA also obscures the evaluation of sampling sufficiency due to its compact intervals.

Table 4.3. The percentage of catchment models (out of 221 catchments) that were sufficiently sampled with a given sampling method relative to the other one. The criteria for relative sampling superiority is EnsembleHMV - SCE-HMV > 0.01 .

\begin{tabular}{lccc|ccc}
\hline \multirow{2}{*}{ Sampling strategy } & \multicolumn{3}{c|}{ SIMHYD } & \multicolumn{3}{c}{ SACRAMENTO } \\
\cline { 2 - 7 } & NSE & KGEss & WIA & NSE & KGEss & WIA \\
\hline LHS ensemble of parameter space & $4 \%$ & $4 \%$ & $0 \%$ & $3 \%$ & $4 \%$ & $1 \%$ \\
\hline SCE search of solution space & $62 \%$ & $44 \%$ & $13 \%$ & $74 \%$ & $62 \%$ & $49 \%$ \\
\hline Both are equal (by a 0.01 margin) & $34 \%$ & $52 \%$ & $87 \%$ & $23 \%$ & $34 \%$ & $50 \%$ \\
\hline
\end{tabular}

Inadequate sampling can lead to missing some plausible model runs, under-utilizing the model structure, and hence under-representation of MWH (e.g. Figures 4.4a, 4.4b, and 4.6e). This is important in large-sample studies as a particular ensemble of parameter sets, regardless of the sampling strategy, may be insufficient in some modeling cases; thus impacting the conclusions based on modelling results. It is also necessary to jointly evaluate 
the sampling sufficiency on both parameter and solution spaces for diagnostic evaluation of model failure in hypothesis testing and rejection based on models.

For instance, Hollaway et al. (2018) recently reported that given some limits of acceptability, no acceptable model run was found to simulate phosphorus load within a uniform random sample of 5 million sets for the SWAT model (based on 39 parameters). They concluded that the SWAT model structure is to be rejected as not fit-for-purpose. They primarily focused on the role of data information content, i.e. uncertainty in the calibration data, within the limits of acceptability approach. While the role of data uncertainty is undeniably crucial in model evaluation, they did not consider the role of parameter sampling sufficiency: (1) Is 5 million random parameter sets sufficient, just by the virtue of sample size, for sampling such a high dimensional parameter space? (2) Is the sampled set sufficient for the model solution space? It is therefore an open question whether or not a more adequate parameter sample would have avoided the model rejection and yielded some $\mathrm{MWH}$ in that study. One solution is to combine the best of the two worlds: to increase the LHS size sequentially, e.g. using Progressive LHS method (Sheikholeslami \& Razavi, 2017), while comparing each sequence against a solution space benchmark.

\subsubsection{On the limitations of this study and future directions}

We acknowledge that in our sensitivity experiment (section 4.3.1) we introduced idealized errors, while in real-world cases errors could be more complex in nature. Streamflow data are uncertain (McMahon \& Peel, 2019; McMillan et al., 2018; Westerberg et al., 2011) and may encompass different epistemic errors and disinformative periods (Beven et al., 2011; Beven \& Westerberg, 2011), with complex interactions with each other and other factors involved in model behavior. That said, here we performed sensitivity analysis under ideal conditions to understand the function of each error metric independent of the quality of the data and the model structure. It would also be interesting to further understand the function of error metrics under common errors in hydrological residuals such as autocorrelation and heteroscedasticity errors.

We used the overall mean of the observed streamflow as the benchmark inherent in the error metrics, while it is a minimal benchmark (Schaefli \& Gupta, 2007). We also did not differentiate between different periods in the data in terms of their information content or 
quality, nor consider the temporal dynamics of runoff generation. Future studies could look further into the dynamics of runoff generation across different seasons or multi-year periods with different characteristics. It would also be interesting to further study the correspondence between flux maps, i.e. dominant modes of model response, and catchment characteristics and attributes to further evaluate the plausibility of flux maps.

Here we evaluated catchment models as hypotheses based on three distinct modes of runoff generation embedded in model structures. Other internal components of process-based models such as evapotranspiration and soil moisture could also be evaluated. Characterizing and evaluating the internal model fluxes provides an avenue to evaluate model processrepresentation, diagnose model structural shortcomings, and ultimately improve processbased models.

We defined a sampling as insufficient if | Ensemble-HMV - SCE-HMV | > 0.01, i.e. based on the value of error metrics. While this can be seen as a test for sampling insufficiency, we emphasized that we cannot be certain about the adequacy of a sample based on this test. We chose the SCE guided search as it is widely used in Earth and environmental modeling. There are other methods that are shown to be more effective and efficient (Arsenault et al., 2013). While we certainly agree to embrace sampling efficiency (Tolson \& Shoemaker, 2008; Vrugt \& Beven, 2018), we further argue for embracing the uniqueness of the model response (and $\mathrm{MWH}$ ), particularly in studies with large samples of catchments, models, and objective functions. Therefore, no matter how robust a search algorithm works under different numerical experiments, the parameter sampling sufficiency should also be evaluated for each modeling case given the choice of error metric and forcing data.

\subsection{Conclusion}

Here we demonstrated that model response is the result of a complex interplay between factors of model structure and parameterization, parameter sampling sufficiency, choice of error metric, and data information content. This interplay is unique to the underlying assumptions and conditions of each modeling case, and variations in each factor can remarkably change the model response. We argued that a hypothesis space can be constructed based on model internal (runoff generating) fluxes, that could be used to characterize and compare process-representation of different models under different 
assumptions. We demonstrated that deficient error metrics and insufficient parameter sampling undermine both model performance and process representation (model-based hypotheses). Conducting sensitivity analysis on the mathematical structure of three widely used error metrics, we demonstrated that KGEss is a more reliable metric than NSE and WIA, even though KGEss has its own limitations. Furthermore, relying on large Latin Hypercube samples of the parameter space, without considering the model solution space, is a major source of uncertainty. It is ultimately our goal to advance theoretical frameworks for process-based evaluation of models as hypotheses to better understand and model humannatural systems under uncertainty and non-stationarity (Khazaei et al., 2019; Lu et al., 2018; Moallemi et al., 2020b; Westerberg et al., 2017).

\section{Acknowledgments}

The authors gratefully acknowledge the support of the University of Melbourne and Australian Government in carrying out this research; Sina Khatami supported by Melbourne International Research and Fee Remission Scholarships (MIRS and MIFRS), Murray Peel the recipient of an Australian Research Council Future Fellowship (FT120100130), and Tim Peterson jointly funded by Australian Research Council Linkage Project LP130100958, Bureau of Meteorology (Australia), Department of Environment, Land, Water and Planning (Vic., Australia), Department of Economic Development, Jobs, Transport and Resources (Vic., Australia) and Power and Water Corporation (N.T., Australia).

\section{Data Availability}

Streamflow data used in this project are from the Australian Bureau of Meteorology's (BOM) Hydrologic Reference Station project website (www.bom.gov.au/hrs). Rainfall data are from the Australian Water Availability Project (AWAP) project (www.bom.gov.au/isp/awap/). Potential evapotranspiration data are from the SILO project (www.longpaddock.qld.gov.au/silo/).

\section{Appendix A: deriving the equation for KGE skill score (KGEss)}

Skill score refers to the relative accuracy of model predictions (or forecasts) for a particular measure of accuracy $(A)$ given a reference value $\left(A_{\text {ref }}\right)$ and perfect value $\left(A_{\text {perf }}\right)$, and is measured as: 


$$
\text { skill score }=\frac{A-A_{\text {ref }}}{A_{\text {pref }}-A_{\text {ref }}}
$$

For $A=K G E$ with $K_{G E} E_{p r e f}=1$ and benchmarked against observed mean $A_{\text {ref }}=K G E(\overline{0})=1-\sqrt{2}$, the KGE skill score (KGEss) derives as below:

$$
K G E S S=\frac{K G E-(1-\sqrt{2})}{1-(1-\sqrt{2})}=\frac{K G E-1+\sqrt{2}}{\sqrt{2}}=1-\frac{1-K G E}{\sqrt{2}}
$$

\section{References}

Arsenault, R., Poulin, A., Côté, P., \& Brissette, F. (2013). Comparison of Stochastic Optimization Algorithms in Hydrological Model Calibration. Journal of Hydrologic Engineering, 19(7), 1374-1384. doi:10.1061/(ASCE)HE.1943-5584.0000938

Asadzadeh, M., \& Tolson, B. (2013). Pareto archived dynamically dimensioned search with hypervolume-based selection for multi-objective optimization. Engineering Optimization, 45(12), 1489-1509. doi:10.1080/0305215X.2012.748046

Bennett, N. D., Croke, B. F. W., Guariso, G., Guillaume, J. H. A., Hamilton, S. H., Jakeman, A. J., et al. (2013). Characterising performance of environmental models. Environmental Modelling \& Software, 40, 1-20. doi:https://doi.org/10.1016/i.envsoft.2012.09.011

Beven, K. (2012). Causal models as multiple working hypotheses about environmental processes. Comptes rendus geoscience, 344(2), 77-88.

Beven, K., \& Binley, A. (1992). The future of distributed models: Model calibration and uncertainty prediction. Hydrological Processes, 6(3), 279-298. doi:10.1002/hyp.3360060305

Beven, K., Smith, P. J., \& Wood, A. (2011). On the colour and spin of epistemic error (and what we might do about it). Hydrol. Earth Syst. Sci., 15(10), 3123-3133. doi:10.5194/hess-153123-2011

Beven, K., \& Westerberg, I. (2011). On red herrings and real herrings: disinformation and information in hydrological inference. Hydrological Processes, 25(10), 1676-1680. doi:10.1002/hyp.7963

Blöschl, G., Bierkens, M. F. P., Chambel, A., Cudennec, C., Destouni, G., Fiori, A., et al. (2019). Twenty-three Unsolved Problems in Hydrology (UPH) - a community perspective. Hydrological Sciences Journal. doi:https://doi.org/10.1080/02626667.2019.1620507

Box, G. E. P., \& Cox, D. R. (1964). An Analysis of Transformations. Journal of the Royal Statistical Society: Series B (Methodological), 26(2), 211-243. doi:10.1111/j.25176161.1964.tb00553.x 
Buchanan, B., Auerbach, D. A., Knighton, J., Evensen, D., Fuka, D. R., Easton, Z., et al. (2018). Estimating dominant runoff modes across the conterminous United States. Hydrological Processes, 32(26), 3881-3890. doi:10.1002/hyp.13296

Burnash, R. J. C. (1995). The NWS River Forecast System - catchment modeling. In V. P. Singh (Ed.), Computer Models of Watershed Hydrology (pp. 311-366): Highlands Ranch, CO.

Burnash, R. J. C., Ferreal, R. L., \& McGuire, R. A. (1973). A generalized streamflow Simulation System: Conceptual Modeling for Digital Computers. Retrieved from

Buytaert, W., \& Beven, K. (2011). Models as multiple working hypotheses: hydrological simulation of tropical alpine wetlands. Hydrological Processes, 25(11), 1784-1799. doi:10.1002/hyp.7936

Chiew, F., Peel, M., \& Western, A. (2002). Application and testing of the simple rainfallrunoff model SIMHYD. In V. P. Singh \& D. Frevert (Eds.), Mathematical models of small watershed hydrology and applications (pp. 335-367).

Chiew, F. H. S., Stewardson, M. J., \& McMahon, T. A. (1993). Comparison of six rainfallrunoff modelling approaches. Journal of Hydrology, 147(1), 1-36.

doi:https://doi.org/10.1016/0022-1694(93)90073-I

Chiew, F. H. S., Whetton, P. H., McMahon, T. A., \& Pittock, A. B. (1995). Simulation of the impacts of climate change on runoff and soil moisture in Australian catchments. Journal of Hydrology, 167(1), 121-147. doi:https://doi.org/10.1016/0022-1694(94)02649-V

Choi, H. T., \& Beven, K. (2007). Multi-period and multi-criteria model conditioning to reduce prediction uncertainty in an application of TOPMODEL within the GLUE framework. Journal of Hydrology, 332(3-4), 316-336.

doi:http://dx.doi.org/10.1016/i.jhydrol.2006.07.012

Clark, M. P., Kavetski, D., \& Fenicia, F. (2011a). Pursuing the method of multiple working hypotheses for hydrological modeling. Water Resources Research, 47(9).

Clark, M. P., McMillan, H. K., Collins, D. B. G., Kavetski, D., \& Woods, R. A. (2011b). Hydrological field data from a modeller's perspective: Part 2: process-based evaluation of model hypotheses. Hydrological Processes, 25(4), 523-543. doi:10.1002/hyp.7902

Clark, M. P., Nijssen, B., Lundquist, J. D., Kavetski, D., Rupp, D. E., Woods, R. A., et al. (2015). A unified approach for process-based hydrologic modeling: 1 . Modeling concept. Water Resources Research, 51(4), 2498-2514. doi:doi:10.1002/2015WR017198

Crochemore, L., Perrin, C., Andréassian, V., Ehret, U., Seibert, S. P., Grimaldi, S., et al. (2015). Comparing expert judgement and numerical criteria for hydrograph evaluation. Hydrological Sciences Journal, 60(3), 402-423. doi:10.1080/02626667.2014.903331

Davtalab, R., Mirchi, A., Khatami, S., Gyawali, R., Massah, A., Farajzadeh, M., et al. (2017). Improving Continuous Hydrologic Modeling of Data-Poor River Basins Using Hydrologic Engineering Center's Hydrologic Modeling System: Case Study of Karkheh River Basin. 
Journal of Hydrologic Engineering, 22(8), 05017011.

doi:https://doi.org/10.1061/(ASCE)HE.1943-5584.0001525

Duan, Q., Sorooshian, S., \& Gupta, V. (1992). Effective and efficient global optimization for conceptual rainfall-runoff models. Water Resources Research, 28(4), 1015-1031. doi:10.1029/91WR02985

Dunn, S. M., Freer, J., Weiler, M., Kirkby, M. J., Seibert, J., Quinn, P. F., et al. (2008). Conceptualization in catchment modelling: simply learning? Hydrological Processes, 22(13), 2389-2393. doi:10.1002/hyp.7070

Dunne, T., \& Black, R. D. (1970). Partial Area Contributions to Storm Runoff in a Small New England Watershed. Water Resources Research, 6(5), 1296-1311.

doi:10.1029/WR006i005p01296

Evin, G., Thyer, M., Kavetski, D., Mclnerney, D., \& Kuczera, G. (2014). Comparison of joint versus postprocessor approaches for hydrological uncertainty estimation accounting for error autocorrelation and heteroscedasticity. Water Resources Research, 50(3), 2350-2375. doi:10.1002/2013WR014185

Fenicia, F., Kavetski, D., \& Savenije, H. H. G. (2011). Elements of a flexible approach for conceptual hydrological modeling: 1 . Motivation and theoretical development. Water Resources Research, 47(11). doi:10.1029/2010wr010174

Fowler, K. J. A., Peel, M. C., Western, A. W., Zhang, L., \& Peterson, T. J. (2016). Simulating runoff under changing climatic conditions: Revisiting an apparent deficiency of conceptual rainfall-runoff models. Water Resources Research, 52(3), 1820-1846.

doi:10.1002/2015WR018068

Freer, J., Beven, K., \& Ambroise, B. (1996). Bayesian Estimation of Uncertainty in Runoff Prediction and the Value of Data: An Application of the GLUE Approach. Water Resources Research, 32(7), 2161-2173. doi:10.1029/95WR03723

Freer, J., McDonnell, J. J., Beven, K. J., Peters, N. E., Burns, D. A., Hooper, R. P., et al. (2002). The role of bedrock topography on subsurface storm flow. Water Resources Research, 38(12), 5-1-5-16. doi:10.1029/2001wr000872

Gharari, S., Hrachowitz, M., Fenicia, F., Gao, H., \& Savenije, H. H. G. (2014). Using expert knowledge to increase realism in environmental system models can dramatically reduce the need for calibration. Hydrol. Earth Syst. Sci., 18(12), 4839-4859. doi:10.5194/hess-18-48392014

Goel, T., Haftka, R. T., Shyy, W., \& Watson, L. T. (2008). Pitfalls of using a single criterion for selecting experimental designs. International Journal for Numerical Methods in Engineering, 75(2), 127-155. doi:10.1002/nme.2242

Grayson, R. B., Moore, I. D., \& McMahon, T. A. (1992). Physically based hydrologic modeling: 1. A terrain-based model for investigative purposes. Water Resources Research, 28(10), 2639-2658. doi:10.1029/92WR01258 
Gueymard, C. A. (2014). A review of validation methodologies and statistical performance indicators for modeled solar radiation data: Towards a better bankability of solar projects. Renewable and Sustainable Energy Reviews, 39, 1024-1034.

doi:https://doi.org/10.1016/j.rser.2014.07.117

Guo, D., Westra, S., \& Maier, H. R. (2017). Impact of evapotranspiration process representation on run off projections from conceptual rainfall-runoff models. Water Resources Research, 53(1), 435-454. doi:10.1002/2016WR019627

Gupta, H. V., Kling, H., Yilmaz, K. K., \& Martinez, G. F. (2009). Decomposition of the mean squared error and NSE performance criteria: Implications for improving hydrological modelling. Journal of Hydrology, 377(1-2), 80-91.

doi:http://dx.doi.org/10.1016/j.jhydrol.2009.08.003

Gupta, H. V., Sorooshian, S., \& Yapo, P. O. (1998). Toward improved calibration of hydrologic models: Multiple and noncommensurable measures of information. Water Resources Research, 34(4), 751-763. doi:doi:10.1029/97WR03495

Hewlett, J. D., \& Hibbert, A. R. (1967). Factors affecting the response of small watersheds to precipitation in humid areas. In W. E. Sopper \& H. W. Lull (Eds.), Forest Hydrology (pp. 275-291). New York: Pergamon Press.

Hirpa, F. A., Salamon, P., Beck, H. E., Lorini, V., Alfieri, L., Zsoter, E., et al. (2018). Calibration of the Global Flood Awareness System (GloFAS) using daily streamflow data. Journal of Hydrology, 566, 595-606. doi:https://doi.org/10.1016/i.jhydrol.2018.09.052

Hollaway, M. J., Beven, K. J., Benskin, C. M. H., Collins, A. L., Evans, R., Falloon, P. D., et al. (2018). The challenges of modelling phosphorus in a headwater catchment: Applying a limits of acceptability' uncertainty framework to a water quality model. Journal of Hydrology, 558, 607-624. doi:https://doi.org/10.1016/i.jhydrol.2018.01.063

Hornberger, G. M., \& Spear, R. C. (1981). An approach to the preliminary analysis of environmental systems. Journal of Environmental Management, 12, 7-18.

Horton, R. E. (1933). The Role of infiltration in the hydrologic cycle. Eos, Transactions American Geophysical Union, 14(1), 446-460. doi:10.1029/TR014i001p00446

Hrachowitz, M., Fovet, O., Ruiz, L., Euser, T., Gharari, S., Nijzink, R., et al. (2014). Process consistency in models: The importance of system signatures, expert knowledge, and process complexity. Water Resources Research, 50(9), 7445-7469. doi:10.1002/2014WR015484

Jehn, F. U., Breuer, L., Houska, T., Bestian, K., \& Kraft, P. (2018). Incremental model breakdown to assess the multi-hypotheses problem. Hydrol. Earth Syst. Sci., 22(8), 45654581. doi:10.5194/hess-22-4565-2018

Kavetski, D., Kuczera, G., \& Franks, S. W. (2006). Bayesian analysis of input uncertainty in hydrological modeling: 1. Theory. Water Resources Research, 42(3), W03407.

doi:10.1029/2005WR004368 
Khatami, S., Peel, M. C., Peterson, T. J., \& Western, A. W. (2019). Equifinality and Flux Mapping: a new approach to model evaluation and process representation under uncertainty. Water Resources Research. doi:https://doi.org/10.1029/2018WR023750

Khazaei, B., \& Hosseini, S. M. (2015). Improving the performance of water balance equation using fuzzy logic approach. Journal of Hydrology, 524(Supplement C), 538-548. doi:https://doi.org/10.1016/i.jhydrol.2015.02.047

Khazaei, B., Khatami, S., Alemohammad, S. H., Rashidi, L., Wu, C., Madani, K., et al. (2019). Climatic or regionally induced by humans? Tracing hydro-climatic and land-use changes to better understand the Lake Urmia tragedy. Journal of Hydrology, 569, 203-217. doi:https://doi.org/10.1016/i.jhydrol.2018.12.004

Kling, H., Fuchs, M., \& Paulin, M. (2012). Runoff conditions in the upper Danube basin under an ensemble of climate change scenarios. Journal of Hydrology, 424-425, 264-277. doi:https://doi.org/10.1016/i.jhydrol.2012.01.011

Knoben, W. J. M., Freer, J. E., \& Woods, R. A. (2019). Technical note: Inherent benchmark or not? Comparing Nash-Sutcliffe and Kling-Gupta efficiency scores. Hydrol. Earth Syst. Sci., 2019, 1-7. doi:10.5194/hess-2019-327

Krause, P., Boyle, D. P., \& Bäse, F. (2005). Comparison of different efficiency criteria for hydrological model assessment. Adv. Geosci., 5, 89-97. doi:10.5194/adgeo-5-89-2005

Krueger, T., Freer, J., Quinton, J. N., Macleod, C. J. A., Bilotta, G. S., Brazier, R. E., et al. (2010). Ensemble evaluation of hydrological model hypotheses. Water Resources Research, 46(7). doi:10.1029/2009wr007845

Lane, R. A., Coxon, G., Freer, J. E., Wagener, T., Johnes, P. J., Bloomfield, J. P., et al. (2019). Benchmarking the predictive capability of hydrological models for river flow and flood peak predictions across over 1000 catchments in Great Britain. Hydrol. Earth Syst. Sci., 23(10), 4011-4032. doi:10.5194/hess-23-4011-2019

Legates, D. R., \& McCabe, G. J. (1999). Evaluating the use of "goodness-of-fit" Measures in hydrologic and hydroclimatic model validation. Water Resources Research, 35(1), 233-241. doi:10.1029/1998WR900018

Lerat, J., Andréassian, V., Perrin, C., Vaze, J., Perraud, J. M., Ribstein, P., et al. (2012). Do internal flow measurements improve the calibration of rainfall-runoff models? Water Resources Research, 48(2). doi:10.1029/2010WR010179

Lu, Z., Wei, Y., Feng, Q., Western, A. W., \& Zhou, S. (2018). A framework for incorporating social processes in hydrological models. Current Opinion in Environmental Sustainability, 33, 42-50. doi:https://doi.org/10.1016/i.cosust.2018.04.011

McInerney, D., Thyer, M., Kavetski, D., Lerat, J., \& Kuczera, G. (2017). Improving probabilistic prediction of daily streamflow by identifying Pareto optimal approaches for modeling heteroscedastic residual errors. Water Resources Research, 53(3), 2199-2239. doi:10.1002/2016wr019168 
McMahon, T. A., \& Peel, M. C. (2019). Uncertainty in stage-discharge rating curves: application to Australian Hydrologic Reference Stations data. Hydrological Sciences Journal, 64(3), 255-275. doi:10.1080/02626667.2019.1577555

McMillan, H. K., Westerberg, I. K., \& Krueger, T. (2018). Hydrological data uncertainty and its implications. Wiley Interdisciplinary Reviews: Water, 5(6), e1319.

doi:doi:10.1002/wat2.1319

Melsen, L. A., Teuling, A. J., Torfs, P. J. J. F., Zappa, M., Mizukami, N., Mendoza, P. A., et al. (2019). Subjective modeling decisions can significantly impact the simulation of flood and drought events. Journal of Hydrology, 568, 1093-1104.

doi:https://doi.org/10.1016/i.jhydrol.2018.11.046

Moallemi, E. A., Elsawah, S., \& Ryan, M. J. (2018). An agent-monitored framework for the output-oriented design of experiments in exploratory modelling. Simulation Modelling Practice and Theory, 89, 48-63. doi:https://doi.org/10.1016/i.simpat.2018.09.008

Moallemi, E. A., Elsawah, S., \& Ryan, M. J. (2020a). Strengthening 'good' modelling practices in robust decision support: A reporting guideline for combining multiple modelbased methods. Mathematics and Computers in Simulation, 175, 3-24.

doi:https://doi.org/10.1016/i.matcom.2019.05.002

Moallemi, E. A., Zare, F., Reed, P. M., Elsawah, S., Ryan, M. J., \& Bryan, B. A. (2020b). Structuring and evaluating decision support processes to enhance the robustness of complex human-natural systems. Environmental Modelling \& Software, 123, 104551. doi:https://doi.org/10.1016/i.envsoft.2019.104551

Moriasi, D., Arnold, J., Van Liew, M., Bingner, R., Harmel, R., \& Veith, T. (2007). Model Evaluation Guidelines for Systematic Quantification of Accuracy in Watershed Simulations. Transactions of the ASABE, 50(3), 885-900. doi:https://doi.org/10.13031/2013.23153

Murphy, A. H. (1988). Skill Scores Based on the Mean Square Error and Their Relationships to the Correlation Coefficient. Monthly Weather Review, 116(12), 2417-2424. doi:10.1175/1520-0493(1988)116<2417:ssbotm>2.0.co;2

Oreskes, N., Shrader-Frechette, K., \& Belitz, K. (1994). Verification, validation, and confirmation of numerical models in the earth sciences. Science, 263(5147), 641-646.

Papacharalampous, G., Koutsoyiannis, D., \& Montanari, A. (2020a). Quantification of predictive uncertainty in hydrological modelling by harnessing the wisdom of the crowd: Methodology development and investigation using toy models. Advances in Water Resources, 136, 103471. doi:https://doi.org/10.1016/j.advwatres.2019.103471

Papacharalampous, G., Tyralis, H., Koutsoyiannis, D., \& Montanari, A. (2020b). Quantification of predictive uncertainty in hydrological modelling by harnessing the wisdom of the crowd: A large-sample experiment at monthly timescale. Advances in Water Resources, 136, 103470. doi:https://doi.org/10.1016/j.advwatres.2019.103470 
Peel, M. C., Chiew, F. H., Western, A. W., \& McMahon, T. A. (2000). Extension of unimpaired monthly streamflow data and regionalisation of parameter values to estimate streamflow in ungauged catchments. Retrieved from Report prepared for the National Land and Water Resources Audit, In Australian Natural Resources Atlas, Pages 37.: http://people.eng.unimelb.edu.au/mpeel/NLWRA.pdf

Peterson, T. J., \& Fulton, S. (2019). Joint Estimation of Gross Recharge, Groundwater Usage, and Hydraulic Properties within HydroSight. Groundwater, 57(6), 860-876. doi:10.1111/gwat.12946

Peterson, T. J., \& Western, A. W. (2014). Nonlinear time-series modeling of unconfined groundwater head. Water Resources Research, 50(10), 8330-8355. doi:10.1002/2013wr014800

Pianosi, F., Beven, K., Freer, J., Hall, J. W., Rougier, J., Stephenson, D. B., et al. (2016). Sensitivity analysis of environmental models: A systematic review with practical workflow. Environmental Modelling \& Software, 79, 214-232. doi:https://doi.org/10.1016/i.envsoft.2016.02.008

Pushpalatha, R., Perrin, C., Moine, N. L., \& Andréassian, V. (2012). A review of efficiency criteria suitable for evaluating low-flow simulations. Journal of Hydrology, 420-421, 171-182. doi:https://doi.org/10.1016/i.jhydrol.2011.11.055

Saffarpour, S., Western, A. W., Adams, R., \& McDonnell, J. J. (2016). Multiple runoff processes and multiple thresholds control agricultural runoff generation. Hydrol. Earth Syst. Sci., 20(11), 4525-4545. doi:10.5194/hess-20-4525-2016

Santos, L., Thirel, G., \& Perrin, C. (2018). Technical note: Pitfalls in using log-transformed flows within the KGE criterion. Hydrol. Earth Syst. Sci., 22(8), 4583-4591. doi:10.5194/hess22-4583-2018

Schaefli, B., \& Gupta, H. V. (2007). Do Nash values have value? Hydrological Processes, 21(15), 2075-2080. doi:10.1002/hyp.6825

Seibert, J., \& McDonnell, J. J. (2002). On the dialog between experimentalist and modeler in catchment hydrology: Use of soft data for multicriteria model calibration. Water Resources Research, 38(11), 23-21-23-14. doi:10.1029/2001WR000978

Seibert, J., Vis, M. J. P., Lewis, E., \& van Meerveld, H. J. (2018). Upper and lower benchmarks in hydrological modelling. Hydrological Processes, 32(8), 1120-1125. doi:10.1002/hyp.11476

Sheikholeslami, R., \& Razavi, S. (2017). Progressive Latin Hypercube Sampling: An efficient approach for robust sampling-based analysis of environmental models. Environmental Modelling \& Software, 93, 109-126. doi:https://doi.org/10.1016/i.envsoft.2017.03.010

Sorooshian, S., \& Dracup, J. A. (1980). Stochastic parameter estimation procedures for hydrologie rainfall-runoff models: Correlated and heteroscedastic error cases. Water Resources Research, 16(2), 430-442. doi:10.1029/WR016i002p00430 
Sorooshian, S., \& Gupta, V. K. (1983). Automatic calibration of conceptual rainfall-runoff models: The question of parameter observability and uniqueness. Water Resources Research, 19(1), 260-268. doi:10.1029/WR019i001p00260

Tolson, B. A., \& Shoemaker, C. A. (2007). Dynamically dimensioned search algorithm for computationally efficient watershed model calibration. Water Resources Research, 43(1). doi:10.1029/2005wr004723

Tolson, B. A., \& Shoemaker, C. A. (2008). Efficient prediction uncertainty approximation in the calibration of environmental simulation models. Water Resources Research, 44(4). doi:10.1029/2007wr005869

Towner, J., Cloke, H. L., Zsoter, E., Flamig, Z., Hoch, J. M., Bazo, J., et al. (2019). Assessing the performance of global hydrological models for capturing peak river flows in the Amazon Basin. Hydrol. Earth Syst. Sci. Discuss., 2019. doi:10.5194/hess-2019-44

Tromp van Meerveld, I., \& McDonnell, J. J. (2005). Comment to "Spatial correlation of soil moisture in small catchments and its relationship to dominant spatial hydrological processes, Journal of Hydrology 286: 113-134". Journal of Hydrology, 303(1), 307-312. doi:https://doi.org/10.1016/i.jhydrol.2004.09.002

Turner, M. (2012). Hydrologic Reference Station Selection Guidelines. Retrieved from Melbourne, Australia:

http://www.bom.gov.au/water/hrs/media/static/papers/Selection Guidelines.pdf

Vrugt, J. A., \& Beven, K. J. (2018). Embracing equifinality with efficiency: Limits of Acceptability sampling using the DREAM(LOA) algorithm. Journal of Hydrology, 559, 954-971. doi:https://doi.org/10.1016/j.jhydrol.2018.02.026

Vrugt, J. A., ter Braak, C. J. F., Clark, M. P., Hyman, J. M., \& Robinson, B. A. (2008). Treatment of input uncertainty in hydrologic modeling: Doing hydrology backward with Markov chain Monte Carlo simulation. Water Resources Research, 44(12), W00B09. doi:10.1029/2007WR006720

Wagener, T. (2003). Evaluation of catchment models. Hydrological Processes, 17(16), 3375-3378. doi:10.1002/hyp.5158

Westerberg, I., Guerrero, J. L., Seibert, J., Beven, K. J., \& Halldin, S. (2011). Stage-discharge uncertainty derived with a non-stationary rating curve in the Choluteca River, Honduras. Hydrological Processes, 25(4), 603-613. doi:10.1002/hyp.7848

Westerberg, I. K., Di Baldassarre, G., Beven, K. J., Coxon, G., \& Krueger, T. (2017). Perceptual models of uncertainty for socio-hydrological systems: a flood risk change example. Hydrological Sciences Journal, 62(11), 1705-1713.

doi:10.1080/02626667.2017.1356926

Westerberg, I. K., Wagener, T., Coxon, G., McMillan, H. K., Castellarin, A., Montanari, A., et al. (2016). Uncertainty in hydrological signatures for gauged and ungauged catchments. Water Resources Research, 52(3), 1847-1865. doi:doi:10.1002/2015WR017635 
Western, A. W., \& Grayson, R. B. (1998). The Tarrawarra Data Set: Soil moisture patterns, soil characteristics, and hydrological flux measurements. Water Resources Research, 34(10), 2765-2768. doi:doi:10.1029/98WR01833

Western, A. W., Zhou, S.-L., Grayson, R. B., McMahon, T. A., Blöschl, G., \& Wilson, D. J. (2005). Reply to comment by Tromp van Meerveld and McDonnell on Spatial correlation of soil moisture in small catchments and its relationship to dominant spatial hydrological processes. Journal of Hydrology, 303(1), 313-315.

doi:https://doi.org/10.1016/i.jhydrol.2004.09.001

Willmott, C. J., Robeson, S. M., \& Matsuura, K. (2012). A refined index of model performance. International Journal of Climatology, 32(13), 2088-2094. doi:10.1002/joc.2419

Willmott, C. J., Robeson, S. M., Matsuura, K., \& Ficklin, D. L. (2015). Assessment of three dimensionless measures of model performance. Environmental Modelling \& Software, 73, 167-174. doi:http://dx.doi.org/10.1016/i.envsoft.2015.08.012

Winsemius, H. C., Schaefli, B., Montanari, A., \& Savenije, H. H. G. (2009). On the calibration of hydrological models in ungauged basins: A framework for integrating hard and soft hydrological information. Water Resources Research, 45(12). doi:doi:10.1029/2009WR007706

Yeo, I. K., \& Johnson, R. A. (2000). A new family of power transformations to improve normality or symmetry. Biometrika, 87(4), 954-959. doi:10.1093/biomet/87.4.954

Zare, F., Guillaume, J. H. A., Jakeman, A. J., \& Torabi, O. (2020). Reflective communication to improve problem-solving pathways: Key issues illustrated for an integrated environmental modelling case study. Environmental Modelling \& Software, 126, 104645.

doi:https://doi.org/10.1016/i.envsoft.2020.104645 


\title{
5. Result Chapter 3
}

This Chapter is prepared to be submitted to journal Hydrology and Earth System Sciences. This chapter is written in American English.

\section{Which catchment attributes control runoff generation hypotheses in Australian catchments?}

\author{
Sina Khatami ${ }^{1}$, Keirnan Fowler ${ }^{1}$, Murray C. Peel ${ }^{1}$, Tim J. Peterson ${ }^{1,2}$, Andrew W. Western ${ }^{1}$ \\ ${ }^{1}$ Department of Infrastructure Engineering, University of Melbourne, Parkville, Victoria, \\ 3010, Australia \\ ${ }^{2}$ Department of Civil Engineering, Monash University, Clayton, Victoria, Australia
}

\subsection{Introduction}

Multiple Working Hypotheses (MWH, (Chamberlin, 1890)) is becoming a conventional approach in hydrological modeling (Beven, 2012; Beven et al., 2012; Buytaert \& Beven, 2011; Clark et al., 2011, 2012; Pfister \& Kirchner, 2017). It is based upon the equifinality principle, which implies that multiple distinct modeling configurations (e.g. model structure, parameter sets, fluxes, etc.) can equally produce acceptable simulations (Khatami et al., 2019). An ensemble of acceptable models can be treated as MWH of catchment processes (Beven, 2019; Fenicia et al., 2008; Krueger et al., 2010).

We previously showed that investigating conceptual catchment model internal runoff fluxes provides insights for characterizing model uncertainties and a basis to formulate MWH about the representation of runoff processes within a model (Khatami et al., 2019). We further demonstrated that the model structure and parameterization, error metric, and information content of the forcing inputs determine runoff generation hypotheses across 
different catchments (Khatami et al., 2020; i.e. Chapter 4 of this thesis). That said, the relationship between catchment attributes (e.g. physical, climatic, and streamflow response) and dynamics of model internal fluxes (e.g. runoff generation fluxes) is less understood. In light of the above, the aim of this paper is to investigate the functional connectivity between catchment attributes and model internal runoff fluxes; these attributes control (dominant) runoff generation in real-world catchments, and model internal fluxes represent those catchment processes.

In doing so, we employ the flux mapping method (explained in section 5.2.4) to formulate runoff generation hypotheses across 221 Australian catchments (section 5.2.1). We use the SIMHYD daily lumped catchment model (Chiew et al., 2002; Peel et al., 2000). The total simulated runoff in SIMHYD is the sum of three internal runoff fluxes: (1) infiltration excess overland flow, (2) interflow and saturation excess overland flow, and (3) baseflow. These three runoff fluxes represent runoff generating mechanisms - i.e. dominant modes of catchment response - namely intensity-based, wetness-based, and slow response, respectively. One million SIMHYD simulations are generated for each catchment, and evaluated using the skill score version of the Kling-Gupta Efficiency metric (KGEss, developed by Khatami et al. (2020)) benchmarked against the calendar day average flow (Schaefli \& Gupta, 2007) of the corresponding catchment. For simulations with acceptable model performance (defined in section 5.2.2) and sufficient parameter sampling (defined in section 5.2.3), MWH are formulated based on equifinal runoff fluxes (defined in section 5.2.4). We then present how different catchment attributes control the strength of each runoff generation hypothesis as well as the degree of model flux equifinality (section 5.3). Our results show a strong connectivity between the model's runoff generation hypotheses and the catchment's actual streamflow response, weaker connectivity to climatic attributes, and least connectivity to physical attributes. As a proof-of-concept study, we limited our choice of model structure to SIMHYD. Finally, we discuss directions to progress this study and improve its limitations in future research (section 5.3.4).

\subsection{Methods}

\subsubsection{Study area and dataset}


Our study area is the Australian network of Hydrologic Reference Stations (HRS) including daily time series of observed streamflow $(Q)$, catchment average precipitation $(P)$, and Morton's areal potential evapotranspiration (PET) at the catchment centroid (see Table 1). The 221 HRS catchments have relatively high-quality data, minimal land-use disturbance or water resources development over the period of record (Turner, 2012, p. 6). Further, for each catchment we also prepared a set of 22 attributes, defined in Table 2, indicating the characteristics of catchment physiography (\#1-6), climate (\#7-16), and streamflow response (\#17-22).

Table 5.1. HRS time series data used for hydrological modeling.

\begin{tabular}{ll}
\hline Dataset & \multicolumn{1}{c}{ Description } \\
\hline Streamflow (Q) & $\begin{array}{l}\text { Owned by various Australian state agencies, but collated and publicly } \\
\text { released by the Bureau of Meteorology (www.bom.gov.au/water/hrs/) }\end{array}$ \\
From the Australian Water Availability Project (AWAP, \\
Precipitation (P) & $\begin{array}{l}\text { www.bom.gov.au/jsp/awap/rain/), calculated as daily spatial average(Jones } \\
\text { et al., 2009). } \\
\text { Potential }\end{array}$ \\
$\begin{array}{l}\text { Morton's Wet Environment Evaporation calculated by the SILO project } \\
\text { (www.longpaddock.qld.gov.au/silo/) for each catchment centroid (Jeffrey et } \\
\text { al., 2001). }\end{array}$ \\
\hline
\end{tabular}

Table 5.2. Overview of the 22 attributes of the 221 HRS catchments.

\begin{tabular}{|c|c|c|}
\hline \# & Attribute & Description [unit] \\
\hline 1 & Area & $\begin{array}{l}\text { Based on catchment boundaries defined by Fowler et al. (2016) using the } \\
\text { elevation dataset. }\left[\mathrm{km}^{2}\right]\end{array}$ \\
\hline 2 & $\begin{array}{l}\text { Forested } \\
\text { Proportion }\end{array}$ & $\begin{array}{l}\text { Forest cover was from Lymburner et al. (2011) and is the sum of the four } \\
\text { land-use types in their "tree" category. [\%] }\end{array}$ \\
\hline 3 & Soil Depth & $\begin{array}{l}\text { Based on data from the Australian Soil Resource Information System (ASRIS, } \\
\text { www.asris.csiro.au/themes/Atlas.html\#Atlas Digital). ASRIS provides spatial } \\
\text { layers showing soil "map units" over Australia, and associated tables } \\
\text { relating each map unit to up to five "principal profile forms" (ppfs). For each } \\
\text { ppf, } 5^{\text {th }}, 50^{\text {th }} \text {, and } 95^{\text {th }} \text { percentile solum thicknesses are provided. Here we } \\
\text { assign a representative solum thickness to each map unit, defined as the } \\
\text { median thickness of its most dominant ppf. Catchment values are } \\
\text { calculated as the spatial average of these representative solum thicknesses. } \\
\text { [m] }\end{array}$ \\
\hline 4 & Slope Average & $\begin{array}{l}\text { Spatial average of cell-by-cell slope calculations based on the below } \\
\text { elevation dataset. [-] }\end{array}$ \\
\hline 5 & Elevation Mean & $\begin{array}{l}\text { Spatial average of elevation across cells from the dataset of Shuttle Radar } \\
\text { Topography Mission (SRTM) post-processed for Australia by Gallant et al. } \\
\text { (2011). [meters above sea level, masl] }\end{array}$ \\
\hline
\end{tabular}




\begin{tabular}{|c|c|c|}
\hline 6 & Elevation Range & $\begin{array}{l}\text { Difference between maximum catchment elevation and elevation at outlet, } \\
\text { from the above elevation dataset. [masl] }\end{array}$ \\
\hline 7 & KG climate num & $\begin{array}{l}\text { This is a categorical variable with } 30 \text { classes corresponding to the } 3^{\text {rd }} \text { level } \\
\text { climate type of the Köppen-Geiger climate classification based on Peel et al. } \\
\text { (2007). [-] }\end{array}$ \\
\hline 8 & PETmean Annual & $\begin{array}{l}\text { Annual average Morton's areal PET over years with complete streamflow } \\
\text { records. [mm/year] }\end{array}$ \\
\hline 9 & $P E T / P$ & Aridity (or dryness) index. [-] \\
\hline 10 & Knoben Im & $\begin{array}{l}\text { Average aridity based on the Thorntwaite's Moisture Index (MI) used in } \\
\text { climate classification of Knoben et al. (2018). [-] }\end{array}$ \\
\hline 11 & Knoben Imr & The seasonality in average aridity (Knoben Im) by Knoben et al. (2018). [-] \\
\hline 12 & Pmean Annual & $\begin{array}{l}\text { Annual average precipitation over years with complete streamflow records. } \\
\text { [mm/year] }\end{array}$ \\
\hline 13 & Pcv Daily & $\begin{array}{l}\text { Coefficient of variation (cv) of daily P calculated on all days where flow is } \\
\text { not missing. [-] }\end{array}$ \\
\hline 14 & Pcv Annual & cv of annual P is calculated over the same years as Qcv Annual. [-] \\
\hline 15 & RainDay Perc & $\begin{array}{l}\text { Percentage of rainy days defined as days with more than } 10^{-4} \mathrm{~mm} \text { of rainfall. } \\
\text { [\%] }\end{array}$ \\
\hline 16 & P Skewness & Skewness of daily precipitation. [-] \\
\hline 17 & Q/P ratio Annual & $\begin{array}{l}\text { Annual rainfall-runoff ratio, which has a }-1 \text { correlation with evaporative } \\
\text { index (defined as actual evapotranspiration, AET, divided by precipitation: } \\
\text { AET/P). [-] }\end{array}$ \\
\hline 18 & Qmean Annual & $\begin{array}{l}\text { Annual average streamflow over years with complete streamflow records. } \\
\text { [mm/year] }\end{array}$ \\
\hline 19 & Qcv Daily & cv of daily streamflow calculated on all days where flow is not missing. [-] \\
\hline 20 & Qcv Annual & $\begin{array}{l}\text { cv of annual streamflow calculated over an April-March Water Year. Only } \\
\text { water years with less than } 5 \% \text { missing } Q \text { are included. [-] }\end{array}$ \\
\hline 21 & FlowDay Perc & $\begin{array}{l}\text { Percentage of flow days defined as days with more than } 10^{-4} \mathrm{~mm} \text { of } \\
\text { streamflow. [\%] }\end{array}$ \\
\hline 22 & Q Skewness & Skewness of daily streamflow. [-] \\
\hline
\end{tabular}

\subsubsection{Model performance and benchmarking}

Gupta et al. (2009) developed the Kling-Gupta Efficiency (KGE) metric. We previously derived its skill score version $\left(K G E_{S S}\right)$ and demonstrated that $K G E_{S S}$ is a better metric than other conventional metrics like Nash-Sutcliffe efficiency and Willmott's refined index of agreement (Khatami et al., 2020). $K G E_{S S}$ compares the distance between the time series of observed and modeled flows $(O$ and $M)$ against the overall observed mean $\bar{O}: K G E_{S S}(O, M, \bar{O})$. A perfect match is the upper benchmark where $K G E_{S S}=1$, while $\bar{O}$ is the lower benchmark where $K G E_{S S}=0$ (Seibert et al., 2018). Schaefli and Gupta (2007) demonstrated the limitations of this lower benchmark, and suggested some alternatives such as the calendar day benchmark model. This benchmark is the series of observed flow averaged for each 
calendar day (hereafter $\bar{O}_{d}$ ), which better reflects the catchment-specific seasonality of flow and average hydroclimate than a constant overall mean (see Figure 5.1).

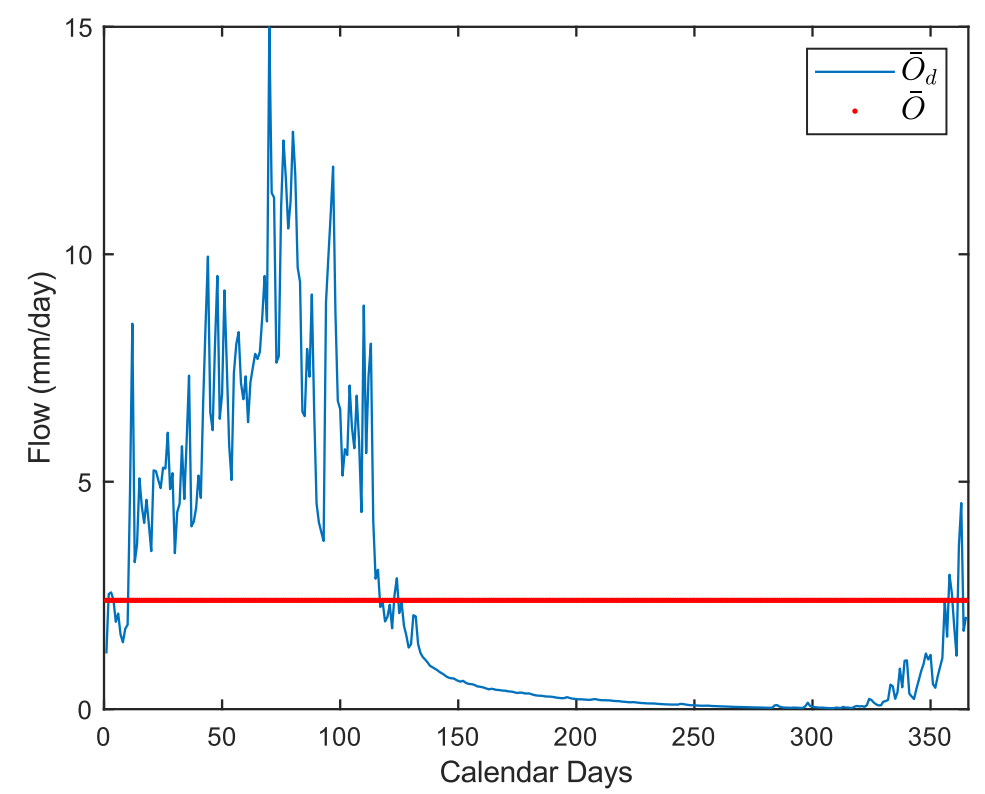

Figure 5.1. Example of the two lower benchmarks for KGEss: blue is calendar day average flow $\left(\bar{O}_{d}\right)$ used in this study, and red is the original benchmark of overall average $(\overline{0})$.

In this study, we characterize model performance using the $\bar{O}_{d}$ benchmark, instead of $\bar{O}$, within the $K G E_{S S}$ to form $K G E_{S S}^{\prime}\left(O, M, \bar{O}_{d}\right)$ as presented in Equation 1:

$K G E_{S S}^{\prime}\left(O, M, \bar{O}_{d}\right)=\frac{K G E_{S S}(O, M, \bar{O})-K G E_{S S}\left(O, \bar{O}_{d}, \bar{O}\right)}{1-K G E_{S S}\left(O, \bar{O}_{d}, \bar{O}\right)}$

where $K G E_{S S}^{\prime}=0$ when $M=\bar{O}_{d}$. In this study, we assumed the arbitrary threshold of $K G E_{S S}^{\prime} \geq$ 0.6 as a minimal (and not adequate nor reliable) criterion for model performance acceptability, and catchment models below this threshold are excluded from further analysis.

\subsubsection{Hydrological model and parameterization}

We use a lumped conceptual model, namely SIMHYD (Chiew et al., 2002; Peel et al., 2000), to simulate daily catchment average runoff. SIMHYD has 7 free parameters, with precipitation and potential evapotranspiration as inputs, and simulates streamflow through runoff generating mechanisms of (1) infiltration excess overland flow, (2) interflow and saturation excess overland flow, and (3) baseflow. Each of these mechanisms correspond to 
a unique internal model flux within SIMHYD. As we discussed before (Khatami et al., 2020), these runoff fluxes can be classified into three groups, or modes of model response, namely intensity-based, wetness-based, and slow response. Each of these response groups represents a type of catchment function/behavior in terms of runoff generation.

A set of 1 million Latin Hypercube Samples (LHS) were generated to sample the model parameter space. The LHS set is then used consistently for all catchments, i.e. model parameter sets do not vary across catchments, producing an ensemble of 1 million SIMHYD simulations. Consistent with our previous studies (Khatami et al., 2019; Khatami et al., 2020), we used the entire available record of $\mathrm{P}$ and PET time series as forcing inputs for model parameterization; i.e. no split sampling of the input data. The performance of each model run is then evaluated based on the entire record of daily $\mathrm{Q}$ using $K G E_{S S}^{\prime}$.

For each catchment we further used the Shuffled Complex Evolution (SCE, (Duan et al., 1992)) as a global search of the solution space of the catchment model. SCE was repeated 10 times for each catchment to account for the inherent randomness of this search routine. The highest $K G E_{S S}^{\prime}$ values from the 1 million LHS $\left(K G E_{S S}^{\prime}-L H S\right)$ and 10 repeats of SCE $\left(K G E_{S S}^{\prime}-S C E\right)$ indicate the efficacy of each parameter sampling strategy, and hence could be used as a relative measure of parameter sampling sufficiency. We define parameter sampling as insufficient if the $K G E_{S S}^{\prime}-S C E$ is higher than $K G E_{S S}^{\prime}-L H S$ by a 0.05 margin: $K G E_{S S}^{\prime}-S C E-$ $K G E_{S S}^{\prime}-L H S \geq 0.05$. That is, if SCE identifies a parameter set within the model solution space with a considerably higher $K G E_{S S}^{\prime}$ value, the LHS sampling is considered insufficient. In other words, SCE is used as an upper benchmark to examine the efficacy of LHS ensemble. This is only a relative test of sampling sufficiency, as it does not guarantee a perfectly representative sample of the parameter space. In order to control parameter sampling as a source of uncertainty and maintain model parameterization consistent across catchments, insufficient cases are not resampled and will be excluded from further analysis.

\subsubsection{Flux mapping and assessment of runoff generation hypotheses}

Distinct combinations of model internal fluxes can give rise to a similar total simulated flow (i.e. model output), also known as model (flux) equifinality (Khatami et al., 2019). For each SIMHYD simulation, the total simulated flow is the sum of the three runoff fluxes (described in section 5.2.3). These internal model fluxes represent different runoff generating 
mechanisms, and hence can be the basis to formulate multi-hypotheses about runoff generation in a catchment. We developed a method called Flux Mapping to formulate hypotheses based on the dynamics of model fluxes (Khatami et al., 2019). For SIMHYD with three runoff fluxes, the flux map is a ternary plot on which each model run is summarized as a single point with three coordinates. Each coordinate corresponds to the percentage of the volumetric portion of each runoff flux to the total simulated flow (Figure 5.2). So, the total area of the flux map triangle represents the hypothesis space (the space of all possibilities), and the point cloud of acceptable model runs represents $\mathrm{MWH}$.

Here, we defined two criteria for model acceptance based on both model performance $\left(K G E_{S S}^{\prime} \geq 0.6\right)$ and parameter sampling sufficiency $\left(K G E_{S S}^{\prime}-S C E-K G E_{S S}^{\prime}-L H S \geq 0.05\right)$. For each catchment the ensemble of acceptable model runs out of the 1 million LHS, if any exist, are flux mapped. Flux map point cloud (i.e. MWH of runoff generation) of each catchment is then summarized with four measures as shown in Figure 5.2: the area of the convex hull of the point cloud (hereafter, flux map area) as well as the average, max, and range of each model flux. For a given ensemble of acceptable model runs, the flux map area measures the relative size of $\mathrm{WMH}$, while the three summary statistics characterize the relative strength of a given runoff generation mechanism.

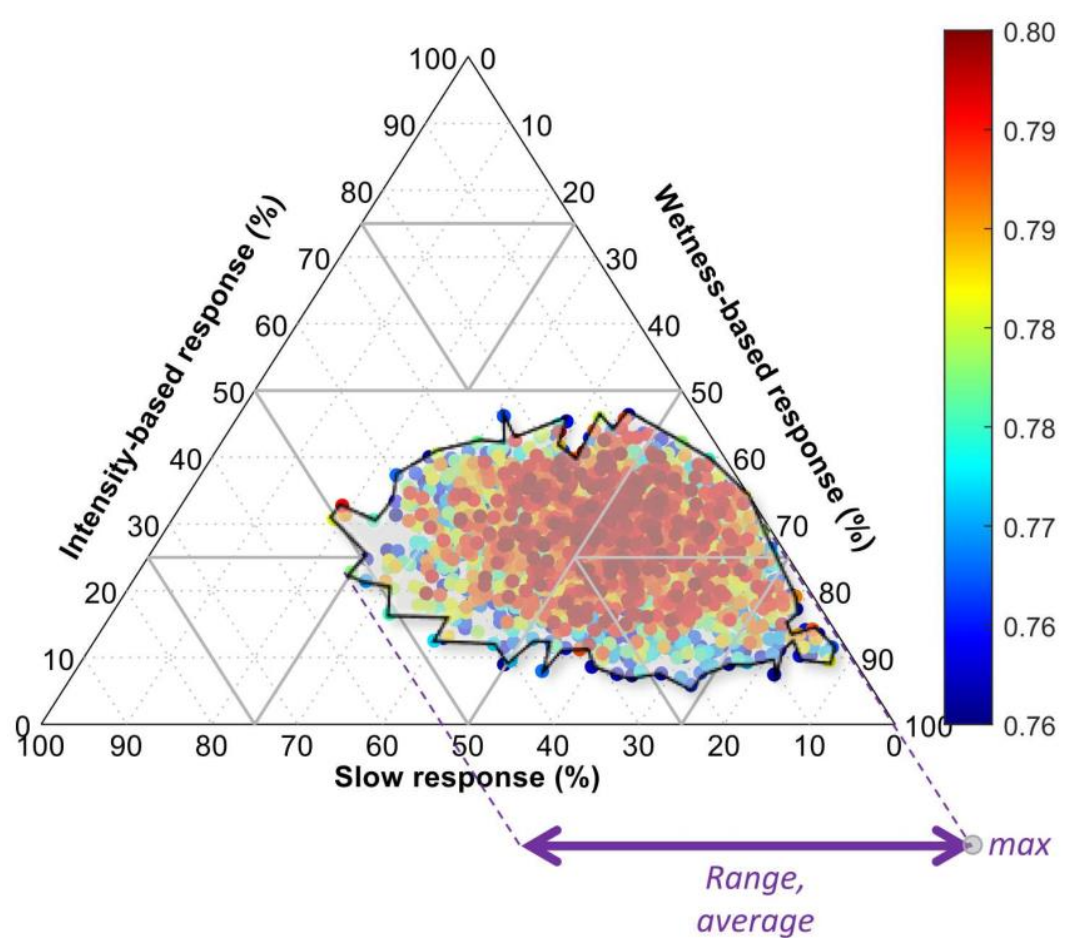

Figure 5.2. A flux map demonstrating the area of the point cloud convex hull (flux map area) as well as the average, range, and max of baseflow runoff flux (slow response hypothesis) as an example. Each model run is color-coded by the corresponding model performance. 
To investigate the association between runoff generation hypotheses and catchment attributes, we used Spearman rank correlation coefficient $\left(R_{S}\right) . R_{S}$ is the robust (i.e. not dependent upon the underlying distribution of the data) and resistant (i.e. not sensitive to extreme values) alternative of Pearson linear correlation coefficient (Khazaei et al., 2019). While Pearson correlation only identifies linear monotonic relationships, $R_{S}$ captures nonlinear monotonic associations as well.

\subsection{Results and discussion}

\subsubsection{SIMHYD performance across Australian HRS catchments}

For each HRS catchment we ran SIMHYD using the 1 million LHS parameter sets. SIMHYD was able to produce at least 1 simulation with acceptable performance ( $\left.K G E_{S S}^{\prime} \geq 0.6\right)$ in 205 catchments (Figure 5.3), and parameter sampling was accepted as sufficient ( $K G E_{S S}^{\prime}-S C E-$ $\left.K G E_{S S}^{\prime}-L H S \geq 0.05\right)$ in 195 catchments. Overall, in 186 catchments SIMHYD passed both model acceptability criteria, in which we further investigate the relationship between runoff generation hypotheses and catchment attributes. As shown in Figure 5.3, SIMHYD performed acceptably in a large portion of catchments across Australia with the exception of $\sim 7 \%$ of HRS catchments, mostly in southern and southwestern Australia. While it is interesting to examine the underlying factors for SIMHYD inadequacy in these catchments, given the scope of this study, we do not further investigate the relationship between model performance and catchment attributes in those catchments. 


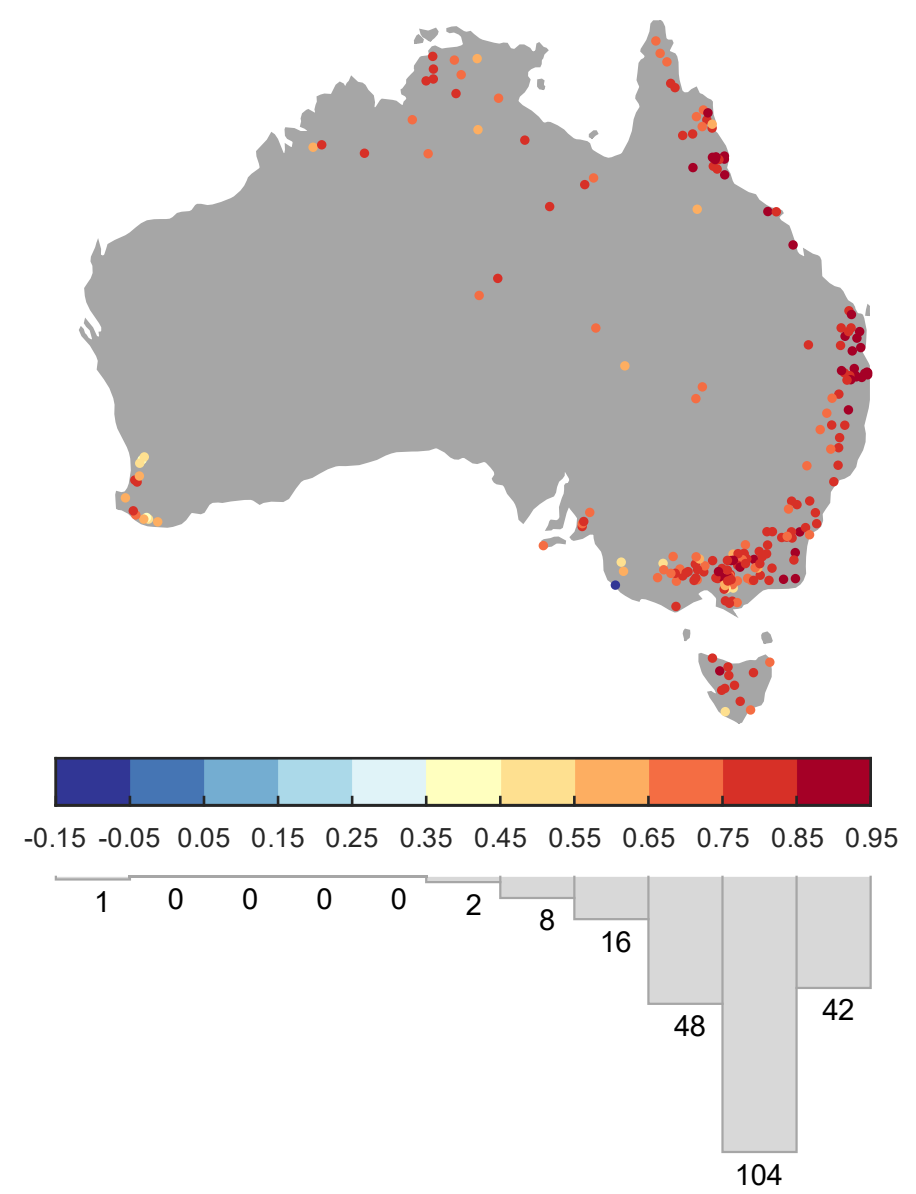

Figure 5.3. 221 Australian HRS catchments color-coded by the SIMHYD performance based on $K G E_{s S}^{\prime}$. The value below each bar (colorbar histogram) is the number of catchments with $K G E_{s s}^{\prime}$ values within the corresponding bin.

\subsubsection{Runoff generation and model equifinality}

Figure 5.4 shows that in most of the 186 study catchments the flux map area is quite constrained $(\leq 10 \%)$. However, there are several catchments with large flux map area, which indicates a higher degree of equifinality of model runoff fluxes. This implies higher uncertainty associated with model process-representation in these catchments. As shown in Figures 5.4-5.5, while high equifinality catchments are spread across Australia, they generally are catchments with smaller area $\left(\sim 6-650 \mathrm{~km}^{2}\right)$ in regionalized clusters in the southeast, east, and north. That said, SIMHYD exhibits a wide range of model flux equifinality in smaller catchments as flux map area ranges between 0-100\% (Figure 5.5), whereas its model equifinality is more constrained (flux map area $\leq 30 \%)$ in larger catchments $(\sim 3,300-238,000$ $\mathrm{km}^{2}$ ). In other words, larger catchments tend to have a more constrained flux equifinality, 
i.e. it is simpler to hypothesize dominant modes of catchment response in larger catchments.

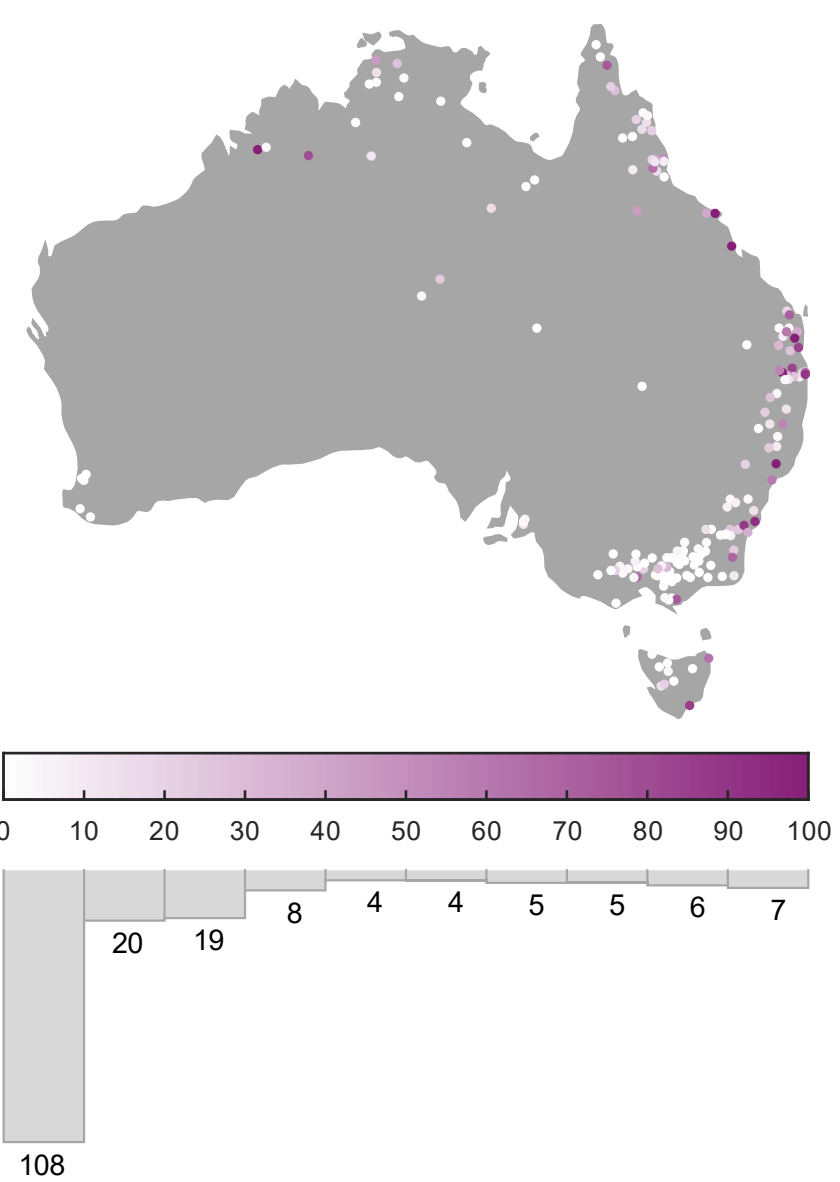

Figure 5.4. Flux map area as the percentage of the flux map triangle across the accepted 186 catchments. The value below each bar (colorbar histogram) is the number of catchments with flux map area within the corresponding bin.

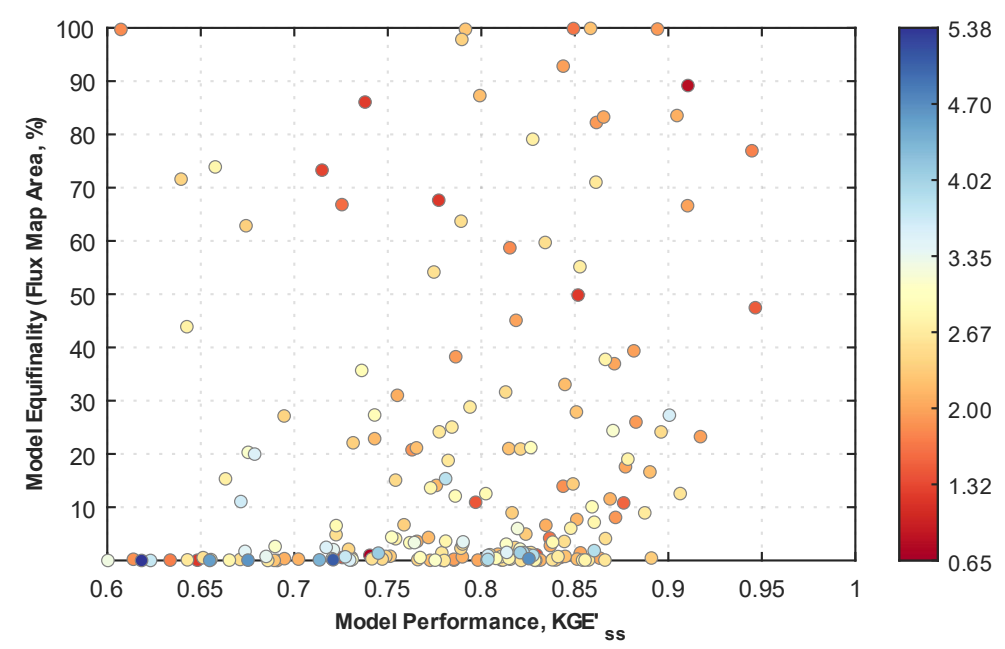

Figure 5.5. Flux map area and model performance of the 186 study catchments, color-coded by the $\log _{10}($ Catchment Area). 
Figure 5.6 summarizes the association between catchment attributes (physical, climatic, and streamflow response), as well as the relationship between catchment attributes and runoff generation hypotheses.

In terms of flux map area (model flux equifinality), physical attributes are the least important factors $\left(R_{s} \leq 0.3\right)$, while flow response attributes (particularly Qcv Daily and $Q$ Skewness) are the most important ones ( $R_{S}=0.67$ and 0.72 , respectively). Among physical attributes, flux map area does not show any (monotonic) dependency on Forested Proportion and Slope Average; presumably because vegetation and topography are not explicitly represented in SIMHYD. Likewise, it does not depend on Q/P ratio Annual and Qmean Annual. In other words, model flux equifinality is independent of long-term annual values of rainfall-runoff ratio and average streamflow. However, Qcv Annual is moderately correlated with flux map area, i.e. higher inter-annual variability of streamflow implies higher uncertainties for modeling runoff generation. That said, the strongest controlling factor of flux equifinality is Q Skewness, which is strongly correlated with Pcv Daily, P Skewness, Qcv Daily, and Qcv Annual. That is, higher daily variations in streamflow with higher frequency of low flows (and rare extremes of high flows) lead to higher uncertainties in representing runoff generation. In addition, there is a positive but weak association between the performance (i.e. $K G E_{S S}^{\prime}-L H S$ values) and degree of flux equifinality (i.e. flux map area) of SIMHYD $\left(R_{S}=0.24, \mathrm{p}\right.$ value $<8.2 \mathrm{e}-4)$ 

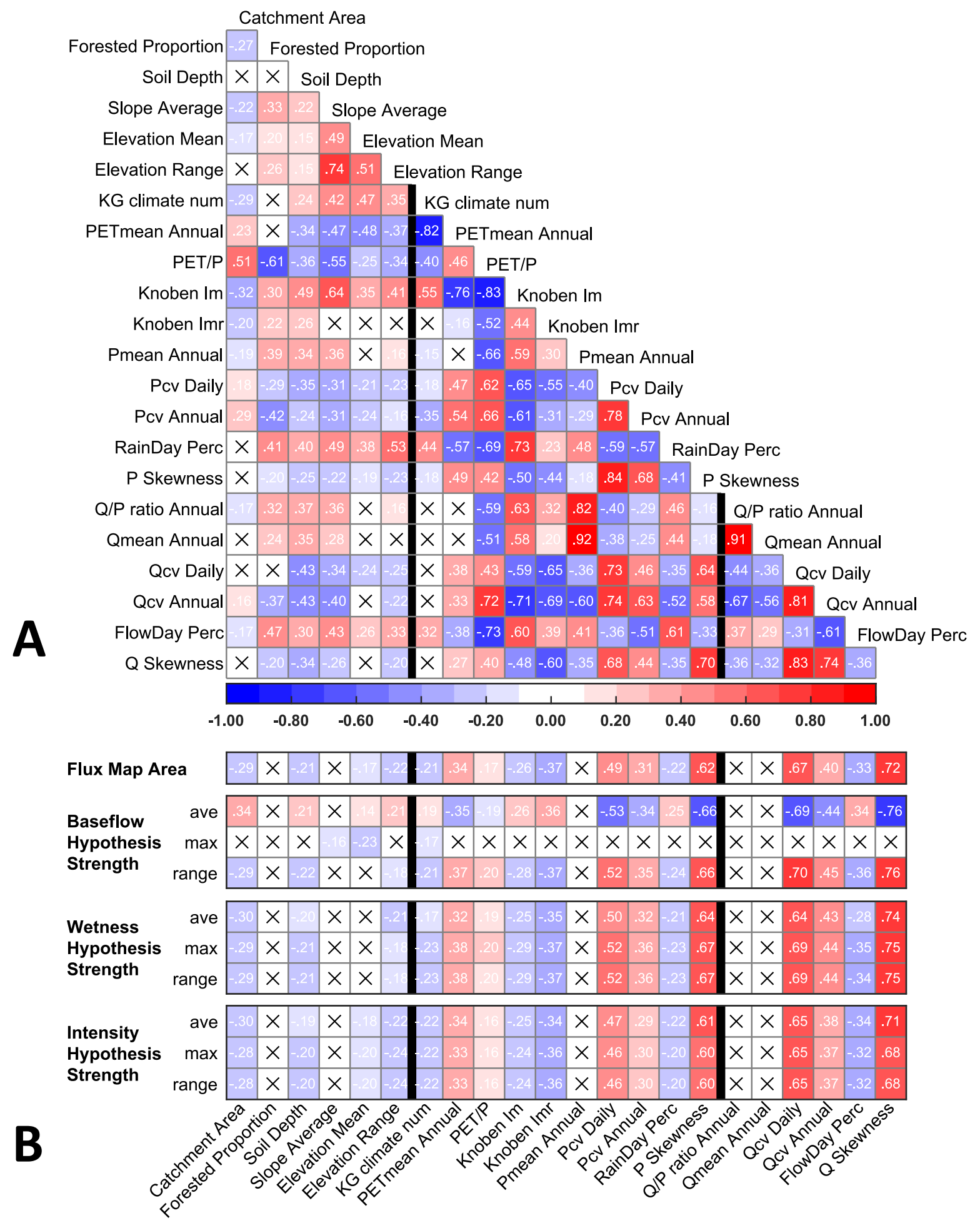

Figure 5.6. (A) Correlation matrix of catchment attributes, and (B) heatmap of flux map characteristics against catchment attributes. Both (A) and (B) are based on $R_{s}$ with correlation values insignificant at $0.05 p$ value presented as a black cross. Three groups of catchment attributes are demarcated with bold, black vertical lines: physical (column 1-6), climatic (column 7-16), and streamflow response (column 17-22) attributes.

In light of the above, larger model equifinality is likely in spite of higher model performance in smaller catchments with highly skewed and variable daily streamflow; which implies 
higher uncertainties, and hence greater challenge for reliable/realistic simulation of runoff processes in these catchments. We speculate that this challenge may be a factor that hinders the transposability of hydrological models across changing conditions, which is one of the unsolved problems of hydrological sciences (Blöschl et al., 2019). This result is compatible with the study by Guo et al. (2020) where higher runoff skewness was associated with lower model robustness (i.e. consistency of model performance across calibration/evaluation data splits).

\subsubsection{Connectivity between runoff generation hypotheses and catchment attributes}

The average strength of slow (baseflow) response hypothesis has a strong inverse correlation with climatic (PCV Daily and P Skewness) and streamflow response (Qcv Daily and $Q$ Skewness) attributes (see Figure 5.6 and note that these four attributes are strongly correlated with one another). That is, as Pcv Daily and P Skewness increase, Qcv Daily and $Q$ Skewness increase accordingly, and as these four increase the average strength of baseflow hypothesis decreases; thus, the average strength of wetness and/or intensity hypothesis must be increasing in order to simulate the observed runoff. The increase in average strength of wetness/intensity hypothesis expands the flux map area, i.e. higher degree of model flux equifinality which implies a higher degree of uncertainty of runoff hypotheses.

That said, the maximum strength of slow response hypothesis is independent of all catchments attributes, except for a weak inverse association with Slope Average, Elevation Mean, and KG Climate Num (which is a categorical variable). Figure 5.7 presents the maximum strength of each of the three runoff generation mechanisms across the 186 study catchments. As shown in Figure 5.7, SIMHYD could acceptably simulate the observed streamflow in all study catchments only through its baseflow runoff flux. In other words, slow response can be seen as the null hypothesis for runoff generation. On the other hand, wetness-dominated and intensity-dominated mechanisms are directly correlated with the same climatic and streamflow response attributes. With similar $R_{S}$ values but in the opposite direction, wetness-dominated and intensity-dominated mechanisms are alternatives (or competing hypotheses) to the null hypothesis of baseflow-dominated response. 


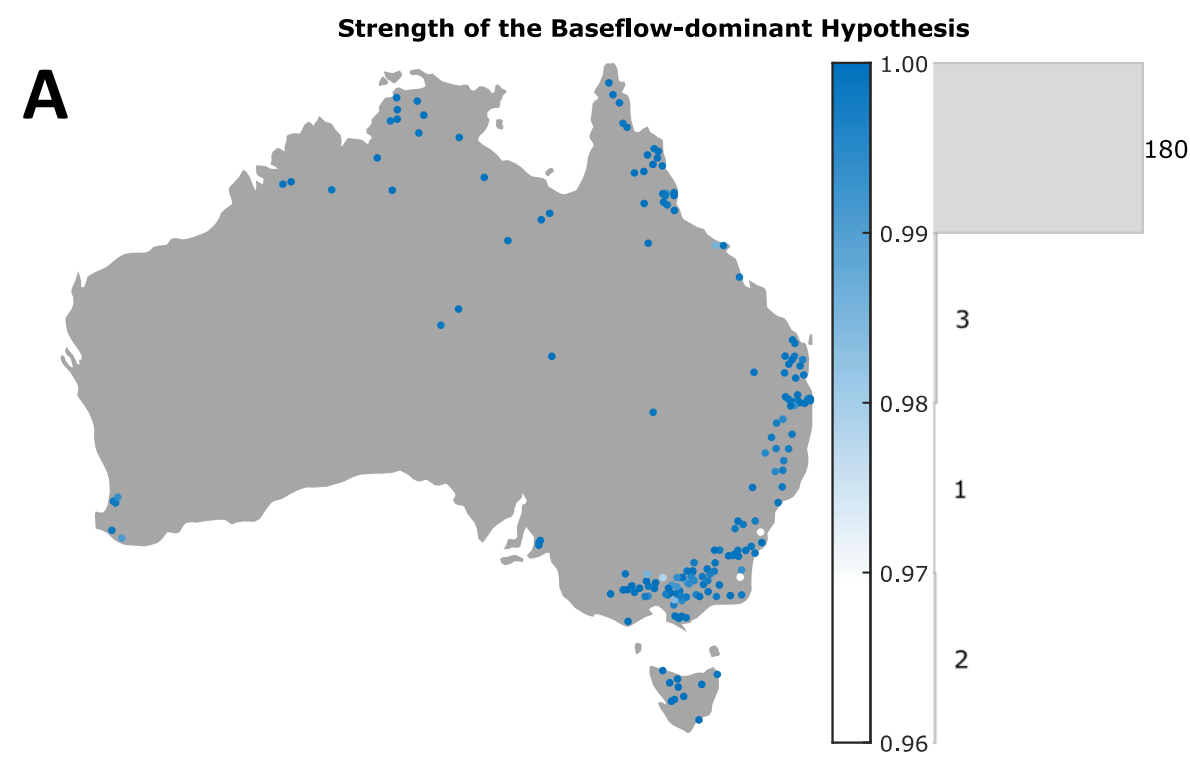

Strength of the Wetness-dominant Hypothesis
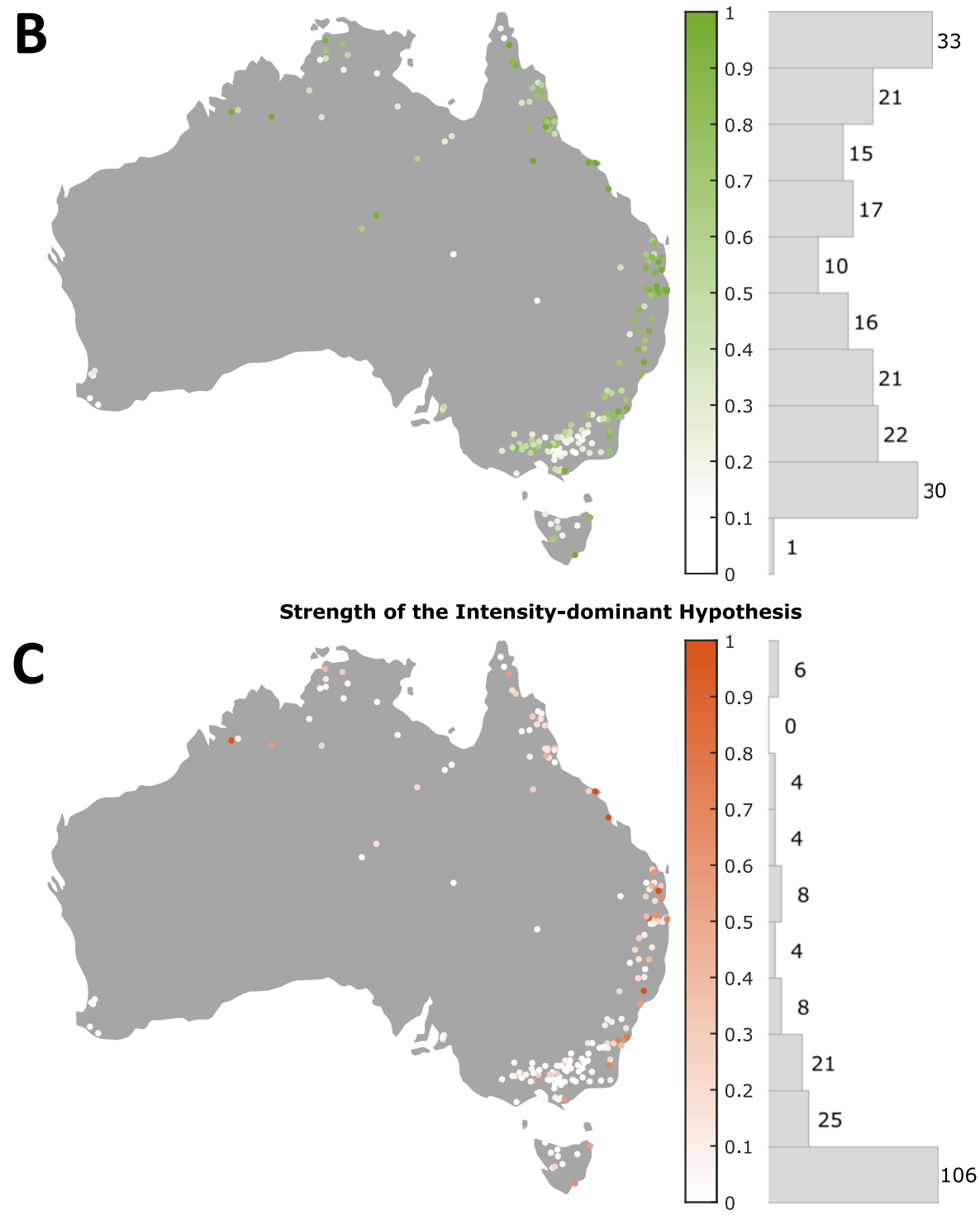

Figure 5.7. Maximum strength of each of the three runoff generation mechanisms (A: slow response, B: wetness-dominated response, and C: intensity-dominated response) across the Australian catchments. 
Wetness-dominated response is a stronger competing hypothesis in more catchments than the intensity-based response (compare the higher number of darker dots in Figures 5.7B than 5.7C). This is not surprising as the intensity-based runoff is mostly driven by sub-daily storm events (Saffarpour et al., 2016). That said, the maximum strength of intensity-based hypothesis is a positive monotonic function of the climatic (Pcv Daily and P Skewness) and streamflow response (Qcv Daily and Q Skewness) attributes (Figure 5.6).

Even though SIMHYD is a lumped model, there is a weak relationship between Catchment Area and runoff generation hypotheses. The average strength of slow response is a positive monotonic function of Catchment Area, while the average strength of wetness-based and

intensity-based responses is a negative function of Catchment Area. The weight of evidence tilts towards the slow response $\left(R_{S}\right.$ is 0.34 for slow response, and 0.30 for the other response hypotheses) as a more plausible runoff generation hypothesis. In other words, it is more likely that slow response streamflow generation is relatively more dominant in larger catchments.

It is worth mentioning that the correlation of Soil Depth and Elevation Range with the average strength of each of the three runoff response hypotheses is similarly weak (positive for slow response, and negative for the other two). That said, the average strength of the wetness-based response is independent of the Elevation Mean, while this attribute has a weak correlation with the average strength of the other two response.

\subsection{Limitations, future directions, and conclusions}

The take home message of this study is that uncertainties (or degree of model equifinality) associated with the representation of runoff processes (in SIMHYD, at least) are a positive monotonic function of climatic (PCV Daily and P Skewness) and streamflow response (QcV Daily and $Q$ Skewness) attributes. These four climatic and streamflow response attributes are strongly correlated with one another. Yet, they are independent of the Catchment Area except for PCV Daily with a weak positive correlation; possibly because higher precipitation heterogeneity in larger catchments can increase the daily variability of spatially-averaged precipitation time series. 
One major limitation of our study is that we only considered a single model structure. The promising results of this study provides a strong proof of concept that the uncertainties of model internal fluxes is a function of catchment attributes; hence should be further studied across both various model structures as well as other model fluxes. Zhang et al. (2020) demonstrated that using readily available (remote sensing and re-analysis) data products of evapotranspiration and soil moisture can constrain model simulations and hence improve model predictions. We hypothesize that using such data products to constrain the corresponding model fluxes will reduce the equifinality of model runoff fluxes. The rationale is that given the water balance equation, $P-\triangle S-A E T=Q$, while $Q$ is constrained by the observed streamflow for a given $\mathrm{P}$ forcing input, the model structure (i.e. model internal processes with free parameters) allows for an interplay between $\Delta S$ (soil moisture changes) and AET (actual evapotranspiration). $Q$ is the sum of internal runoff fluxes determined by other model fluxes and stores including $\triangle \mathrm{S}$ and $\mathrm{AET}$. So, constraining $\triangle \mathrm{S}$ and $\mathrm{AET}$ with the aforementioned data products should improve model realism and help constrain the runoff fluxes, thus reducing modelling uncertainties associated with the representation of runoff generating processes.

In addition, we we did not consider the temporal dynamics of runoff fluxes, and their dependency on catchment attributes. It would be insightful to evaluate the correspondence between the temporal evolution of catchment attributes, such as vegetation coverage and climatic attributes (Savenije \& Hrachowitz, 2017; Troch et al., 2013), and the representation of catchment processes by conceptual models at the catchment scale. Moreover, we only considered monotonic relationships between catchment attributes and model hypotheses using Spearman rank correlation $\left(R_{S}\right)$. Therefore, our results are an under-estimation of these relationships as non-monotonic dependencies are not explored. We should mention that we initially used distance correlation (Székely \& Rizzo, 2012, 2013; Szekely et al., 2007) as a measure of non-monotonic dependencies, but did not achieve informative results possibly due to the small length of the dataset (186 catchments only). More sophisticated and robust measures of non-monotonic and non-linear relationship would be valuable for future exploratory analyses.

\section{Acknowledgments}


The authors gratefully acknowledge the support of the University of Melbourne and Australian Government in carrying out this research; Sina Khatami was supported by Melbourne International Research and Fee Remission Scholarships (MIRS and MIFRS), Murray Peel was the recipient of an Australian Research Council Future Fellowship (FT120100130), and Tim Peterson was jointly funded by Australian Research Council Linkage Project LP130100958, Bureau of Meteorology (Australia), Department of Environment, Land, Water and Planning (Vic., Australia), Department of Economic Development, Jobs, Transport and Resources (Vic., Australia) and Power and Water Corporation (N.T., Australia).

\section{References}

Beven, K. (2012). Causal models as multiple working hypotheses about environmental processes. Comptes rendus geoscience, 344(2), 77-88.

Beven, K. (2019). Towards a methodology for testing models as hypotheses in the inexact sciences. Proceedings of the Royal Society A: Mathematical, Physical and Engineering Sciences, 475(2224), 20180862. doi:doi:10.1098/rspa.2018.0862

Beven, K., Smith, P., Westerberg, I., \& Freer, J. (2012). Comment on "Pursuing the method of multiple working hypotheses for hydrological modeling" by P. Clark et al. Water Resources Research, 48(11), W11801. doi:10.1029/2012WR012282

Blöschl, G., Bierkens, M. F. P., Chambel, A., Cudennec, C., Destouni, G., Fiori, A., et al. (2019). Twenty-three Unsolved Problems in Hydrology (UPH) - a community perspective. Hydrological Sciences Journal. doi:https://doi.org/10.1080/02626667.2019.1620507

Buytaert, W., \& Beven, K. (2011). Models as multiple working hypotheses: hydrological simulation of tropical alpine wetlands. Hydrological Processes, 25(11), 1784-1799. doi:10.1002/hyp.7936

Chamberlin, T. C. (1890). The method of multiple working hypotheses. Science, 15, 92-96.

Chiew, F., Peel, M., \& Western, A. (2002). Application and testing of the simple rainfallrunoff model SIMHYD. In V. P. Singh \& D. Frevert (Eds.), Mathematical models of small watershed hydrology and applications (pp. 335-367).

Clark, M. P., Kavetski, D., \& Fenicia, F. (2011). Pursuing the method of multiple working hypotheses for hydrological modeling. Water Resources Research, 47(9).

Clark, M. P., Kavetski, D., \& Fenicia, F. (2012). Reply to comment by K. Beven et al. on "Pursuing the method of multiple working hypotheses for hydrological modeling". Water Resources Research, 48(11). 
Duan, Q., Sorooshian, S., \& Gupta, V. (1992). Effective and efficient global optimization for conceptual rainfall-runoff models. Water Resources Research, 28(4), 1015-1031.

doi:10.1029/91WR02985

Fenicia, F., Savenije, H. H. G., Matgen, P., \& Pfister, L. (2008). Understanding catchment behavior through stepwise model concept improvement. Water Resources Research, 44(1). doi:doi:10.1029/2006WR005563

Fowler, K. J. A., Peel, M. C., Western, A. W., Zhang, L., \& Peterson, T. J. (2016). Simulating runoff under changing climatic conditions: Revisiting an apparent deficiency of conceptual rainfall-runoff models. Water Resources Research, 52(3), 1820-1846.

doi:10.1002/2015WR018068

Gallant, J., Dowling, T., Read, A., Wilson, N., Tickle, P., \& Inskeep, C. (2011). second SRTM derived digital elevation models user guide. Retrieved from Canberra, ACT, Australia: www.ga.gov.au/topographic-mapping/digital-elevation-data.html

Guo, D., Zheng, F., Gupta, H., \& Maier, H. R. (2020). On the Robustness of Conceptual Rainfall-Runoff Models to Calibration and Evaluation Dataset Splits Selection: A Large Sample Investigation. Water Resources Research. doi:10.1029/2019wr026752

Gupta, H. V., Kling, H., Yilmaz, K. K., \& Martinez, G. F. (2009). Decomposition of the mean squared error and NSE performance criteria: Implications for improving hydrological modelling. Journal of Hydrology, 377(1-2), 80-91.

doi:http://dx.doi.org/10.1016/i.jhydrol.2009.08.003

Jeffrey, S. J., Carter, J. O., Moodie, K. B., \& Beswick, A. R. (2001). Using spatial interpolation to construct a comprehensive archive of Australian climate data. Environmental Modelling \& Software, 16(4), 309-330. doi:https://doi.org/10.1016/S13648152(01)00008-1

Jones, D. A., Wang, W., \& Fawcett, R. (2009). High-quality spatial climate data-sets for Australia. Australian Meteorological and Oceanographic Journal, 58(4), 233-248. doi:10.22499/2.5804.003

Khatami, S., Peel, M. C., Peterson, T. J., \& Western, A. W. (2019). Equifinality and Flux Mapping: a new approach to model evaluation and process representation under uncertainty. Water Resources Research. doi:https://doi.org/10.1029/2018WR023750

Khatami, S., Peterson, T., Peel, M. C., \& Western, A. W. (2020). Evaluating catchment models as multiple working hypotheses: on the role of error metrics, parameter sampling, model structure, and data information content. doi:https://doi.org/10.1002/essoar.10504066.1

Khazaei, B., Khatami, S., Alemohammad, S. H., Rashidi, L., Wu, C., Madani, K., et al. (2019). Climatic or regionally induced by humans? Tracing hydro-climatic and land-use changes to better understand the Lake Urmia tragedy. Journal of Hydrology, 569, 203-217. doi:https://doi.org/10.1016/i.jhydrol.2018.12.004 
Knoben, W. J. M., Woods, R. A., \& Freer, J. E. (2018). A Quantitative Hydrological Climate Classification Evaluated With Independent Streamflow Data. Water Resources Research, 54(7), 5088-5109. doi:doi:10.1029/2018WR022913

Krueger, T., Freer, J., Quinton, J. N., Macleod, C. J. A., Bilotta, G. S., Brazier, R. E., et al. (2010). Ensemble evaluation of hydrological model hypotheses. Water Resources Research, 46(7). doi:10.1029/2009wr007845

Lymburner, L., Tan, P., Mueller, N. T., R., Thankappan, M. I., A., Lewis, A., \& Randall, L. S., U. (2011). The National Dynamic Land Cover Dataset. Retrieved from Symonston, ACT: http://www.ga.gov.au/scientific-topics/earth-obs/accessing-satellite-imagery/landcover

Peel, M. C., Chiew, F. H., Western, A. W., \& McMahon, T. A. (2000). Extension of unimpaired monthly streamflow data and regionalisation of parameter values to estimate streamflow in ungauged catchments. Retrieved from Report prepared for the National Land and Water Resources Audit, In Australian Natural Resources Atlas, Pages 37.:

http://people.eng.unimelb.edu.au/mpeel/NLWRA.pdf

Peel, M. C., Finlayson, B. L., \& McMahon, T. A. (2007). Updated world map of the KöppenGeiger climate classification. Hydrol. Earth Syst. Sci., 11(5), 1633-1644. doi:10.5194/hess-111633-2007

Pfister, L., \& Kirchner, J. W. (2017). Debates-Hypothesis testing in hydrology: Theory and practice. Water Resources Research, 53(3), 1792-1798. doi:10.1002/2016wr020116

Saffarpour, S., Western, A. W., Adams, R., \& McDonnell, J. J. (2016). Multiple runoff processes and multiple thresholds control agricultural runoff generation. Hydrol. Earth Syst. Sci., 20(11), 4525-4545. doi:10.5194/hess-20-4525-2016

Savenije, H. H. G., \& Hrachowitz, M. (2017). HESS Opinions "Catchments as metaorganisms - a new blueprint for hydrological modelling". Hydrol. Earth Syst. Sci., 21(2), 11071116. doi:10.5194/hess-21-1107-2017

Schaefli, B., \& Gupta, H. V. (2007). Do Nash values have value? Hydrological Processes, 21(15), 2075-2080. doi:10.1002/hyp.6825

Seibert, J., Vis, M. J. P., Lewis, E., \& van Meerveld, H. J. (2018). Upper and lower benchmarks in hydrological modelling. Hydrological Processes, 32(8), 1120-1125. doi:10.1002/hyp.11476

Székely, G. J., \& Rizzo, M. L. (2012). On the uniqueness of distance covariance. Statistics \& Probability Letters, 82(12), 2278-2282. doi:https://doi.org/10.1016/i.spl.2012.08.007

Székely, G. J., \& Rizzo, M. L. (2013). The distance correlation t-test of independence in high dimension. Journal of Multivariate Analysis, 117, 193-213.

doi:https://doi.org/10.1016/i.jmva.2013.02.012

Szekely, G. J., Rizzo, M. L., \& Bakirov, N. K. (2007). Measuring and testing dependence by correlation of distances. Ann. Statist., 35(6), 2769-2794. doi:10.1214/009053607000000505 
Troch, P. A., Carrillo, G., Sivapalan, M., Wagener, T., \& Sawicz, K. (2013). Climatevegetation-soil interactions and long-term hydrologic partitioning: signatures of catchment co-evolution. Hydrol. Earth Syst. Sci., 17(6), 2209-2217. doi:10.5194/hess-17-2209-2013

Turner, M. (2012). Hydrologic Reference Station Selection Guidelines. Retrieved from Melbourne, Australia:

http://www.bom.gov.au/water/hrs/media/static/papers/Selection Guidelines.pdf

Zhang, Y., Chiew, F. H. S., Liu, C., Tang, Q., Xia, J., Tian, J., et al. (2020). Can remotely sensed actual evapotranspiration facilitate hydrological prediction in ungauged regions without runoff calibration? Water Resources Research. doi:10.1029/2019wr026236 


\section{Conclusions}

\subsection{Summary of main findings and contributions}

The underlying premise of this thesis has been evaluating catchment models as Multiple Working Hypotheses under Uncertainty. Below, I briefly discuss the main findings and contributions of each chapter, each investigating particular aspects of this premise.

Chapter 2 Theoretical Underpinnings (Paper 1): In short, the main contribution of this chapter has been developing a theoretical framework to advance system-theoretic understanding of hydrological processes (real-world systems) and their models (conceptual systems). I discussed that the concept of equifinality is conflated with uncertainty; while the two are deeply interconnected, they are not equivalent. In addition, despite the widespread use of the term equifinality within hydrological and geosciences literature, it is mostly understood as model structure or parameter equifinality, undermining the multi-faceted nature of equifinality. Based on a meta-synthesis of a broad body of literature, I proposed a theoretical framework to conceptualise various dimensions of equifinality and their interrelationships. The three main facets of equifinality are:

- process-equifinality: real-world possibilities than can equally lead to a given phenomenon before it occurs. A feature of the real world itself independent of our knowledge of the real world;

- model-equifinality: various models can plausibly represent a real-world phenomenon for a particular purpose and given some underlying assumptions and conditional on our knowledge uncertainty; and

- explanation-equifinality: various plausible explanations for a given phenomenon can be inferred conditional on our knowledge uncertainty.

I further discussed the inter-connection of various aspects of equifinality and uncertainty; particularly the crucial role of knowledge uncertainty that implies partial and approximate understanding of real-world phenomena at best. Scientific models, which are the main tools 
for knowledge acquisition, are in turn approximate representations of real-world processes. This approximate nature of both knowledge and models in addition to equifinality (inherent to both real-world systems and their models) give rise to multiple hypotheses (including models) of real-world phenomena. Therefore, inference under uncertainty (incomplete information) implies formulating and testing multiple working hypotheses (MWH). In other words, model-based inferences require developing and evaluating plausible model ensembles that adequately fit the purpose.

Chapter 3 (Paper 2): In light of the framework outlined in Chapter 2, I focused on modelequifinality in this chapter. Particularly, I furthered the theoretical discussion by identifying six distinct, yet interconnected, facets of model equifinality: equifinality of model structures, parameters, performance metrics, initial/boundary conditions, forcing inputs, and internal fluxes of models. I argued that while the convention is to account for the equifinality of model parameters, evaluating the equifinality of internal fluxes within a given model structure provides valuable insights into the model behaviour and process representation, which are not easily (or even at all) inferable by conventional methods. I developed a new method called flux mapping to evaluate catchment models based on the equifinality of their runoff generating fluxes. Using a set of Australian catchments as examples, I demonstrated that even within a very narrow margin of model error, distinct combinations of runoff fluxes can equally simulate an observed streamflow. These runoff fluxes represent different modes of catchment response. In SIMHYD for example, the infiltration excess overland flow flux represents intensity-based response, interflow and saturation excess overland flow flux corresponds to wetness-based response, and baseflow flux denotes slow response for runoff generation at the catchment scale. I illustrated that while the distribution of SIMHYD parameters are similar across the example catchments, their flux maps are distinct. This is a new insight into characterising the representation of runoff generation in catchment models.

Chapter 4 (Paper 3): Model behaviour and hence the flux map is the result of the interplay between factors of model structure and parameterisation, information content of forcing and evaluation data, and error metrics. The main contribution of this chapter has been to disentangle the role of each factor, and demonstrate how each may impact model-based inferences (i.e. MWH) about catchment-scale runoff generation. First, I conducted a 
sensitivity analysis of three widely-used error metrics - namely Nash-Sutcliffe Efficiency (NSE), Kling-Gupta Efficiency skill score (KGEss), and Willmott's refined Index of Agreement (WIA) - to different synthetic error types. This analysis helped to characterise the behaviour of these metrics under different hypothetical errors, independent of any modelling. I illustrated that KGEss consistently accounts for bias, variability, and correlation errors, whereas NSE is less sensitive to bias and variability errors relative to correlation errors. This finding has important implications to improve the reliability of catchment model evaluations: improving the interpretations of model performance metrics, avoiding deficient metrics, as well as offering new guidelines for developing future error metrics. That said, based on the analysis of 221 Australian catchments using two catchment models of SIMHYD and SACRAMENTO (with comparable runoff fluxes), I could not discern a systematic relationship between the error metric, number of acceptable model runs, sampling sufficiency, and size/type of the corresponding flux maps generalisable to all cases. I presented various examples to demonstrate that it is not possible to generalise model-based inferences founded only on one or few of these factors, given the complex and non-linear nature of their interactions in generating model simulations. For instance, the number of acceptable model runs is not a function of performance metric, acceptability threshold, or the model structure. A higher model dimensionality (e.g. SACRAMENTO has more stores, fluxes, and parameters than SIMHYD) does not necessarily imply more flexibility in the model space to produce a larger set of runoff hypotheses (whether in terms of the number of acceptable model runs or runoff mechanisms). Further, I concluded that relying on large random (e.g. Latin Hyper Cube) samples of parameter sets ( $>10^{6}$ sets), without considering the model solution space (e.g. using guided search routine), is a major source of uncertainty in evaluating catchment models and formulating $\mathrm{MWH}$. To produce large ensembles of model runs, I used two strategies for sampling the model parameter space; namely random Latin Hypercube Sampling (LHS), and guided search of Shuffled Complex Evolution (SCE) routine. I showed that although SCE is not superior to LHS in all cases, it outperforms LHS in most cases in identifying parameter sets with higher model performance. That said, due to its inherent random sampling, it was inferior to LHS in $4 \%$ of modelling cases, even when SCE was repeated 10 times in each modelling case. Therefore, I concluded that employing guided-search routines for sampling the model space and generating MWH is a more reliable strategy. 
Chapter 5 (Paper 4): To study the role of data information content, in Chapter 4, I compared the flux map of HRS catchments with different forcing inputs to their catchment models. I could not derive a systematic relationship as discussed. So, the aim of this chapter was to study the relationship between catchment attributes (i.e. physiographic, climatic, and streamflow response characteristics) and flux maps of the corresponding catchment models. In other words, to study how different catchment characteristics control the runoff generation hypotheses across HRS catchments. Using SIMHYD ensembles of $10^{6}$ model runs for each HRS catchment, runoff generation hypotheses were formulated based on the interaction of intensity-based, wetness-based, and slow responses of SIMHYD. The hypotheses were derived from model runs with acceptable performance and sufficient parameter sampling. For model performance acceptability, I benchmarked KGEss against the catchment-specific calendar day average observed flow model, which is more informative than the conventional benchmark of average overall observed flow. Relative parameter sampling sufficiency was also defined based on the difference in the efficacy of LHS and SCE in each catchment. I examined the dependency of these hypotheses on 22 different catchment attributes across 186 of the HRS catchments with acceptable model performance and sufficient parameter sampling. I used Spearman rank correlation coefficient $\left(R_{s}\right)$ which measures linear and non-linear monotonic relationships. I identified that generally streamflow characteristics have the first order of influence on runoff hypotheses, followed by climate and then physiographic attributes. Particularly, daily flow coefficient of variability (Qcv) and skewness ( $Q$ Skewness), followed by the same summary statistics of precipitation (PCV and P Skewness). These four attributes are strongly correlated with one another, and represent the dynamics of rainfall-runoff signal within a catchment system. Higher PcV and Qcv denotes higher day-to-day variability in rainfall input to the catchment and its associated flow response, thus higher the uncertainties in the system behaviour. This uncertainty propagates through the catchment model and translates into a higher degree of equifinality in model runoff fluxes, i.e. higher uncertainties around the representation of runoff generation in the catchment model. This confirms that while the representation of runoff generation at the catchment scale within catchment models is a simplification of reality, these models are process informed and hence informative in simulating catchment processes. 
With the exception of catchment area, other physiographic attributes such as catchment topography and vegetation coverage showed a weak control (i.e. lower $R_{s}$ values). This shows that despite the lumped nature of catchment models aggregating the catchment heterogeneity into a single spatial unit, the footprint of catchment area is present in the model simulations. Higher degree of flux equifinality - in smaller catchments with higher CV and skewness in their daily $\mathrm{P}$ and $\mathrm{Q}$ - implies larger uncertainties associated with the representation of runoff processes at catchment scale, despite the smaller model errors (higher performance metric values). This poses a greater challenge for reliable and realistic simulation and prediction of streamflow in such cases. The findings of this chapter provides insights into the functional connectivity of catchment attributes and the internal dynamics of model runoff fluxes.

\subsection{Limitations and future directions}

While the findings of this thesis provides major contributions to the domain of catchment modelling, this work has its limitations. I discussed some of these limitations in more detail within each chapter. Here, I coalesce the discussion of limitations including suggestions to progress catchment model evaluations in future.

Among various internal components of catchment models, I only focused on runoff fluxes. The approaches and methods for model evaluations conducted in this thesis, could be extended to other model fluxes and stores; namely, evapotranspiration fluxes and soil moisture stores. Particularly that remote sensing and re-analysis data products are readily available for actual evapotranspiration and soil moisture globally. Incorporating these data in evaluating and constraining the model internal behaviour can be a major step forward to both improve model simulations (Zhang et al., 2020), as well as identifying and reducing uncertainties associated with model structure and predictions. Further, the scope of this study was limited to only two model structures (SIMHYD and SACRAMENTO), as they have comparable runoff fluxes. Future studies can benefit from a larger set of models with comparable fluxes to better characterise the model structural uncertainties. Likewise, the sample size of study catchments and their attributes could also be extended to cover a broader range of climates and landscapes, and reduce the geographical bias in hydrological sciences (Burt \& McDonnell, 2015). In doing so, it is also insightful to examine different time 
periods and scales, e.g. how the equifinality of model fluxes and their dependencies on catchment attributes change across different seasons, years, and decades. In Chapter 5, I used a single long-term average value for each catchment attribute. This may not be as important for attributes such as topography (elevation and slope) with slower rates of variability and change. That said, attributes such as vegetation coverage usually have significant variability on seasonal, annual, and decadal scales, and may significantly change due to local human activities (Khazaei et al., 2019). Therefore, it would be interesting to study the relationship between these highly variable attributes and the corresponding model response across different time periods/scales, in catchments where the underlying data for those attributes are available.

On a more technical level, I suggest that using advanced parameter sampling methods, such as Progressive Latin Hypercube Sampling (Sheikholeslami \& Razavi, 2017) and Dynamically Dimensioned Search routine (Asadzadeh \& Tolson, 2013; Tolson \& Shoemaker, 2007), would enhance model parameterisation; instead of relying on large random samples that implies higher sampling uncertainty and are computationally costly. Furthermore, for studying the relationship between catchment attributes and model internal dynamics, I suggest using more sophisticated measures that can capture non-monotonic relationships as well; such as entropy-based or other information theoretic measures (Bennett et al., 2019) as well as machine learning techniques (Papacharalampous et al., 2019; Tyralis et al., 2019).

In this thesis, I examined how different components of a hydrograph are simulated within a catchment model, namely model fluxes representing infiltration-excess overland flow, saturation-excess overland flow and interflow, and baseflow. The spatio-temporal scale, i.e. catchment and daily scale, is an important limitation of this work, similar to other studies of catchment modelling. Using lumped daily models, catchments are treated as a single spatial unit, where heterogeneity and sub-daily variations of their processes are overlooked and aggregated into daily catchment averages. Despite such simplifications and other sources/types of modelling uncertainties, a conceptual model and its internal dynamics can still be indicative of different (dominant) catchment processes (Dunn et al., 2008; Guo et al., 2017; Lerat et al., 2012). That said, justifying the suitability of catchment models for hypothesis testing of processes that are primarily sub-daily, such as infiltration excess overland flow generation, is the Achilles' heel of this work. Moreover, in order to evaluate 
which runoff $\mathrm{MWH}$ are more plausible in a given catchment and period, direct field measurements of such fluxes are needed, which are often limited in both time and space. Therefore, evaluation of the realism of these simulated fluxes is a fundamental limitation. A possible solution can be to integrate field measurements such as stable water isotopes into model evaluation (McGlynn \& McDonnell, 2003). Isotopic data could be informative to constrain the model internal fluxes (Ala-aho et al., 2017), for which it is required to characterise dominant runoff generating mechanisms at the catchment scale compatible with model internal fluxes. This approach can facilitate a symbiotic learning of catchment processes and their model representations and to bridge the gap between modellers and experimental hydrologists (Seibert \& McDonnell, 2002).

Another implication of the finding of this study is for simulating runoff in ungauged basins (Hrachowitz et al., 2013). I established in Chapter 5 that there is a strong relationship between rainfall-runoff variability in the real-world catchment, and the variability of runoff fluxes within the corresponding catchment model. Rainfall variability in time is indicated by day-to-day variation of rainfall (coefficient of variability of rainfall, $P c v$ ). The variability of the rainfall magnitude is measured by the skewness of its distribution ( $P$ Skewness), with higher P Skewness indicating higher frequency of small rainfalls with rare large extremes (distribution tail). This variation of rainfall is strongly coupled with streamflow variability, which in turn translates into variability of model runoff fluxes (i.e. equifinality of model runoff fluxes). This cascade of variability from rainfall (as input to both catchment and its model) to runoff (both in catchment response and fluxes of its models) could be used as a benchmark for evaluating (and possibly constraining) the internal behaviour of models for simulating ungauged catchments; i.e. as a signature for ungauged catchments (Westerberg et al., 2016).

\section{References}

Ala-aho, P., Tetzlaff, D., McNamara, J. P., Laudon, H., \& Soulsby, C. (2017). Using isotopes to constrain water flux and age estimates in snow-influenced catchments using the STARR (Spatially distributed Tracer-Aided Rainfall-Runoff) model. Hydrol. Earth Syst. Sci., 21(10), 5089-5110. doi:10.5194/hess-21-5089-2017

Asadzadeh, M., \& Tolson, B. (2013). Pareto archived dynamically dimensioned search with hypervolume-based selection for multi-objective optimization. Engineering Optimization, 45(12), 1489-1509. doi:10.1080/0305215X.2012.748046 
Bennett, A., Nijssen, B., Ou, G., Clark, M., \& Nearing, G. (2019). Quantifying Process Connectivity With Transfer Entropy in Hydrologic Models. Water Resources Research, 55(6), 4613-4629. doi:10.1029/2018wr024555

Burt, T. P., \& McDonnell, J. J. (2015). Whither field hydrology? The need for discovery science and outrageous hydrological hypotheses. Water Resources Research, 51(8), 59195928. doi:10.1002/2014WR016839

Dunn, S. M., Freer, J., Weiler, M., Kirkby, M. J., Seibert, J., Quinn, P. F., et al. (2008). Conceptualization in catchment modelling: simply learning? Hydrological Processes, 22(13), 2389-2393. doi:10.1002/hyp.7070

Guo, D., Westra, S., \& Maier, H. R. (2017). Impact of evapotranspiration process representation on run off projections from conceptual rainfall-runoff models. Water Resources Research, 53(1), 435-454. doi:10.1002/2016WR019627

Hrachowitz, M., Savenije, H. H. G., Blöschl, G., McDonnell, J. J., Sivapalan, M., Pomeroy, J. W., et al. (2013). A decade of Predictions in Ungauged Basins (PUB) - a review. Hydrological Sciences Journal, 58(6), 1198-1255. doi:10.1080/02626667.2013.803183

Khazaei, B., Khatami, S., Alemohammad, S. H., Rashidi, L., Wu, C., Madani, K., et al. (2019). Climatic or regionally induced by humans? Tracing hydro-climatic and land-use changes to better understand the Lake Urmia tragedy. Journal of Hydrology, 569, 203-217. doi:https://doi.org/10.1016/i.jhydrol.2018.12.004

Lerat, J., Andréassian, V., Perrin, C., Vaze, J., Perraud, J. M., Ribstein, P., et al. (2012). Do internal flow measurements improve the calibration of rainfall-runoff models? Water Resources Research, 48(2). doi:10.1029/2010WR010179

McGlynn, B. L., \& McDonnell, J. J. (2003). Quantifying the relative contributions of riparian and hillslope zones to catchment runoff. Water Resources Research, 39(11). doi:10.1029/2003wr002091

Papacharalampous, G., Tyralis, H., \& Koutsoyiannis, D. (2019). Comparison of stochastic and machine learning methods for multi-step ahead forecasting of hydrological processes. Stochastic Environmental Research and Risk Assessment, 33(2), 481-514. doi:10.1007/s00477-018-1638-6

Seibert, J., \& McDonnell, J. J. (2002). On the dialog between experimentalist and modeler in catchment hydrology: Use of soft data for multicriteria model calibration. Water Resources Research, 38(11), 23-21-23-14. doi:10.1029/2001WR000978

Sheikholeslami, R., \& Razavi, S. (2017). Progressive Latin Hypercube Sampling: An efficient approach for robust sampling-based analysis of environmental models. Environmental Modelling \& Software, 93, 109-126. doi:https://doi.org/10.1016/i.envsoft.2017.03.010

Tolson, B. A., \& Shoemaker, C. A. (2007). Dynamically dimensioned search algorithm for computationally efficient watershed model calibration. Water Resources Research, 43(1). doi:10.1029/2005wr004723 
Tyralis, H., Papacharalampous, G., Burnetas, A., \& Langousis, A. (2019). Hydrological postprocessing using stacked generalization of quantile regression algorithms: Large-scale application over CONUS. Journal of Hydrology, 577, 123957.

doi:https://doi.org/10.1016/j.jhydrol.2019.123957

Westerberg, I. K., Wagener, T., Coxon, G., McMillan, H. K., Castellarin, A., Montanari, A., et al. (2016). Uncertainty in hydrological signatures for gauged and ungauged catchments. Water Resources Research, 52(3), 1847-1865. doi:doi:10.1002/2015WR017635

Zhang, Y., Chiew, F. H. S., Liu, C., Tang, Q., Xia, J., Tian, J., et al. (2020). Can remotely sensed actual evapotranspiration facilitate hydrological prediction in ungauged regions without runoff calibration? Water Resources Research. doi:10.1029/2019wr026236 


\section{Supporting Information for Chapter 3 (Paper 2)}

This Supporting Information is published (citation below) and included in this thesis with the permission of the publisher John Wiley and Sons.

Khatami, S., Peel, M. C., Peterson, T. J., \& Western, A.

W. (2019). Equifinality and flux mapping: A new approach to model

evaluation and process representation under uncertainty. Water Resources

Research, 55, 8922-8941. https://doi.org/10.1029/2018WR023750

It is also available for download from the link http://go.unimelb.edu.au/4aej. 


\section{Supporting Information for Chapter 4 (Paper 3)}
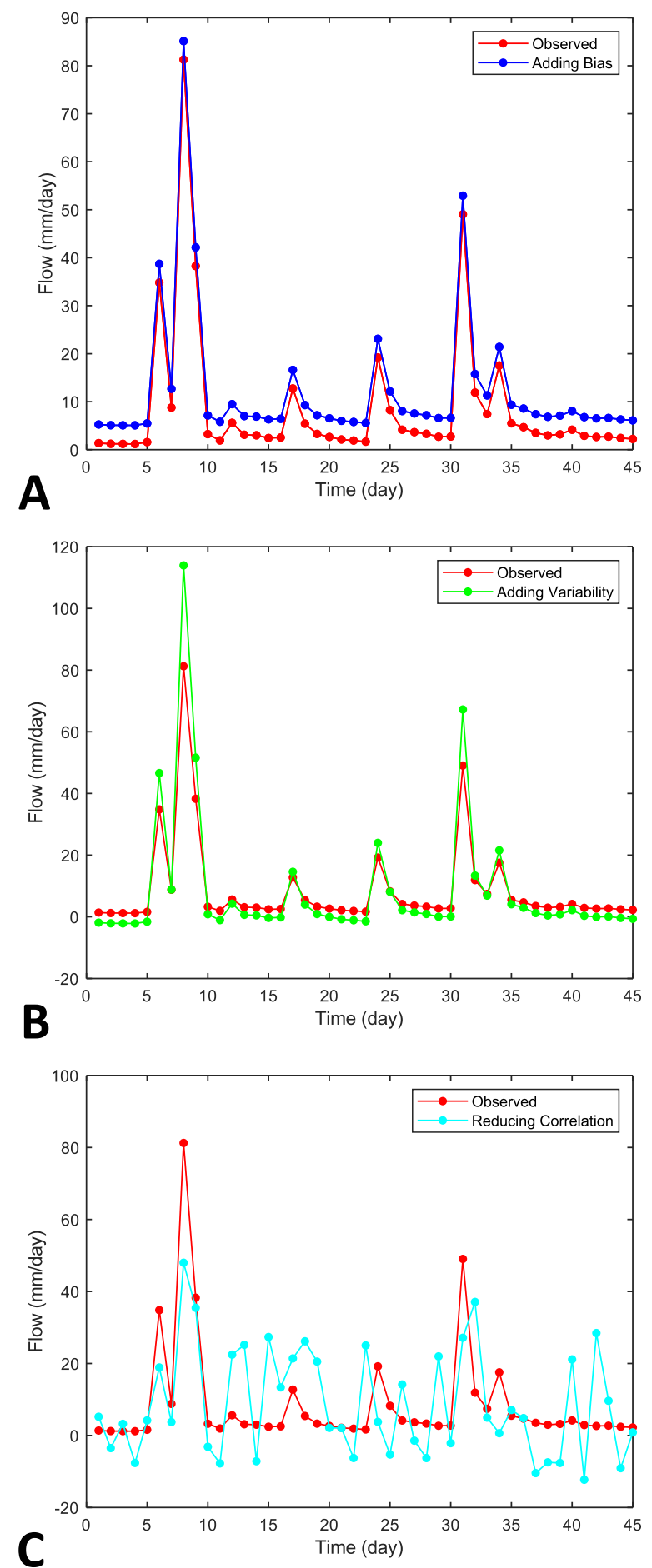

Figure S1. Illustration of how the three error types of bias (A), variability (B), and correlation (C) corrupt an observed series, step 1. 
Table S1. The original flow series $(0)$ and the three sets of corrupted series that were used in error metric sensitivity analysis. Each set of the three corruptions - biascorrupted (B), variability-corrupted (V), and correlation-corrupted (C) - entails 20 steps (e.g. B1, B2, ... B20) based on the description in section 2.5 of the manuscript.

Excel file for this table is downloadable from the link http://go.unimelb.edu.au/5aej.

\begin{tabular}{|c|c|c|c|c|c|c|c|c|c|c|c|c|c|c|c|c|c|c|c|c|}
\hline \multirow{2}{*}{$\begin{array}{c}\text { Original } \\
\text { series }\end{array}$} & \multicolumn{20}{|c|}{ Corrupted series by Bias Error } \\
\hline & Step 1 & Step 2 & Step 3 & Step 4 & Step 5 & Step 6 & Step 7 & Step 8 & Step 9 & Step 10 & Step 11 & Step 12 & Step 13 & Step 14 & Step 15 & Step 16 & Step 17 & Step 18 & Step 19 & Step 20 \\
\hline 1.37 & 1.80 & 2.24 & 2.67 & 3.10 & 3.53 & 3.96 & 4.39 & 4.83 & 5.26 & 5.69 & 6.12 & 6.55 & 6.98 & 7.41 & 7.85 & 8.28 & 8.71 & 9.14 & 9.57 & 10.00 \\
\hline 1.23 & 1.66 & 2.09 & 2.52 & 2.95 & 3.38 & 3.82 & 4.25 & 4.68 & 5.11 & 5.54 & 5.97 & 6.41 & 6.84 & 7.27 & 7.70 & 8.13 & 8.56 & 8.99 & 9.43 & 9.86 \\
\hline 1.21 & 1.64 & 2.07 & 2.50 & 2.93 & 3.36 & 3.80 & 4.23 & 4.66 & 5.09 & 5.52 & 5.95 & 6.38 & 6.82 & 7.25 & 7.68 & 8.11 & 8.54 & 8.97 & 9.41 & 9.84 \\
\hline 1.19 & 1.62 & 2.05 & 2.49 & 2.92 & 3.35 & 3.78 & 4.21 & 4.64 & 5.07 & 5.51 & 5.94 & 6.37 & 6.80 & 7.23 & 7.66 & 8.10 & 8.53 & 8.96 & 9.39 & 9.82 \\
\hline 1.59 & 2.02 & 2.45 & 2.88 & 3.32 & 3.75 & 4.18 & 4.61 & 5.04 & 5.47 & 5.90 & 6.34 & 6.77 & 7.20 & 7.63 & 8.06 & 8.49 & 8.93 & 9.36 & 9.79 & 10.22 \\
\hline 34.82 & 35.25 & 35.68 & 36.11 & 36.54 & 36.97 & 37.41 & 37.84 & 38.27 & 38.70 & 39.13 & 39.56 & 39.99 & 40.43 & 40.86 & 41.29 & 41.72 & 42.15 & 42.58 & 43.01 & 43.45 \\
\hline 8.78 & 9.21 & 9.65 & 10.08 & 10.51 & 10.94 & 11.37 & 11.80 & 12.23 & 12.67 & 13.10 & 13.53 & 13.96 & 14.39 & 14.82 & 15.26 & 15.69 & 16.12 & 16.55 & 16.98 & 17.41 \\
\hline 81.26 & 81.69 & 82.12 & 82.55 & 82.98 & 83.41 & 83.84 & 84.28 & 84.71 & 85.14 & 85.57 & 86.00 & 86.43 & 86.86 & 87.30 & 87.73 & 88.16 & 88.59 & 89.02 & 89.45 & 89.89 \\
\hline 38.26 & 38.69 & 39.13 & 39.56 & 39.99 & 40.42 & 40.85 & 41.28 & 41.71 & 42.15 & 42.58 & 43.01 & 43.44 & 43.87 & 44.30 & 44.73 & 45.17 & 45.60 & 46.03 & 46.46 & 46.89 \\
\hline 3.25 & 3.69 & 4.12 & 4.55 & 4.98 & 5.41 & 5.84 & 6.28 & & & & & & & & 9.73 & & 10.59 & 11.02 & 11.45 & 11.88 \\
\hline 1.94 & 2.37 & 2.80 & 3.24 & 3.67 & 4.10 & 4.53 & 4.96 & 5.39 & 5.83 & 6.26 & 6.69 & 7.12 & 7.55 & 7.98 & 8.41 & 8.85 & 9.28 & 9.71 & 10.14 & 10.57 \\
\hline 5.61 & 6.05 & 6.48 & 6.91 & 7.34 & 7.77 & 8.20 & 8.63 & 9.07 & 9.50 & 9.93 & 10.36 & 10.79 & 11.22 & 11.66 & 12.09 & 12.52 & 12.95 & 13.38 & 13.81 & 14.24 \\
\hline 3.12 & 3.55 & 3.98 & 4.42 & 4.85 & 5.28 & 5.71 & 6.14 & 6.57 & 7.00 & 7.44 & 7.87 & 8.30 & 8.73 & 9.16 & 9.59 & 10.03 & 10.46 & 10.89 & 11.32 & 11.75 \\
\hline 3.00 & 3.43 & 3.87 & 4.30 & 4.73 & 5.16 & 5.59 & 6.02 & 6.46 & 6.89 & 7.32 & 7.75 & 8.18 & 8.61 & 9.04 & 9.48 & 9.91 & 10.34 & 10.77 & 11.20 & 11.63 \\
\hline 2.43 & 2.86 & 3.30 & 3.73 & 4.16 & 4.59 & 5.02 & 5.45 & 5.88 & 6.32 & 6.75 & 7.18 & 7.61 & 8.04 & 8.47 & 8.91 & 9.34 & 9.77 & 10.20 & 10.63 & 11.06 \\
\hline 2.54 & 2.98 & 3.41 & 3.84 & 4.27 & 4.70 & 5.13 & 5.57 & 6.00 & 6.43 & 6.86 & 7.29 & 7.72 & 8.15 & 8.59 & 9.02 & 9.45 & 9.88 & 10.31 & 10.74 & 11.18 \\
\hline 12.75 & 13.18 & 13.61 & 14.04 & 14.47 & 14.90 & 15.33 & 15.77 & 16.20 & 16.63 & 17.06 & 17.49 & 17.92 & 18.35 & 18.79 & 19.22 & 19.65 & 20.08 & 20.51 & 20.94 & 21.38 \\
\hline 5.42 & 5.85 & 6.28 & 6.71 & 7.15 & 7.58 & 8.01 & 8.44 & 8.87 & 9.30 & 9.74 & 10.17 & 10.60 & 11.03 & 11.46 & 11.89 & 12.32 & 12.76 & 13.19 & 13.62 & 14.05 \\
\hline 3.29 & 3.73 & 4.16 & 4.59 & 5.02 & 5.45 & & 6.32 & & & & & & & & 9.77 & & 10.63 & & & 11.93 \\
\hline 2.66 & 3.10 & 3.53 & 3.96 & 4.39 & 4.82 & 5.25 & 5.68 & 6.12 & 6.55 & 6.98 & 7.41 & 7.84 & 8.27 & 8.71 & 9.14 & 9.57 & 10.00 & 10.43 & 10.86 & 11.29 \\
\hline 2.13 & 2.56 & 2.99 & 3.43 & 3.86 & 4.29 & 4.72 & 5.15 & 5.58 & 6.01 & 6.45 & 6.88 & 7.31 & 7.74 & 8.17 & 8.60 & 9.04 & 9.47 & 9.90 & 10.33 & 10.76 \\
\hline 1.91 & 2.34 & 2.77 & 3.20 & 3.63 & 4.06 & 4.50 & 4.93 & 5.36 & 5.79 & 6.22 & 6.65 & 7.08 & 7.52 & 7.95 & 8.38 & 8.81 & 9.24 & 9.67 & 10.11 & 10.54 \\
\hline 1.67 & 2.10 & 2.54 & 2.97 & 3.40 & 3.83 & 4.26 & 4.69 & 5.12 & 5.56 & 5.99 & 6.42 & 6.85 & 7.28 & 7.71 & 8.15 & 8.58 & 9.01 & 9.44 & 9.87 & 10.30 \\
\hline 19.21 & 19.64 & 20.07 & 20.50 & 20.94 & 21.37 & 21.80 & 22.23 & 22.66 & 23.09 & 23.52 & 23.96 & 24.39 & 24.82 & 25.25 & 25.68 & 26.11 & 26.54 & 26.98 & 27.41 & 27.84 \\
\hline 8.26 & 8.69 & 9.12 & 9.56 & 9.99 & 10.42 & 10.85 & 11.28 & 11.71 & 12.15 & 12.58 & 13.01 & 13.44 & 13.87 & 14.30 & 14.73 & 15.17 & 15.60 & 16.03 & 16.46 & 16.89 \\
\hline 4.16 & 4.59 & 5.02 & 5.46 & 5.89 & 6.32 & 6.75 & 7.18 & 7.61 & 8.05 & 8.48 & 8.91 & 9.34 & 9.77 & 10.20 & 10.63 & 11.07 & 11.50 & 11.93 & 12.36 & 12.79 \\
\hline 3.66 & 4.09 & 4.52 & 4.96 & 5.39 & 5.82 & 6.25 & 6.68 & 7.11 & 7.55 & 7.98 & 8.41 & 8.84 & 9.27 & 9.70 & 10.13 & 10.57 & 11.00 & 11.43 & 11.86 & 12.29 \\
\hline 3.30 & 3.74 & 4.17 & 4.60 & 5.03 & 5.46 & 5.89 & 6.32 & 6.76 & 7.19 & 7.62 & 8.05 & 8.48 & 8.91 & 9.34 & 9.78 & 10.21 & 10.64 & 11.07 & 11.50 & 11.93 \\
\hline 2.70 & 3.13 & 3.56 & 4.00 & 4.43 & 4.86 & 5.29 & 5.72 & 6.15 & 6.58 & 7.02 & 7.45 & 7.88 & 8.31 & 8.74 & 9.17 & 9.61 & 10.04 & 10.47 & 10.90 & 11.33 \\
\hline
\end{tabular}




\begin{tabular}{|c|c|c|c|c|c|c|c|c|c|c|c|c|c|c|c|c|c|c|c|c|}
\hline 2.74 & 3.18 & 3.61 & 4.04 & 4.47 & 4.90 & 5.33 & 5.77 & 6.20 & 6.63 & 7.06 & 7.49 & 7.92 & 8.35 & 8.79 & 9.22 & 9.65 & 10.08 & 10.51 & 10.94 & 11.37 \\
\hline 49.04 & 49.47 & 49.90 & 50.34 & 50.77 & 51.20 & 51.63 & 52.06 & 52.49 & 52.92 & 53.36 & 53.79 & 54.22 & 54.65 & 55.08 & 55.51 & 55.95 & 56.38 & 56.81 & 57.24 & 57.67 \\
\hline 11.90 & 12.33 & 12.76 & 13.19 & 13.62 & 14.05 & 14.49 & 14.92 & 15.35 & 15.78 & 16.21 & 16.64 & 17.08 & 17.51 & 17.94 & 18.37 & 18.80 & 19.23 & 19.66 & 20.10 & 20.53 \\
\hline 7.42 & 7.85 & 8.28 & 8.72 & 9.15 & 9.58 & 10.01 & 10.44 & 10.87 & 11.31 & 11.74 & 12.17 & 12.60 & 13.03 & 13.46 & 13.89 & 14.33 & 14.76 & 15.19 & 15.62 & 16.05 \\
\hline 17.54 & 17.97 & 18.40 & 18.83 & 19.27 & 19.70 & 20.13 & 20.56 & 20.99 & 21.42 & 21.86 & 22.29 & 22.72 & 23.15 & 23.58 & 24.01 & 24.44 & 24.88 & 25.31 & 25.74 & 26.17 \\
\hline 5.49 & 5.92 & 6.35 & 6.78 & 7.22 & 7.65 & 8.08 & 8.51 & 8.94 & 9.37 & 9.81 & 10.24 & 10.67 & 11.10 & 11.53 & 11.96 & 12.39 & 12.83 & 13.26 & 13.69 & 14.12 \\
\hline 4.70 & 5.13 & 5.56 & 5.99 & 6.42 & 6.85 & 7.29 & 7.72 & 8.15 & 8.58 & 9.01 & 9.44 & 9.87 & 10.31 & 10.74 & 11.17 & 11.60 & 12.03 & 12.46 & 12.90 & 13.33 \\
\hline 3.51 & 3.94 & 4.38 & 4.81 & 5.24 & 5.67 & 6.10 & 6.53 & 6.96 & 7.40 & 7.83 & 8.26 & 8.69 & 9.12 & 9.55 & 9.99 & 10.42 & 10.85 & 11.28 & 11.71 & 12.14 \\
\hline 2.97 & 3.40 & 3.83 & 4.27 & 4.70 & 5.13 & 5.56 & 5.99 & 6.42 & 6.86 & 7.29 & 7.72 & 8.15 & 8.58 & 9.01 & 9.44 & 9.88 & 10.31 & 10.74 & 11.17 & 11.60 \\
\hline 3.21 & 3.64 & 4.07 & 4.50 & 4.94 & 5.37 & 5.80 & 6.23 & 6.66 & 7.09 & 7.53 & 7.96 & 8.39 & 8.82 & 9.25 & 9.68 & 10.11 & 10.55 & 10.98 & 11.41 & 11.84 \\
\hline 4.17 & 4.60 & 5.03 & 5.47 & 5.90 & 6.33 & 6.76 & 7.19 & 7.62 & 8.06 & 8.49 & 8.92 & 9.35 & 9.78 & 10.21 & 10.64 & 11.08 & 11.51 & 11.94 & 12.37 & 12.80 \\
\hline 2.90 & 3.33 & 3.76 & 4.19 & 4.63 & 5.06 & 5.49 & 5.92 & 6.35 & 6.78 & 7.21 & 7.65 & 8.08 & 8.51 & 8.94 & 9.37 & 9.80 & 10.23 & 10.67 & 11.10 & 11.53 \\
\hline 2.65 & 3.08 & 3.51 & 3.94 & 4.37 & 4.80 & 5.24 & 5.67 & 6.10 & 6.53 & 6.96 & 7.39 & 7.82 & 8.26 & 8.69 & 9.12 & 9.55 & 9.98 & 10.41 & 10.85 & 11.28 \\
\hline 2.73 & 3.16 & 3.59 & 4.02 & 4.45 & 4.89 & 5.32 & 5.75 & 6.18 & 6.61 & 7.04 & 7.47 & 7.91 & 8.34 & 8.77 & 9.20 & 9.63 & 10.06 & 10.50 & 10.93 & 11.36 \\
\hline 2.43 & 2.86 & 3.29 & 3.72 & 4.15 & 4.58 & 5.02 & 5.45 & 5.88 & 6.31 & 6.74 & 7.17 & 7.61 & 8.04 & 8.47 & 8.90 & 9.33 & 9.76 & 10.19 & 10.63 & 11.06 \\
\hline 2.23 & 2.66 & 3.09 & 3.52 & 3.96 & 4.39 & 4.82 & 5.25 & 5.68 & 6.11 & 6.54 & 6.98 & 7.41 & 7.84 & 8.27 & 8.70 & 9.13 & 9.56 & 10.00 & 10.43 & 10.86 \\
\hline
\end{tabular}

\section{Corrupted series by Variability Error}

\begin{tabular}{|c|c|c|c|c|c|c|c|c|c|c|c|c|c|c|c|c|c|c|c|}
\hline Step 1 & Step 2 & Step 3 & Step 4 & Step 5 & Step 6 & Step 7 & Step 8 & Step 9 & Step 10 & Step 11 & Step 12 & Step 13 & Step 14 & Step 15 & Step 16 & Step 17 & Step 18 & Step 19 & Step 20 \\
\hline 1.01 & 0.65 & 0.28 & -0.08 & -0.44 & -0.80 & -1.17 & -1.53 & -1.89 & -2.26 & -2.62 & -2.98 & -3.34 & -3.71 & -4.07 & -4.43 & -4.80 & -5.16 & -5.52 & -5.88 \\
\hline 0.86 & 0.49 & 0.12 & -0.25 & -0.62 & -0.99 & -1.36 & -1.73 & -2.10 & -2.48 & -2.85 & -3.22 & -3.59 & -3.96 & -4.33 & -4.70 & -5.07 & -5.44 & -5.81 & -6.18 \\
\hline 0.84 & 0.46 & 0.09 & -0.28 & -0.65 & -1.02 & -1.39 & -1.76 & -2.13 & -2.51 & -2.88 & -3.25 & -3.62 & -3.99 & -4.36 & -4.73 & -5.10 & -5.48 & -5.85 & -6.22 \\
\hline 0.82 & 0.45 & 0.08 & -0.30 & -0.67 & -1.04 & -1.41 & -1.78 & -2.16 & -2.53 & -2.90 & -3.27 & -3.64 & -4.02 & -4.39 & -4.76 & -5.13 & -5.50 & -5.88 & -6.25 \\
\hline 1.24 & 0.89 & 0.53 & 0.18 & -0.17 & -0.52 & -0.87 & -1.23 & -1.58 & -1.93 & -2.28 & -2.64 & -2.99 & -3.34 & -3.69 & -4.04 & -4.40 & -4.75 & -5.10 & -5.45 \\
\hline 36.13 & 37.43 & 38.74 & 40.05 & 41.36 & 42.67 & 43.98 & 45.29 & 46.60 & 47.91 & 49.22 & 50.53 & 51.84 & 53.15 & 54.46 & 55.76 & 57.07 & 58.38 & 59.69 & 61.00 \\
\hline 8.79 & 8.80 & 8.81 & 8.81 & 8.82 & 8.83 & 8.84 & 8.84 & 8.85 & 8.86 & 8.87 & 8.87 & 8.88 & 8.89 & 8.90 & 8.90 & 8.91 & 8.92 & 8.93 & 8.93 \\
\hline 84.89 & 88.52 & 92.15 & 95.78 & 99.41 & 103.04 & 106.67 & 110.30 & 113.94 & 117.57 & 121.20 & 124.83 & 128.46 & 132.09 & 135.72 & 139.35 & 142.99 & 146.62 & 150.25 & 153.88 \\
\hline 39.74 & 41.23 & 42.71 & 44.19 & 45.67 & 47.15 & 48.63 & 50.11 & 51.60 & 53.08 & 54.56 & 56.04 & 57.52 & 59.00 & 60.49 & 61.97 & 63.45 & 64.93 & 66.41 & 67.89 \\
\hline 2.99 & 2.72 & 2.45 & 2.18 & 1.91 & 1.64 & 1.37 & 1.10 & 0.84 & 0.57 & 0.30 & 0.03 & -0.24 & -0.51 & -0.78 & -1.05 & -1.32 & -1.58 & -1.85 & -2.12 \\
\hline 1.61 & 1.27 & 0.94 & 0.60 & 0.27 & -0.06 & -0.40 & -0.73 & -1.07 & -1.40 & -1.74 & -2.07 & -2.41 & -2.74 & -3.07 & -3.41 & -3.74 & -4.08 & -4.41 & -4.75 \\
\hline 5.46 & 5.31 & 5.16 & 5.01 & 4.86 & 4.71 & 4.56 & 4.41 & 4.26 & 4.11 & 3.95 & 3.80 & 3.65 & 3.50 & 3.35 & 3.20 & 3.05 & 2.90 & 2.75 & 2.60 \\
\hline 2.85 & 2.57 & 2.29 & 2.02 & 1.74 & 1.47 & 1.19 & 0.92 & 0.64 & 0.37 & 0.09 & -0.18 & -0.46 & -0.74 & -1.01 & -1.29 & -1.56 & -1.84 & -2.11 & -2.39 \\
\hline 2.72 & 2.44 & 2.16 & 1.88 & 1.60 & 1.32 & 1.03 & 0.75 & 0.47 & 0.19 & -0.09 & -0.37 & -0.65 & -0.94 & -1.22 & -1.50 & -1.78 & -2.06 & -2.34 & -2.62 \\
\hline 2.12 & 1.81 & 1.50 & 1.19 & 0.88 & 0.57 & 0.26 & -0.05 & -0.36 & -0.67 & -0.98 & -1.29 & -1.60 & -1.91 & -2.22 & -2.53 & -2.84 & -3.15 & -3.46 & -3.77 \\
\hline
\end{tabular}




\begin{tabular}{|c|c|c|c|c|c|c|c|c|c|c|c|c|c|c|c|c|c|c|c|}
\hline 2.24 & 1.94 & 1.63 & 1.33 & 1.02 & 0.72 & 0.41 & 0.11 & -0.19 & -0.50 & -0.80 & -1.11 & -1.41 & -1.72 & -2.02 & -2.32 & -2.63 & -2.93 & -3.24 & -3.54 \\
\hline 12.95 & 13.16 & 13.36 & 13.57 & 13.77 & 13.98 & 14.19 & 14.39 & 14.60 & 14.80 & 15.01 & 15.21 & 15.42 & 15.63 & 15.83 & 16.04 & 16.24 & 16.45 & 16.65 & 16.86 \\
\hline 5.26 & 5.10 & 4.94 & 4.78 & 4.62 & 4.46 & 4.30 & 4.14 & 3.98 & 3.81 & 3.65 & 3.49 & 3.33 & 3.17 & 3.01 & 2.85 & 2.69 & 2.53 & 2.37 & 2.21 \\
\hline 3.03 & 2.76 & 2.49 & 2.23 & 1.96 & 1.69 & 1.43 & 1.16 & 0.89 & 0.63 & 0.36 & 0.09 & -0.17 & -0.44 & -0.71 & -0.97 & -1.24 & -1.51 & -1.77 & -2.04 \\
\hline 2.37 & 2.07 & 1.77 & 1.47 & 1.17 & 0.87 & 0.58 & 0.28 & -0.02 & -0.32 & -0.62 & -0.92 & -1.21 & -1.51 & -1.81 & -2.11 & -2.41 & -2.71 & -3.00 & -3.30 \\
\hline 1.81 & 1.48 & 1.16 & 0.83 & 0.51 & 0.18 & -0.14 & -0.47 & -0.79 & -1.12 & -1.44 & -1.77 & -2.09 & -2.42 & -2.74 & -3.07 & -3.39 & -3.72 & -4.04 & -4.37 \\
\hline 1.57 & 1.23 & 0.90 & 0.56 & 0.23 & -0.11 & -0.45 & -0.78 & -1.12 & -1.46 & -1.79 & -2.13 & -2.46 & -2.80 & -3.14 & -3.47 & -3.81 & -4.15 & -4.48 & -4.82 \\
\hline 1.32 & 0.98 & 0.63 & 0.28 & -0.07 & -0.41 & -0.76 & -1.11 & -1.46 & -1.81 & -2.15 & -2.50 & -2.85 & -3.20 & -3.55 & -3.89 & -4.24 & -4.59 & -4.94 & -5.29 \\
\hline 19.74 & 20.27 & 20.80 & 21.32 & 21.85 & 22.38 & 22.91 & 23.44 & 23.97 & 24.50 & 25.03 & 25.56 & 26.09 & 26.61 & 27.14 & 27.67 & 28.20 & 28.73 & 29.26 & 29.79 \\
\hline 8.24 & 8.22 & 8.21 & 8.19 & 8.17 & 8.15 & 8.13 & 8.11 & 8.10 & 8.08 & 8.06 & 8.04 & 8.02 & 8.00 & 7.98 & 7.97 & 7.95 & 7.93 & 7.91 & 7.89 \\
\hline 3.94 & 3.71 & 3.49 & 3.27 & 3.04 & 2.82 & 2.60 & 2.37 & 2.15 & 1.93 & 1.70 & 1.48 & 1.26 & 1.03 & 0.81 & 0.59 & 0.36 & 0.14 & -0.08 & -0.31 \\
\hline 3.41 & 3.16 & 2.92 & 2.67 & 2.42 & 2.17 & 1.92 & 1.67 & 1.43 & 1.18 & 0.93 & 0.68 & 0.43 & 0.18 & -0.07 & -0.31 & -0.56 & -0.81 & -1.06 & -1.31 \\
\hline 3.04 & 2.77 & 2.50 & 2.24 & 1.97 & 1.71 & 1.44 & 1.17 & 0.91 & 0.64 & 0.37 & 0.11 & -0.16 & -0.43 & -0.69 & -0.96 & -1.22 & -1.49 & -1.76 & -2.02 \\
\hline 2.40 & 2.11 & 1.81 & 1.52 & 1.22 & 0.92 & 0.63 & 0.33 & 0.03 & -0.26 & -0.56 & -0.86 & -1.15 & -1.45 & -1.75 & -2.04 & -2.34 & -2.64 & -2.93 & -3.23 \\
\hline 2.45 & 2.16 & 1.86 & 1.57 & 1.27 & 0.98 & 0.68 & 0.39 & 0.10 & -0.20 & -0.49 & -0.79 & -1.08 & -1.38 & -1.67 & -1.96 & -2.26 & -2.55 & -2.85 & -3.14 \\
\hline 51.06 & 53.08 & 55.10 & 57.12 & 59.14 & 61.16 & 63.18 & 65.21 & 67.23 & 69.25 & 71.27 & 73.29 & 75.31 & 77.33 & 79.35 & 81.37 & 83.39 & 85.41 & 87.43 & 89.45 \\
\hline 12.06 & 12.22 & 12.39 & 12.55 & 12.71 & 12.88 & 13.04 & 13.20 & 13.37 & 13.53 & 13.69 & 13.86 & 14.02 & 14.18 & 14.35 & 14.51 & 14.67 & 14.84 & 15.00 & 15.16 \\
\hline 7.36 & 7.30 & 7.24 & 7.18 & 7.12 & 7.06 & 7.00 & 6.94 & 6.88 & 6.82 & 6.76 & 6.70 & 6.64 & 6.58 & 6.51 & 6.45 & 6.39 & 6.33 & 6.27 & 6.21 \\
\hline 17.99 & 18.43 & 18.88 & 19.32 & 19.77 & 20.21 & 20.66 & 21.10 & 21.55 & 21.99 & 22.44 & 22.89 & 23.33 & 23.78 & 24.22 & 24.67 & 25.11 & 25.56 & 26.00 & 26.45 \\
\hline 5.33 & 5.18 & 5.02 & 4.86 & 4.71 & 4.55 & 4.39 & 4.23 & 4.08 & 3.92 & 3.76 & 3.61 & 3.45 & 3.29 & 3.14 & 2.98 & 2.82 & 2.66 & 2.51 & 2.35 \\
\hline 4.50 & 4.30 & 4.11 & 3.91 & 3.71 & 3.52 & 3.32 & 3.12 & 2.93 & 2.73 & 2.53 & 2.34 & 2.14 & 1.94 & 1.75 & 1.55 & 1.35 & 1.16 & 0.96 & 0.76 \\
\hline 3.26 & 3.00 & 2.74 & 2.49 & 2.23 & 1.98 & 1.72 & 1.47 & 1.21 & 0.95 & 0.70 & 0.44 & 0.19 & -0.07 & -0.33 & -0.58 & -0.84 & -1.09 & -1.35 & -1.61 \\
\hline 2.69 & 2.41 & 2.12 & 1.84 & 1.56 & 1.27 & 0.99 & 0.71 & 0.42 & 0.14 & -0.14 & -0.42 & -0.71 & -0.99 & -1.27 & -1.56 & -1.84 & -2.12 & -2.40 & -2.69 \\
\hline 2.94 & 2.67 & 2.40 & 2.13 & 1.85 & 1.58 & 1.31 & 1.04 & 0.77 & 0.50 & 0.23 & -0.04 & -0.31 & -0.58 & -0.86 & -1.13 & -1.40 & -1.67 & -1.94 & -2.21 \\
\hline 3.95 & 3.73 & 3.50 & 3.28 & 3.06 & 2.83 & 2.61 & 2.39 & 2.17 & 1.94 & 1.72 & 1.50 & 1.27 & 1.05 & 0.83 & 0.60 & 0.38 & 0.16 & -0.06 & -0.29 \\
\hline 2.61 & 2.33 & 2.04 & 1.75 & 1.47 & 1.18 & 0.89 & 0.61 & 0.32 & 0.03 & -0.25 & -0.54 & -0.83 & -1.11 & -1.40 & -1.69 & -1.97 & -2.26 & -2.55 & -2.83 \\
\hline 2.35 & 2.05 & 1.75 & 1.45 & 1.15 & 0.85 & 0.55 & 0.25 & -0.05 & -0.35 & -0.64 & -0.94 & -1.24 & -1.54 & -1.84 & -2.14 & -2.44 & -2.74 & -3.04 & -3.34 \\
\hline 2.43 & 2.14 & 1.84 & 1.55 & 1.25 & 0.96 & 0.66 & 0.37 & 0.07 & -0.22 & -0.52 & -0.81 & -1.11 & -1.40 & -1.70 & -1.99 & -2.29 & -2.58 & -2.88 & -3.17 \\
\hline 2.12 & 1.81 & 1.50 & 1.19 & 0.88 & 0.57 & 0.26 & -0.05 & -0.36 & -0.68 & -0.99 & -1.30 & -1.61 & -1.92 & -2.23 & -2.54 & -2.85 & -3.16 & -3.47 & -3.78 \\
\hline 1.91 & 1.59 & 1.27 & 0.95 & 0.63 & 0.31 & -0.01 & -0.33 & -0.65 & -0.97 & -1.29 & -1.61 & -1.93 & -2.25 & -2.57 & -2.89 & -3.21 & -3.53 & -3.85 & -4.17 \\
\hline
\end{tabular}

Corrupted series by Correlation Error

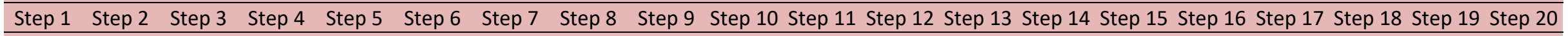

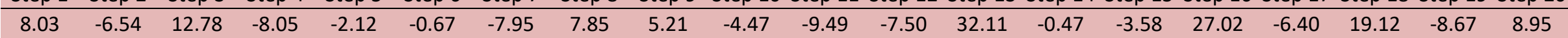




\begin{tabular}{|c|c|c|c|c|c|c|c|c|c|c|c|c|c|c|c|c|c|c|c|}
\hline 1.38 & 8.06 & 12.85 & 8.00 & -3.55 & 6.42 & -7.55 & 17.74 & -3.50 & -10.07 & 7.19 & 23.11 & -1.34 & 28.55 & -12.27 & 9.56 & 12.07 & 21.87 & 0.11 & -4.19 \\
\hline 0.91 & 14.17 & -1.12 & -9.48 & -4.73 & -0.18 & 6.50 & -19.70 & 3.23 & -11.51 & 8.95 & 27.27 & 5.35 & -3.70 & 2.35 & 2.10 & 27.18 & 10.29 & 30.97 & 12.86 \\
\hline 4.76 & 0.88 & -3.55 & -3.11 & 10.88 & 14.97 & 14.38 & -1.92 & -7.63 & 13.98 & -9.90 & -9.12 & -5.20 & -11.30 & 8.35 & 26.45 & -15.80 & 7.05 & 25.82 & 24.07 \\
\hline 5.45 & 2.02 & 5.71 & 0.77 & -7.65 & 12.15 & 9.97 & 19.32 & 4.20 & -17.22 & 8.32 & 21.43 & -1.96 & 7.35 & 7.94 & -11.44 & 27.87 & 25.07 & -6.64 & 0.54 \\
\hline 40.31 & 39.75 & 37.45 & 40.65 & 32.67 & 24.86 & 37.55 & 27.88 & 18.90 & 27.43 & 28.22 & 16.69 & 20.14 & 6.04 & 15.67 & -5.19 & -4.30 & 5.23 & 4.38 & 35.59 \\
\hline 5.33 & 19.27 & 19.43 & -4.95 & 13.73 & 3.21 & 26.97 & -13.91 & 3.73 & 23.78 & 25.85 & 26.66 & 2.75 & 26.97 & 18.24 & -4.82 & -2.47 & 27.57 & 17.17 & 21.45 \\
\hline 77.58 & 76.79 & 72.20 & 64.50 & 61.25 & 68.52 & 45.33 & 48.08 & 47.98 & 41.06 & 50.16 & 39.86 & 46.53 & 45.62 & 6.67 & 47.49 & 12.64 & 3.90 & 8.29 & -5.67 \\
\hline 31.62 & 25.82 & 39.41 & 22.23 & 23.16 & 14.02 & 20.05 & 40.99 & 35.47 & 22.74 & 9.28 & 20.10 & -3.14 & 27.31 & 35.24 & 3.11 & 27.79 & 22.68 & -3.24 & 12.82 \\
\hline 9.48 & 16.00 & 16.72 & 5.61 & 17.86 & 9.12 & 10.19 & 20.68 & -3.14 & -12.72 & 10.93 & 22.29 & -13.60 & 2.50 & -6.46 & 2.64 & -17.11 & -0.15 & -14.94 & 30.57 \\
\hline-1.82 & -8.76 & 18.67 & -10.03 & -3.44 & -2.22 & 7.51 & -6.81 & -7.75 & 24.11 & 2.33 & -9.08 & 19.71 & 4.94 & 16.98 & -9.74 & 1.38 & 10.65 & 17.81 & 19.68 \\
\hline-0.96 & -2.55 & -4.96 & 19.03 & 5.64 & -3.58 & 11.52 & 6.68 & 22.45 & 13.25 & 20.92 & -6.83 & & -5.00 & 0.67 & -8.31 & -6.92 & -9.41 & 11.25 & 21.16 \\
\hline 9.71 & -4.05 & 6.87 & -2.79 & -4.40 & 13.50 & -8.74 & -15.52 & 25.19 & 20.56 & -16.32 & 11.66 & -7.68 & 8.20 & 6.17 & -0.06 & 16.73 & 28.76 & -15.78 & -9.41 \\
\hline 7.04 & -4.63 & 0.89 & -5.67 & -8.72 & 8.33 & 14.59 & -11.18 & -7.14 & & -7.62 & & & & 6.74 & 17.82 & 17.96 & & & 6.94 \\
\hline 1.04 & 12.69 & 0.63 & -6.95 & -11.86 & 20.07 & 10.42 & 7.12 & 27.35 & -2.45 & 8.07 & -1.91 & 14.26 & 2.97 & 31.33 & 16.38 & 21.01 & -11.16 & 31.75 & 19.60 \\
\hline 5.55 & -6.94 & 1.51 & 15.98 & 18.46 & -7.19 & -11.28 & -4.74 & 13.36 & -4.27 & -0.16 & 11.57 & -5.71 & 12.15 & 14.29 & 27.63 & 5.19 & 20.11 & 30.74 & 29.47 \\
\hline 13.12 & 12.13 & 7.12 & 20.40 & 5.37 & 19.17 & 2.55 & -0.79 & 21.40 & -7.42 & 16.41 & -11.09 & 19.38 & -7.04 & -15.83 & 33.95 & 22.99 & 9.55 & -2.78 & 8.84 \\
\hline 10.17 & -3.62 & 2.14 & 12.46 & 16.52 & -2.35 & -6.02 & 2.54 & 26.17 & 17.62 & -5.16 & 26.83 & 20.05 & -12.10 & -18.47 & -8.55 & 12.73 & 14.65 & -14.62 & 10.92 \\
\hline 0.28 & -1.15 & 6.71 & 16.58 & 14.03 & & 8.04 & & 20.52 & & & & & & & & & & & 21.51 \\
\hline-1.51 & 6.05 & 15.50 & 0.14 & 16.79 & 21.68 & 1.78 & 28.26 & 2.11 & -1.71 & 30.26 & 10.17 & 30.44 & -3.51 & 17.47 & 0.17 & -4.33 & 31.58 & 3.37 & 13.90 \\
\hline-3.92 & 10.05 & 16.14 & 8.63 & -5.97 & -7.18 & 2.16 & 21.63 & 2.07 & & & 16.21 & & & & & 20.05 & & 7.49 & -8.09 \\
\hline-1.08 & 5.20 & 8.17 & 15.59 & -9.13 & -6.40 & 27.37 & -0.90 & -6.26 & 4.44 & 0.14 & -14.75 & -11.65 & 28.86 & -7.40 & -3.18 & -5.73 & -13.64 & 4.19 & 17.46 \\
\hline-2.02 & 4.33 & 1.41 & -9.31 & -2.00 & -10.92 & 11.27 & 23.41 & 25.02 & 11.30 & 5.44 & 15.23 & -12.13 & 6.75 & 13.10 & 15.12 & 16.17 & 13.89 & 28.16 & -10.28 \\
\hline 16.11 & 23.77 & 22.29 & 25.05 & 13.20 & 10.75 & 11.43 & 16.73 & 3.77 & -4.08 & 18.28 & 9.06 & 24.96 & -8.72 & 21.90 & 3.27 & 16.27 & -9.36 & -4.16 & 33.21 \\
\hline 14.21 & 5.35 & 17.53 & 12.29 & -3.64 & 7.32 & 6.18 & 5.26 & -5.29 & 28.59 & 28.12 & 11.28 & 22.97 & 14.77 & 30.00 & -3.33 & 17.10 & 25.47 & 25.93 & -5.39 \\
\hline-0.56 & 3.41 & 5.90 & 6.00 & 20.14 & -2.57 & -3.14 & -7.14 & 14.17 & 6.12 & 11.87 & 18.90 & -6.43 & -6.12 & -13.40 & 9.38 & -5.03 & -7.52 & -14.01 & 10.32 \\
\hline-2.17 & 11.99 & -0.98 & 4.11 & 12.74 & 16.29 & -10.18 & 10.09 & -1.44 & 4.18 & -14.20 & 25.81 & 19.56 & 28.61 & 12.11 & 12.21 & -15.66 & 29.98 & -8.86 & -8.90 \\
\hline 1.64 & 0.98 & -6.29 & 8.65 & 8.19 & 15.71 & 0.31 & 3.13 & -6.27 & -12.84 & -8.79 & 15.83 & 6.50 & -4.36 & -15.56 & -13.41 & -9.46 & 15.22 & 6.39 & 27.24 \\
\hline-1.62 & 9.63 & -8.92 & -10.62 & 0.32 & 19.13 & 13.21 & -4.87 & 21.98 & 15.14 & 25.06 & -0.58 & 12.48 & 21.66 & 17.60 & 9.48 & -19.11 & 6.47 & 5.34 & 19.66 \\
\hline-1.11 & 8.23 & 3.10 & 18.74 & -4.06 & -3.50 & -7.53 & 7.95 & -2.13 & -2.98 & 15.93 & -3.75 & 7.57 & 20.05 & 8.13 & 12.16 & 27.06 & -8.22 & 3.17 & -5.83 \\
\hline 48.85 & 43.08 & 33.79 & 39.59 & 41.58 & 37.69 & 48.35 & 35.16 & 27.14 & 27.39 & 3.36 & 18.80 & 13.32 & 0.37 & 36.02 & -0.10 & 25.36 & 36.25 & 34.45 & -3.21 \\
\hline 7.19 & -0.14 & 3.71 & 8.18 & 4.55 & 16.52 & 25.26 & -0.57 & 37.10 & 21.15 & 14.49 & -5.08 & -0.68 & 23.14 & 30.76 & -12.66 & -4.34 & -12.71 & 27.40 & -5.93 \\
\hline 13.52 & 8.39 & 10.79 & 21.78 & 6.53 & -5.94 & -3.91 & 13.79 & 4.96 & 11.37 & 18.63 & 24.15 & -6.65 & 17.19 & 13.21 & -3.25 & -17.09 & 25.52 & 23.06 & 24.00 \\
\hline 10.46 & 17.59 & 5.21 & 8.02 & 28.53 & 14.59 & 30.75 & 7.83 & 0.64 & 33.02 & 23.81 & 32.69 & 11.21 & 14.26 & -1.49 & 31.33 & 23.00 & 7.09 & 2.33 & 23.01 \\
\hline 13.22 & 6.20 & 19.34 & 2.59 & 6.99 & -7.77 & 1.00 & 7.99 & 7.09 & 14.29 & -13.08 & 16.67 & -7.95 & -11.20 & 12.14 & -0.11 & 5.18 & 25.56 & 26.26 & 11.76 \\
\hline 8.45 & 0.19 & 1.59 & 7.69 & 3.55 & 11.85 & -1.63 & 20.63 & 4.82 & 27.75 & -2.99 & 14.62 & -7.65 & 10.58 & 9.47 & 27.96 & 6.81 & 13.88 & 15.29 & 2.28 \\
\hline
\end{tabular}




$\begin{array}{cccccccccccccccccccc}10.92 & -1.41 & -3.43 & 16.51 & 18.57 & 26.19 & -8.25 & -8.40 & -10.44 & -7.64 & -2.21 & 2.10 & 16.73 & 20.67 & -3.93 & 0.17 & -0.76 & -6.08 & 3.26 & 13.10 \\ -0.16 & 6.39 & 0.35 & 3.36 & 23.11 & -8.51 & -7.24 & -3.06 & -7.46 & -11.46 & 2.81 & -1.77 & 8.03 & -15.19 & 25.59 & 14.99 & 22.86 & 23.39 & 8.77 & -9.72 \\ 10.63 & 9.72 & -1.93 & -5.43 & -2.67 & 4.42 & -1.53 & 23.05 & -7.63 & 3.37 & 9.55 & 14.54 & 26.66 & 9.33 & 3.46 & -13.95 & 28.87 & -12.33 & -16.82 & -17.34 \\ 7.53 & -0.35 & 8.41 & 6.42 & 23.46 & 16.99 & 0.34 & 7.72 & 21.13 & 6.28 & 35.57 & 24.38 & 5.28 & 17.60 & 24.64 & -4.76 & 7.43 & -13.40 & 9.16 & 23.12 \\ -3.80 & 3.90 & 0.15 & 11.83 & -9.05 & 14.89 & 9.33 & -4.51 & -12.30 & 13.32 & 6.36 & -9.74 & 23.94 & 5.09 & 0.97 & 18.20 & 24.90 & -2.16 & 9.26 & 20.52 \\ 2.17 & 0.69 & -9.14 & -0.93 & -0.68 & -10.24 & 18.11 & 15.27 & 28.45 & -16.14 & 4.57 & -15.88 & 24.31 & -13.52 & -24.87 & 16.14 & 9.39 & -2.13 & 21.96 & -6.83 \\ 6.86 & 2.49 & 1.71 & 2.59 & 2.67 & -9.40 & 24.94 & 13.66 & 9.64 & 17.75 & 33.19 & -16.14 & 24.05 & 25.28 & 7.16 & 15.68 & 28.94 & 1.70 & 11.77 & -19.04 \\ -0.28 & 7.75 & 0.58 & -7.45 & 22.43 & 11.53 & -9.78 & 16.38 & -9.07 & -9.10 & -1.61 & 5.06 & 32.24 & 21.38 & 9.46 & 31.72 & -3.96 & 10.55 & 29.79 & -0.83 \\ 5.87 & 5.68 & -8.52 & 17.53 & -1.42 & 23.00 & 26.47 & -4.23 & 0.86 & 20.73 & 9.49 & -15.92 & -8.76 & 22.27 & 16.99 & 14.40 & 16.18 & -6.97 & -12.98 & -15.58\end{array}$

